\title{
Tank Closure Reducing Grout
}

by

T. B. Caldwell

Westinghouse Savannah River Company Savannah River Site

Aiken, South Carolina 29808

This paper was prepared in connection with work done under the above contract number with the U.S. Department of Energy. By acceptance of this paper, the publisher and/or recipient acknowledges the U. $\dot{S}$. Government's right to retain a nonexclusive, royalty-free license in and to any copyright covering this paper, along with the right to reproduce and to authorize others to reproduce all or part of the copyrighted paper. 
WSRC-TR-97-0102

\title{
TANKK CLOSURE REDUCING GROUT (U)
}

\author{
T. B. Caldwell
}

April 18, 1997

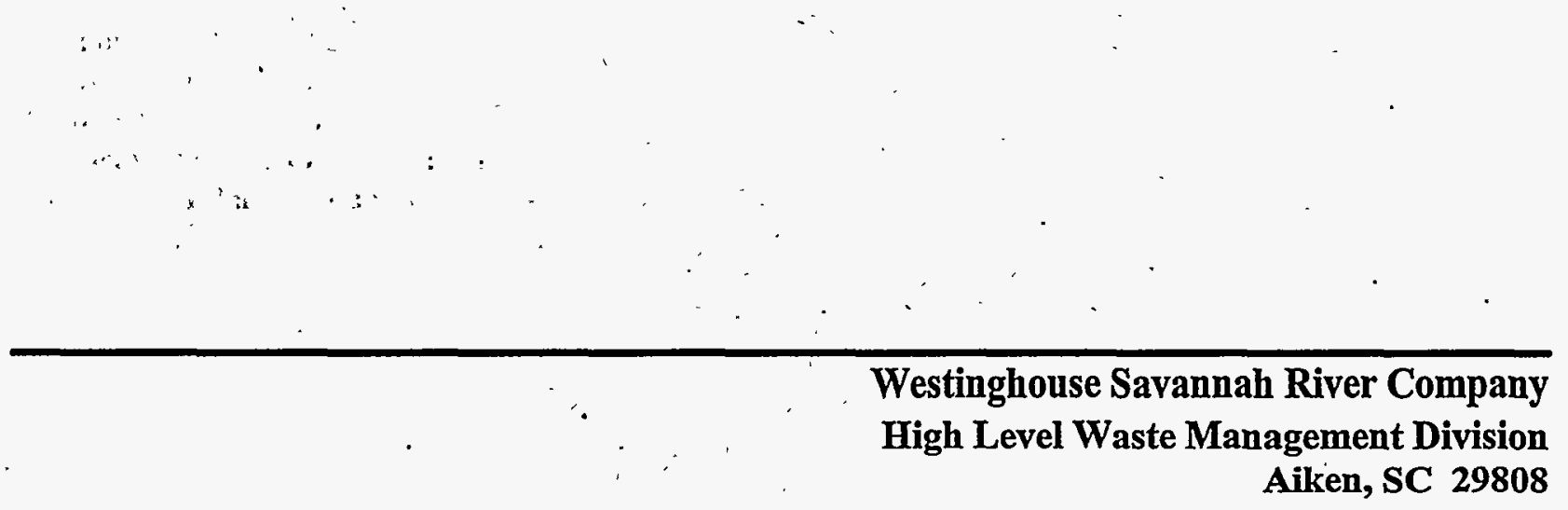

Prepared for the U. S. Department of Energy under Contract DE-AC09-96SR18500 


\section{DISCLAIMER}

This report was prepared as an account of work sponsored by an agency of the United States Government. Neither the United States Government nor any agency thereof, nor any of their employees, makes any warranty, express or implied, or assumes any legal liability or responsibility for the accuracy, completeness, or usefulness of any information, apparatus, product, or process disclosed, or represents that its use would not infringe privately owned rights. Reference herein to any specific commercial product, process, or service by trade name, trademark, manufacturer, or otherwise does not necessarily constitute or imply its endorsement, recommendation, or favoring by the United States Government or any agency thereof. The views and opinions of authors expressed herein do not necessarily state or reflect those of the United States Government or any agency thereof.

This report has been reproduced directly from the best availlable copy.

Available to DOE and DOE contractors from the Office of Scientific and Technical Information, -P.O. Box 62, Oak Ridge, TN 37831; prices available from (615) 576-8401.

Available to the public from the National Technical Information Service, U.S. Department of Commerce, 5285 Port Royal Road, Springfield, VA 22161. 
HIGH LEVEL WASTE ENGINEERING

TANK FARM PROJECT ENGINEERING

Tank Closure Reducing Grout (U)

T. B. Caldwell

Isșued: April 17, 1997

by
WSRC-TR-97-0102

REVISION: 0

Keywords:

tank closure

reducing

grout

Retention:

Permanent

Classification: $U$

2Does Not Contain UCNI .

Gaul D.d'otremmat ADC/RO

\section{APPROVALS}

T. B. Caldwell, Author, HLWE

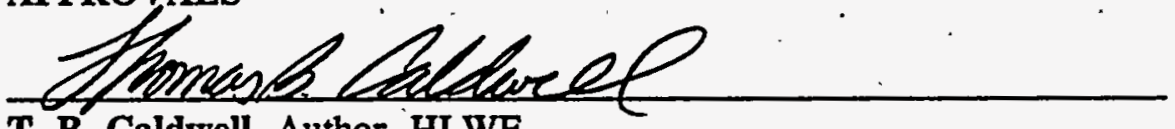

$\longrightarrow$ Pleermen

J. Z. Newman, Technical Reviewer, HLWR

C.a. Lanaton by deflickest per telecon

C. A. Langton, Technical Reviewer, SRTC

Gaul Did'intremsy

P. D. d'Entremont, Technical Reviewer, HLWE
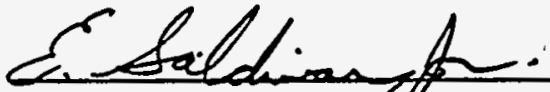

E. Saldivar, Manager, Waste Remoyal Group

T qu 727 nechor

T. M. Monahon, Manager HLWE
Date: $4 / 17 / 97$

Date: $4 / 17 / 9$

Date: $4 / 18 / 97$

Date: $4 / 17 / 97$

Date: $4 / 18 / 97$

Date: $4 / 18 / 97$ 


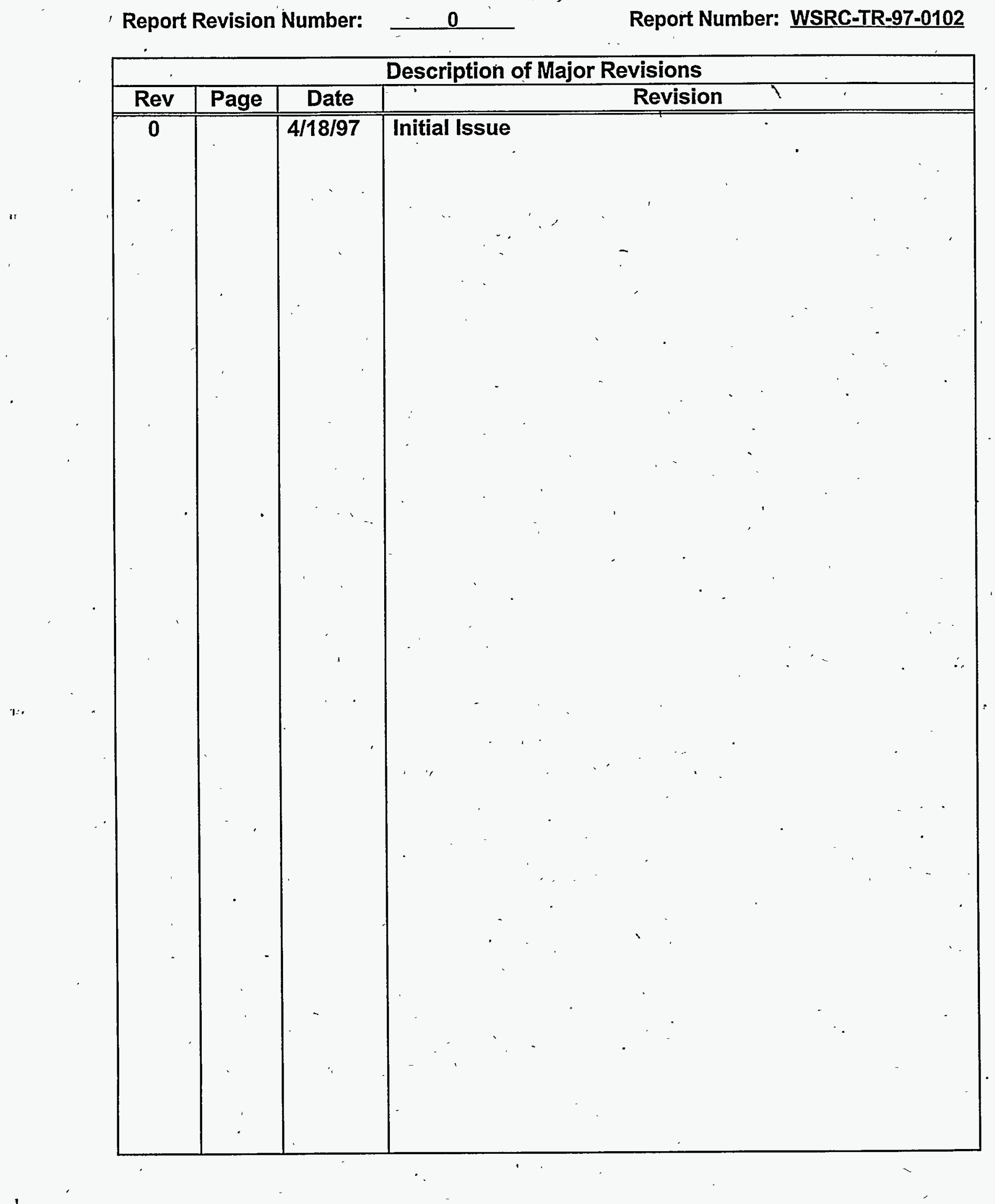


WSRC-TR-97-0102

Revision 0

Page 2

\section{Table of. Contents}

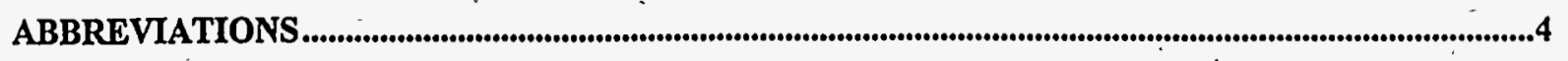

SUMMARY

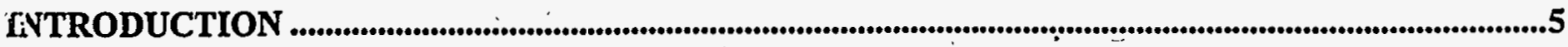

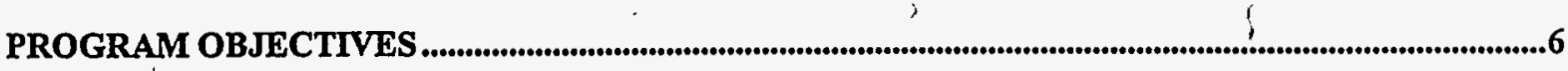

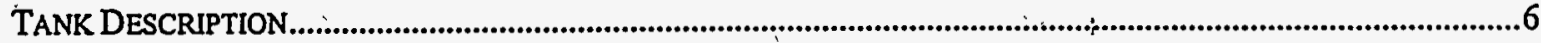

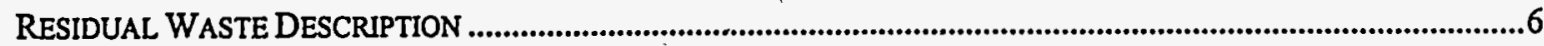

PERFORMANCE REQUIREMENTS AND ACCEPTANCE CRITERIA ...........................................................................7

Chemical Stabilization...................................................................................................................................7

Mechanical Entrapment ..............................................................................................................................

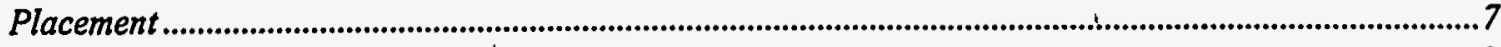

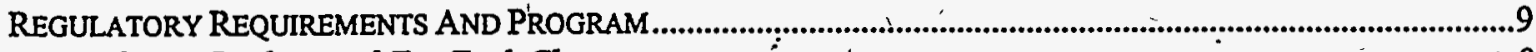

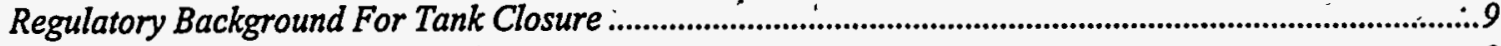

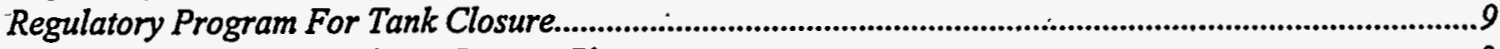

High Level Waste Tank Closure Program Plan........................................................................................................... 9

Industrial Wastewater Closure Plan For F-And H-Area HLW Tank Systems............................................................ 9

Tank 20 And Tank 17 Industrial Wastewater Closure Modules For The HLW System ............................................. 10

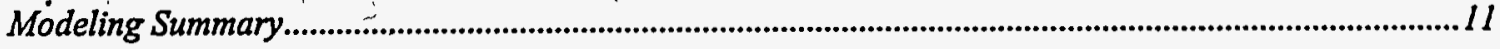

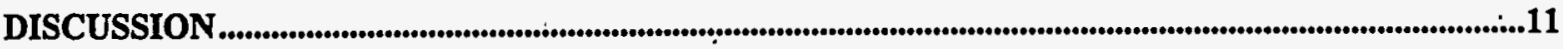

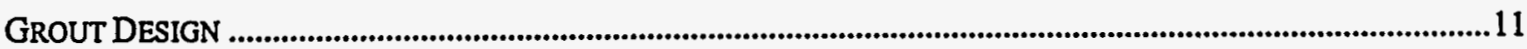

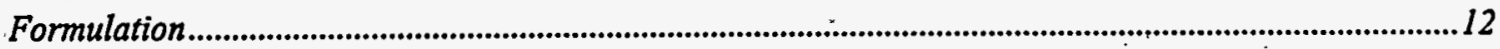

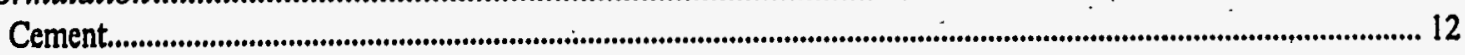

Ground Blast Furnace Slag and Sodium Thiosulfate................................................................................................ 13

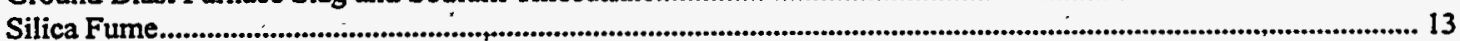

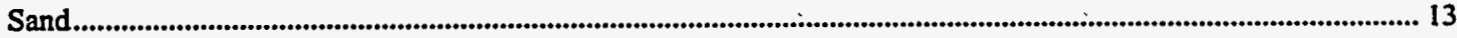

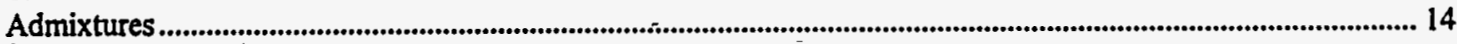

Grout Properties...........................................................................................................................................14

Redox Potential .................................................................................................................................................. 14

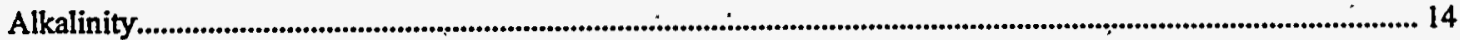

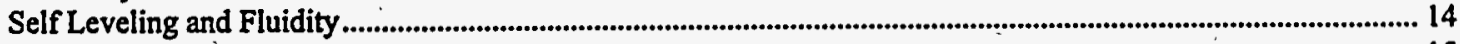

Compressive Strength................................................................................................................................................... 15

Cohesiveness ......................................................................................................................................................... 15

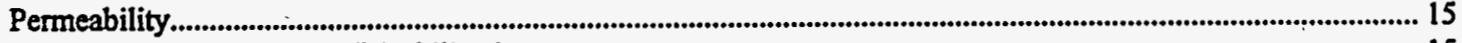

Chemisorption Capacity and Stabilization ........................................................................................................ 15

Set Time ........................................................................................................................................................................ 15

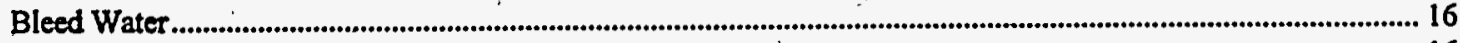

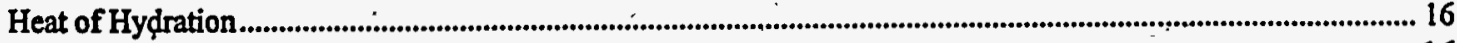

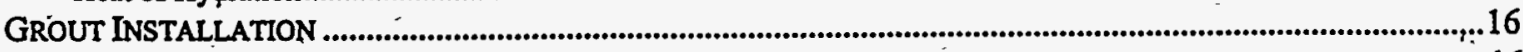

Specification Development ............................................................................................................................16

Batch Plant Design and Operation..............................................................................................................16

Placement Method ........................................................................................................................................17

Tank Modifications.......................................................................................................................................17

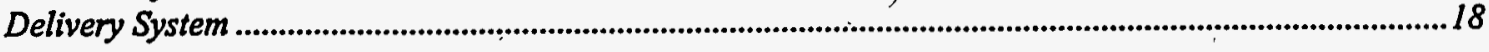

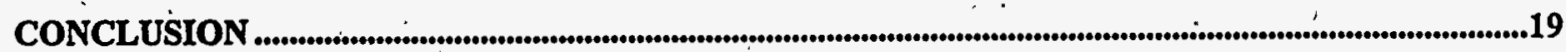

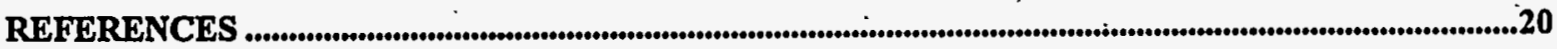


WSRC-TR-97-0102

Revision 0

Page 3

\section{List Of Tables}

TABle 1. PERformanCE REQUIREMENTS AND ACCEPTANCE CRITERIA ............................................................8

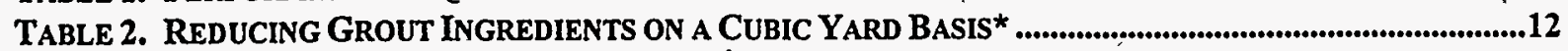

TABLE 3. TYPE.V CEMENT CHEMICAL COMPOSITION............................................................................................12

TABLE 4. PERFORMANCE REQUIREMENTS AND ACCEPTANCE CRITERIA ..............................................................19

\section{Appendix}

Appendix A. CTL Final Report, Development of Reducing Grout for

Closure of Savannah River Site Tank \#20, October 1996...................................................................21

Appendix B. CTL Draft Report, Demonstration of Reducing Grout and Sludge

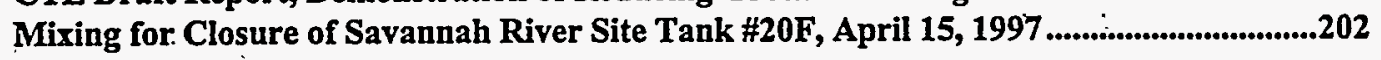




\section{Abbreviations}

ARAR Applicable or relevant and appropriate requirements

ASTM American Society of Testing and Materials

CERCLA Comprehensive Environmental Response, Compensation, and Liability Act

TTL

DOE

Construction Technology-Laboratories, Inc.

$\mathrm{E}_{h}$

EPA

FFA

HLW

$\mathrm{mV}$

$\mathrm{pH}$

United States Department of Energy

Oxidation (or redox) potential in millivolts ( $\mathrm{mV}$ )

United States Environmental Protection Agency.

Federal Facility Agreement

High-level waste

Millivolt

psi

Negative logarithm of the hydronium ion $\left(\mathrm{H}^{+}\right)$

RCRA

Pounds-force per square inch

SCDHEC South Carolina Department of Health and Environmental Control

SRS

wt\%

Savannah River Site

Weight percent 


\section{Summary}

A reducing grout has been developed for closing high level waste tanks at the Savannah River Site in Aiken, South Carolina. The grout has a low redox potential, which minimizes the mobility of $\mathrm{Sr}^{90}$, the radionuclide with the highest dose potential after closure. The grout also has a high $\mathrm{pH}$ which reduces the solubility of the plutohium isotopes. The grout has a high compressive strength and low permeability, which enhances its ability to limit the migration of contaminants after closure. The grout was designed and tested by Construction Technology Laboratories, Inc. Placement methods were developed by the Savannah River Site personnel.

Plans are to place this grout into Tank 20, the first tank to be closed, in several stages. The first layer will be placed in liquid form using multiple entry points. The dense grout will lift the waste sludge, which is less dense, off of the tank bottom and will spread it into a pattern across the tank. The loose waste sludge will then be immobilized by blowing the powdered grout in dry form into the tank. The dry particles will hydrate, incorporating the water into the grout powder. The grout will then be poured from the center tank location to form a domed cap which fully encapsulates the waste in the grout layers. The remainder of the tank will then be closed using controlled low strength material.

Work is still ongoing to develop techniques for placing grout. Grout in other tanks may be placed. similarly to Tank 20 or may be placed using newly developed methods.

\section{Introduction}

Waste Tanks $17 \mathrm{~F}$ and $20 \mathrm{~F}$ of the F-Area high level waste tank farm system are the first waste tanks scheduled for closure. The tanks were formerly used to store salt concentrate processed from the 242-F evaporator system as part of processing low heat waste from F-Canyon facility. The salt form was comprised mostly of sodium nitrate. Waste removal was conducted on Tank $17 \mathrm{~F}$ in 1988 and Tank 20F in 1986. Spray washing of the walls, ceiling, and bottom was conducted on each of these tanks as part of the waste removal effort. Residual amounts of insoluble sludge remains in each tank. Approximately 1000 gallons of sludge remain in Tank 20F. Tank 17F has less than 5000 gallons of sludge remaining, and plans are to remove most of this before closure.

The Tank Closure Plan ${ }^{1}$ prescribes that the closure method is to fill the tank and void spaces with a flowable backfill material. Residual sludge has been evaluated for long term environmental impact. and the performance assessment is summarized in the Tank $17 \mathrm{~F}$ and Tank $20 \mathrm{~F}$ closure modules. ${ }^{2,3}$ A chemically reducing grout has been designed to be placed on the bottom of Tank $17 \mathrm{~F}$ and $20 \mathrm{~F}$ to immobilize the residual waste.

Immobilization is accomplished through two methods. First the waste is maintained in a chemically reduced state which ensures certain species remain as an insoluble oxide or sulfide. In particular, $\mathrm{Tc}^{99}$ becomes relatively insoluble under reducing conditions. $\mathrm{Tc}^{99}$ is the radionuclide that produces the highest doses in Tank $17 \mathrm{~F}$ and $20 \mathrm{~F}$ tank performance evaluations. The grout is also highly alkaline, which reduces the solubility of the plutonium isotopes.

' DOE, 1996, Wastewater Closure Plan for F-and H-Area High-Level Waste Tank Systems, Revision 1.

${ }^{2}$ DOE, 1997, Closure Module Tank 17 System, Revision 0.

${ }^{3}$ DOE, 1996, Closure Module Tank 20 System, Revision 0. 
Secondly, the waste shall be entrapped in the grout form through strategic placement of the grout mix. This method of encapsulation has not been credited in the performance assessment but is considered added assurance in stabilization of the waste form.

A grout development and emplacement testing program was enacted to first design a rugged grout form and then develop a practical means of installing the grout in the waste tank. This report summarizes this program and provides a technical basis for the use of this grout in Tanks $17 \mathrm{~F}$ and 20F. If the performance evaluations for future tanks show that they also need grout with reducing and alkaline properties, then this report may provide the technical basis for those tanks also.

\section{Program Objectives}

\section{Tank Description}

Tank $17 \mathrm{~F}$ and $20 \mathrm{~F}$ are steel-lined single-shell cylindrical tanks with a 1.3 million gallon capacity, concrete walls, and a concrete domed roof without internal support columns or beams. There are no internal cooling coils. Seven (7) tank openings (or risers) are accessed from the tank top. Six (6) 24 -inch internal diameter openings are located at $60^{\circ}$ azimuth positions with the centerline of each riser located approximately five (5) feet from the edge of the tank. The seventh riser is located at the tank center. The distance from the ceiling at the tank center to the tank bottom is approximately 36 feet. The height of the walls is approximately 28 feet.

\section{Residual Waste Description}

A residual heel of sludge material remains in each tank bottom. Samples of the sludge appears to be typical of previous sludge samples on other tanks. Tank farm sludge typically is between $10-40$ wt\% water with a specific gravity of roughly 1.8 and is composed mostly of iron and aluminum compounds (oxides and hydroxides). Tank 20F samples revealed a significant amount of sodium compounds (nitrate, nitrite, oxalate, sulfate, carbonate, and hydroxide). Compounds of manganese and fluoroaluminates (in the form of cryolite) were also identified. ${ }^{4}$ Tank 17F revealed similar compounds but the oxalates, sulfates, carbonates, and cryolite were orders of magnitude lower than that discovered in Tank 20F. ${ }^{5}$ Fission products in small quantities exist in each tank. Radionuclides of concern are technetium $\left(\mathrm{Tc}^{99}\right)$, selenium $\left(\mathrm{Se}^{79}\right)$, and plutonium. These and other compounds were evaluated for migration in the fate and transport modeling conducted for each tank as part of the closure modules.

${ }^{4}$ P. D. d'Entremont and J. R. Hester, WSRC-TR-96-0267, March 17, 1997.

${ }^{5}$ M. S. Hay, WSRC-RP-97-066, January 28, 1997. 


\section{Performance Requirements and Acceptance Criteria}

The reducing grout must accomplish the following functions:

- Provide a chemically stable condition in which key waste constituents will be immobilized.

- Provide a mechanically binding condition in which the waste is entrapped and in contact or close proximity to the chemically reducing matrix.

- Capable of installation from above the tank top.

The chemical reduction coupled with mechanical entrapment provides a more stable condition for long term disposition of the waste.

\section{Chemical Stabilization}

A chemically reducing and alkaline will reduce the mobility of the radionuclides of concern. The environmental performance evaluation conducted in the tank closure modules for. Tanks $17 \mathrm{~F}$ and $20 \mathrm{~F}$ assumed that the first backfill added to these tanks would be reducing and alkaline.

Reducing agents have been added to the grout in the form of sodium thiosulfate (in aqueous form) and ground blast furnace slag. The presence of sulfides provides a chemically reducing environment where the oxidation potential $\left(E_{h}\right)$ is less than $0 \mathrm{mV}$. This environment is maintained to chemically reduce technetium, selenium, and certain other constituents of concern. For example, a reducing grout with $\mathrm{E}_{h}<0 \mathrm{mV}$ will reduce $\mathrm{Tc}^{+7}$ to $\mathrm{Tc}^{+4}$ and consequently precipitate the $\mathrm{Tc}^{+4}$ as $\mathrm{TcS}$. Thus, the reducing environment greatly reduces the mobility of $\mathrm{Tc}^{99}$ The grout is alkaline because it is a cement based material that naturally has a high $\mathrm{pH}$. Studies have shown that $\mathrm{Pu}$ compounds are relatively insoluble at high $\mathrm{pH}$ conditions. ${ }^{6}$

\section{Mechanical Entrapment}

The grout must be placed in such a manner in which any residual waste form will not accumulate in any one location and that grout/waste incorporation is encouraged. This ensures that the residual waste is in close proximity or in direct contact with the chemically reducing environment. Furthermore, the grout must also be strong enough to withstand a subsequent overburden so that long term subsidence is kept to a minimum.

\section{Placement}

The grout must be flowable to allow a near level placement. The near level placement ensures that the reducing agent is deployed properly over the bottom of the waste tank. Furthermore, the leveling capability along with strategic placement locations prevents accumulation of residual waste in any one particular location.

${ }^{6}$ J. R. Cook, SRT-WED-96-0223, August 5, 1996. 
Chemically the reducing grout is required to set. A set time less than 72 hours is desirable to facilitate expeditious installation. The setting occurs as the unhydrated cement pozzolonic and other hydraulic components (e.g. slag and silica fume) react with water to form insoluble phases. These components form the matrix that binds the sand aggregate into a solid, cohesive material.

Table 1 is a tabulation of the performance requirements and the acceptance criteria for the grout material.

Table 1. Performance Requirements and ACCEPTANCE Criteria

\begin{tabular}{|c|c|c|c|}
\hline Requirement & $\begin{array}{l}\text { Measurable } \\
\text { Property }\end{array}$ & $\begin{array}{c}\text { Acceptable } \\
\text { Performance Range }\end{array}$ & Comments \\
\hline \multicolumn{4}{|l|}{ Chemical Stabilization } \\
\hline Alkalinity & $\mathrm{pH}$ & $>9.5 \mathrm{pH}$ units & \\
\hline Chemical Reduction & Oxidation Potential & $<0 \mathrm{mV}$ & \\
\hline \multicolumn{4}{|l|}{ Mechanical Entrapment. } \\
\hline $\begin{array}{l}\text { Full incorporation of } \\
\text { grout with the } \\
\text { residual waste }\end{array}$ & Visual observation & $\begin{array}{l}\text { No residual waste } \\
\text { after final reducing } \\
\text { grout placement. }\end{array}$ & $\begin{array}{l}\text { Placement method } \\
\text { verified by field test }\end{array}$ \\
\hline $\begin{array}{l}\text { Residual waste } \\
\text { distributed over large } \\
\text { surface area. }\end{array}$ & Visual observation & $\begin{array}{l}\text { Residual waste not } \\
\text { located predominately } \\
\text { in one general area } \\
\text { and area of residual } \\
\text { waste after first grout } \\
\text { placement must be } \\
\text { greater than } 25 \% \text { of } \\
\text { total area of tank } \\
\text { bottom. }\end{array}$ & $\begin{array}{l}\text { Placement method } \\
\text { verified by field test } \\
\end{array}$ \\
\hline Compressive Strength & $\begin{array}{l}\text { Compressive strength } \\
\text { after } 72 \text { hours of } \\
\text { placement }\end{array}$ & $>500 \mathrm{psi}$ & $\begin{array}{l}50 \text { psi is required to } \\
\text { comply with the Tank } \\
20 \text { Waste Closure } \\
\text { Module, however, } \\
>500 \text { psi after } 3 \text { days } \\
\text { was observed by } \\
\text { Construction } \\
\text { Technology } \\
\text { Laboratories. }\end{array}$ \\
\hline \multicolumn{4}{|l|}{ Placement } \\
\hline Flowability & Flow cone & $<20$ seconds & $\begin{array}{l}\text { Japanese specification } \\
\text { Kodan } 304\end{array}$ \\
\hline Set time & Compressive strength & $>500 \mathrm{psi}$ in 72 hours & See above \\
\hline
\end{tabular}


WSRC-TR-97-0102

Revision 0

Page 9

\title{
Regulatory Requirements And Program
}

\author{
Regulatory Background For Tank Closure
}

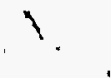

DOE intends to remove from service those HLW tank systems that do not meet the standards set forth in Appendix B of the SRS Federal. Facility Agreement (FFA). DOE, the U.S. Environmental Protection Agency (EPA), and the SCDHEC signed the FFA pursuant to Section 120 of the Comprehensive Environmental Response, Compensation, and Liability Act (CERCLA) for the comprehensive environmental remediation of SRS; the agreement became effective in August 1993. After wastes are removed from individual tank systems, they will be closed under, then removed from, the industrial wastewater permits that regulate their operation.

\section{Regulatory Program For Tank Closure}

\section{High, Level Waste Tank Closure Program Plan}

This Program Plan is the mechanism for managing HLW tank system closures. This document is the highest level Tank Closure Program document. The Program Plan, first completed in December, 1996, is a living document and is to be updated annually. ' The Program Plan includes:

- a general description of the tank system closure program

- a description of the roles of the regulator community in the tank closure

- process

- rationale for the tank closure sequence (which tanks first) - waste removal schedules

- a description of the process for field investigations and remedial áctions.

- monitoring of soils surrounding the tank groupings as they are closed

- method for modeling impacts to the environment

\section{Industrial Wastewater Closure Plan For F-And H-Area HLW Tank Systems}

The purpose of this document is to set forth the general protocol by which DOE intends to close the F- and H-Area HLW tank systems at SRS to protect public health and the environment in accordance with South Carolina Regulation R.61-82, "Proper Closeout of Wastewater Treatment Facilities." This plan presents the environmental regulatory standards and guidelines pertinent to closure of the tanks and describes the process for evaluating and selecting the closure configuration (i.e., residual source term and method of stabilizing the tank system and residual waste material). The plan also describes the integration of HLW tank system closure activities with existing commitments to remove waste from the tanks before closure and ultimately to remediate the F- and HArea Tank Farms. This document was approved by SCDHEC and EPA in July, 1996.

\footnotetext{
${ }^{7}$ DOE, High-Level Waste Tank Closure Program Plan, December 1996.
} 
WSRC-TR-97-0102

Revision 0

Page 10

The specific objectives of this plan are as follows:

- Identify the resources (e.g., human populations, land use, natural and cultural resources) potentially affected by contamination remaining in the tanks after waste removal.

- Describe the relationship between the HLW tank system closure activities and the SRS FFA (Section IX.E) and present the logistics for integrating tank closure activities with the requirements of the agreement.

- Describe the methods DOE will use to remove wastes from the tank systems and stabilize the tank systems and residual waste material.

- Identify the Federal and South Carolina environmental requirements and guidance that apply to the tank closure (e.g., groundwater, surface water, and air emission limits).

- Describe the methodology of using fate and transport modeling to calculate potential exposure concentrations or radiological dose rates from residual wastes in the tank systems.

- Provide the methodology for apportioning environmental standards, through the use of groundwater transport segments as an estimate of contaminate flow, to derive specific performance objectives and other criteria for individual tank systems such that the closure of all F- and HArea tank systems will comply with environmental standards.

- Describe the methods by which DOE will use tank-specific performance objectives and other criteria to select appropriate options for waste removal and closure of individual tank systems and the method for obtaining regulatory approval for those options.

The process outlined in this plan is intended to comply with the requirements of South Carolina R.61-82, and be consistent with the requirements of the Resource Conservation and Recovery Act (RCRA) and CERCLA, under which the F- and H-Area Tank Farms will eventually be remediated. Thus, evaluation and selection of a proposed closure configuration by the process described in this plan will be consistent with evaluation against the following CERCLA criteria [40 CFR 300.430(e)(9)]: (1) overall protection of human health and the environment; (2) compliance with applicable or relevant and appropriate requirements (ARARs); (3) long-term effectiveness and permanence; (4) reduction of toxicity, mobility, or volume through treatment; (5) short-term effectiveness; (6) implementability; (7) cost; (8) state acceptance; and (9) community acceptance.

Tank 20 And Tank 17 Industrial Wastewater Closure Modules For The HLW System

Thus far two Modules have been developed for closing out specific tank systems. Tank 20 Module has been approved by SCDHEC, Tank 17 Module is pending SCDHEC approval. The purpose of these tank specific closure modules is to set forth the plan by which we intend to close the system in accordance with SC Regulation R.61-82 and in a manner consistent with the ultimate remediation 
of the HLW tank farms under the SRS FFA. Because the modules tier from the general closure plan and the Program Plan, its objectives are consistent with those two documents.

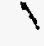

\section{Modeling Summary}

Fate and transport modeling was performed for all of the tanks in the F-Area Tank Farm to support the closure of Tanks $20 \mathrm{~F}$ and $17 \mathrm{~F}$. This modeling estimates potential human health and ecological impacts of residual contamination remaining in Tanks $20 \mathrm{~F}$ and $17 \mathrm{~F}$ after closure. It also estimates the groundwater concentrations and dose levels at the groundwater outcropping ( seepline), which is the established point of exposure.

The modeling assumed (1) use of a reducing grout for isotope stabilization; (2) institutional control for 100 years and subsequent industrial land use; (3) the area immediately around the F-Area Tank Farm remains in commercial/industrial use for the entire 10,000-year period of analysis; (4) the area of commercial/industrial land use extends between Fourmile Branch and Upper Three Runs in the-vicinity of the FArea Tank Farm.

It has been determined that the collective impacts from closing every tank in the FArea Tank farm are below the various regulatory performance objectives. For example, the Tank 20 contribution to the maximum F-Area tank farm dose from drinking groundwater at the seepline is 0.0055 millirem per year out of a total impact of 1.9 millirem per year. This is well within the performance objective of 4 millirem per year.

\section{Discussion}

\section{Grout Design}

Construction Technology Laboratories, Inc., (CTL) of Skokie, Illinois, was tasked to develop a reducing grout for use in Tank $20 \mathrm{~F}$ which could later be applied to Tank 17F. CTL focused primarily on developing a reducing grout that had the following attributes:

- Reducing conditions and alkalinity

- Flowability, self leveling capability

- Compressive strength

- Cohesiveness and avoidance of segregation

- Low water/cement ratio, low permeability

- Chemical composition to incorporate constituents of concern

- Engineering properties (adequate strength, appropriate setting time)

- Minimal bleeding to encourage aspiration of sludge water

Three different formulations of grout were tested by CTL. The basic constituents of each mix were held constant. The variable ingredient was the type of cement. The amounts of cement were adjusted to correct for flowability. CTL recommended a mix design that used 
Type V.cement as its base. All mixes satisfied the performance characteristics however, the Type V cement excelled in fluidity, sulfate and oxalate resistance. Refer to Appendix A.

\section{Formulation}

TABLE 2. REDUCING GROUT INGREDIENTS ONA CUBIC YARd BASIS*

\begin{tabular}{|c|c|c|}
\hline \multicolumn{2}{|c|}{ Reducing Grout Ingredient } & Amount \\
\hline Type V Cement (ASTM C150) & . & $1353 \mathrm{lbs}$ \\
\hline Water (ASTM C94) & & 86.4 gallons \\
\hline \multicolumn{2}{|c|}{ Sand (ASTM C136 passing the following screens): } & $1625 \mathrm{lbs}$ \\
\hline - No. 4 mesh & $100 \%$ & \\
\hline - No. 16 mesh & $70-95 \%$ & \\
\hline - $\quad$ No, 30 mesh & $40-75 \%$ & \\
\hline - No. 50 mesh & $20-40 \%$ & \\
\hline - No. 100 mesh & $10-25 \%$ & \\
\hline \multicolumn{2}{|c|}{$\begin{array}{l}\text { Ground Blast Furnace Slag (ASTM C989 Grade } \\
100 \text { or better) }\end{array}$} & $209 \mathrm{lbs}$ \\
\hline \multicolumn{2}{|c|}{ Silica Fume (ASTM C1240 added in slurry form) } & $90 \mathrm{lbs}$ \\
\hline \multicolumn{2}{|c|}{ Sodium Thiosulfate (Technical Grade), } & $2.1 \mathrm{lbs}$ \\
\hline \multicolumn{2}{|c|}{ High Range Water Reducer (ASTM C494 Type F) } & $175 \mathrm{oz}$. (fluid) \\
\hline \multicolumn{2}{|c|}{ Set Retarder (ASTM C494 Type C or D) } & $56 \mathrm{oz}$ (fluid)" \\
\hline
\end{tabular}

* Manufactured to within the tolerances of the batching facility.

**Amounts considered nominal and are adjusted in the field to achieve the

desired flow cone measurements

\section{Cement}

The mineralogical composition of the Type V Portland cement used for Tanks 17 and 20 is as follows:

Table 3. Type V Cement Chemical Composition

\begin{tabular}{|c|c|c|c|c|}
\hline Compound & $\begin{array}{l}\text { Chemical } \\
\text { Formula }\end{array}$ & Abbreviation & Remarks & $\begin{array}{l}\text { Max. } \\
\text { Wt \% }\end{array}$ \\
\hline $\begin{array}{l}\text { Tricalcium } \\
\text { Silicate }\end{array}$ & $3 \mathrm{CaO} \cdot \mathrm{SiO}_{2}$ & $\overline{C_{3} S}$ & $\begin{array}{l}\text { Initial compound to hydrate and provides } \\
\text { the mix with the initial set and strength . }\end{array}$ & $\overline{38}$ \\
\hline $\begin{array}{l}\text { Dicalcium } \\
\text { Silicate }\end{array}$ & $2 \mathrm{CaO} \cdot \mathrm{SiO}_{2}$ & $\mathrm{C}_{2} \mathrm{~S}$ & $\begin{array}{l}\text { Hardens slower than } \mathrm{C}_{3} \mathrm{~S} \text { and is } \\
\text { predominately responsible for the strength } \\
\text { gains at ages beyond one week }\end{array}$ & 43 \\
\hline $\begin{array}{l}\text { Tricalcium } \\
\text { Aluminate }\end{array}$ & $3 \mathrm{CaO} \cdot \mathrm{Al}_{2} \mathrm{O}_{3}$ & $\mathrm{C}_{3} \mathrm{~A}$ & $\begin{array}{l}\text { Has high heat of hydration and provides } \\
\text { some early strength. Gypsum added during } \\
\text { the cement grinding process slows down } \\
\text { the hydration rate. Cement mixes with low } \\
\mathrm{C}_{3} \mathrm{~A} \text { are resistant to sulfate exposure. }\end{array}$ & -4 \\
\hline $\begin{array}{l}\text { Tetracalcium } \\
\text { Aluminoferrite }\end{array}$ & $\begin{array}{l}4 \mathrm{CaO} \cdot \mathrm{Al}_{2} \mathrm{O}_{2} \cdot \\
\mathrm{Fe}_{2} \mathrm{O}_{3}\end{array}$ & $\mathrm{C}_{4} \mathrm{AF}$ & $\begin{array}{l}\text { Aids in the manufacturing of cement by } \\
\text { lowering the clinker temperature. It } \\
\text { participates in the hydration process but } \\
\text { aids little strength. }\end{array}$ & 9 \\
\hline
\end{tabular}


When these compounds react with water, new compounds are formed:

$\mathrm{C}_{3} \mathrm{~S}: \quad 2\left(3 \mathrm{CaO} \cdot \mathrm{SiO}_{2}\right)+6 \mathrm{H}_{2} \mathrm{O} \rightarrow 3 \mathrm{Ca}(\mathrm{OH})_{2}+3 \mathrm{CaO} \cdot 2 \mathrm{SiO}_{2} \cdot 3 \mathrm{H}_{2} \mathrm{O}$

$\mathrm{C}_{2} \mathrm{~S}: \quad 2\left(2 \mathrm{CaO} \cdot \mathrm{SiO}_{2}\right)+4 \mathrm{H}_{2} \mathrm{O} \rightarrow \mathrm{Ca}(\mathrm{OH})_{2}+3 \mathrm{CaO} \cdot 2 \mathrm{SiO}_{2} \cdot 3 \mathrm{H}_{2} \mathrm{O}$

$\mathrm{C}_{3} \mathrm{~A}: \quad 3 \mathrm{CaO} \cdot \mathrm{Al}_{2} \mathrm{O}_{3}+3 \mathrm{CaSO}_{4} \cdot 2 \mathrm{H}_{2} \mathrm{O}+26 \mathrm{H}_{2} \mathrm{O} \rightarrow 3 \mathrm{CaO} \cdot \mathrm{Al}_{2} \mathrm{O}_{3} \cdot 3 \mathrm{CaSO}_{4} \cdot 32 \mathrm{H}_{2} \mathrm{O}$

$\mathrm{C}_{4} \mathrm{AF}: 4 \mathrm{CaO} \cdot \mathrm{Al}_{2} \mathrm{O}_{2} \cdot \mathrm{Fe}_{2} \mathrm{O}_{3}+2 \dot{\mathrm{Ca}}(\mathrm{OH})_{2}+6 \mathrm{CaSO}_{4} \cdot 2 \mathrm{H}_{2} \mathrm{O}+50 \mathrm{H}_{2} \mathrm{O} \rightarrow$ $3 \mathrm{CaO} \cdot \mathrm{Al}_{2} \mathrm{O}_{3} \cdot 3 \mathrm{CaSO}_{4} \cdot 32 \mathrm{H}_{2} \mathrm{O}+3 \mathrm{CaO} \cdot \mathrm{Fe}_{2} \mathrm{O}_{3} \cdot 3 \mathrm{CaSO}_{4} \cdot 32 \mathrm{H}_{2} \mathrm{O}$

The Type $V$ cement chosen for Tanks 17 and 20 is resistant to sulfate attack, and possesses a low heat of hydration (and thereby reducing the formation of undesirable phases). The cement shall comply with ASTM Specification C150 (1995) Standard Specification for Portland Cement.

\section{Ground Blast Furnace Slag and Sodium Thiosulfate}

Slag has been shown to possess chemically reducing properties that are favorable for technetium reduction and for plutonium and selenium. ${ }^{8}$ In addition, the finely ground slag reacts in high alkaline conditions to form calcium silicate hydrate, which decreases permeability, adds strength, and promotes densification. The slag utilized for the reducing grout shall comply with ASTM Specification C989 (Revision A-94) Standard Specification, for Ground Granulated Blast Furnace Slag. Sodium thiosulfate $\left(\mathrm{Na}_{2} \mathrm{~S}_{2} \mathrm{O}_{3} \cdot \mathrm{H}_{2} \mathrm{O}\right)$ was included in the mix design to create immediate reducing conditions. These conditions established by the sodium thiosulfate will continue until the sulfides from the slag become available.

\section{Silica Fume}

CTL recommended silica fume to be added in a slurried non-densified form to provide a fine particle size constituent. The fine particle size improves flowability in low water to cement ratios. Silica fume is also used to improve cohesiveness and reduce' segregation potential. The silica fume shall comply with ASTM Specification A1240 (Revision A-95) Standard Specification for Silica Fume for Use in Hydraulic Cement, Concrete, and Mortars.

\section{Sand}

Fine mortar sand is added to each mix as a volumetric stabilizer and is used primarily to reduce shrinkage. Because of the relatively large particle size and resultant low relative surface area, sand is essentially an inert material used for filler. The sand selected had strict criteria on particle size. This was necessary to maintain grout fluidity. The sand shall comply with ASTM Specification A136 (Revision A95) Standard Test Method for Sieve Analysis of Fine and Coarse Aggregates.

\footnotetext{
'Langton, 1987.
} 


\section{Admixtures.}

A highly flowable grout is desired with minimal excess water. This was accomplished by using dispersing additives. A high range water reducing agent (commonly known as superplasticizers) was added to maintain grout flowability and cohesiveness. The superplasticizer used for the Tank $17 \mathrm{~F}$ and $20 \mathrm{~F}$ reducing grout shall comply with ASTM C494 Type F. Also,-a set retarding agent will be used to slow the hydration process to allow for a more manageable placement. This admixture shall comply with ASTM C494 Type A or D. CTL reported that the set retarder also helped maintain grout fluidity. The admixtures will be added at doses greater than that used for routine construction concrete. ASTM Specification C494 (1992) is entitled Standard Specification for Chemical Admixtures for Concrete.

\section{Grout Properties}

\section{Redox Potential}

The redox (or oxidation) potential $\left(\mathrm{E}_{h}\right)$ for the grout is designed to be less than $0 \mathrm{mV} .9$ The addition of ground blast furnace slag and sodium thiosulfate provides free sulfides ayailable for reduction with metal cations, specifically plutonium, selenium, and technetium. CTL test results demonstrate the oxidation potential to be less than $-90 \mathrm{mV}$.

\section{Alkalinity}

High $\mathrm{pH}$ conditions are provided by the calcium hydroxide which is a byproduct of the cement hydration reactions. Cured cement is therefore naturally alkaline. The radionuclides of concern are more soluble at low $\mathrm{pH}$ conditions, therefore an alkaline environment has been provided assure greater insolubility with these species. CTL tests demonstrate the $\mathrm{pH}$ to be greater than 12 .

Self Leveling and Fluidity

The reducing grout must be fluid to ensure level distribution in the waste tanks. The grout was initially designed to be poured from the center riser of each tank and allowed to flow to the outer edges. This approach has since been revised to permit multiple pour locations, however the grout must be flowable nonetheless. The grout mix was tested by CTL to show the mix can flow unimpeded for $42 \frac{1}{2}$ linear feet at the expected delivery rate. A special flow cone test was used to determine grout fluidity and homogeneity. The results from the Japanese Kodan 304 flow cone test must be below 20 seconds (and ideally 8 seconds) to ensure proper spreading. It was also shown that the grout possesses strong thixotropic flow behavior with the grout mounding up and then slipping to initiate flow. This "stick and slip" flow behavior

9 J. R. Cook, SRT-WED-96-0230, August 28, 1996. 
is especially evident when pouring onto a unobstructed surface such as from the center riser of a waste tank.

The Type $\mathrm{V}$ cement based grout was primarily chosen because of its relative inertness to the presence of oxalates and sulfates. Tank $20 \mathrm{~F}$ was sampled and shown to have high concentrations $(>10 \mathrm{wt} \%)$ of oxalates and sulfates. Sulfates are considered a set accelerator which would adversely affect flow properties. The oxalates would form calcium oxalate crystals which have a tendency to stiffen the grout mix. CTL reported that the Type V-cement based grout was more resilient to these contaminants and provides a more amenable installation.

\section{Compressive Strength}

The reducing grout has a cement to water ratio and a high cement to filler ratio, therefore, the compressive strength for the material is very high. After three days of curing, lab tests show that the compressive strength exceeds 3000 psi; and after 7 days of curing, strength exceeds 5000 psi. The final strength of the material will approach and possibly exceed 10,000 psi.

\section{Cohesiveness}

The grout has been designed to minimize segregation and enhance cohesiveness. This has been accomplished by selecting constituents that have fine particle sizes. The small size particles are less likely to separate out under free flowing conditions. The grout has the consistency of paint which is chiefly attributed to the fine constituents. Testing at CTL has confirmed that segregation does not occur from free fall drop heights of greater than 20 feet. Testing has also shown an insignificant degradation in compressive strength from drop heights greater than 20 feet. Refer to Appendix B for the test results.

\section{Permeability}

A low permeability grout is qualitatively desired for waste encapsulation but not considered a modeled parameter in the fate and transport modeling for offsite releases. A low permeability material prevents inadvertent moisture intrusion, however, testing for permeability was not conducted.

\section{Chemisorption Capacity and Stabilization}

CTL reports that the chief hydration product, calcium silicate hydrate $\left(\mathrm{CaO} \cdot 2 \mathrm{SiO}_{2} \cdot 3 \mathrm{H}_{2} \mathrm{O}\right)$, is a material with a high surface area that can significantly reduce the mobility of metals via chemisorption (Appendix A).

\section{Set Time}

The set time. for the reducing grout must be slow enough to maintain flowability during installation but rapid enough to permit multiple layering within a week's time. 
WSRC-TR-97-0102

Revision 0

Page 16

CTL has reported, through the use of set retarders, that the grout will not significantly set during the first few hours of installation. But the grout will be sufficiently hard in three days to permit additional lifts.

\section{Bleed Water}

Bleed water is the amount of excess water that floats to the surface of a grout or concrete pour. During routine construction activities, bleed water is not considered a major concern. It is simply drained off. However during tank closure, bleed water management is a logistical problem because any bleed water would have to be considered radioactively contaminated. The reducing grout for tank closure has been designed to essentially eliminate the formation of bleed water.

\section{Heat of Hydration}

The hydration reaction is an exothermic reaction emitting large amounts of heat. Because of the dense nature of grout, heat cannot rapidly escape and is allowed to build up within the volume of grout. CTL tests have shown that the peak temperatures in a 2 foot grout mat have exceeded $180^{\circ} \mathrm{F}$. This heat eventually dissipates. Such heat is not considered a problem from a tank structural or grout integrity perspective. The heating expands the grout. During cooling, shrinkage occurs causing microcracks to form. Fate and transport modeling assumes a permeable grout membrane, and therefore the presence of cracks (or no cracks) is not germane.

\section{Grout Installation}

\section{Specification Development}

SRS Specification No. C-SPP-F-00038 was developed for Tank 17F and 20F backfill materials. The specification incorporated the design requirements for the reducing grout as well as any testing/verification requirements to ensure quality control. Any parameter that may affect the final composition has been incorporated into the specification. The specification has been written to be used by an off-site batching plant or an on-site continuous feed volumetric plant. This allowed procurement flexibility for competitive bidding without sacrificing product quality.

A sole subcontractor has been procured for furnishing Tank $17 \mathrm{~F}$ and $20 \mathrm{~F}$ backfill materials. George L. Throop Co., of Pasadena, California, has been selected to provide the reducing grout and the other backfill materials for Tank $17 \mathrm{~F}$ and $20 \mathrm{~F}$ closure.

\section{Batch Plant Design and Operation}

G. L. Throop Co., located a batching/continuous feed plant approximately 100 yards northwest of the F-Area Tank Farm. The grout is manufactured using a continuous auger feeder. Raw materials is metered onto a conveyor line where they are mixed 
in an auger. The output is intended to have fully mixed grout material. A 4-inch diameter header is fed from the pumping hopper at the grout plant to Tanks $17 \mathrm{~F}$ and 20F.

\section{Placement Method}

The initial plan for grout placement was to pour the material through the center riser of each tank. However CTL testing has shown that the grout displaces the sludge such that any loose sludge floats on top of the grout. Projections are that if the grout were poured through the center riser of the tank, most of the residual sludge in the tank would end up on top of the reducing grout within a few feet of the tank wall. This is an undesirable location for the contaminants after closure, especially in a tank such as Tank 20F that has on the order of 1000 gallons of waste sludge. A more desirable location for the contaminants would be to have the contaminants spread across the tank floor and completely-incorporated in the grout layer.

On March 19-20, 1997, in a test in a 24-foot diameter simulated tank at the Central Shops Facility; it was successfully shown that the distribution of contaminants after closure can be improved by pouring the grout into the tank in more than one location and by pouring the grout in two lifts with an addition of a dry grout mixture between lifts. Grout was alternately poured through six opposing locations then center poured for a total of seven simulating the location of the seven risers in Tanks 17 and 20. After the first lift, dry grout was sprinkled on top of the lift, and then a second lift was poured the next day. The simulated slúdge was effectively incorporated within the grout layer (30\% incorporation on the first lift, $65 \%$ incorporation within the dry grout, and $5 \%$ in the second lift). ${ }^{10}$

This method has proven to be a successful method of grout placement for tank closure and plans are to use it in Tanks $17 \mathrm{~F}$ and $20 \mathrm{~F}$. Other methods of placement are being investigated that may be used in other tanks. For example, it may be possible to push all the sludge to one point in a tank (or a few points) for easier removal. Also, if the amount of sludge in the tank is reduced, other-placement methods become viable, for example, immobilizing the sludge with dry grout before the first pour.

\section{Tank Modifications}

To pour from seven locations on each tank, access holes must be made available from the tank top. Tank $20 \mathrm{~F}$ does not have access to the $\mathrm{W}$ and $\mathrm{NW}$ risers. Access is unavailable for the SW on Tank 17F. Therefore, 8-inch diameter core drills were made in the vicinity of these risers.

${ }^{10}$ Caldwell and Langton, WSRC-TR-97-0101, April 9, 1997. 


\section{Delivery System}

A multiple header system was designed to permit delivery of the grout into each of the access holes. The 4-inch diameter header was fed to a diversion box located on the tank superstructure. Each access hole is set up with a downcomer and delivery pipe which is fed into the diversion box. Construction workers connect a flexible hose from the main grout header to the appropriate access hole delivery nozzle. When each location has been completed, construction crews will disconnect the flexible hose and reconnect it to another location: This will continue until all of the reducing grout is placed.

The dry grout material will placed initially from the center riser using a shot pot blower system. A temporary ventilation system will be rigged to the tank to maintain tank vacuum for contamination control. 


\section{Conclusion}

A reducing grout has been designed for use in the closure of Tanks $17 \mathrm{~F}$ and $20 \mathrm{~F}$ and other tanks need a reducing, alkaline grout. The grout has been shown to chemically and mechanically bind up the residual waste in the tanks. Techniques to deliver the grout to Tank $17 \mathrm{~F}$ and $20 \mathrm{~F}$ have been $\therefore$ zveloped to entrap any remaining loose sludge, and work is ongoing to define how grout should be poured in subsequent tanks. The methods planned for Tanks $17 \mathrm{~F}$ and $20 \mathrm{~F}$ use standard construction practices and equipment. Comparison of the grout properties to the Acceptance Criteria are as follows:

TAble 4. Performance ReQuirements and ACCePtance Ciriteria

\begin{tabular}{|c|c|c|c|}
\hline Requirement & $\begin{array}{c}\text { Measurable } \\
\text { Property }\end{array}$ & $\begin{array}{c}\text { Acceptable } \\
\text { Performance Range }\end{array}$ & Test Results \\
\hline \multicolumn{4}{|l|}{ Chemical Stabilization } \\
\hline Alkalinity & $\mathrm{pH}$ & $>9.5 \mathrm{pH}$ units & $>12 \mathrm{pH}$ units \\
\hline Chemical Reduction & Oxidation Potential & $<0 \mathrm{mV}$ & $<-90 \mathrm{mV}$ \\
\hline \multicolumn{4}{|l|}{ Mechanical Entrapment } \\
\hline $\begin{array}{l}\text { Full incorporation of } \\
\text { grout with the } \\
\text { residual waste }\end{array}$ & Visual observation & $\begin{array}{l}\text { No residual waste } \\
\text { after final reducing } \\
\text { grout placement. }\end{array}$ & $\begin{array}{l}\text { Full incorporation } \\
\text { verified by field tests }\end{array}$ \\
\hline $\begin{array}{l}\text { Residual waste } \\
\text { distributed over large } \\
\text { surface area }\end{array}$ & Visual observation & $\begin{array}{l}\text { Residual waste not } \\
\text { located predominately } \\
\text { in one general area } \\
\text { and area of residual } \\
\text { waste after first grout } \\
\text { placement must be } \\
\text { greater than } 25 \% \text { of } \\
\text { total area of tank } \\
\text { bottom. }\end{array}$ & $\begin{array}{l}\text { Field test verified } \\
\text { sludge spread over } \\
\text { approximately } 34 \% \text { of } \\
\text { tank bottom with } \\
\text { sludge simulant not } \\
\text { concentrated in any } \\
\text { one area. }\end{array}$ \\
\hline Compressive Strength & $\begin{array}{l}\text { Compressive strength } \\
\text { after } 72 \text { hours of } \\
\text { placement }\end{array}$ & $>500 \mathrm{psi}$ & $>3000 \mathrm{psi}$ \\
\hline Placement & & & 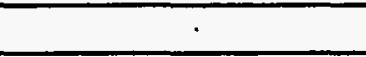 \\
\hline Flowability & Flow cone & $<20$ seconds & $>8$ seconds \\
\hline Set time & Compressive strength & $>500 \mathrm{psi}$ in 72 hours & $>3000 \mathrm{psi}$ \\
\hline
\end{tabular}

It is concluded that the reducing grout meets or exceeds the physical and chemical requirements for use as a closure medium for high level waste tanks. 
WSRC-TR-97-0102

Revision 0

Page 20

\section{References}

Caldwell, T. B., and Langton, C. A., Sludge Displacement Verification for Reducing Grout Report, WSRC-TR-97-0101, Revision 0, High Level Waste Engineering, Westinghouse Savannah River Co., Savannah River Site, Aiken, South Carolina, April 9, 1997.

Cook, J.'R., Interoffice Memorandum to B. T. Butcher, "Basis for Partition Coefficient Values Used in Tank Closure Modeling Study," SRT-WED-96-0223, Savannah River Technology Center, Westinghouse Savannah River Co., Savannah River Site, Aiken, South Carolina, August 5 , 1996.

Cook, J. R., Interoffice Memorandum to B. T. Butcher, "Evaluation of Early Test Results of Grout at CTL," SRT-WED-96-0230, , Savannah River Technology Center, Westinghouse Savannah River Co., Savannah River Site, Aiken, South Carolina, August 28, 1996.

.d'Entremont, P. D., and Hester, J. R., Characterization Tank 20 Residual Waste, WSRC-TR-96-0267, Revision 0, High Level Waste Engineering, Westinghouse Savannah River Co., Savannah River Site, Aiken, South Carolina, March 17, 1997.

Hay, M.S., Interoffice Memorandum to B. T. Butcher, "Characterization of Tank $17 \mathrm{~F}$ Samples in Support of Tank Closure (U)," WSRC-RP-97-066, Savannah River Technology Center, Westinghouse Savannah River Co., Savannah River Site, Aiken, South Carolina, January 28, 1997.

Langton, C. A., "Slag-based saltstone formulations," Mater. Res. Soc. Symp. Proc.: 112 (Sci. Basis Nucl. Waste Management. -11) pp. 61-70, 1987.

United States Department of Energy, High-Level Waste Tank Closure Program Plan, Savannah River Site, Revision 0, Savannah River Operations Office, Aiken, South Carolina, December, 1996

United States Department of Energy, Industrial Wastewater Closure Module for the High-Level Waste Tank 20 System, Savannah River Site, Construction Permit No. 17,424-IW, Savannah River Operations Office, Aiken, South Carolina, January 8, 1997.

United States Department of Energy, Industrial Wastewater Closure Module for the High-Level Waste Tank 17 System, Savannah River Site. Construction Permit No. 17,424-IW, Savannah River Operations Office, Aiken, South Carolina, April, 1997.

United States Department of Energy, Industrial Wastewater Closure Plan for F-and H-Area HighLevel Waste Tank Systems, Savannah River Site, Construction Permit No. 14,338, 14,520, 17,424-IW, Revision 1, Savannah River Operations Office, Aiken, South Carolina,

. July 10, 1996. 
WSRC-TR-97-0102

Revision 0

Page 21

APPENDIX A 


\section{Final Report \\ for \\ WESTINGHOUSE SAVANNAH RIVER COMPANY \\ and \\ UNTED STATES DEPARTMENT OF ENERGY \\ Aiken, S.C. \\ DEVELOPMENT OF REDUCING GROUT FOR \\ CLOSURE OF SAVANNAH RIVER SITE \\ TANK \#20}

UNDER WSRC SUBCONTRACT NO. AB84977S

October, 1996 


\section{TABLE OF CONTENTS}

1. Development of Reducing Grout for Closure of Tank \#20............ 1

Abstract............................................................. 1

Executive Summary ............................................... 1

Background and Concerns ...................................... 3

Background for Tank \#20 .................................. 3

Radionuclides of Concern.................................... 3

Finalization of Experimental Grout Compositions ................. 4

Criteria of Importance and Priorities.......................... 4

Grout Properties Considered Important by CTL................ 5

Trial Compositions and Reasons for Choice...................... 6

Thermal Considerations-Heat of Hydration................... 7

Grout Selection Procedure ..................................... 8

2. Testing Results ..................................................... 10

Large Scale Pour Test .......................................... 10

Vertical and Horizontal Drop Tests.............................. 10

Physical Testing Properties of Grouts and Grouted Sludges ...... 11

Sludge Leaching and Sequential Batch Leaching of

Grouted Sludges .................................................. 11

Grout Diffusion Tests ........................................... 12

Thermal Considerations and Heat of Hydration Tests .............. 12

Effects of Oxalate and Sulfate..................................13

3. Conclusions and Data Analysis...................................... 19

4. References.......................................................... 19

5. Appendices

Appendix A - Procedures

Appendix B - Optical Microscopical Studies of Grouts and

Grouted Sludges

Appendix C - Physical Testing Results

Appendix D - Figures - Leaching of Sludge and Grouted Sludges

Appendix E - Scanning Electron Microscopy/Energy Dispersive

$\mathrm{X}$-ray Analysis

Appendix F - Thermal Properties of Grouts

Appendix G - Heat of Hydration by Conduction Calorimetry

Appendix H - Literature Review, Stabilization of Radionuclides 


\section{List of Acronyms}

CLSM

CTL

DOE

WSRC

SRS

Type I Cement

Type V Cement

Type K Cement

SEM

EDAX

$\mathrm{pH}$

Eh

$\mathrm{C}_{3} \mathrm{~S}$

$\mathrm{C}_{2} \mathrm{~S}$

$\mathrm{C}_{3} \mathrm{~A}$

$\mathrm{C}_{4} \mathrm{AF}$

$\mathrm{C}_{3} \mathrm{~S}_{2} \mathrm{H}_{3}$
Consolidated Low Strength Material (to be added to Tank \#20 over the reducing grout)

Construction Technology Laboratories, Inc.

U.S. Department of Energy

Westinghouse Savannah River Company

Savannah River Site

Portland cement as defined in ASTM Specification C 150

Portland cement as defined in ASTM Specification C 150

A special shrinkage-compensating cement containing the Klein component, $4 \mathrm{CaO} \cdot 3 \mathrm{Al}_{2} \mathrm{O}_{3} \cdot \mathrm{SO}_{3}$

Scanning electron microscopy

Energy-dispersive X-ray analysis

The negative logarithm of the hydrogen ion concentration

The redox potential of an aqueous solution relative to that of the standard hydrogen electrode

Tricalcium silicate (a cement mineral)

Dicalcium silicate (a cement mineral)

Tricalcium aluminate (a cement mineral)

Tetracalcium aluminoferrite (a cement mineral)

A representation for calcium silicate hydrate, a hydration product of portland cement

$\mathrm{C}_{3} \mathrm{~A} \cdot 3 \mathrm{CaSO}_{4} \cdot 32 \mathrm{H}_{2} \mathrm{O}$ Ettringite, a calcium sulfoaluminate hydrate from hydration of hydraulic cement

GBFS Ground granulated blast fumace slag

WRDA
Formulation of high-range water reducing admixture 
WSRC-TR-97-0102

APPENDIX "A"

Revision 0

CTL Tank 20 Reducing Grout Report

Page 25

\title{
Final Report \\ Development of Reducing Grout for Closure of Savannah River Site Tank \#20
}

\begin{abstract}
Three reducing grout formulations were developed and tested for use in closure of a tank formerly containing high-level radioactive waste at the U.S. Department of Energy

Savannah Riyer Site near Aiken, South Carolina: All three grout formulations were shown to possess the desired properties of high $\mathrm{pH}$, low $\mathrm{E}_{\mathrm{h}}$, and high flowability. In addition low permeability, adequate strength, and minimal segregation were prevalent. After careful consideration, the grout selected was based on a composition of Type $V$ portland cement, blast furnace slag, silica fume, fine sand, superplasticizer, water-reducing/retarding admixture, and sodium thiosulfate. This grout is judged to be the most "forgiving" of the three compositions with respect to placement and stabilization requirements.
\end{abstract}

\section{Executive Summary}

Construction Technology Laboratories was subcontracted by Westinghouse Savannah - River Company (WSRC), the prime site contractor for the Savannah River Site (SRS) of the U.S. Department of Energy (DOE), to develop a grout formulation for use in closure of Tank 20, a steel tank containing a residue of high-level radioactive waste at the SRS. A 1000 gallon sludge waste heel remains in the otherwise empty 1.3 million gallon tank. The grout to be developed was to have reducing properties (negative $E_{h}$ ), to fumish a high $\mathrm{pH}$ (>9.5), and to be highly flowable, pumpable, and self-leveling. The compressive strength at 3 days was to be greater than 500 psi. Minimum bleed water was also a desirable characteristic. According to WSRC, the radionuclides of concern for environmental impact are technetium, selenium, and plutonium. Cesium and strontium are of secondary concern.

CTL developed three candidate grout compositions. All three contain fine silica sand, ground granulated blast furnace slag and silica fume. The first contains Type I portland cement, the second a combination of Type I and Type $K$ șhinkage compensating cement, and the third Type $\mathrm{V}$ (low- $\mathrm{C}_{3} \mathrm{~A}$ ) portland cement. All compositions incorporate a highrange water reducing agent and retarding admixture; and sodium thiosulfate $\left(\mathrm{Na}_{2} \mathrm{~S}_{2} \mathrm{O}_{3}\right)$ as a water-soluble reducing agent. The compositions were chosen for their potential, through several different chemical mechanisms, to stabilize the various radionuclides, while at the same time assuring the physical and engineering properties required.

A literature review was conducted during the course of the project. Although the timetable did not permit completing this review before commencing the laboratory work, the results of the review in large part supported the choices made.

It was not possible to work with the actual sludge waste heel from the tank because of its. radioactivity, but a simulated sludge with similar chemical and physical properties was furnished by WSRC. Its composition was adjusted with reagent chemicals to reflect the knowledge of WSRC on the probable actual tank contents. Because it could not be spiked with radioactive elements, non-radioactive isotopes were chosen when possible.

Technetium and plutonium have no non-radioactive isotopes. After careful consideration, it was decided to use molybdenum and thenium as surrogates for technetium, and uranium and cerium as surrogates for plutonium. It was judged that the chemistry of the surrogates was as close as could be obtained to that of the actual radioisotopes. 
The grout formulations were tested for flowability using the Japanese standard flow cone J14. A retention time of less than about 8 seconds was considered necessary for adequate flowability. The compounded grouts were tested for flow and sludge incorporation, as well as ability to avoid segregation. One grout was tested in a large scale pour, using a fo: $m$ which was 90 feet in length and 8 feet in width, with a larger circular central zone. The flowability was good; however, as anticipated, the grout proved to be thixotropic. This result underscores the necessity of maintaining a high flux of grout flow during the actual field placement.

The grouted sludge samples were cored, and selected samples subjected to scanning electron microscopy/energy dispersive X-ray analysis (SEM/EDAX), to detect the degree of incorporation, physically and chemically. Selected samples from the large-scale pour were also examined with an optical microscope. There was some incorporation of sludge within the grout, but the degree of incorporation was found to vary with the rate of flow of the grout.

To investigate the diffusion of the radionuclides of concem into grout assuming no mixing, small samples of all candidate grouts were placed in beakers and covered with a thin layer of sludge. After curing for fourteen days at $48^{\circ} \mathrm{C}$, these samples were also examined using SEM/EDAX. No evidence of diffusion was found; however, this is not surprising since only fourteen days had elapsed. This process usually takes months even with small ions like chloride. Therefore, no applicable comparative data resulted from these tests.

Since the most critical properties of the grouts were high $\mathrm{pH}$ arid reducing capability, the grouts and grouted sludges were tested for $\mathrm{pH}$ and $\mathrm{E}_{\mathrm{h}}$ in the plastic state. The $\mathrm{pH}$ values of the grouts were around 12.5 , with $E_{h}$ values ranging from -140 to $-260 \mathrm{mV}$. Fresh samples of grouted sludge ( 1 part sludge to 5 parts grout) were also adequately alkaline and reducing; they had $\mathrm{pH}$ values near 14 , and $\mathrm{E}_{\mathrm{h}}$ values in the range of -30 to -60 . To investigate which of the grout formulations was most effective in stabilizing the radionuclides of concern, grouted sludges ( 1 part sludge to 5 parts grout) were mixed in a Hobart mixer and cured for 14 days. The specimens were then crushed to pass a $9.5 \mathrm{~mm}$ sieve, and subjected to sequential batch leaching using $0.1 \mathrm{~N}$ acetic acid and $\mathrm{pH} 5$ simulated acid rain (or acidic groundwater) as leachants. A sample of sludge spiked with calcium hydroxide and calcium sulfide (to ensure high $\mathrm{pH}$ and low $\mathrm{E}_{\mathrm{h}}$ ) was also batch leached. The results showed that, in general, grout stabilization was better than mere pH and $E_{h}$ control. For most elements, the three grouts performed approximately equivalently, within the probable reproducibility of the tests. Surrogates for plutonium, cerium and uranium, and also iron, manganese, nickel, and silver were well stabilized in all the grouted sludges. Moderate stabilization was achieved for mercury, selenium, strontium, and molybdenum, a technetium surrogate. Cesium and thenium were stabilized to the smallest degree in grouted sludges. However, extension of the curing time would almost certainly have further improved the stabilization of the elements of concern for all three grouts.

A study evaluating the thermal properties of the grouts on hydration was carried out using conduction calorimetry followed by a thermal modelling calculation procedure. The resulting heat transfer modeling indicates that heat buildup should not be a problem with these grout compositions.

It developed during the course of the project that less water could be pumped out and, therefore, the amount of water in Tank 20 might be greater than had been assumed. To ensure that the grout could maintain its cohesiveness with this greater amount of water, at least to ensure that high $\mathrm{pH}$ and low $\mathrm{E}_{\mathrm{h}}$ reached the sludge, a small experiment was conducted with 0.25 in. of sludge, covered by 1.75 in. of water, and then by 12 inches of 
grout. $E_{\mathrm{h}}$ and $\mathrm{pH}$ measurements verified that penetration would in fact occur all the way to the bottom. It was also discovered that the sludge in Tank 20 contained high levels of oxalate and sulfate heretofore unsuspected. This occasioned a new series of flow cone tests with grout and sludge spiked with oxalate and sulfate, which caused the flow to be g.eatly reduced. It was then decided to carry out another series of flow tests in forms. The irrst form was to contain sludge as received from WSRC, with its own "as received" supernatant liquid. The second was to contain sludge spiked with oxalate and sulfate. with . a supematant liquid spiked with oxalate and sulfate, and also nitrite, nitrate, fluoride. and carbonate. The final form was to contain this spiked sludge and supernatant liquid, but subsequently treated with a $10 \%$ limewater slury containing sodium thiosulfate and calcium sulfide. The final treated form showed the best flow and incorporation of sludge in the grout. Chemical testing for $\mathrm{E}_{\mathrm{h}}$ and $\mathrm{pH}$ showed satisfactory results for all samples.

The ultimate conclusion is that all grouts would probably fulfill the requirements, although Grout \#1 could have flowability problems if the pretreatment option to precipitate oxalate and sulfate is not exercised. Soluble oxalate and sulfate can act as set accelerators for cement, and decrease fluidity. CTL concluded that Grout \#3 is the best option, because of its ability to function under the widest range of conditions.

\section{Background and Concerns}

\section{Background for. Tank \#20}

This tank ( $85 \mathrm{ft}$ in diameter, $35 \mathrm{ft}$ in height, and with a capacity of 1.3 million gallons) is a single-shelled cylindrical tank with $3 / 8$ in. thick carbon steel welded plates for the walls. It had been used for the storage of radioactive wastes derived largely from the separation of uranium and plutonium from fission products in the SRS Canyon buildings. In this process assemblies were dissolved in nitric acid, then these highly acidic solutions were neutralized by the addition of sodium hydroxide before transfer to the tank. The result is a sodium salt waste solution/slurry with precipitated hydroxide sludge, high in iron and aluminum, and with a $\mathrm{pH}>12$. The vast majority of the fluids have been pumped out of the tank to be incorporated in an onsite vitrification process, in the course of which the inorganic constituents are bound in a glass.

There is a residue in the bottom of this tank $(\approx 1000$ gallons sludge and covered by $\approx 3500$ gallons supernate). Early sample results revealed some salts precipitated, including cryolites (alkali fluoroaluminates) and sodium carbonate, but also sludge, high in iron and aluminum hydroxides, alkali carbonates and nitrites/nitrates. From later chemical analytical results, it has been determined that there is a high concentration of sodium compounds (oxalate, carbonate, sulfate, and hydroxide) in the residual sludge and supernate.

\section{Radionuclides of Concern}

The actual amount of radioactive material remaining in this tank is very small. The radionuclides of concern are plutonium, technetium, and selenium, with a lesser degree of concern for cesium and strontium. The levels of these elements are shown in Table 1 (d'Entremont and Hester, 1996). While these concentrations are low, they will benefit from an aggressive control scheme optimizing alkalinity and redox conditions to stabilize the nuclides of concern. 
Table 1-Radioactive Elements-Tank' \#20

$\begin{array}{ccccc}\text { Element } & \begin{array}{c}\text { Curies/L of } \\ \text { sludge }\end{array} & \begin{array}{c}\text { Total } \\ \text { curies }\end{array} & \text { g/curie } & \begin{array}{c}\text { Total } \\ \text { grams }\end{array} \\ \text { Se-79 } & 9.26 \times 10^{-6} & 0.035 & 14.3 & 0.5005 \\ \text { Sr-90 } & 1.16 & 4390 & 0.00719 & 31.5641 \\ \text { Tc-99 } & 2.65 \times 10^{-4} & 1.0 & 58.5 & 58.5 \\ \text { Cs }-137 & 0.078 & 294 & 0.0115 & 3.381 \\ \text { Eu-154 } & 7.35 \times 10^{-3} & 27.8 & 0.00353 & 0.098134 \\ \text { Pu-239 } & 1.1 \times 10^{-3} & 4.15 & 16.1 & 66.815\end{array}$

\section{Finalization of Experimental Grout Compositions}

\section{Criteria of Importance and Priorities}

The following criteria were developed by WSRC as essential properties for any candidate grouts:

\section{Reducing Conditions and Alkalinity}

Modeling has shown that the radionuclides of greatest concern present in the tank include plutonium, selenium, and technetium. All these elements are capable of several valence states. The lower oxidation states, in general, are less soluble in water than the higher oxidation states. It was therefore decided that the grout needed to possess chemically reducing properties, to favor the formation of tetravalent Tc, Pu, and Se. Heptavalent Tc and hexavalent $\mathrm{Pu}$ and Se tend to be more soluble and more difficult to stabilize in cement hydration products than the tetravalent species. It is also considered essential to ensure high $\mathrm{pH}$ in the system, as most of the radionuclides of concern are more soluble at low $\mathrm{pH}$ than under alkaline conditions (Cook, August 1996). The high $\mathrm{pH}$ and chemically reducing features of the grout are regarded as the most critical criteria possessed by the grout.

\section{Flowability, Self-leveling Capability}

The tank is $85 \mathrm{ft}$ in diameter and $35 \mathrm{ft}$ in height. There is only one convenient access to the tank - in the center of the top. The grout will therefore have to be introduced from this access point. It will be difficult to induce horizontal momentum on the flow of the grout, owing to the difficulties in placing bends in the tremie pipe to be used for the introduction of the grout. For these reasons, the grout must have a very high flowability and capability for self-leveling. These criteria are also important, because it is essential for the grout to reach the perimeter of the tank.

\section{Compressive Strength}

The actual compressive strength requirements of this grout are modest (about 500 psi at 3 days). From a structural engineering point of view, it is necessary only for the material to be able to support the weight of CLSM and strong grout to be placed on top of it." 
WSRC-TR-97-0102

APPENDIX "A"

Revision 0

CTL Tank 20 Reducing Grout Report

Page 29

\section{Grout Properties Considered Important by CTL}

Based on experience, CTL considered additional properties to be significant for the performance of the grout. These were as follows:

\section{C: :hesiveness and Avoidance of Segregation}

There is a likelihood that the grout will have to "free fall" a certain distance from the tremie pipe to the floor of the tank. Also, it will have to flow over the floor of the tank from the center to the perimeter. A fluid grout may tend to experience segregation during these procedures if steps are not taken to prevent it. Segregation may tend to cause the sand to sink to the bottom of the grout, and thus be in closest contact with the sludge. It may', in unfavorable cases, serve as a barrier between the sludge and the cement paste matrix, thereby deterring the access of alkaline, reducing species to the sludge. Also, the permeability of the grout may suffer, and the strength may also decrease. The grout was therefore designed to minimize segregation, and assure cohesiveness of the material.

\section{Low Water/Cement Ratio, Low Permeability}

Even though it is important that the grout be flowable, this fluidity must not be obtained with high water/cement ratios. The strength, durability, permeability, and other engineering properties of the hardened grout would all be affected by high water content. This is particularly important since approximately 1000 gallons of sludge and about 3500 gallons of liquid remain in the tank after pumping.

\section{Chemical Composition, to Incorporate Constituents of Concern}

Certain elements are knowin to be readily incorporated into the lattice of cement hydration products. For example, $\mathrm{Cr}^{3+}$ can substitute for aluminum in the lattice of the material ettringite $\left(3 \mathrm{CaO} \cdot \mathrm{Al}_{2} \mathrm{O}_{3} \cdot 3 \mathrm{CaSO}_{4} \cdot 32 \mathrm{H}_{2} \mathrm{O}\right.$ ), and selenium as $\mathrm{SeO}_{4}=$ or $\mathrm{SeO}_{3}=$ can substitute for sulfur in the same material. Also, the main hydration product of cement, calcium silicate hydrate, is a material of very high surface area that can significantly reduce the mobility of a number of metals via chemisorption. The other hydration product of portland cement, calcium hydroxide, is effective in maintaining a high $\mathrm{pH}$.

\section{Ėngineering Properties (Adequate strength. Appropriate Setting Time)}

The question of compressive strength was discussed above. However, strength is a readily measurable property that can be used to reflect other parameters, such as permeability, porosity. For this additional reason, adequate strength is a desirable goal of this grout. The grout will have to have a setting time that will be fast enough to permit the addition of a second lift within several days of placement of the first lift. but a setting time that is too fast will tend to impede the flow characteristics of the grout.

\section{Minimal Bleeding to Encourage Aspiration of Sludge Water}

One important advantage of a low water/cement ratio in the grout is that the water that is associated with the sludge will be more likely to be aspirated into the grout. This desiccation of the sludge by the first layer of grout will tend to physically immobilize any sludge which is presently on top of the grout, so that the second lift of grout can effectively encapsulate it.

To ensure that the aspiration of sludge water occurs, it is desirable to minimize bleed water formation on top of the grout. In a sense, this goal is concomitant with the goal of 
segregation avoidance. As a practical matter, it may be difficult to avoid some bleeding, but it is desirable to minimize it, if such minimization does not compromise the achievement of the above higher-priority objectives.

\section{Tsial Compositions and Reasons for Choice}

\section{Blast Fumace Slag}

It was decided to include blast furnace slag.in all test compositions. Slag has been shown to possess chemically reducing properties that are particularly favorable for the stabilization of technetium (Bostic et al, 1988), and probably also plutonium and selenium (Langton, 1987 and Gilliam et al, 1990). In addition, slag can react with the calcium hydroxide generated by the hydration of the cement to produce additional caicium silicate hydrate, which will decrease the permeability and porosity characteristics of the hardened grout. Slag also tends to make important contributions to later strength gain. By the action of the high sodium content of the sludge, the slag will be activated to make earlier contributions to strength and densification.

\section{Silica Fume}

Silica fume is a useful component of the grout composition for several reasons. First, it will react with calcium hydroxide to produce more calcium silicate hydrate, which will improve the strength, porosity, and permeability of the system. Secondly, it is well known that silica fume improves cohesiveness in mortars and grouts. Since it is necessary to have a very fluid grout, silica fume plays a major role in avoiding serious śegregation problems. In CTL's view, silica fume is an essential ingredient in the grout compositions developed and tested.

\section{Cement Composition Váriables and Reasons (Type I. Type K. Type V)}

Basic Cement Chemistry

Portland cement contains as fundamental mineralogical constituents the materials $\mathrm{C}_{3} \mathrm{~S}$ $\left(3 \mathrm{CaO} \cdot \mathrm{SiO}_{2}\right), \mathrm{C}_{2} \mathrm{~S}\left(2 \mathrm{CaO} \cdot \mathrm{SiO}_{2}\right), \mathrm{C}_{3} \mathrm{~A}\left(3 \mathrm{CaO} \cdot \mathrm{Al}_{2} \mathrm{O}_{3}\right)$, and $\mathrm{C} 4 \mathrm{AE}\left(4 \mathrm{CaO} \cdot \mathrm{Al}_{2} \mathrm{O}_{3} \cdot \mathrm{Fe}_{2} \mathrm{O}_{3}\right)$. Gypsum $\left(\mathrm{CaSO}_{4} \cdot 2 \mathrm{H}_{2} \mathrm{O}\right)$ is added to control the setting of the calcium aluminates. When these minerals hydrate (i.e., when they react with water), new compounds are formed:

- $2 \mathrm{C}_{3} \mathrm{~S}+6 \mathrm{H}_{2} \mathrm{O} \longrightarrow 3 \mathrm{Ca}(\mathrm{OH})_{2}+\mathrm{C}_{3} \mathrm{~S}_{2} \mathrm{H}_{3}$

- $2 \mathrm{C}_{2} \mathrm{~S}+4 \mathrm{H}_{2} \mathrm{O} \longrightarrow \mathrm{Ca}(\mathrm{OH})_{2}+\mathrm{C}_{3} \mathrm{~S}_{2} \mathrm{H}_{3}$

- $\mathrm{C}_{3} \mathrm{~A}+3 \mathrm{CaSO}_{4} \cdot 2 \mathrm{H}_{2} \mathrm{O}+26 \mathrm{H}_{2} \mathrm{O} \longrightarrow \mathrm{C}_{3} \mathrm{~A} \cdot 3 \mathrm{CaSO}_{4} \cdot 32 \mathrm{H}_{2} \mathrm{O}$ (ettringite)

- $\mathrm{C}_{4} \mathrm{AF}+2 \mathrm{Ca}(\mathrm{OH})_{2}+6 \mathrm{CaSO}_{4} \cdot 2 \mathrm{H}_{2} \mathrm{O}+50 \mathrm{H}_{2} \mathrm{O} \longrightarrow \mathrm{C}_{3} \mathrm{~A} \cdot 3 \mathrm{CaSO}_{4} \cdot 32 \mathrm{H}_{2} \mathrm{O}+$ $\mathrm{C}_{3} \mathrm{~F} \cdot 3 \mathrm{CaSO}_{4} \cdot 32 \mathrm{H}_{2} \mathrm{O}$

Ettringite. 'its iron analog, and calcium silicate hydrate $\left(\mathrm{C}_{3} \mathrm{~S}_{2} \mathrm{H}_{3}\right)$ have all been shown cffective in stabilization of various metal cations. Anions, on the other hand. may compete with sulfate for sites in ettringite or its iron-substituted analog. The metals of concern are present both as cations (cerium. strontium, cesium) and as anions (selenium, molybdenum, technetium. rhenium). Uranium and plutonium could be present either as oxycations or oxyanions (as can also molybdenum, if reducing conditions are present). It was therefore judged prudent to include candidate grout formulations that produce higher quantities of ettringite, and also that produce lower amounts.

The amount of mixing of grout and sludge that may occur is unknown. In accordance with the Closure Plan (U.S. DOE. 1996), mixing is not required. To the extent that such 
mixing does occur, it is desirable to provide a cement component whose hydration products have a high likelihood of offering stabilization to the radionuclides of interest in the cementitious matrix; to the extent that this occurs, it will yield a better stabilization than can be achieved with high $\mathrm{pH}$ and low $\mathrm{E}_{\mathrm{h}}$ alone. Type I cements, which contain more $\mathrm{C}_{3} \mathrm{~A}$ th:..l other types of portland cement, and Type K cements, which contain $3 \mathrm{C} .2 \mathrm{O} \cdot 3 \mathrm{Al}_{2} \mathrm{O}_{3} \cdot \mathrm{CaSO}_{4}$, have higher contents of the aluminate component which ultimately can be converted into ettringite. Since stabilization of the elements of concem in aluminate hydration products may be favorable, it was decided that these cements should be included in some of the candidate grout compositions. One of the oxyanions of concem, selenium, is known to produce a selenium-substituted ettringite, which has a solubility far lower than simple pH control can achieve. Grouts with a high content of cement paste will also tend to be susceptible to shrinkage and Type $\mathrm{K}$ cements reduce shrinkage.

If, on the other hand, a high aluminate content proves to be unfavorable, it was deemed advisable to also-include a cement with low content of aluminates. Type V cement was selected to represent this chemistry. Another reason for selecting the Type $V$ cement is the lower heat of hydration characteristic of such low $C_{3} A$ cements. It is desirable, as will be discussed later, to limit the heat of hydration, to avoid too high a temperature in the final hydrated system.

\section{Need for Water Reducer and Superplasticizer to Ensure Low W/C Ratio}

As previously stated, this grout must have a very fluid consistency, must flow and be selfleveling, yet must have good cohesiveness and minimal segregation. At the same time, it is desirable for the grout to have a low water/cement ratio for minimal permeability and good strength characteristics. The simultaneous satisfaction of all these criteria dictates the need for the inclusion of a high dosage of super plasticizer (high-range water reducing agentASTM C 494, Type F). This material must be used at dosage rates considerably higher than normal for construction concrete, and at these dosage rates, this type of admixture may act as a retarder as well as a super fluidifier.

It was also considered of value to include a water reducer/retarder admixture (ASTM C 494-Type $A$ or D). The principal purposes of this material are helping maintain fluidity and slowing down the generation of heat. This material is also added at a dosage rate greater than that used in normal construction concrete.

\section{Thermal Considerations-Heat of Hydration}

\section{Effects on Volume Stability}

-High internal temperatures have an effect on the process of hydration of the portland cement. If the internal temperature were to exceed $70^{\circ} \mathrm{C}\left(158^{\circ} \mathrm{F}\right)$, for example, the ettringite already formed would decompose, and further ettringite formation would be precluded until the temperature again was reduced below $70^{\circ} \mathrm{C}$ (Taylor, 1996). The formation of ettringite after the system has already developed rigidity can also cause expansion and cracking. Also, since the grout has such a high cement factor, the cooling can cause thermal cracking. While this cracking is ackrowledged to be tolerable, it does increase the permeability of the system. In the distant future, when the rainwater percolates down through the reducing grout, the alkalinity and reducing character of the grout would not last as long. For these reasons it is desirable to limit heat evolution on grout hydration. In all probability, however. the degree of any such cracking will be minor, and the net effect will probably be inconsequential to the stabilization properties of the grout. 


\section{Effects on Chemical Stabilization}

Even in cases where the temperatures do not reach $70^{\circ} \mathrm{C}$, the microstructure of the paste is affected by the temperature. General knowledge in the industry has shown that ambient clring temperatures around $20^{\circ} \mathrm{C}\left(68^{\circ} \mathrm{F}\right)$ give a better microstructure than higher iemperatures.

Effects on Incorporation of Sludge

This is expected to be an indirect effect. If the higher temperatures speed the process of cement hydration, the grout will thicken and harden faster, which may deter sludge . incorporation.

\section{Grout Selection Procedure}

With the above series of criteria as a guideline, the procedure described in "Procedure for Optimization of Grout Compositions" in Appendix A was followed. The testing resulted in the selection of three candidate formulations shown in Table 2: 


\section{Table 2-Grout Formulations}

Mix 1

Type I Cement, Slag, Silica Fume, Masonry Sand

lab mix, grams \% by weight Lbs per.cubic yard

Type 1 Cement

GBFS

894

28.07

165

5.18

1062

Silica Fume

120

3.77

1440

45.21

Masonry Sand

.525

33

16.48

196

WRDA, $g$

6

1.04

143

Retarder, $\mathrm{mL}$

1.9

0.19

$\mathrm{Na}_{2} \mathrm{~S}_{2} \mathrm{O}_{3}$ hydrate

3184.9

0.0597

1710

Total

30

100

WRDA, $\mathrm{mL}$

Unit Wt., \#/ft ${ }^{3}$

140.1

Mix 2

Type 1 Cement, Type K Cement, Slag, Silica Fume, Masonry Sand

$\begin{array}{lccc} & \text { lab mix, grams } & \% \text { by weight } & \text { Lbs per cubic yard } \\ \text { Type I Cement } & 760 & 23.91 & 907 \\ \text { Type K Cement } & 165 & 5.19 & 197 \\ \text { GBFS } & 165 & 5.19 & 197 \\ \text { Silica Fume } & 90 & 2.83 & 107 \\ \text { Masonry Sand } & 1440 & 45.30 & 1718 \\ \text { Water } & 522 & 16.42 & 623 \\ \text { WRDA, g } & 29.7 & 0.93 & 5640 z . \\ \text { Retarder, mL } & 4.5 & 0.14 & 850 z . \\ \text { Na2S } \mathrm{O}_{3} \text { hydrate. } & 2.85 & 0.0896 & 3.40 \\ \text { Total } & 3179.05 & 100 & 3794 \\ \text { WRDA, mL } & 27 & & \end{array}$

Unit Wt., \#/ft3

140.5

$\operatorname{Mix} 3$

Type $V$ (low $C_{3} A$ Cement, Slag, Silica Fume, Masonry Sand

lab mix, grams \% by weight

Type V Cement GBFS

Silica Fume

Masonry Sand

Water

WRDA.g

Retarder," $\mathrm{mL}$

Na2S2O3 hydrate.

Total

WRDA, mL

Unit Wt., \#//t ${ }^{3}$
33.67

5.20

2.25

40.44

17.94

0.34

0.11

0.0534

10.0

\section{4}

1.9
Lbs per cubic yard 1353

209

90

1625

721

219 oz.

$\begin{array}{ll}-71 & 0 z .\end{array}$

2.15

.4018 


\section{Testing Results}

\section{Large Scale Pour Test}

Berause of the essential nature of the flowability of the grout, it was decided to provide a reduced-scale simulation of the grout pour using a smaller cross section of a $90 \mathrm{ft}$. circle. The details of the procedure are given in Appendix A. Grout Composition \#2 was chosen as the material for the test and unspiked sludge from WSRC described in Appendix A was spread at several locations in the form. The extent of flow of the grout was as shown in Appendix A. Several important conclusions from this pour were as follows:

- The material self-leveled quite well. The maximum thickness in the middle of the form was 4.5 inches, tapering to about 1 inch at the leading edge which was $39.6 \mathrm{ft}$ from the middle.

- There was some incorporation of the sludge in the grout. When the flow velocity was very slow, the grout tended to flow on top of the sludge, with minimal incorporation. When the velocity was faster, it tended to lift the sludge and fold it back on top of the grout.

- Considering the rather small total volume of grout poured, the distance of traverse was quite satisfactory.

- The grout flowed well when in motion. However, it exhibited thixotropic behavior, in that when it stopped moving, it required some force to overcome the inertia and maintain momentum.

- The flow was better on the west side of the form, where no barriers had been included.

In order to evaluate the cohesiveness (lack of segregation), the sludge incorporation, and the overall grout quality, six samples of grout and grouted sludge were removed from the monolith for examination by optical microscopy and by scanning electron microscopy/ energy dispersive X-ray analysis (SEM/EDAX). Photographs depicting the appearance of the cores are given in Appendix B. These photographs document that there was very little segregation. A thin paste rich layer of about $1 \mathrm{~mm}$ appears on the surface, but in other respects, on a macro scale, the distribution of grout components appears quite uniform.

\section{Vertical and Horizontal Drop Tests}

The purpose of these tests was to further evaluate segregation and bleeding that might occur as a function of the "free fall" height from which the grout was dropped, and to further . investigate the degree of sludge incorporation in grout. These tests were repeated for all three grouts. Forms $2 \mathrm{ft} \times 2 \mathrm{ft}$ by 6 in. were made of lumber and lined with high density polyethylene sheeting. Three forms were available for each grout. In one form, grout was introduced from a height of two ft. and in a second form, the drop height was five ft. A thin layer (about $1 / 2$ in.) of sludge spiked with surrogate elements was placed in the third form. and grout was introduced in a gentle stream horizontally, immediately above the level of the sludge. The form was totally filled with grout, and all forms were allowed to cure about 7 days at ambient temperature and humidity. The forms were then removed. and the contents were cored. The cores were split longitudinally, and half of each core was examined visually and under the stereomicroscope. 
The photographs depicting the appearance of the cores are included in Appendix B, pages 1-14. In general, it can be stated that for all grout compositions, segregation was completely acceptable. Grout 1 experienced the most segregation, and Grout 2 the least. There was no major change in segregation of the various grouts with a $5 \mathrm{ft}$ vertical drop, as crmpared to a $2 \mathrm{ft}$ vertical drop. We conclude that a $5 \mathrm{ft}$ drop probably would not in aterially detract from the cohesiveness of the candidate grouts.

With respect to incorporation of sludge in the grout, Grout 2 appeared to incorporate the sludge more effectively than did the other grouts. The photographs exhibit this difference quite clearly. Because this testing scheme cannot completely simulate that to be used in the actual placement, it is uncertain how much significance can be attached to these differences.

\section{Physical Testing Properties of Grouts and Grouted Sludges}

The engineering properties that were considered important for the performance of the grout were compressive strength, setting time, and volume stability. The requirements were for the setting time to be less than 3 days, the compressive strength to reach 500 psi in 3 days, and for the shrinkage to be low (this latter property was not considered important enough to forego other desirable properties just to minimize shrinkage). ${ }_{1}$ Appendix $C$ details the physical testing data obtained; all criteria were, readily met.

\section{Sludge Leaching and Sequential Batch Leaching of Grouted Sludges}

Using the procedure described in Appendix A ("Procedure for Sequential Batch Leaching"), the sludge was treated with calcium hydroxide and calcium sulfide to ensure high $\mathrm{pH}$ and low $\mathrm{E}_{\mathrm{h}}$. It was subjected to leaching with distilled water, with measurement of $\mathrm{pH}$ and $\mathrm{E}_{\mathrm{h}}$ carried out for each leaching step. The leachates were analyzed for the elements of concern (U, Ce, Mo, Re, Se, Cs, Sr).

The sludge was mixed with samples of each of the three candidate grout compositions, at a ratio of one part sludge to five parts grout. The grouted sludges were examined for $\mathrm{pH}$ and $E_{h}$. After 14 days curing, they were subjected to sequential batch leaching using two leachants - simulated acid rain (at $\mathrm{pH} 5$ ) and $0.1 \mathrm{M}$ acetic acid. The procedure for leaching is described in Appendix A ("Procedure for Sequential Batch Leaching"). The leachates were analyzed for the above èlements, and also for non-radioactive cations $(\mathrm{Hg}$, $\mathrm{Ag} . \mathrm{Mn}, \mathrm{Fe})$ and anions ( $\mathrm{Cl}^{-}, \mathrm{ClO}_{3}{ }^{\circ}, \mathrm{F}^{*}$, and chromate).

The results, together with more detail on the leaching procedures, can be found in Appendix D. In general, the following conclusions can be drawn:

1. Uranium is generally very insoluble in both $\mathrm{pH} / \mathrm{E}_{\mathrm{h}}$ adjusted sludge and grouted sludge matrices. It is better stabilized in the grouts than in the sludge alone. The degree of stabilization with all three grouts is comparable.

2. Cerium is also very insoluble in all low $\mathrm{E}_{\mathrm{h}}$, high $\mathrm{pH}$ matrices. The leachability from the sludge is comparable to that from the grouts at higher $E_{h}$. The leachability at $E_{h}$ values greater than $+200 \mathrm{mv}$ is higher, with Grouts \#1 and \#2 outperforming Grout \#3. Therefore, to the extent that $\mathrm{U}$ and $\mathrm{Ce}$ are reasonable sumogates for plutonium, $\mathrm{Pu}$ would be expected to be very well stabilized.

3. Se is very poorly stabilized in low $\mathrm{E}_{\mathrm{h}}$, high $\mathrm{pH}$ sludge. It is significantly better stabilized in all three grouts. In the simulated acid rain leaching, all three grouts performed approximately equivalently. With the acetic acid leaching, below $E_{h}$ of +250 . all three 
grouts are also roughly equivalent. Above this value, Grouts \#1 and \#2 show lower leachability. The grout makes an important contribution to reduce Se leaching.

4. Re is poorly stabilized in all systems. Chemically, it is rather similar to Tc in most respects, but the reduction potential of highly mobile perrhenate ion $(510 \mathrm{mV})$ is much srialler than that of the also highly mobile pertechnetate ion $(782 \mathrm{mV})$. It is therefore much harder to reduce perrhenate than pertechnetate. A better surrogate is needed. Molybdenum in the hexavalent state proved to be very sensitive to $\mathrm{E}_{\mathrm{h}}$.

5. Sr is much better stabilized in the grouts than in sludge alone, irrespective of $E_{h}$. Cs was not well stabilized in any of the systems studied. However, in the case of both these metals, it is considered likely that longer curing of the grouts would significantly improve retention.

\section{Grout Diffusion Tests}

\section{Summary}

The purpose of these tests was to see whether elements from the sludge would migrate into the grout under the "worst case" condition of no initial mixing of the two. Over an extended period of contact between the two, it is expected that the primary mechanism of transport would be diffusion. The dominant transport mechanism during the exposure time of these specimens is expected to be capillary suction of the soluble'elements from the sludge into the grout. The electron microscope examination described below thus concentrated on the regions near the surface of each specimen, specifically on the cracks that emanated from the surface. At least some of these cracks had formed during the curing of the grout and could be expected to serve as conduits for elements from the sludge into the grout. X-ray dot maps of the areas around these cracks, however, showed that if any elements did enter the grout, their concentrations were below the minimum detection limits of the microscope. It is concluded that a longer time period is necessary to observe the postulated mechanisms. The discussion of the results obtained can be found in Appendix E.

\section{Thermal Considerations and Heat of Hydration Tests}

As has been noted earlier, it was necessary to assess the amount of heat that would be generated in the tank by the hydration of the cementitious materials. This was to ensure that the grout microstructure would not be compromised, or that durability problems associated with alkali or sulfur reactions would not distress the grout physically. The heat of hydration was determined using conduction calorimetry.

In this procedure, a cementitious sample, without sand, is hydrated under pseudoisothermal conditions in a very stable water bath at $23.0^{\circ} \mathrm{C}$. A detailed procedure of the steps required to obtain the data appears in Appendix A. Heat generated by the hydration reaction is nearly simultaneously measured and removed from the sample by a very large heat sink. Data collection began one hour after hydration was initiated. The initial heat in the first hour usually amounts to only 5 to $10 \%$ of the total heat generated. The field production of the grout was expected to occur at a plant where it would be transferred to trucks for delivery. Any heat generated in this period would be lost from the material and 'would not be significant to subsequent calculations of material temperatures in the tank, therefore, beginning data collection one hour after initial hydration was acceptable. If grout production and delivery is planned in another manner, the impact of these assumptions on the calculations of material temperatures in the tank will need to be re-examined. 
The results indicated all three grouts are substantially retarded with the earliest maximum heat generation occurring for Grout \#3 after 32 hours and the latest for Grout \#1, after 83.9 hours. Complete mixing of sludge and grout accelerated the reaction significantly with the strongest interaction between sludge and Grout \#1. When mixed with sludge, the earliest $\pi 1$ ximum heat generation occurred with Grout $\# 1$ and sludge after 11.4 hours and the latest fo: Grout \#2 and sludge after 20.4 hours. A more detailed discussion of these experiments, including figures, appears in Appendix G.

The time that maximum heat generation occurs can be adjusted somewhat by adjusting the amount of set retarder in the mixes; some retardation of set and also a later peak maximum is caused by the superplasticizer. Time of the maximum heat generation will decrease with smaller doses of set retarder. Actual maximum heat generation time of the material, when placed in the tank, will be affected by the amount of sludge and grout mixing. The time of the maximum probably will be intermediate between the two cases at this dosage level.

Cumulative heat of hydration after 112 hours was the greatest for Grout \#3. A greater percentage of this mix was cement than in the other grouts (see Table 2), and the higher cumulative heat, in part, is due to the higher cement content.

The findings were used in calculating the temperature profile in the tank as a function of time, for all three grouts and for all three grouts perfectly intermixed with sludge. These findings are given in Appendix F. Based on these results, there will be no adverse thermal effects resulting from grout hydration for any of the three grouts.

\section{Effects of Oxalate and Sulfate}

During the course of the investigation, samples of actual Tank 20 sludge were being analyzed at WSRC. The results became available in late August, well into the testing program, and showed that the actual sludge in the tank had high concentrations of sodium salts, including carbonate, sulfate and oxalate, and also nitrite and nitrate. The high concentration of sulfate and oxalate were unexpected, as they had not been found in samples of sludges previously analyzed by WSRC. These materials (other than the nitrate) were not present in the simulated sludge with which the early studies had been carried out. : This raised a concern about the flowability of the grout, as calcium ions from cement hydration could interact with carbonate, oxalate, and sulfate to precipitate slightly soluble calcium salts, which could impact flowability. Also, sodium sulfate, and to a lesser extent sodium nitrite and nitrate, are known set accelerators in concrete. For this reason, it was decided to carry out two studies to investigate the extent of the problem.

\section{Flow Cone Tests}

The first of these was a measurement of the flowability using the flow cone method. Each grout formulation was mixed with $20 \%$ of its weight of spiked sludge, spiked with oxalate and sulfate at the $15 \%$ and $8 \%$ by mass levels determined at Savannah River. The flow , cone readings on the grouts without added sludge were as shown in Table 5 below. With unspiked sludge, the flow cone readings for Grout 3 are also given in Table 5. With spiked sludge, all grouts failed to flow from the flow cone, at times after mixing as shown in Table 5. Each grouted sludge was then mixed with $250 \mathrm{ml}$ of extra water. In the case of grouts 2 and 3 , flowability was restored, and acceptable flow characteristics achieved; in the case of Grout 1. however, there was still no flow. 
Table 5-Flow Cone versus Time Tests for 3 Candidate Reducing Grouts

\begin{tabular}{|c|c|c|c|c|c|}
\hline \multicolumn{2}{|c|}{ Grout 1 } & \multicolumn{2}{c|}{ Grout 2 } & \multicolumn{2}{c|}{ Grout 3 } \\
\hline $\begin{array}{c}\text { Min. after } \\
\text { start }\end{array}$ & $\begin{array}{c}\text { Flow Cone, } \\
\text { Sec. }\end{array}$ & $\begin{array}{c}\text { Min. after } \\
\text { start }\end{array}$ & $\begin{array}{c}\text { Flow Cone, } \\
\text { Sec. }\end{array}$ & $\begin{array}{c}\text { Min. after } \\
\text { start }\end{array}$ & $\begin{array}{c}\text { Flow Cone, } \\
\text { Sec. }\end{array}$ \\
\hline 8 & 13.30 & 6.5 & 9.55 & 6 & 11.99 \\
\hline 12 & 12.91 & 12 & 11.07 & 12 & 7.75 \\
\hline 20 & 10.09 & 20 & 11.84 & 20 & 9.84 \\
\hline 30 & 9.49 & 30 & 13.30 & 30 & 11.79 \\
\hline
\end{tabular}

\begin{tabular}{|c|c|c|c|c|c|}
\hline $\begin{array}{c}\text { Grout } 1 \text { with spiked } \\
\text { sludge }\end{array}$ & $\begin{array}{c}\text { Grout } 2 \text { with spiked } \\
\text { sludge }\end{array}$ & $\begin{array}{c}\text { Grout 3 with spiked } \\
\text { sludge }\end{array}$ \\
\hline \multicolumn{8}{|c|}{$\begin{array}{c}\text { Min. after } \\
\text { start }\end{array}$} & $\begin{array}{c}\text { Flow Cone, } \\
\text { Sec. }\end{array}$ & $\begin{array}{c}\text { Min. after } \\
\text { start }\end{array}$ & $\begin{array}{c}\text { Flow Cone, } \\
\text { Sec. }\end{array}$ & $\begin{array}{c}\text { Min. after } \\
\text { start }\end{array}$ & $\begin{array}{c}\text { Flow Cone, } \\
\text { Sec. }\end{array}$ \\
\hline 11 & NO FLOW & 9 & NO FLOW & 10 & NO FLOW \\
\hline
\end{tabular}

\begin{tabular}{|c|c|c|c|c|c|}
\hline \multicolumn{6}{|c|}{ Grouts with oxalate \& sulfate spiked sludge after addition of $250 \mathrm{ml}$} \\
extra \\
water
\end{tabular}

Evaluation of Pretreatment Solutions

The results indicated a need to consider pretreatment of the sludge prior to introduction of the grout. It seemed reasonable to treat the sludge with a combination of calcium hydroxide slurry, sodium thiosulfate, and calcium sulfide. Sodium sulfate is an accelerator for cement hydration, and sodium oxalate is also a stiffener of grouts, since it precipitates insoluble calcium oxalate. Pretreating with calcium hydroxide would precipitate most of the oxalate and sulfate as calcium salts before grout addition, greatly diminishing interactions with the calcium in the grout. The inclusion of the two reducing agents was reached by running a test of the $\mathrm{E}_{\mathrm{h}}$ of solutions made up with various amounts of sodium thiosulfate, and then augmenting the $\mathrm{Na}_{2} \mathrm{~S}_{2} \mathrm{O}_{3}$ with $\mathrm{CaS}$. The $\mathrm{E}_{\mathrm{h}}$ values of the $\mathrm{Na}_{2} \mathrm{~S}_{2} \mathrm{O}_{3}$ by itself were not considered low enough. The addition of small amounts of calcium sulfide had a major impact on the $E_{h}$, as shown in Table 6 . The addition of CaS used was $5 \mathrm{~mL}$ of saturated solution to each $100 \mathrm{~mL}$ of sodium thiosulfate solution. 
WSRC-TR-97-0102

APPENDIX "A"

Revision 0

CTL Tank 20 Reducing Grout Report

Page 39

Table 6-Reducing Potential of Sodium Thiosulfate and Calcium Sulfide

\begin{tabular}{|c|c|c|c|c|}
\hline Sample Number & $\mathrm{GmS} \mathrm{Na}_{2} \mathrm{~S}_{2} \mathrm{O}_{3}$ & mL water & $\mathrm{E}_{\mathrm{h}}$ & $\mathrm{E}_{\mathrm{h}}$ w/CaS addn. \\
\hline 1 & 0.2600 & 100 & 134 & -209 \\
\hline 2 & 0.5846 & 100 & 120 & -204 \\
\hline 3 & 1.0191 & 100 & 94 & -209 \\
\hline 4 & 1.9954 & 100 & 77 & -207 \\
\hline 5 & 4.0753 & 100 & .61 & -208 \\
\hline
\end{tabular}

Flowability Restriction Caused by Oxalate/Sulfate - Grout \#3 Flow Test

To evaluate how severe a flowability problem is posed by the oxalate and sulfate content of the sludge, it was decided to carry out a flow and mixing test. Three trapezoidal forms, 8 $\mathrm{ft}$. in length were constructed and lined with heavy-duty polyethylene. The bottom of each form was covered with a 0.1 in. sludge layer. In the first form, considered the control, or alternately, the simulant for a washed sludge, the sludge was unspiked; it was as received . from WSRC. Sludge procedures and analyses are shown in Appendix A. The supernatant liquid provided by WSRC together with the surrogate (unspiked) sludge was used; a depth of $0.6 \mathrm{in}$. was added. In the second form, the sludge was spiked with the appropriate levels of sulfate and oxalate. In this case, the supernatant liquid was also spiked with sodium carbonate, sodium sulfate, sodium oxalate, sodium fluoride, sodium nitrite, sodium nitrate, and sodium hydroxide. This second sludge and supernate is more representative of the contents of Tank 20 than the unspiked sludge in Form 1. In the third form, the sludge was also spiked, and the spiked supernate was used. In this case, however. the system was further treated with 1.2 in. of a slurry of calcium hydroxide (10\% by mass) with added sodium thiosulfate $(1 \%)$ and calcium sulfide $(0.015 \mathrm{~g} / 100 \mathrm{~mL})$.

It was decided to determine the $\mathrm{pH}$ and $\mathrm{E}_{\mathrm{h}}$ characteristics of the materials in the forms, to clarify interpretation of the measurements to be made after the grout pour. The $\mathrm{pH}$ and $\mathrm{E}_{\mathrm{h}}$ values obtained are given in Table 7 for the unspiked sludge and supernate (Form 1), the spiked sludge and spiked supernatant liquid (Form 2). The spiked sludge with spiked supernate, treated with modified lime slurry (Form 3, wide end and narrow end), and the synthetic supernate itself.

Table 7-pH and $E_{h}$ Values for Samples Prior to Grout Addition

\begin{tabular}{|c|c|c|}
\hline Sample & $\mathrm{pH}(\mathrm{pH}$ units) & Eh. mv \\
\hline Form 1 (unspiked sludge + fumished supernate) & 10.35 & 109 \\
\hline Form 2 (spiked sludge and spiked supernate) & 12.55 & -18 \\
\hline Form 3 (spiked sludge and supernate. pretreated-narrow) & 12.70 & -101 \\
\hline Form 3 (spiked sludge and supernate. pretreated-wide) & 12.75 & -109 \\
\hline Svnthetic spiked supernate & 12.58 & -48 \\
\hline
\end{tabular}

After all three forms had stood overnight for 12 hours, the grout pour was initiated. The procedure involved mixing the grout in a $1 \mathrm{ft}^{3}$ mixer for 5 minutes, then pouring the grout into 5 gallon buckets. The buckets were then emptied into a portable hopper, with adelivery pipe situated directly over the narrow end of the forms. Grout flow was initiated, very gently. to avoid creating unrealistic degrees of turbulence. The progress of the grout front was monitored on a minute-by-minute basis. Table 8 below gives some of the measurement quantities. 
Table 8-Flowability Test to Evaluate Effects of Oxalate and Sulfate

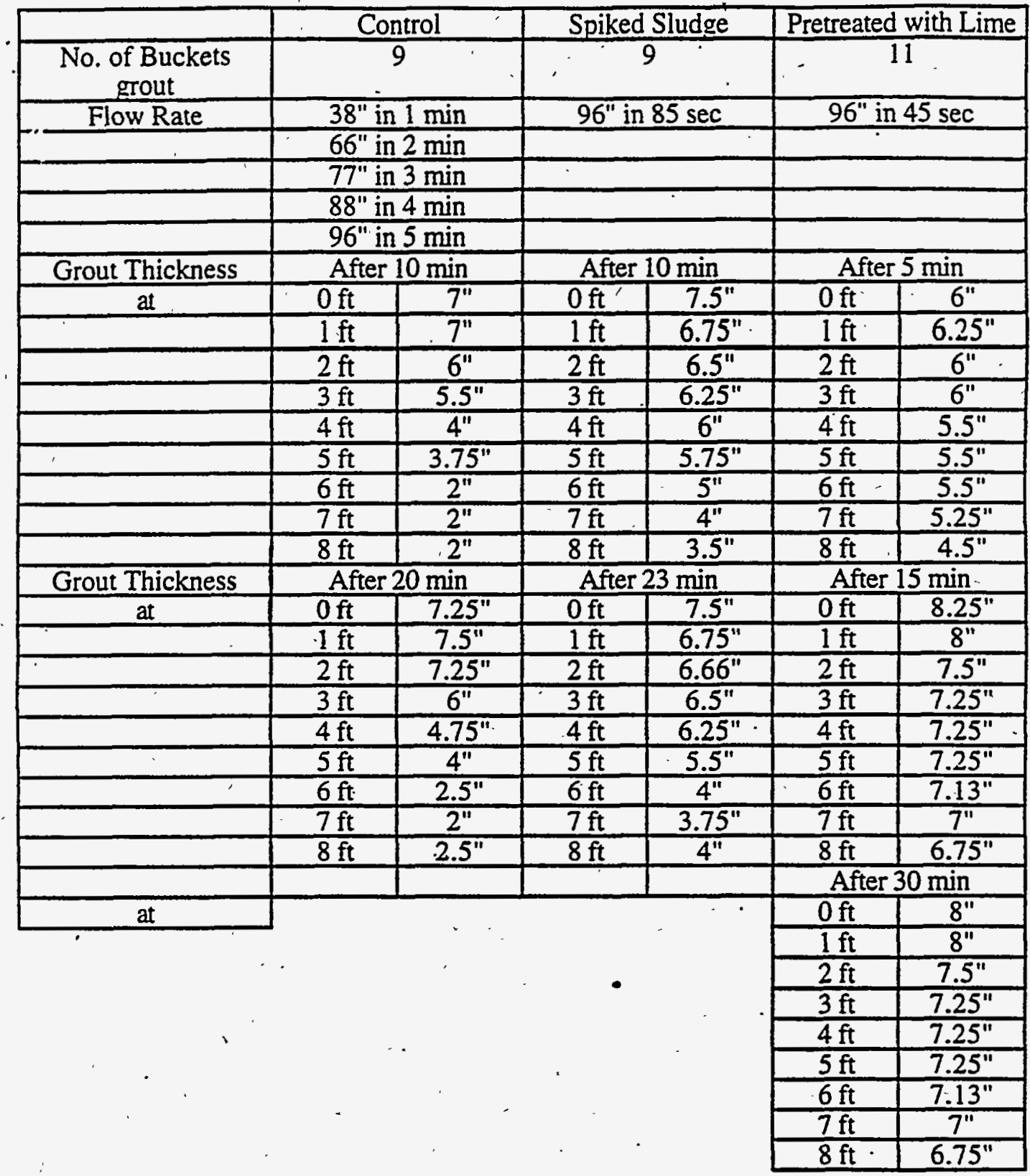

All three experiments gave distinctly different results. In the case of the control, the flow was quite sluggish. The material developed a thickness of 7.25 inches at the feed end of the form. and only $2.5 \mathrm{in}$. at the far end of the form. It did not successfully incorporate -very much of the sludge. A large pool of water and sludge remained on the sample for three days; the sludge was not appreciably desiccated except at its trailing edge. The grout flowed better, surprisingly, in the case of the spiked sludge and spiked supernatant liquid (Form 2). Here also, there was an accumulation of sludge and water at the leading edge of the grout advance. Here however, the grout advariced to the end better. The pretreated sample was radically different in its behavior. The grout immediately flowed to the end of 
the form, and then began advancing upwards through the water, displacing lime and water as it moved. The grout proved to be perfectly self-leveling in this case; the thickness of the grout was nearly constant throughout the length of the form. There was no sludge floating on the top of the grout; in other words, other than the small amount of sludge at the bottom of the form, most of it.was well incorporated within the grout. This experiment represented the best flow and the best sludge incorporation by far. The spiked sludge unexpectedly appeared to hinder the grout flow less than the control, and also to become incorporated in the grout more efficiently.

With respect to incorporation of water in the three cases, the pretreated sample incorporated water most efficiently. There was a uniform 1/8" layer of white material on the top of this specimen after 3 days; this material was probably largely hydrated lime and a little calcium carbonate. The sample with the spiked sludge showed a small amount of supernatant water on the surface, but more sludge and water were incorporated here than in the unspiked sludge sample. In this last case, the water remaining on the surface was substantial.

\section{Cores from the Grout \#3 Flow Test}

The three forms had roughly 6 in. to 8 in. high sides which formed a trapezoid; this defined the bottom of all three forms and all were trapezoids with bases of $3 \mathrm{ft}$, sides of $8 \mathrm{ft}$, and 9 in. tops. After the grout was poured and hardened, 2 cores were taken in each form. Positions of the cores were measured as the distance from the narrow end of the trapezoid to the center of the cores. The cores had 4.25 in. diameters and were taken no closer than $5 \mathrm{in}$. from the sides and most were near the center of the forms. The poured grout was not level and so the length of the cores varied. Next to the wide end of the form, grout depth was measured at several places. In Form \#1 (control), grout depth varied from 1.2 in. to 2.6 in.; in Form.\#2, containing spiked sludge, depths were between 3.5 in. and 4.0 in.; and in the form with pretreated spiked sludge depths varied from 6.2 in. to 6.8 in. All six cores were sawed in half; one half was used for petrographic examination and the other half for $\mathrm{E}_{\mathrm{h}}$ and $\mathrm{pH}$ measurements. Positions and dimensions of the cores are shown above the respective $\mathrm{E}_{\mathrm{h}}$ and $\mathrm{pH}$ data in Table 9.

\section{$E_{h}$ and $\mathrm{pH}$ of Core Sections from the Grout \#3 Flow Test}

The half sections of the cores were sampled by taking approximately 0.25 in. slices from the botrom and middle of each core to obtain 12 samples. Three other samples came from additional slices obtained from the top of cores PSSL2, SSL4, and WSL6 and three slices were obtained high in the core, near the top, for cores PSSL1, SSL3, and WSL5. These slices were crushed in mortar and pestle to a size sufficiently small enough to pass a $3 / 8^{\prime \prime}$. $(9.5 \mathrm{~mm})$ sieve. Weighed portions, each $25.0 \mathrm{~g}$, of these sieved materials were placed in eighteen $500 \mathrm{~mL}$ HDPE bottles along with $450 \mathrm{~mL}$ of deionized water and rotated for two hours on a wheel that tums at $24 \mathrm{rpm}$. Measurement of the $\mathrm{pH}$ and $\mathrm{E}_{\mathrm{h}}$ was carried out according to the procedure in the Appendix A. The bottles were removed and the $\mathrm{pH}$ and $E_{h}$ of the solutions in the bottles were measured with the results as shown in Table 9.

These results show that Grout \#3 provides a matrix with high $\mathrm{pH}(\mathrm{pH}>11)$ and low $\mathrm{E}_{\mathrm{h}}$, uniformly throughout the depth of the grout, and persisting when varying amounts of sludge and grout have intermixed. The high $\mathrm{pH}$ and low $\mathrm{E}_{h}$ conditions are provided in the presence or absence of oxalate and with or without pretreatment. Reducing conditions. indicated by $E_{h}$ values less than $-50 \mathrm{mv}$, are provided throughout the depth of the grout after placement into a sludge layer. Reducing potential is approximately the same, whether a large or small amount of sludge incorporation has occured. 
Table 9-E $\mathrm{E}$ and $\mathrm{pH}$ from Extracts of Crushed Samples from Cores Removed from the Three Forms of the Grout \#3 Flow Test

Cores in Form \#1 and Location of Samples for $E_{h}$ and $\mathrm{pH}$ Tests

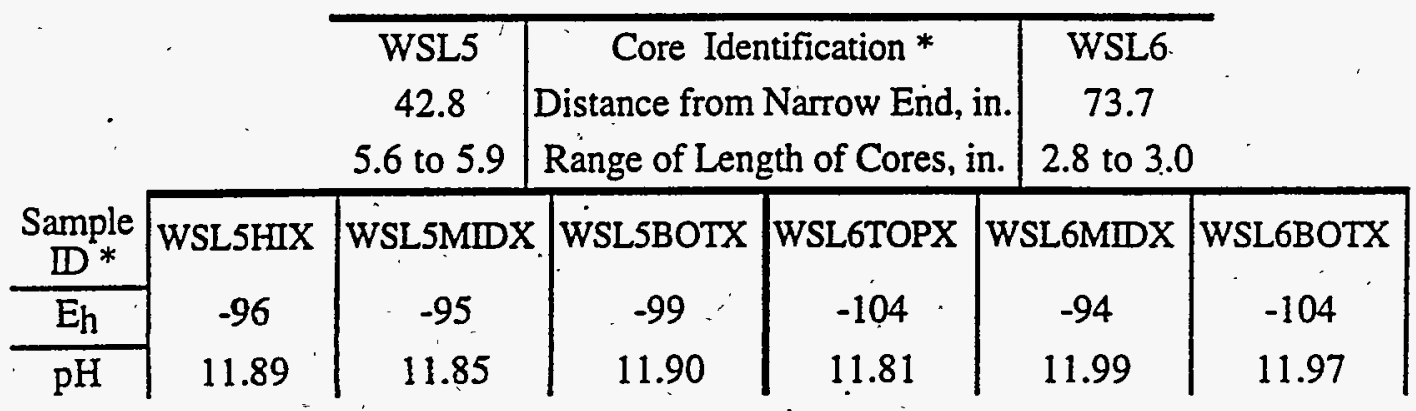

Cores in Form \#2 and Location of Samples for $\mathrm{E}_{\mathrm{h}}$ and $\mathrm{pH}$ Tests

\begin{tabular}{|c|c|c|c|c|c|c|c|}
\hline \multirow[b]{2}{*}{$\begin{array}{c}\text { Sample } \\
\text { ID }^{*}\end{array}$} & & $\begin{array}{c}\text { SSL3 } \\
38.1 \\
6.0 \text { to } 6.25\end{array}$ & \multicolumn{3}{|c|}{\begin{tabular}{|c|} 
Core Identification $*$ \\
Distance from Narrow End, in. \\
Range of Length of Cores, in.
\end{tabular}} & \multicolumn{2}{|c|}{\begin{tabular}{|c|} 
SSLA \\
72.1 \\
4.4 to 4.8 \\
\end{tabular}} \\
\hline & SSL3HIX & SSL3MIDX & SSL3BOTX & SSLATOPX & & SL4MIDX & SSL4BOTX \\
\hline$E_{h}$ & -105 & -106 & -104 & $-156-$ & & -124 & -97 \\
\hline$\overline{\mathrm{pH}}$ & 11.93 & 11.94 & 11.94 & 11.98 & & 11.88 & 11.92 \\
\hline
\end{tabular}

Cores in Form \#3 and Location of Samples for $\mathrm{E}_{\mathrm{h}}$ and $\mathrm{pH}$ Tests

\begin{tabular}{|c|c|c|c|c|c|c|}
\hline \multirow[b]{2}{*}{$\begin{array}{c}\text { Sample } \\
\text { ID* }\end{array}$} & & $\begin{array}{c}\text { PSSL1 } \\
52.7 \\
5.9 \text { to } 6.2\end{array}$ & \multicolumn{2}{|c|}{$\begin{array}{c}\text { Core Identification * } \\
\text { Distance from Narrow End, in } \\
\text { Range of Length of Cores, in. }\end{array}$} & \multicolumn{2}{|l|}{$\begin{array}{c}\text { PSSL2 } \\
88.1 \\
6.2 \text { to } 6.5\end{array}$} \\
\hline & PSSL1HIX & PSSL1MIDX & PSSLIBOTX & PSSL2TOPX & PSSL2MIDX & PSSL2BOTX \\
\hline$E_{h}$ & -96 & -93 & -106 & -114 & -111 & -106 \\
\hline $\mathrm{pH}$ & 11.88 & 11.92 & 12.01 & 12.02 & 11.81 & 11.92 \\
\hline
\end{tabular}

*- WSL denotes "washed" sludge: SSL, spiked sludge; and PSSL, pretreated spiked sludge. Position of the slice of the core is indicated in the Sample ID by bottom=BOT. middle=MID. high $=\mathrm{HI}$, and Top=TOP. $\mathrm{E}_{\mathrm{h}}$ and $\mathrm{pH}$ samples all were extracts indicated by $\mathrm{X}$. 


\section{Petrographic Examination of Core Sections from the Grout \#3 Flow Test}

Optical microscopy with the use of the stereomicroscope confirmed the physical observations. The sludge in the pretreated sample was well incorporated, with the r-xception of a very small amount that was at the bottom of the core. There was a little incorporation in the case of the spiked sludge, but almost none in the control. These findings are documented on pages 15-17 of Appendix B.

\section{Conclusions and Data Analysis}

Based on the combined results of all the testing carried out in the course of this project, CTL concludes that Grout Composition \#3 is the best of the three grout compositions evaluated. All grout compositions tested have good flowability and self-leveling capability. All grouts have the required high $\mathrm{pH}$ and low $\mathrm{E}_{\mathrm{h}}$ values. All grouts can be discharged from as much as five feet above the surface without appreciable segregation. All grouts are believed to be able to maintain their cohesiveness through the, water (1.75 in.) and reach the sludge. All grouts have adequate strength, volume stability, and setting time characteristics, if it is assumed that two lifts of one foot thickness will be placed, with three days in between. All grouts have the potential to provide better stabilization than just $\mathrm{pH}$ and $E_{h}$ control, if some mixing of grout and sludge occur. The principal reason Grout \#3 is suggested is associated with its relative chemical tolerance for high sodium sulfatesodium oxalate - sodium nitrite conditions. Sodium sulfate is an accelerator for cement hydration, and sodium oxalate is also a stiffener of grouts, since it precipitates insoluble calcium oxalate. Grout \#3 has the lowest content of calcium aluminates in the cementitious constituents. Calcium aluminates are the most hydraulically reactive phase in cements, and the most sensitive to the level and form of sulfates.

CTL also believes that the pretreatment of the sludge with lime slurry containing reducing species such as calcium sulfide and sodium thiosulfate will help to ensure success in this tank closure. Pretreatment is recommended to precipitate most of the oxalate and sulfate from the supemate. Test results appear to suggest that this pretreatment is not necessary to ensure that the sludge is maintained at high $\mathrm{pH}$ and low $\mathrm{E}_{\mathrm{h}}$. On the other hand, the grout flowability is greatly enhanced by the pretreatment, and the sludge is clearly more thoroughly incorporated into the grout. Although some segregation appears to result from the extra water present in the pretreatment, it is not considered severe, and is outweighed by the benefits.

\section{References}

Bostic, W. D.; Shoemaker, J. L.; Fellows, R.L.: Spence, R. D.; Gilliam, T. M.; McDaniel, E. W.; Evans-Brown, B.S., "Blast furnace slag-cement grout blends for the immobilization of technetium-containing waste, "Oak Ridge Gaseous Diffusion Plant, Oak Ridge, TN, 62 pp, 1988.

Cook, J. R.. "Basis for Partition Coefficient Values Used in Tank Closure Modeling . Study," SRT-WED-96-0223, Aug. 5, 1996.

d'Entremont, P. D. and Hester, J. R., "Characterization of Tank 20 Residual Waste," WSRC-TR-96-0267, September, 1996. 
4. Gilliam, T. M.; Spence, R. D.; Bostick, W. D.; Shoemaker, J. L.,

"Solidification/stabilization of technetium in cement-based grouts," J. Hazard. Mater., Vol. 24(2-3), pp. 189-97, 1990.

Langton, C. A., "Slag-based saltstone formulations," Mater. Res. Soc. Symp. Proc.: 112

ol (s.i. Basis Nucl. Waste Manage. -11) pp. 61-70, 1987.

Q.2. Taylor, H.F.W., "Ettringite in Cement Paste and Concrete," presented at the conference "Beton: du materiau a la structure," Arles, France, September, 1996.

of United States Department of Energy, "Industrial Wastewater Closure Plan for F- and HArea High-Level Waste Tanks, Savannah River Site," Rev. 1, 10 July 1996.

Appendices

Appendix A- Procedures

Appendix B-Optical Microscopical Studies of Grouts and Grouted Sludges

Appendix C- Physical Testing Results

Appendix D-Figures-Leaching of Sludge and Grouted Sludges

Appendix E- Scanning Electron Microscopy/Energy Dispersive X-ray Analysis

Appendix F- Thermal Properties of Grouts

Appendix G- Heat of Hydration by Conduction Calorimetry

Appendix H-Literature Review, Stabilization of Radionuclides 
Appendix A Procedures 


\section{Standard Procedures Used in Development of Reducing Grout}

The following standards were used in obtaining data for this project for Westinghouse Savannah River Co.

\section{Standard Methods}

- Modified ASTM C 109, "Standard Test Method for Compressive Strength of Hydraulic Mortars," (modified by using the composition of Grouts \#1, \#2, and \#3 instead of the specified composition).

- $\quad$ Modified ASTM C 151, "Standard Test Method for Length Change of Hardened Hydraulic-Cement Mortar and Concrete," (modified by demolding bars at 3 days and following the curing and measurement schedule specified in the text and Appendix C).

- $\quad$ ASTM C 191, "Standard Test Method for Time of Setting of Hydraulic Cement by Vicat Needle."

- $\quad$ ASTM C 939, "Standard Test Method for Flow of Grout for Preplaced-Aggregate Concrete (Flow Cone Method)."

- KODAN 304, "Method of Consistency Test for Non-Shrinkage Mortar." (Test from Japan Highway Public Cooperation using a J14.cone.)

- U.S. EPA, SW-846, Method 311, "Toxicity Characteristic Leaching Procedure" (TCLP).

Standard Practices

- $\quad$ ASTM C 856, "Standard Practice for Petrographic Examination of Hardened Concrete."

- $\quad$ ASTM D 1498, "Standard Practice for Oxidation-Reduction Potential of Water."

\section{Standard Specifications}

- $\quad$ ASTM C 494, "Standard Specification for Chemical Admixtures for Concrete." 


\section{Procedure for Optimizátion of Grout Compositions}

\section{A constant content of slag is chosen for all mix candidates.}

2. The additional cementitious components are selected for their expected chemical capability to stabilize various metals. A cement/sand volumetric ratio of between $1 / 1$ and $1 / 1.5$ is selected. A trial silica fume quantity is estimated based on the anticipated tendency . of the mix to segregate.

\section{The determined amounts of sand, cement(s), slag, and silica fume are weighed.}

4. A water/cementitious ratio between 0.44 and 0.48 is selected, and the water measured out. Sodium thiosulfate (0.06-0.09\% by weight of total grout) is added to the mixing water together with a trial quantity of superplasticizer and retarder.

5. The mixing water, with additives, is placed in the mixing bowl of a Hobart mixer. The cementitious ingredients are added, then the mixer is started at slow speed and mixed for 30 seconds.

6. The sand is added gradually over about 30 seconds, and the mixing continued, still at slow' speed. The consistency is judged during the mixing, and additional superplasticizer or retarder are added as deemed necessary to achieve the desired flow cone reading. If material accumulates at the bottom or on the sides of the bowl, it is scraped down with a rubber scraper.

7. After 5-8 minutes of mixing, the mixing paddle is removed and the grout poured into the flow cone (J14), after placing a gloved finger at the discharge of the cone to prevent leakage. The finger is removed, and the time required to empty the cone is determined. If - the flow cone reading is greater than 12 seconds, the batch is retumed to the mixing bowl for more adjustments with admixtures. If the desired flow has not been achieved by 15 minutes after the first contact of cement and water, the batch is discarded and the process repeated.

8. If a satisfactory flow cone reading has been obtained, the material is poured into a $1 \mathrm{~L}$ plastic graduated cylinder to the $800 \mathrm{~mL}$ mark. The cylinder is gently rocked to consolidate the grout. The sample is allowed to set, and the bleed water determined. The material is examined visually after hardening for segregation.

9. If the grout shows acceptable cohesion, bleeding, and flow cone readings, it is accepted. If the material segregates, more silica fume is added, or the cement/sand ratio is further increased at constant water/cementitious ratio. Either of these steps has been found to reduce segregation. If the material bleeds excessively, silica fume can also help. If the material is inadequately flowable, the content of water reducing admixtures is increased. The water content is not increased. 


\section{Procedure - Large Scale Flowability Test}

- The grout-pouring operation is conducted utilizing two double-compartment grout pumps. Previously batched grout ingredients are charged into the mixing compartments and mixed for approximately 5 minutes to produce uniform grout mixes suitable for pumping.

- The nominal batch size is $2 \mathrm{cu} \mathrm{ft}$, and the grout is prepared to a flow of approximately $27 \mathrm{sec}$ (ASTM C 939) or $6 \mathrm{sec}$ (J 14 funnel).

- Upon mixing, the grout is pumped into a receiving hopper installed on a $15-\mathrm{ft}$ tall scaffold. The hopper's discharge opening is connected to 1 -in i.d. PVC vertical tremie pipe, where the grout flows under gravity until discharged at $2 \mathrm{ft}$ from the surface. Mixing and pumping operations are synchronized to assure a reasonably uninterrupted flow of grout in the tremie.

- Upon discharge from the tremie, the grout flows into a 90-ft long trough made of plywood and covered with polyethylene. The trough is shaped in such a manner that its opposite sides radiate from the zone of grout discharge, roughly forming sectors of the 90-ft diameter circle on either side. Under the circumstances, the trough of this shape produces the closest simulation of circular flow pattem consistent with a moderate volume of grout.

- Simulated sludge is placed on the surface of the trough at various distances from the point of grout discharge, and the rest of the trough surface is sprayed with water to simulate surface condition at the bottom of the tank. 


\section{Results of Flowability Test}

- Tabulated below is the distance from the point of discharge to the leading edge of the poured grout at different time intervals after commencement of the pour.

Time elapsed.

Distance from point of discharge to leading edge on $\min$ west end east end

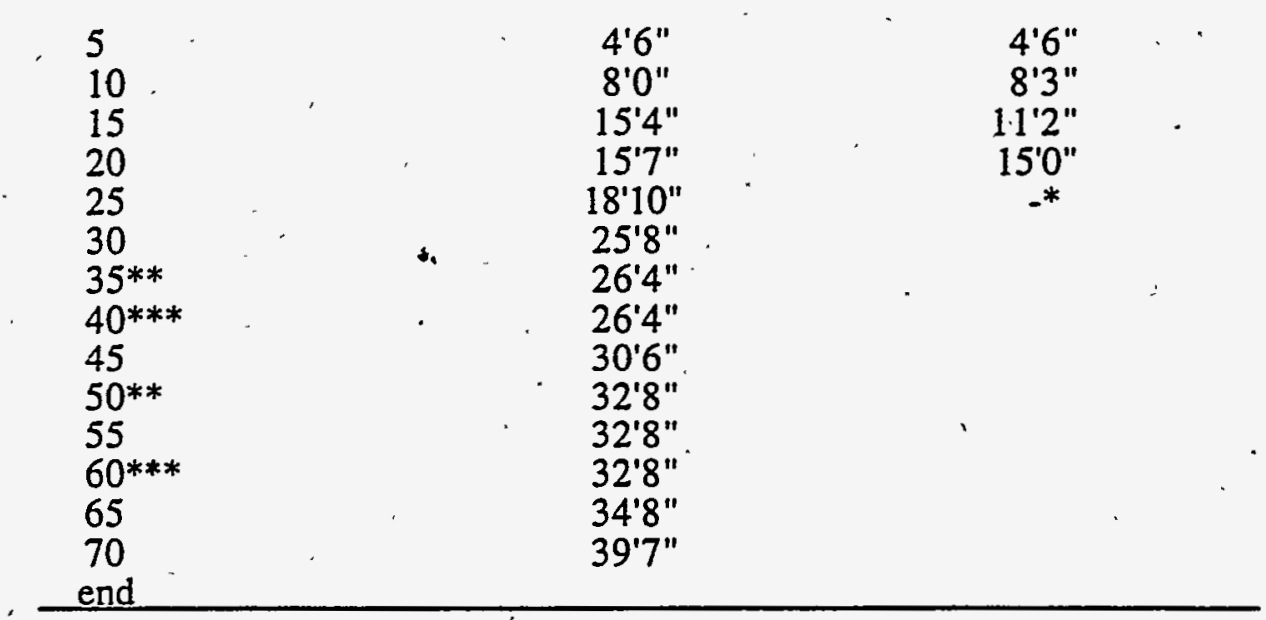

* End of movement of leading edge

** Pour stopped temporarily

*** Pour resumed

- Nominal thickness of grout in place was 4 inches at the point of discharge, tapering down to 1 inch at leading edges of the poured grout 


\section{Procedure for the Preparation of Sludge and Spiking}

- All sludge preparation began with the washed sludge provided to CTL from WSRC. This washed sludge had been prepared for testing of the vitrification process at-SRS. All the chemical processing steps that produced the waste sludge were.duplicated except no radioactive material was used. This resulted in a cold sludge similar in chemical and physical properties to the high level waste sludge in Tank \#20 and similar tanks. This sludge contained $13.98 \%$ solids according to WSRC; chemical analysis of the washed sludge, provided by WSRC, appears in the table below.

- This solids in the washed sludge, as received, settle out and it appears that about 50\% of the volume is clear supernatant and the rest wet solids. At CTL the sludge container was positioned so that the wet solids from the bottom could be drawn off and little of the supernate was withdrawn. Although the weight percent solids varied somewhat, it is thought that the chemical analysis of the dry solids was nearly identical. The weight percent solids (dried at $110^{\circ} \mathrm{C}$ ) varied from 16 to $25 \%$ between - batches drawn at different times and on standing very little supernate separated from the damp solids.

- This thickened washed sludge was used in the large scale pour test and placed at. several locations in the form, then spread out to approximately 0.3 in. thickness. It was also used in Form \#1 of the Grout \#3 Flow. test and the batch used was measured at $22.4 \%$ dry solids. A special leveling tool was used to spread the damp sludge 0.1 in. deep over the bottom. Supernate was removed from the same 55 gallon drum which contained the washed sludge and was used to cover the sludge in Form \#1.

- Spiked sludges were made from thickened washed'sludge which was all obtained before any additions. The whole batch of sludge was thoroughly mixed and then sampled. A dry weight percent was determined and used as the basis for calculating the amount of each compound added to the sludge in order to spike it. One batch of sludge was spiked with surrogates for radioactive elements and other elements to adjust the sludge to closely match a WSRC estimate of the chemical constituents in Tank \#20. Compounds of the following elements were added: uranium, strontium, sodium, cerium, molybdenum, cesium, selenium, silver, aluminum, chromium, cadmium, rhenium, mercury, cobalt, potassium. This surrogate spiked sludge was used in the horizontal drop test into a $2 \mathrm{ft}$ form, the making of grouted sludges prior to the leaching experiments, the sludge leaching experiment, and the grout diffusion experiment.

- A spiked sludge was made by adding only sodium oxalate and sodium sulfate. The batch of washed sludge that was used had been analyzed as containing $16.7 \% \mathrm{dry}$ solids. After the spiking additions, it was determined that the sample had 23:4\% dry solids. This oxalate and sulfate spiked sludge was used in flow cone tests and the Grout \#3 Flow Test in Forms \#2 and \#3.

- An analysis of the washed sludge sample was supplied by WSRC for the containers of sludge that they sent to CTL. The analysis is shown below in three parts. general tests, cation and anions, and elemental analysis of the solid. 


\section{WSRC Analysis of Washed Sludge}

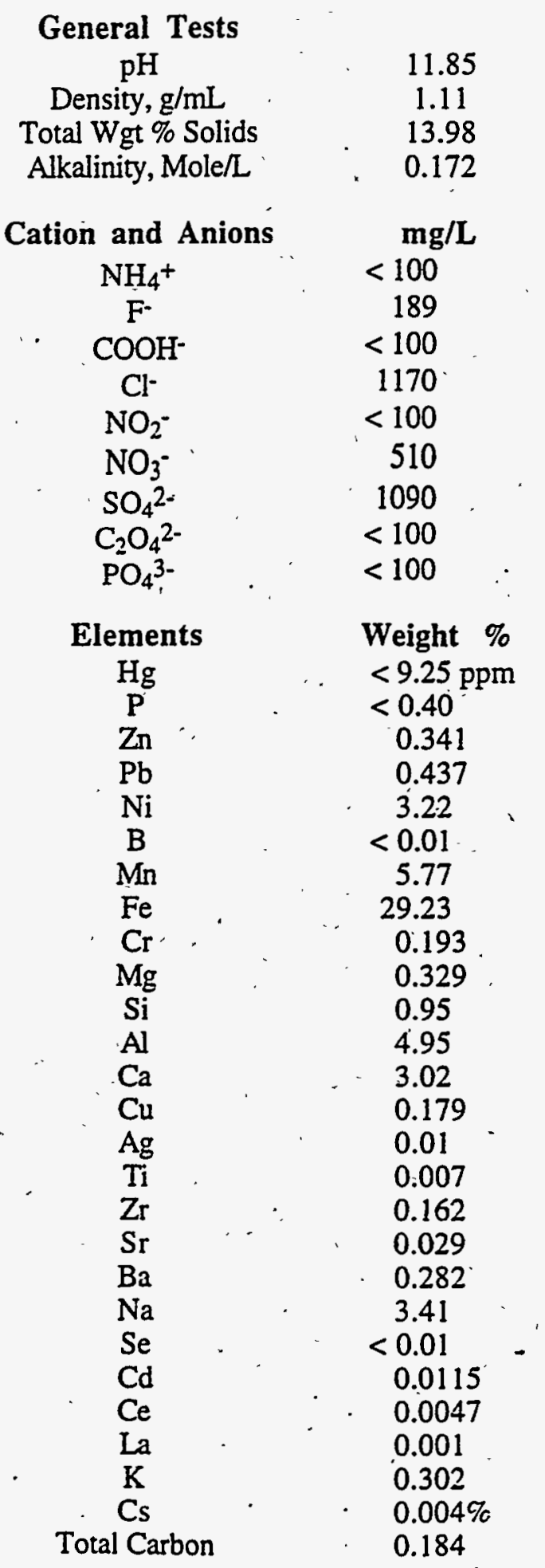




\section{Procedure for Sequential Batch Leaching}

1. The total weight of grout materials is held at 5 times the weight of spiked sludge to be stabilized.

2. The mix water, with rapid reducing agent (sodium thiosulfate), superplasticizer, and retarding admixure are placed in the mixing bowl. The water is mixed for a few seconds at low speed.

3. The cementitious materials are added with mixing during about 30 seconds. The paste is then mixed for about $11 / 2$ minutes. The mixer is stopped during this time to scrape down any paste or water adhering to the sides of the bowl

4. The mixer is stopped, and the sand is added all at once. The mixer is then restarted and the grout is mixed for about 2 minutes, stopping during the mixing to scrape down any grout adhering to the sides of the bowl.

5. The grout is transferred to a small bowl. Only very small quantities of grout may be left in the mixing bowl. The mixing bowl is then tared, and 370 grams of spiked sludge are weighed into the bowl.

6. The grout is rapidly reintroduced to the mixing bowl, and the sludge-grout mixture is mixed at slow speed for at least five minutes. Care is taken to ensure that no unmixed grout or sludge are left at the bottom or the sides of the mixing bowl.

7. The mixer is stopped, and the mixing paddle removed from the mixer. The sludge-grout mixture is introduced into the $25.4 \mathrm{~mm}$ (1 inch) cube molds in two lifts. The remainder of the specimens are cast in $100 \mathrm{~mL}$ plastic beakers.

8 . First the cube molds, then the plastic cups are vibrated on a small vibrating table to remove any air bubbles. The excess sludge-grout is removed from the top of the cube molds, and all specimens are placed in the moist cabinet $\left(100 \%\right.$ relative humidity, $\left.73^{\circ} \mathrm{F}\right)$ to cure.

9. The cubes are demolded at 2 days, and returned to moist curing. Compressive strengths are determined at 3,7 , and 14 days.

10. The beaker samples are allowed to cure for 14 days.

11. The samples are removed from the beakers, and crushed to pass a $9.5 \mathrm{~mm}\left(3 / 8^{\prime \prime}\right)$ sieve.

12. Separate samples of the crushed grouted sludges are leached with a.) Acetic acid of appropriate concentration, starting with $0.1 \mathrm{~N}$ acid, b.) Groundwater simulant, $\mathrm{pH} 4.5-5$, low buffering capacity, acidified with $60 \%$ sulfuric, $40 \%$ nitric acid.

13. A sample of the spiked sludge alone is leached with water, with $\mathrm{pH}$ and $\mathrm{E}_{\mathrm{h}}$ adjusted to match those of the filtrates from the grouted sludges.

14. Both grouted sludge and pure sludge samples are agitated in their leachants in plastic

: bottles for 18 hours at ambient temperature. 
15 At the end of the leaching period, the bottles are removed and the material allowed to set:le for roughly 30 to 120 minutes. The material in the leaching bottles is filtered through Büchner filter funnels, using glass fiber filters, and the leachate collected. Acid-washed glass fiber filters $\left(0.7 \mu \mathrm{m}\right.$ pore size) meeting TCLP criteria are used. The $\mathrm{pH}$ and $\mathrm{E}_{\mathrm{h}}$ of the liquid are immediately measured and recorded. The solid on the filter paper and filter paper are returned to the original leaching bottle; this bottle is filled with another $450 \mathrm{~mL}$ of fresh leaching solution for the next day of leaching; the filter paper is removed before beginning the agitation.

16. The filtrate is then submitted for chemical analysis. 


\section{Procédure for Measuring $\mathrm{pH}$ and $\mathrm{E}_{\mathrm{h}}$}

\section{pH}

1. The $\mathrm{pH}$ electrode is washed with deionized water and after wiping nearly dry with a fresh laboratory tissue, is immersed in standard $\mathrm{pH} 7$ buffer solution and standardized.

2. The electrode is then rinsed with deionized water, wiped nearly dry, and immersed together with the temperature probe in standard $\mathrm{pH} 10$ buffer solution for adjustment of the slope of response vs $\mathrm{pH}$ in the alkaline region.

3. The electrode is then rinsed and reintroduced with the temperature probe into standard $\mathrm{pH} 7$ buffer solution, which is measured as an unknown. If the $\mathrm{pH}$ is within $0.05 \mathrm{pH}$. units of 7.00 , the standardization is considered successful.

4. After rinsing with deionized water, the electrode and temperature probe are immersed in the solution to be measured, and the $\mathrm{pH}$ measured.

5. Measurement of the $\mathrm{pH}$ of additional solutions is done is a similar manner after rinsing the probes with deionized water and wiping them nearly dry between each pair of readings.

5. The sensors are then rinsed and reintroduced into the $\mathrm{pH} 10$ buffer solution to ensure that standardization has remained valid.

$\mathrm{E}_{\mathbf{h}}$

1. E $\mathrm{h}$ measurements are made using a single body combination $\mathrm{Ag} / \mathrm{AgCl}$ reference and platinum redox electrode as an $E_{h}$ electrode. The potential of the $E_{h}$ electrode, in conjunction with the temperature probe, is measured in a ferrous ammonium sulfate/ferric anmonium sulfate standard. This solution should have a potential of $+475 \pm 10 \mathrm{mV}$. It is then checked against a standard potassium ferrocyanide/potassium ferricyanide solution, which should have a potential of $+234 \pm 10 \mathrm{mV}$. If the electrode gives the proper reading with these two solutions, it is reading properly.

2. Immediately before the $E_{h}$ measurement of standard or sample solution, the temperture and $E_{h}$ probes are rinsed with deionized water and wiped nearly dry with a fresh laboratory tissue.

3. The $\mathrm{E}_{\mathrm{h}}$ electrode is introduced into the sample solution, and the potential measured. Solutions with $\mathrm{E}_{\mathrm{h}}$ values less than about $+250 \mathrm{mV}$ are considered to be reducing.

4. Immediately after measuring the potential of a series of sample solutions, the potential of a standard solution is rechecked to ensure calibration stability.

5. Leachate $E_{h}$ values are measured with minimum exposure to the atmosphere, to ensure that atmospheric oxygen does not compromise the validity of the reading. The high content of reducing components in grout or sludge/ grout systems make these measurements less subject to error. 


\section{Procedure for Diffusion into Grout}

1. Each grout is mixed in turn according to the following sequence:

- Weigh out each of the cementitious materials.

- Thoroughly mix the cementitious materials in the dry state.

- Place the water and chemical admixtures (retarder and superplasticizer) into the bowl of the Hobart mixer.

- $\quad$ Add the cementitious materials.

- $\quad$ Mix at speed 3 (fast speed) for one minute.

- Stop the mixer and scrape down the sides and bottom of the bowl with a rubber scraper to dislodge any dry material adhering to the bowl.

- Restart the mixer and add the sand in a steady stream.

- Mix two minutes at speed 3.

- Stop the mixer and scrape the sides and bottom of the bowl.

- $\quad$ Mix an additional minute at speéd 3.

2. The grout is then cast into a $400 \mathrm{~mL}$ beaker to a level of approximately $250 \mathrm{~mL}$.

3. Each beaker is covered with a square of parafilm to prevent moisture loss.

4. The beakers are placed into the laboratory oven, which has been preheated to $48^{\circ} \mathrm{C}$.

5. After at least four hours of curing at $48^{\circ} \mathrm{C}$, approximately $50 \mathrm{~mL}$ of spiked sludge is carefully poured onto the top of each grout to avoid disturbing the grout surface.

6. Each beaker is covered with a new piece of parafilm and retumed to the oven.

7. The grouts are left to cure at $48^{\circ} \mathrm{C}$ for 14 days with the sludge in place.

8. At age 14 days, the sludge is removed from the specimens and discarded in accordance with accepted environmental procedures. The grout is removed from the beaker. If the grout samples cannot be processed immediately, each one is placed inside a ziplock freezer bag and frozen to prevent further diffusion.

9. Two specimens are to be sawcut from each grout sample: one near the surface and one in the interior for comparison purposes. All cutting and polishing is to be done without the use of aqueous coolants or lubricants in order to avoid the dissolution of the materials to be examined. The two specimens are to be approximately $1 \mathrm{~cm}$ cubes.

10. One surface of each cube, chosen from those that were originally perpendicular to the grout surface, is to be polished using a series of successively finer polishing grits to form a smooth surface that will not interfere with the $\mathrm{X}$-ray data.

11. The polished surface of each specimen is to be sputter-coated with carbon to conduct electrons away from the surface, thus preventing charging (which interferes with the data collection). Carbon is selected in preference to gold coating because it causes less interference in the detection of elements of lower atomic mass. 
12. Using an electron microscope, $\mathrm{X}$-ray maps of the elements of interest will be taken at a suitable magnification to be chosen on the basis of the distance of penetration observed. The companion specimens (from the surface and interior of the same grout sample) will be examined together and compared. The maps will show the locations and qualitative concentrations of the various elements. From the scale of the micrograph, it can be seen which elements have penetrated to what depth into the grout. No attempts will be made to quantify the concentrations of the elements in the specimen, as it is believed that after such a short time there is little likelihood of significant penetration. If significant penetration is indicated, and if time allows, attempts will be made to quantify elemental concentrations using the microprobe. 


\section{Procedure for the Conduction Calorimetry Measurement of Heat of Hydration}

- All the cement ingredients, cements, silica fume, and blast furnace slag for each of the three mixes, previously described, were dry blended in large quantities to insure accurate proportions and good blending. No sand was used.

- A supply of approximately $50 \mathrm{~mL}$ of water and admixtures was prepared with correct proportions for each of the thiree grout mixes. These liquids contained water; sodium thiosulfate, WRDA-19 superplasticizer, and Daratard 17 retarder in the proper amounts for each mix.

- Samples for an experiment were placed in a plastic bag and then heat sealed with a plastic bag sealer. Blended cementious ingredients (cement(s), ground blast furnce slag, and silica fume) weighing 8.00 grams were introduced first and then the correct volume of blended admixtures and water was added by pipette when only the cement for a grout mix was tested. If grout and sludge were being tested then sludge weighing $20 \%$ of the combined cement ingredients and mix water solution amount was placed in the bag first followed by 8.00 grams of cementious ingredients and then the proper volume of mix water solution. After sealing, the contents of the bag was quickly and thoroughly mixed.

- The bag was placed in the conduction calorimeter cell wrapped around an internal calibration heater and placed on the heat sensors. The electrical connections were made and then the outer shell was sealed and placed in the water bath. One hour after mix. water and cement ingredients were combined the computer data acquisition program was begun, after the cell had thermally equilibrated with the bath water. Data points were obtained at 6 minute intervals over the majority of the conduction calorimeter measurement.

- A JAF Wexham Conduction Calorimeter from C\&CA Services in England was used to obtain the data utilizing their software. At the end of the run, the instrument was calibrated using the internal heater in the cell. The millivolt output was converted to the rate of heat generation using the constants determined in the calibration and the Tian-Calvet equation. Numerical integration of the rate yields the total heat generated expressed in kilojoules per kilogram. 


\section{Procedure for the Grout \#3 Flow Test into Three Forms}

Objective: To determine effects of oxalates and sulfates in a Tank \#20 surrogate sludge and supemate on the flow properties of grout \#3, the effect of pretreatment of the sludge, and the effect of both on the $E_{h}$ and $\mathrm{pH}$ of the mixture of sludge and reducing grout after it has hardend.

1. In all three forms $0.1 \mathrm{in}$. of sludge covered the entire bottom of the form. The first form contained washed cold sludge sent earlier from SRS to CTL. The other forms contained washed cold sludge spiked with $15 \%$ oxalate ion and $8 \%$ sulfate ion. The added material was calculated as a weight percent of the dried sludge.

2. Three plastic-lined trapezoidal forms were used; the sides of the trapezoid were $8 \mathrm{ft}$ long, the base was $3 \mathrm{ft}$ wide and the top 9 inches wide. All forms were constructed with lumber and mounted on a $4 \mathrm{ft} \times 8 \mathrm{ft}$ plywood sheet. The sides of the first form were made with 2 in. $x 6$ in. lumber (actual depth 5.6 in.), the second form was made in the same way but, in addition, had trim strips at the narrow end to increase the depth to 7 in. The sides of the third form were made with 2 in. $x 8$ in. lumber with an actual depth of 7.6 inches.

3. Supernate liquid was added to all the forms to a calculated depth of $0.6 \mathrm{in}$. If the sludge and supernate depths were additive, it would total 0.7 in. In the first form the supernate wasnobtained from the drum of washed cold sludge at CTL. In the other forms a synthetic supernate, as described by Chris Langton in a 9/9/96 fax to CTL, was added; this was a solution of $2 \mathrm{M}$ sodium carbonate, $0.7 \mathrm{M}$ sodium nitrite, $0.17 \mathrm{M}$ sodium hydroxide, and lesser concentrations of sodium salts of sulfate, fluoride, nitrate, and oxalate. A minimum of 6 hours was allowed to let the sludge solids settle after addition of the supernate.

4. A pretreatment solution was added to the third form in a volume calculated to have a depth of 1.2 in., twice the depth of the supernate. If additive, the total depth would be 1.9 inches. The pretreatment solution was primarily a lime slurry; it was composed of $10 \mathrm{~g} / 100 \mathrm{~mL}$ of calcium hydroxide, $1 \mathrm{~g} / 100 \mathrm{~mL}$ of sodium thiosulfate, and $0.015 \mathrm{~g} / 100 \mathrm{~mL}$ of calcium sulfide. This slurry was added at the narrow end of the form using a $1.5 \mathrm{in}$. horizontal discharge similar to the manner of grout addition. A minimum of 12 hours elapsed after addition of pretreatment solution and before addition of grout.

5. A portable hopper, rougly $3 \mathrm{ft}$ square at the top, discharged down through a valve and then through a $90^{\circ}$ elbow to direct the grout horizontally. This hopper was positioned at the narrow end of each form before grout placement. Buckets of grout poured into the hopper were counted to measure the volume of grout added. Grout was mixed in a standard grout mixer with ingredients added in the following order: water, admixtures, and reducing agent first, the preweighed cementitious ingredients second, and the masonry sand last. Each batch was mixed between 3 and 5 minutes before grout was pumped. 
6. Measured volumes of grout \#3, containing a low $\mathrm{C}_{3} \mathrm{~A}$ Type $\mathrm{V}$ portland cement as described earlier by CTL and used in other experiments for WSRC, was added to each form while maintaining a slow non-turbulent continuous flow by horizontal discharge slightly above the narrow end of each form. The volume of grout was sufficient to reach the far end of the form and have a depth there of greater than 2 inches. Grout flow was monitored by timing the advance of the front of the grout.

7. After the grout was poured, the depth of liquid at the wide end of the form was measured and then the forms were covered with plastic and cured for 3 days. After 3 days the depth of liquid at the same place in the form was measured.

8. After 4 days, the material in the forms had hardend and vertical cores of the grout were obtained at two locations in each form. Each core of material was cut into at least three sections. Each cut section was ground sufficiently to pass through a $9.5 \mathrm{~mm}$ sieve and 25.0 $g$ of this ground material was placed in a $500 \mathrm{~mL}$ HDPE bottle and $450 \mathrm{~mL}$ of deionized water was added. The closed bottles were placed near the rim of a wheel. The wheel slowly rotated for a minimum of two hours. After removal from the wheel, the $\mathrm{pH}$ and the $E_{h}$ of the equilibrated solution was obtained. 
Appendix B

Petrographic Examination of Grouts and Grouted Sludges 


\section{CTL}

\section{PETROGRAPHIC SERVICES REPORT}

Client.: Westinghouse Savannah River

Project: Reducing Grout Formulation

Contact: Mr. Dale Bignell

Submitter: F. M. Miller

Samples Recv'd: August 1996

Date: September 20, 1996

\section{Scope of Work:}

An abbreviated petrographic examination of the samples submitted was performed in general accordance with the procedures given in ASTM C 856-83 (reapproved 1988), "Standard , Practice for Petrographic Examination of Hardened Concrete." The samples were visually inspected. Each sample was cut longitudinally and one of the resulting halves was lapped for examination using a stereomicroscope at magnifications up to $45 \mathrm{X}$. Freshly broken surfaces were also studied with the stereomicroscope. The samples were examined for evidence of segregation, cracking, and incorporation of the sludge simulant.

The results of the brief examinations are presented on the following pages with photographs showing the lapped, longitudinally cut surfaces of the cores. The samples are identified by grout mix number and treatment, according to the information provided.

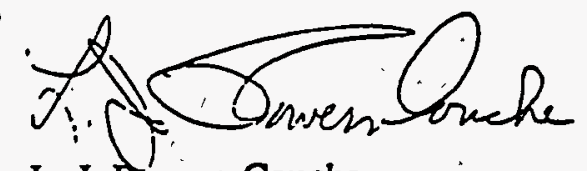

L. J. Powers-Couche

Senior Petrographer

Petrographic Services 
$i=$

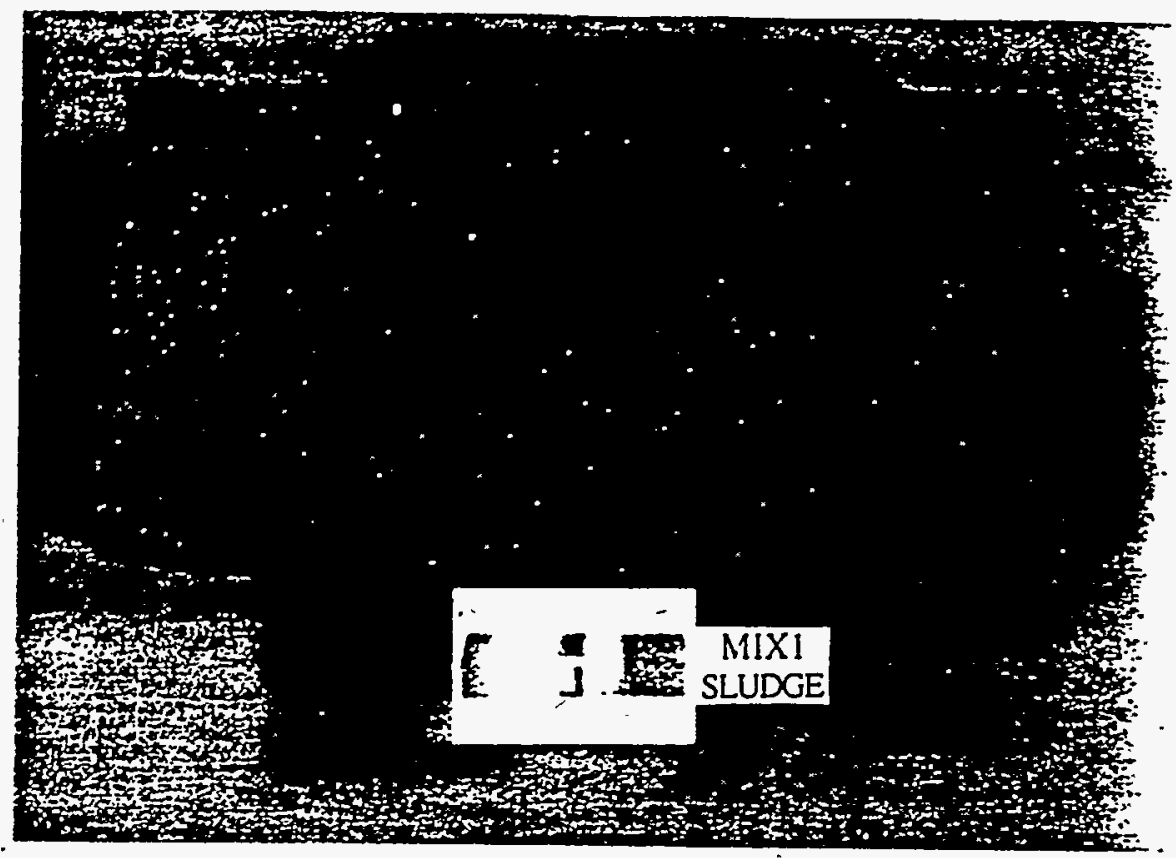

MXX 1 SLUDGE 1: Fairly uniform distribution of constituents with only minor local variations in paste volume and air content mostly limited to the top and bottom 0.1 to 0.2 in. Sludge does not appear to be incorporated into the grout. Vertical microcracks extend to $1.2 \mathrm{in.}$. from top.surface and 0.5 in. from bottom surface.

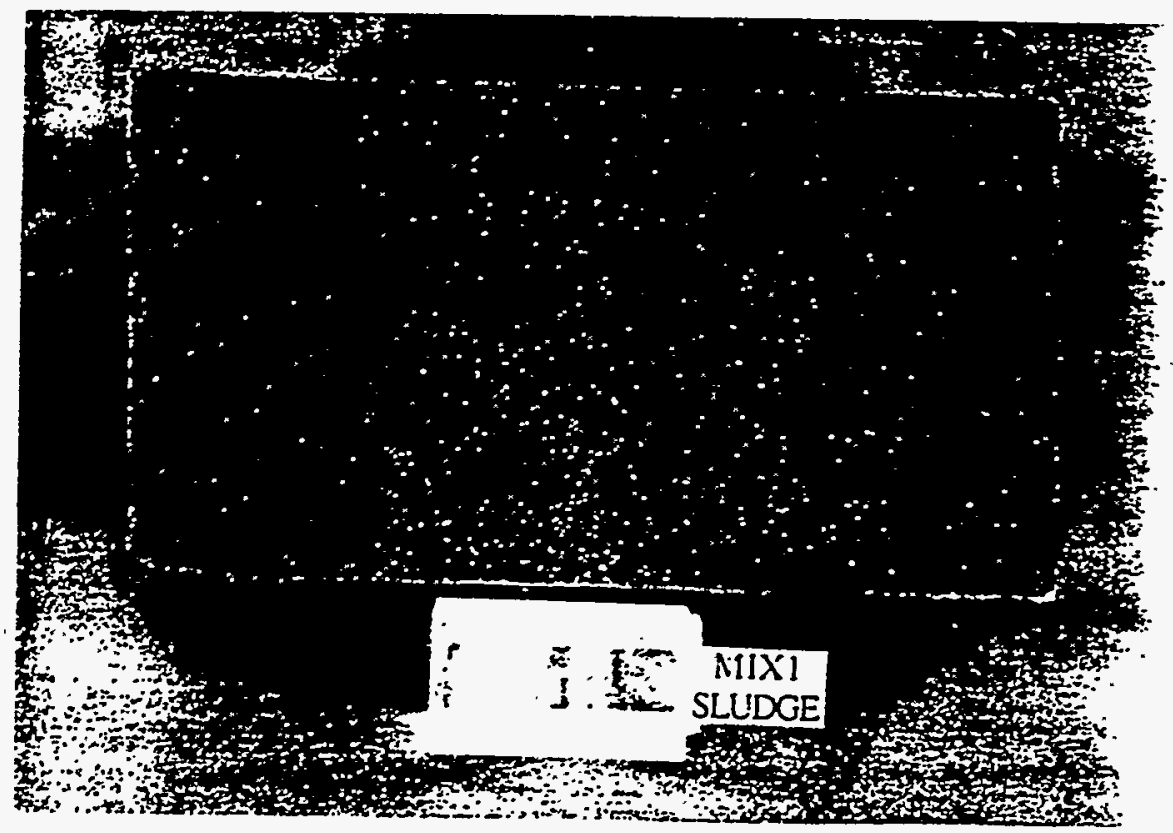

MIX 1 SLUDGE 2: Similar to sample shown above. Sludge does not appear to have been incorporated. 
is

$\therefore .:$

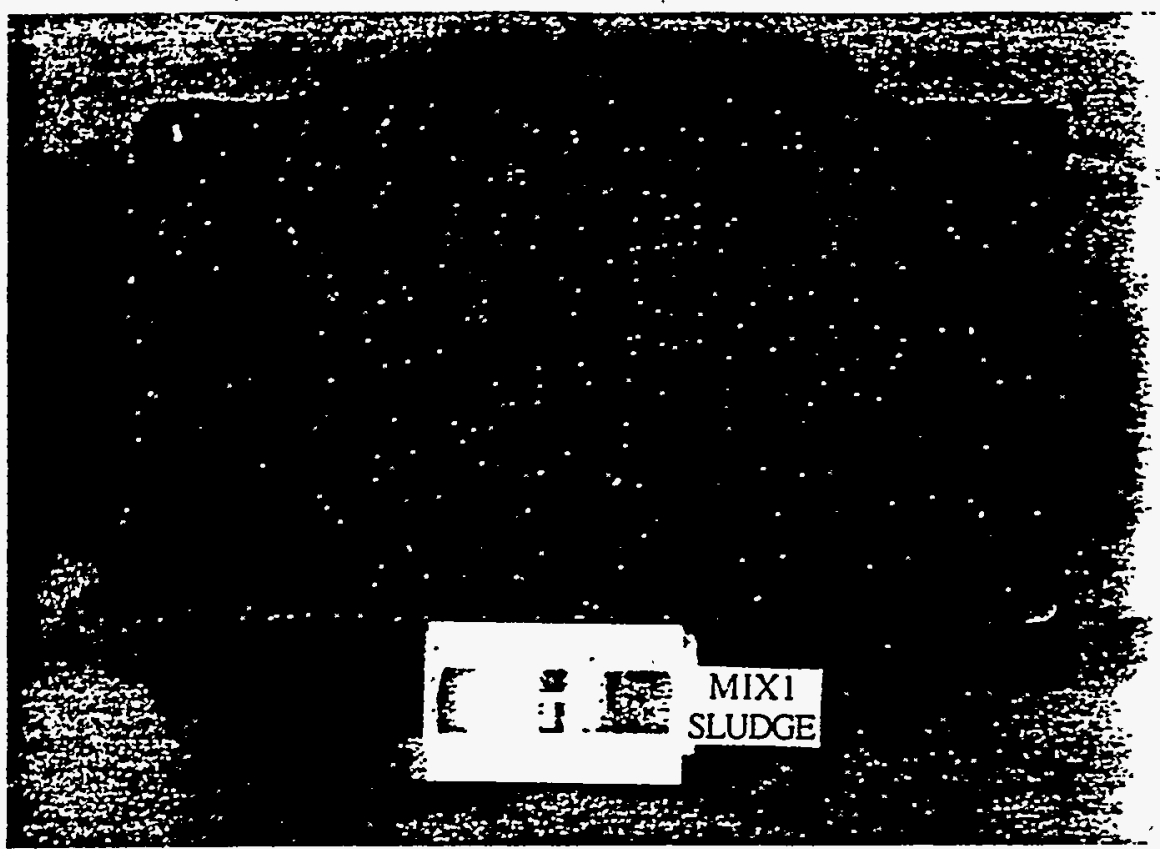

MIX 1 SLUDGE 3: Fairly uniform distribution of constituents with only minor local variations in paste volume and air content mostly limited to the top and bottom 0.2 in. Sludge does not appear to be incorporated into the grout. Vertical microcracks extend to $1.0 \mathrm{in}$. from top surface and $0.3 \mathrm{in}$. from bottom surface.

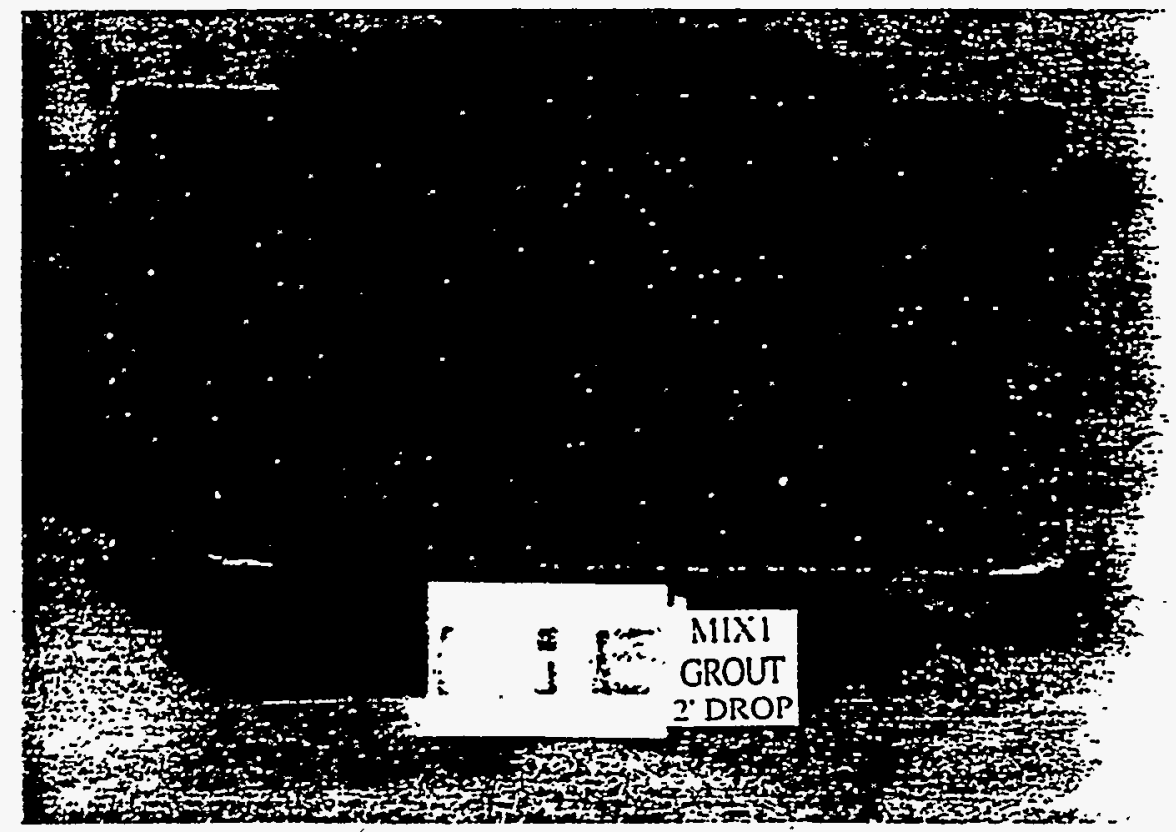

MIX 1 GROLT 2' DROP 1: Relatively minor variations in paste volume and air content occur throughout the core. A paste-rich layer occurs in the top 0.1 in. Approximately vertical microcracks extend from the top surface to a depth of 0.3 in. and from the bottom surface to a depth of 0.4 in. 
$\approx=-$

$-\vdots 2$

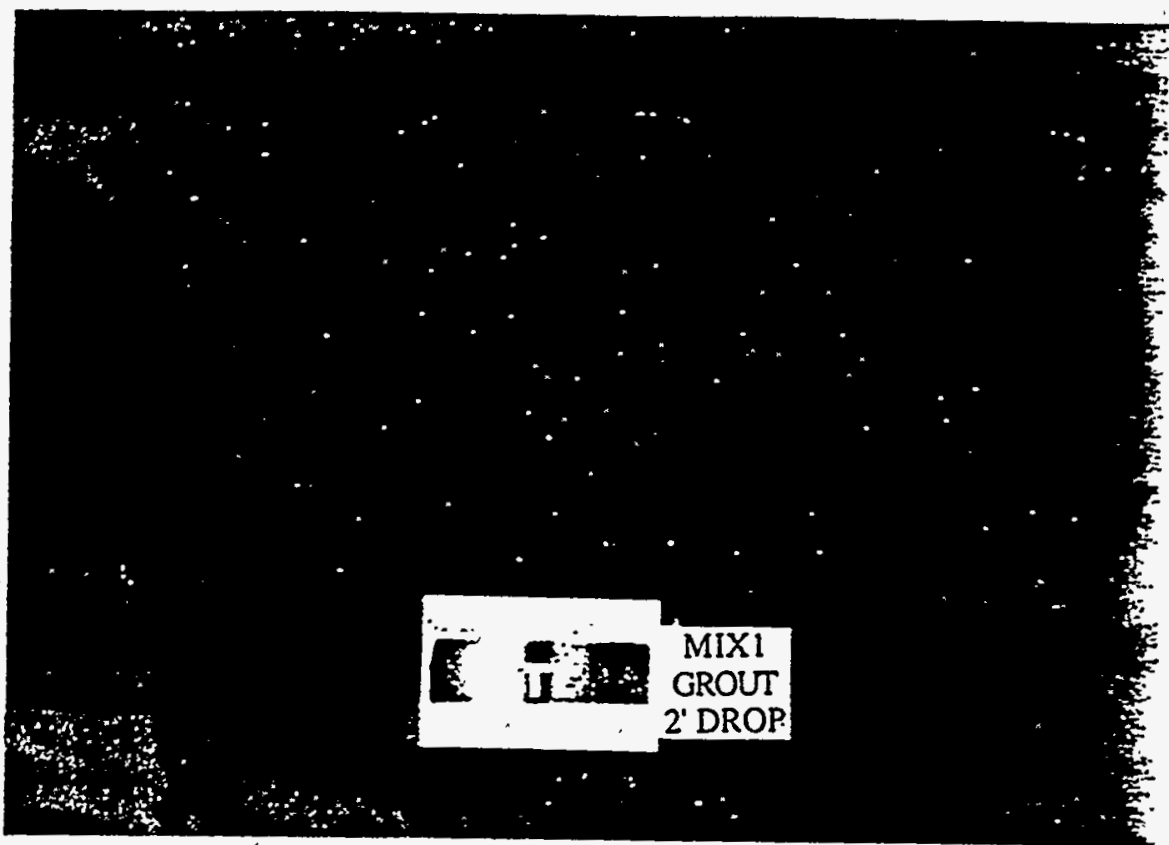

MIX 1 GROUT 2' DROP 2: Fairly uniform distribution of constituents with only minor local variations in paste volume and air content mostly limited to the top and bottom 0.1 in. Air content is lower in thin layer at each end of core. Vertical microcracks extend to 0.6 in. from top surface and 0.4 in. from bottom surface.

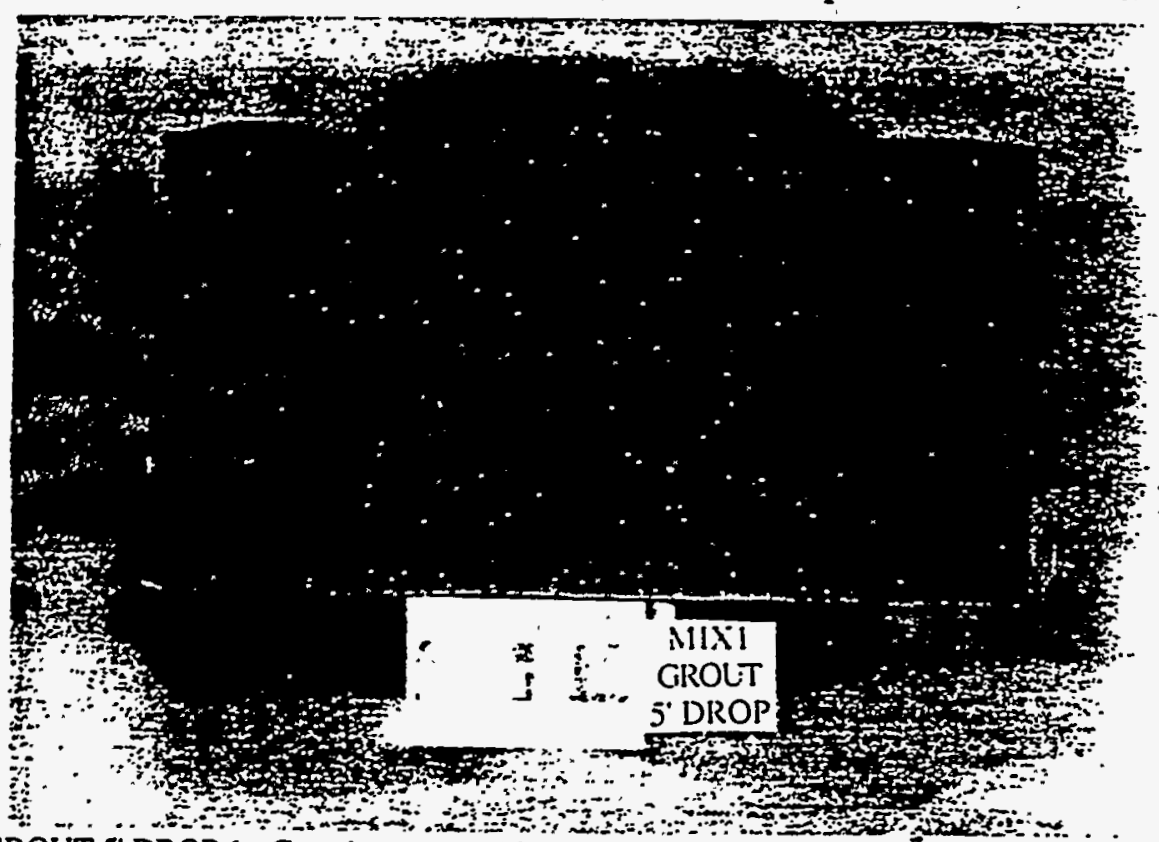

IIX I GROLT 5 DROP 1: Constituents are fairly uniformly distributed with only minor local variations in paste volume and air content. Paste-rich; low air content layer occurs in the bottom 0.3 in. of the sample. Vertical microcracks extend from the top surface to a depth of 1.3 in. and from the tottom surfasc to $0.6 \mathrm{in}$. 
$\therefore$ :.

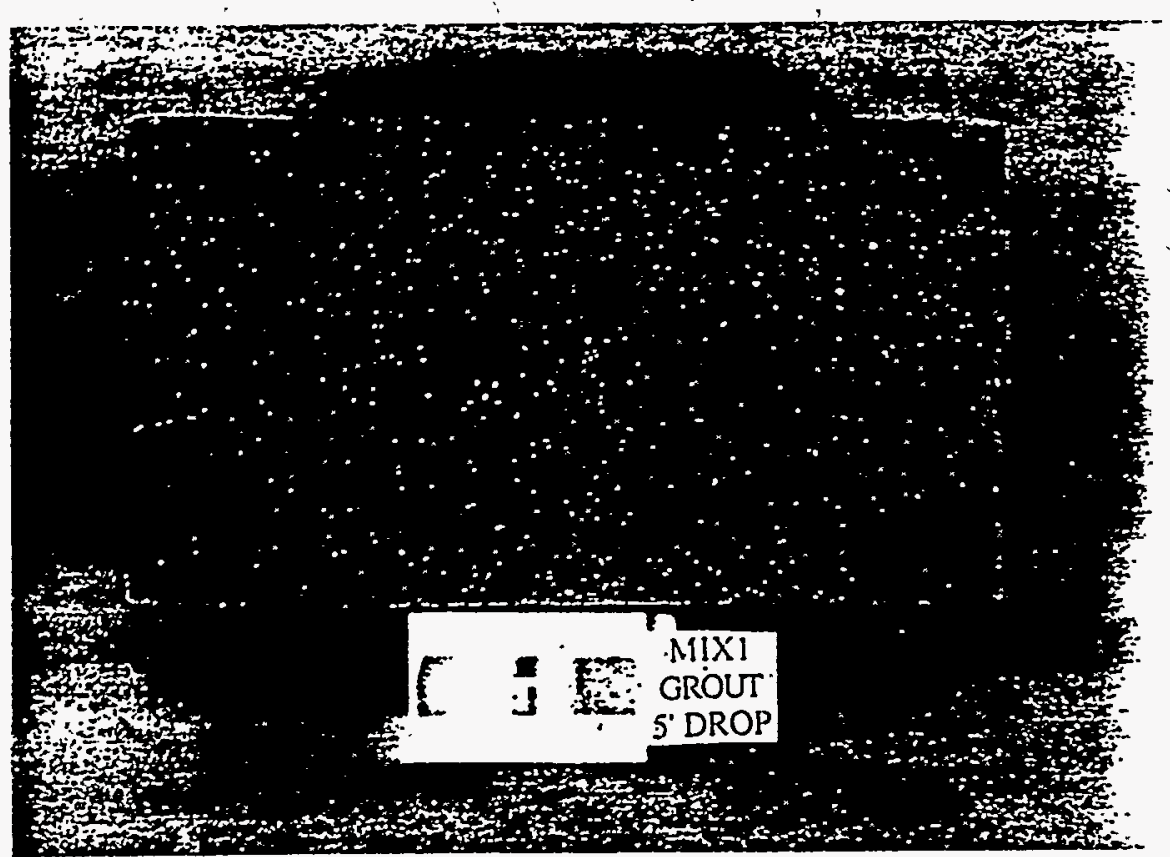

MIX 1 GROUT 5' DROP 2: Fairly uniform distribution of constituents with only minor local variations in paste volume and air content mostly limited to the top and bottom 0.1 to 0.3 in. Vertical microcracks extend from top surface to a depth of $1.1 \mathrm{in}$. and from bottom surface to a depth of $0.4 \mathrm{in}$.

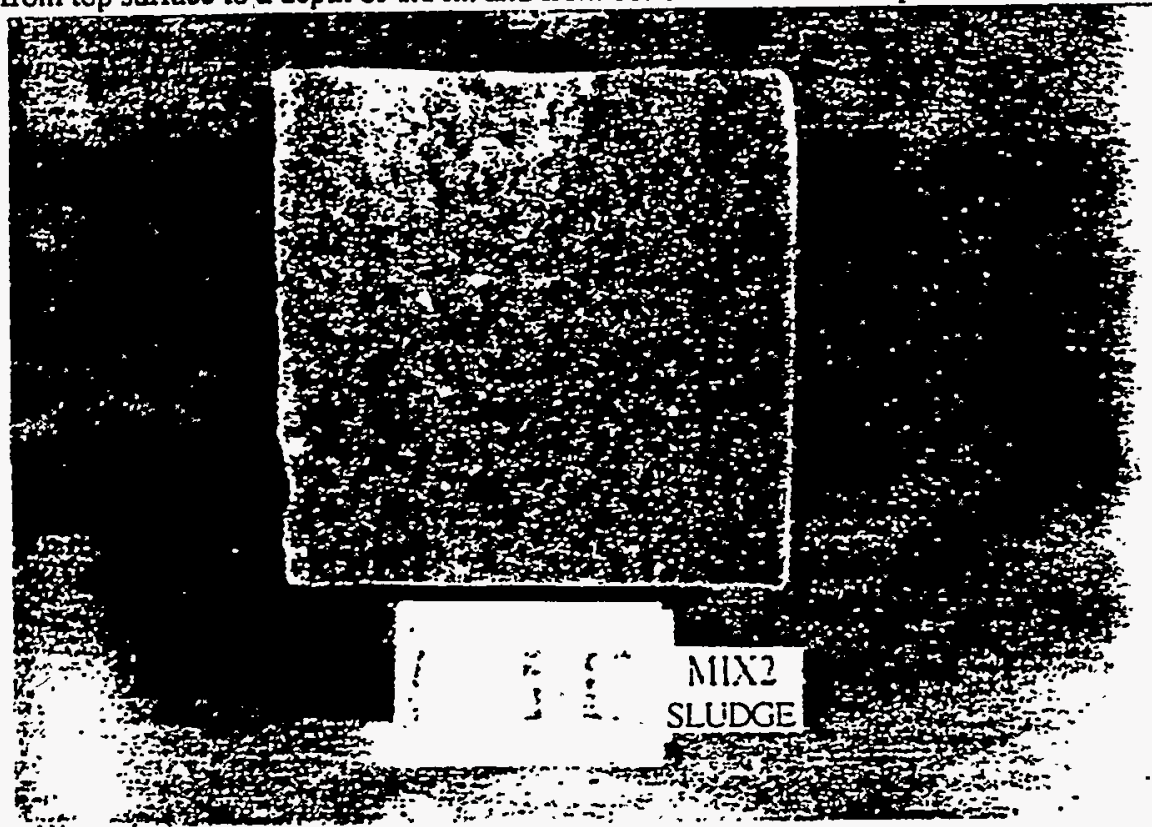

AIX 2 SLUDGE 1: The distribution of sand is fairly uniform. The sample exhibits only local variations in the paste volume and air content. The top 0.05 to 0.1 in. is sornewhat paste rich. Sludge is incorporated throughout the sample but small clumps and stringers, shown above in swirl pattern, are more abundant near the top surface and to in the middle third of the core. Microcracks $\alpha c c u r$ throughou: the core. 
$\because$

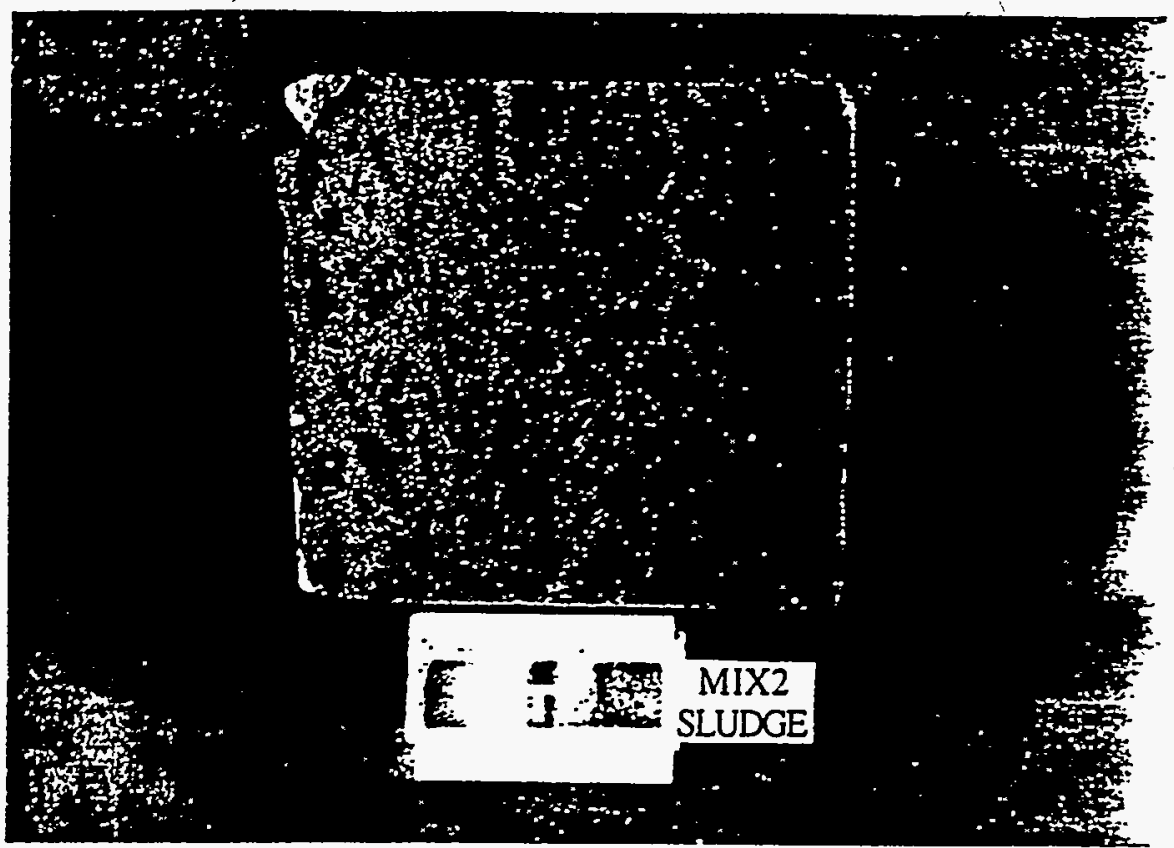

IIIX 2 SLUDGE 2: Distribution of sand is fairly uniform. The sample shows local variations in paste volume and air content. Sludge is incorporated throughout the sample but with greater concentrations in the top 1.2 in. and clumps in the upper 0.5 in. Horizontal cracks occur in the upper 0.2 in. Microcracks occur throughout. Vertical microcracks extend to a depth of 0.5 in. from the top surface.

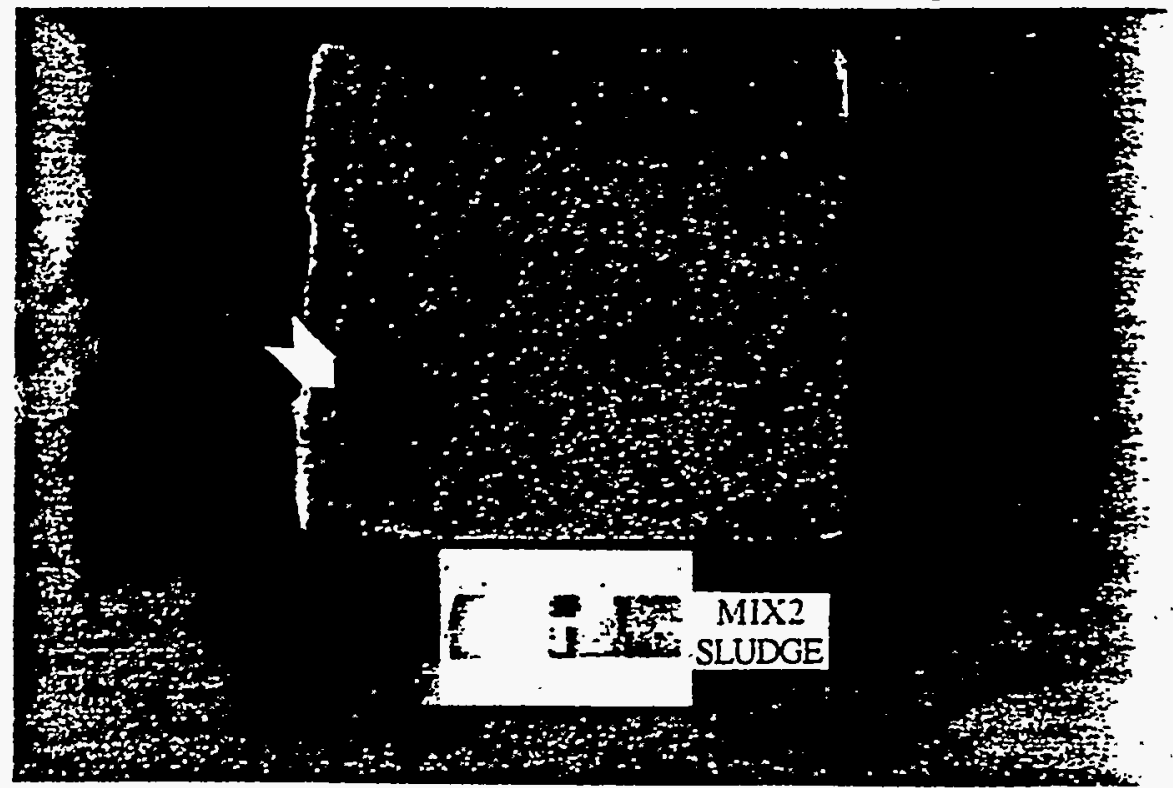

MIX 2 SLLDGGE 3: Constiuents are generally uniformly distributed with only local variations in paste volume and air content. A 0.15 -in.-thick sand lens is present 0.2 in. below the top surface. A plastic tear or horizontal crack is present 0.15 to 0.25 in. below the top surface (arrow). Concentrations of slud ze $\propto c c u r$ mosly near the top and middle portion of the sample. Vertical microcracks occur in the top 1.75 in. 
is:

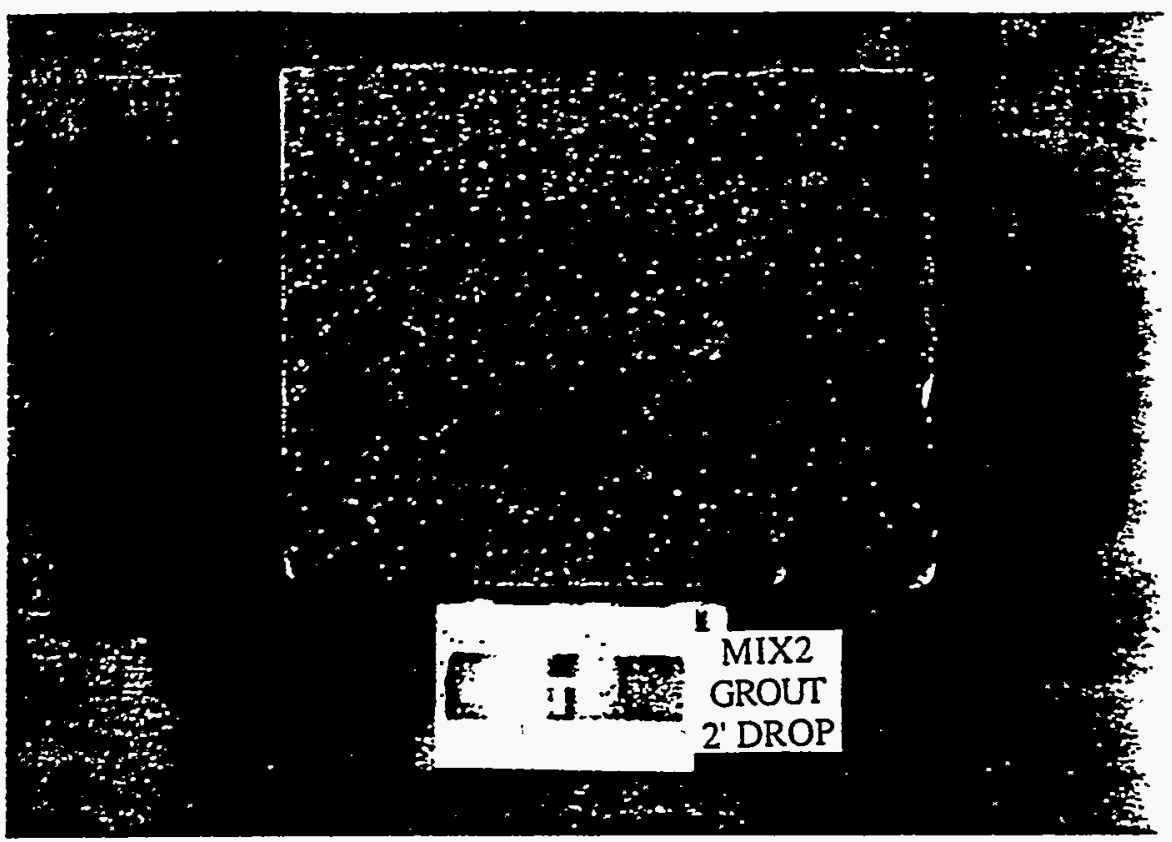

MIX 2 GROUT 2' DROP 1: Fairly uniform distributión of constituents with only minor local variations : in paste volume and air content mostly limited to the top and bottom 0.1 in. Vertical microcracks extend to. a depth of $1.1 \mathrm{in}$. from top surface and $0.75 \mathrm{in}$. from bottom surface.

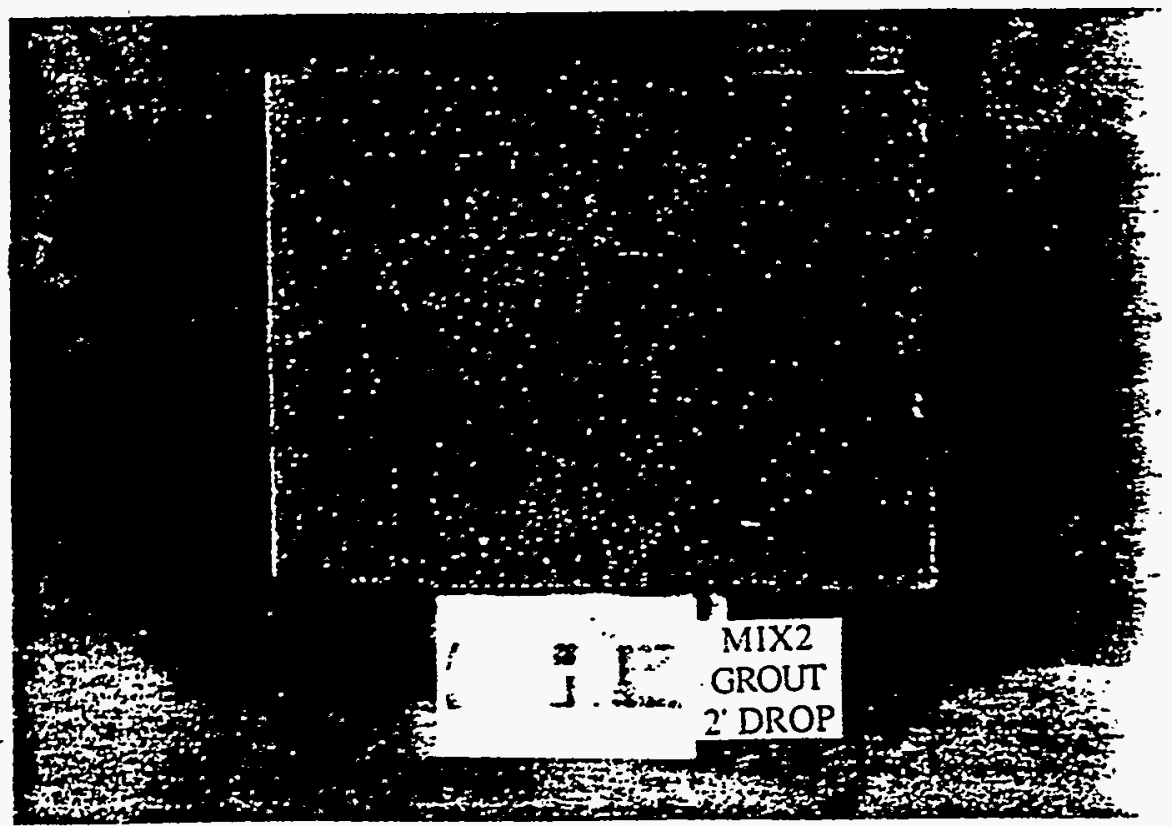

IIX 2 GROUT 2. DROP 2: Similar to sample shown above. Vertical microcracks extend from the bollom surface to 0.3 in.. 
ti.

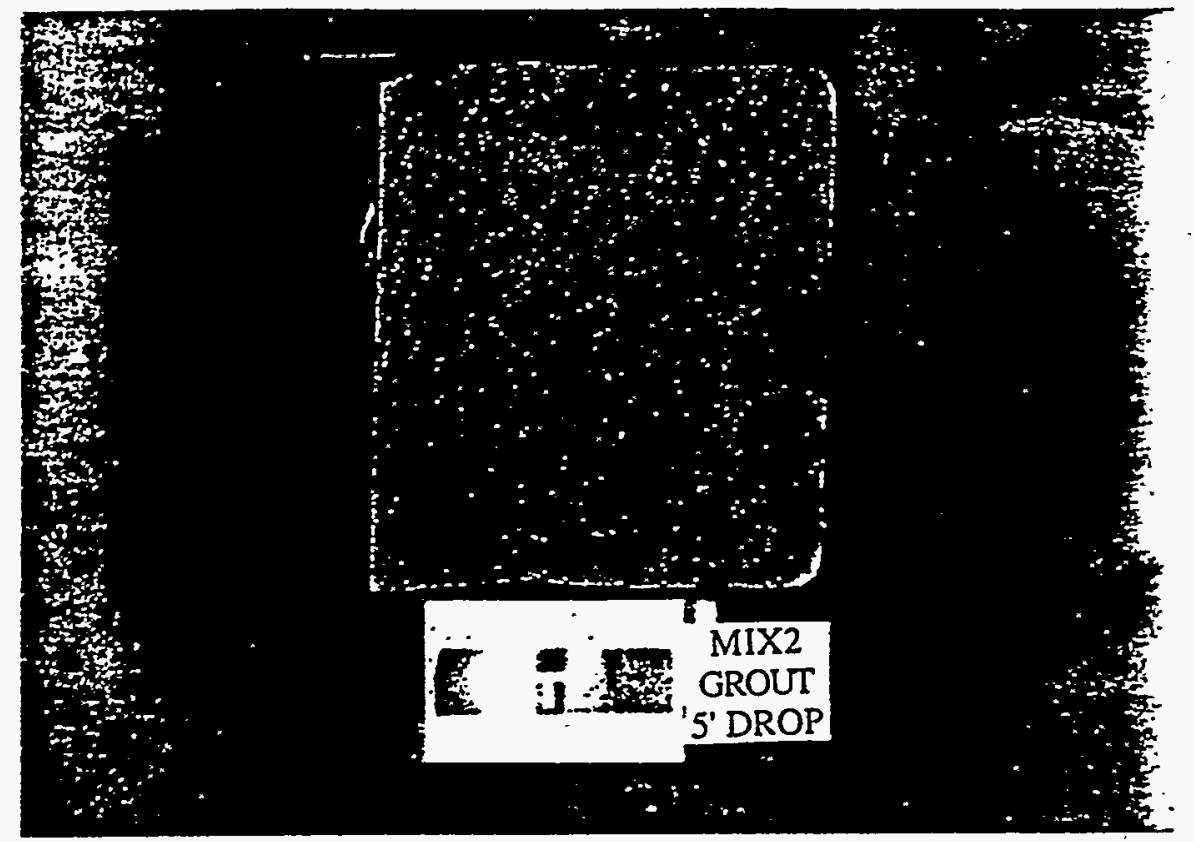

MIX 2 GROUT 5' DROP 1: The distribution of constituents is mostly uniform. Microcracks are not observed. A 0.02 to 0.05 -in.-thick paste layer is present at the top and bottom.

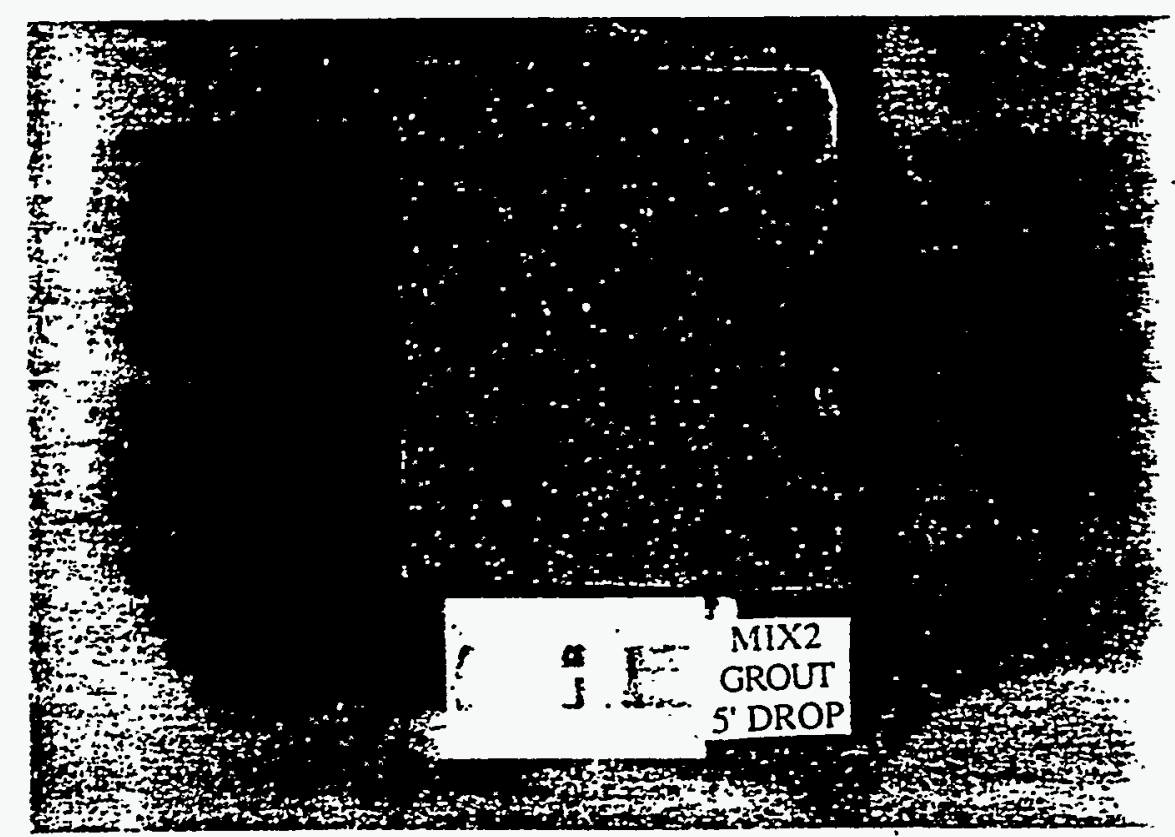

MIX 2 GROUT 5' DROP 2: Similar to sample shown above. 
$\therefore=$

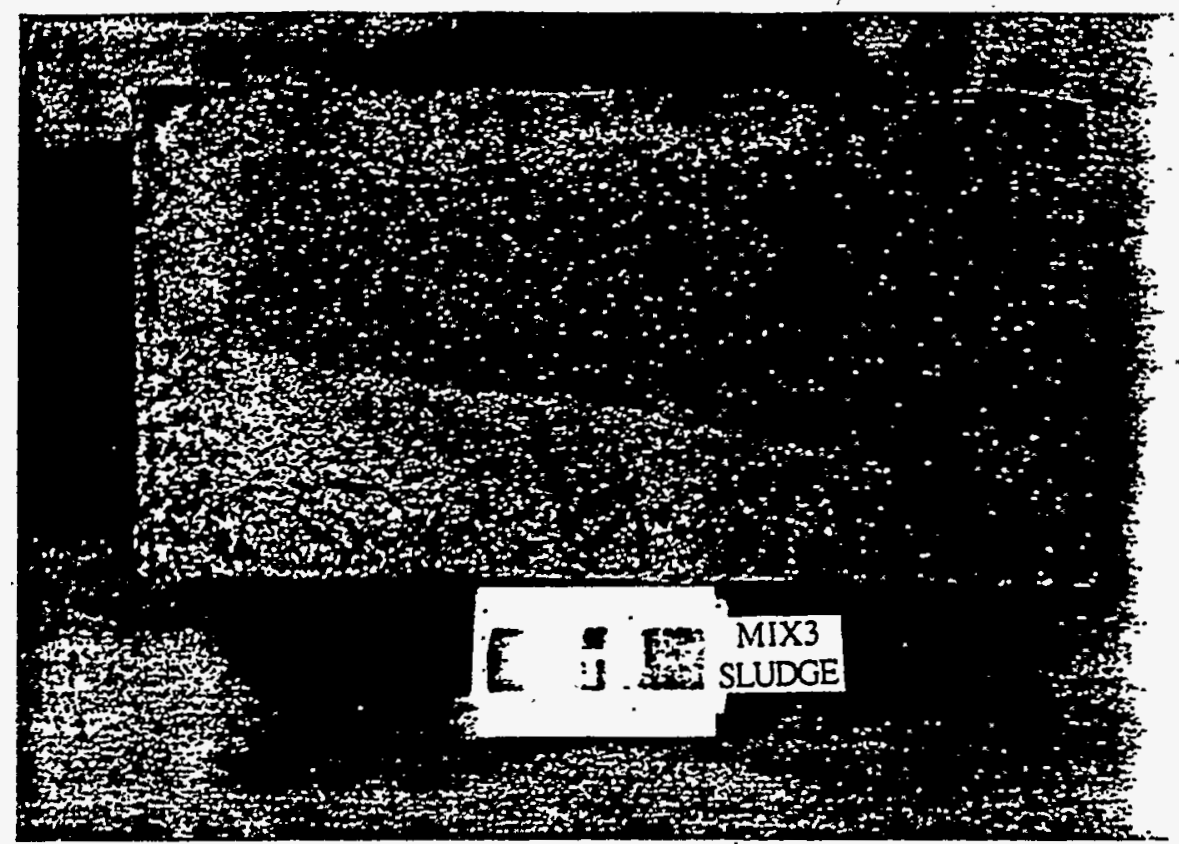

MIX 3 SLUDGE 1: Fairly uniform distribution of the constituents of the grout with only minor local variations in paste volume and air content mostly limited to the top and bottom 0.1 to $0.2 \mathrm{in}$. Sludge is incorporated throughout the grout with small clumps and stringers concentrated in the bottom 2.3 in. Vertical microcracks extenid from the top surface to a depth of 0.7 in.

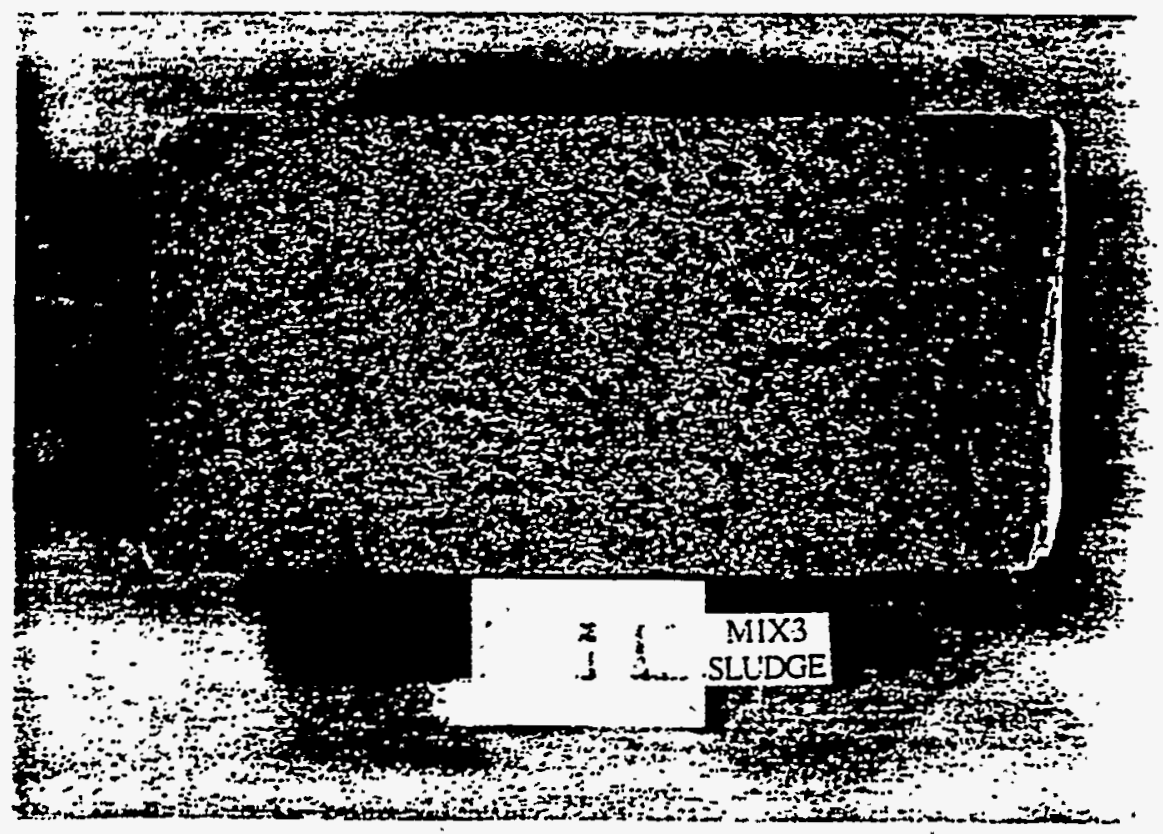

MIIX 3 SLLDGE 2: Similar to sample shown above. Sludge clumps and stringers showing flou ILnss occur in the bottom 1.1 in. microcracks extend from the top surface to a depth of 0.2 in. 
$\therefore:$

$\therefore \therefore$

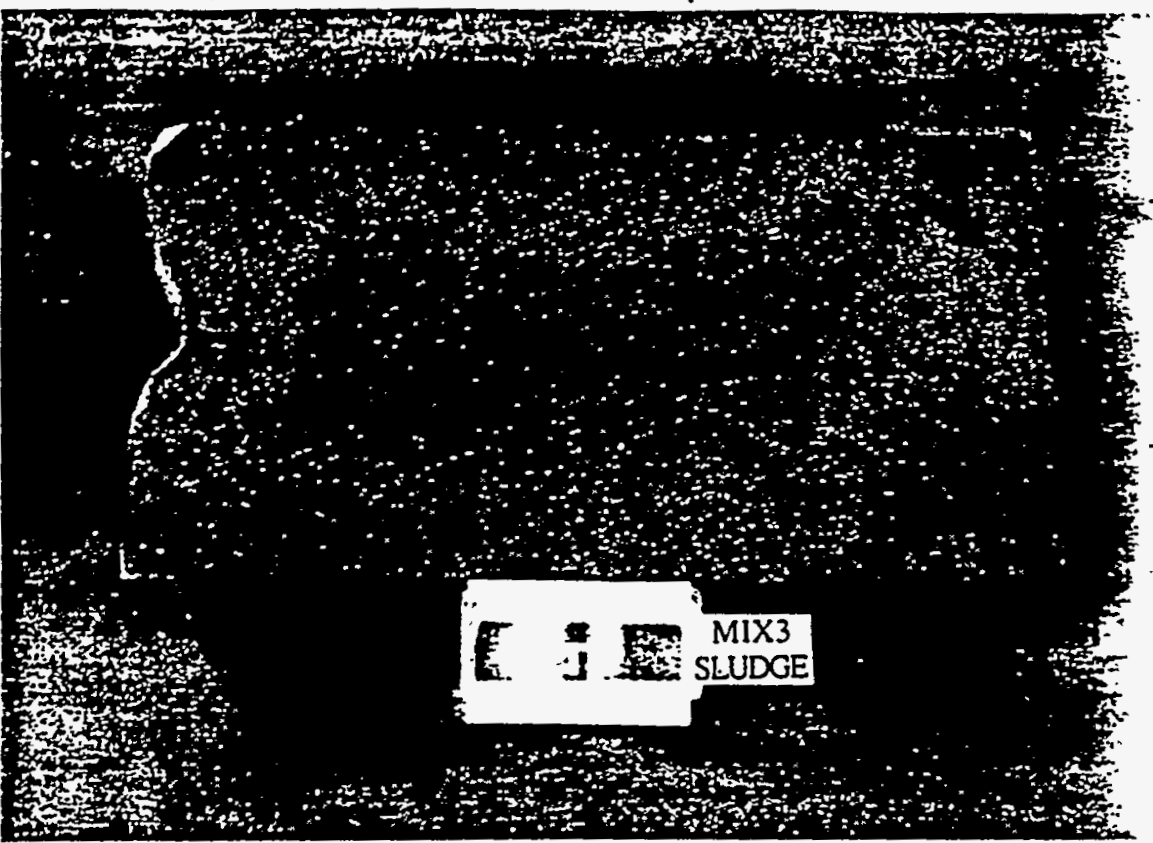

MIX 3 SLUDGE 3: The constituents of the grout are uniformly distributed with only minor local variations in paste volume and air content mostly limited to the top 0.2 in. and the bottom 0.5 in. Sludge is nonuniformly incorporated into the grout. A thin horizontal lens occurs at a depth of 0.6 in. from the top surface and several steeply dipping lenses occur just belo the horizontal lens. A vertical microcrack extends from top surface to adeph of 1 in.

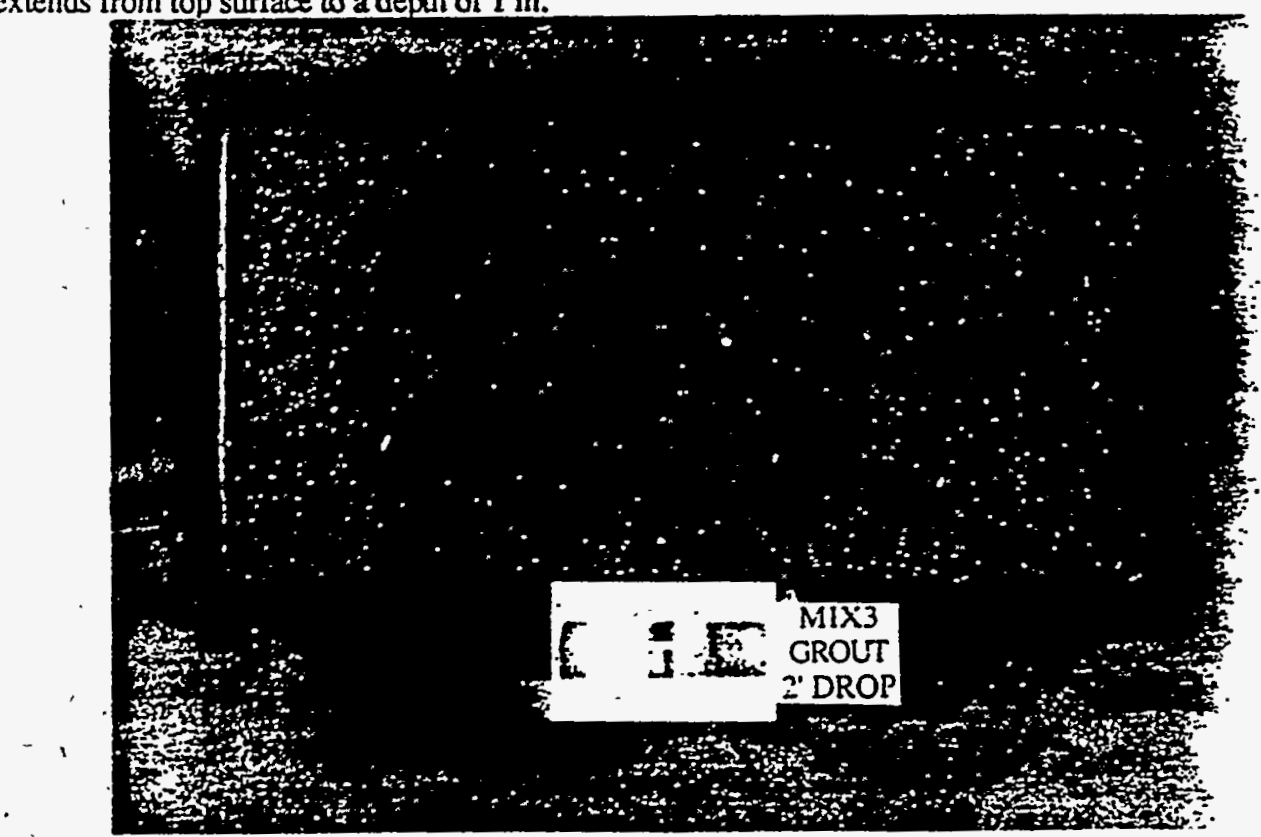

1.IXX 3 GROUT 2' DROP 1: The constituents are generally uniformly distributed with minor variations in paste volume and air content locally. A high-paste, low-air lens occurs at a depth of about 1.5 in. below the top surface. No microcracks are observed. 
$\therefore$

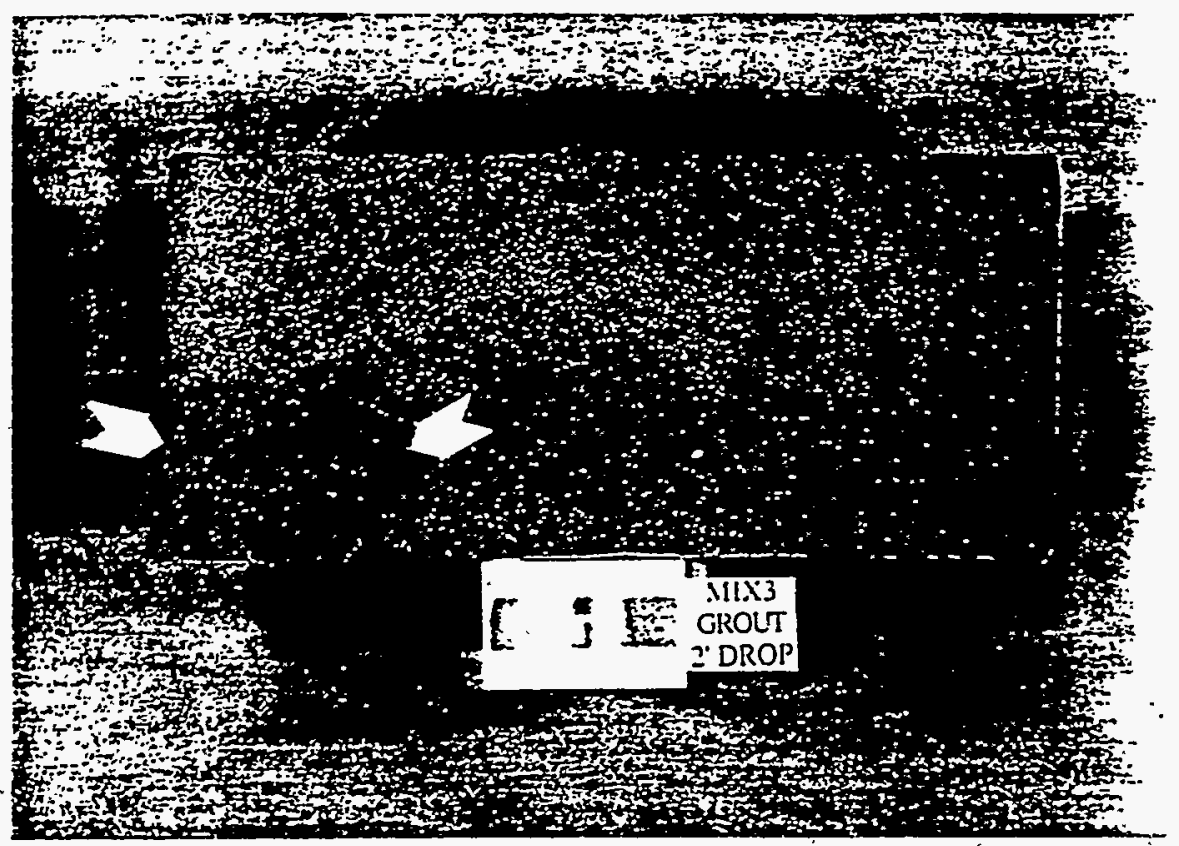

MIX 3 GROUT 2' DROP 2: The constituents of the grout are uniformly distributed with only minor local variations in paste volume and air content mostly limited to the top and bottom 0.2 in. A dark, teardropshaped feature extends from a depression on the top surface to a depth of 2 in. Several nearly vertical, hairline cracks extend up to $I$ in. from the bottom surface.

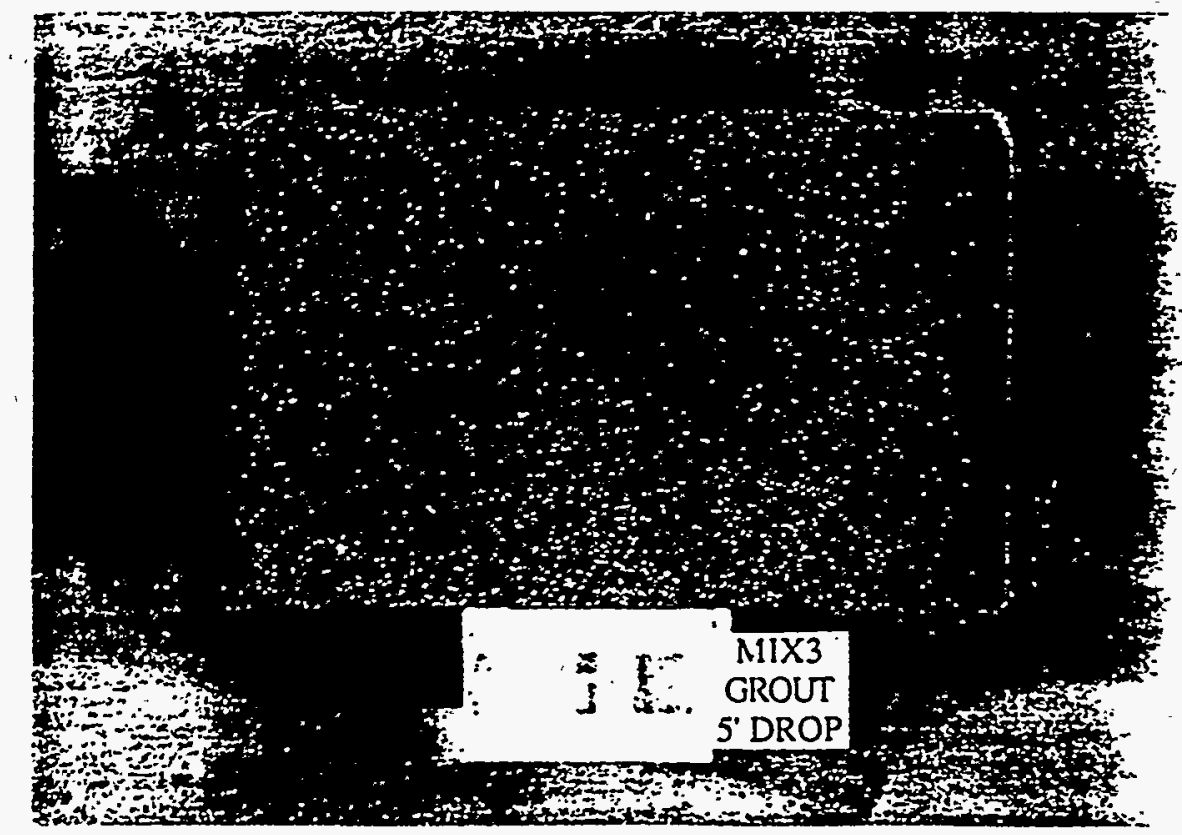

MIX 3 GROLT 5 DROP 1: The constituents are generally uniformly distributed with minor variations in paste volume and air content mostly in the top and bottom 0.1 to 0.2 in. No microcracks are observed. 
$\therefore=$

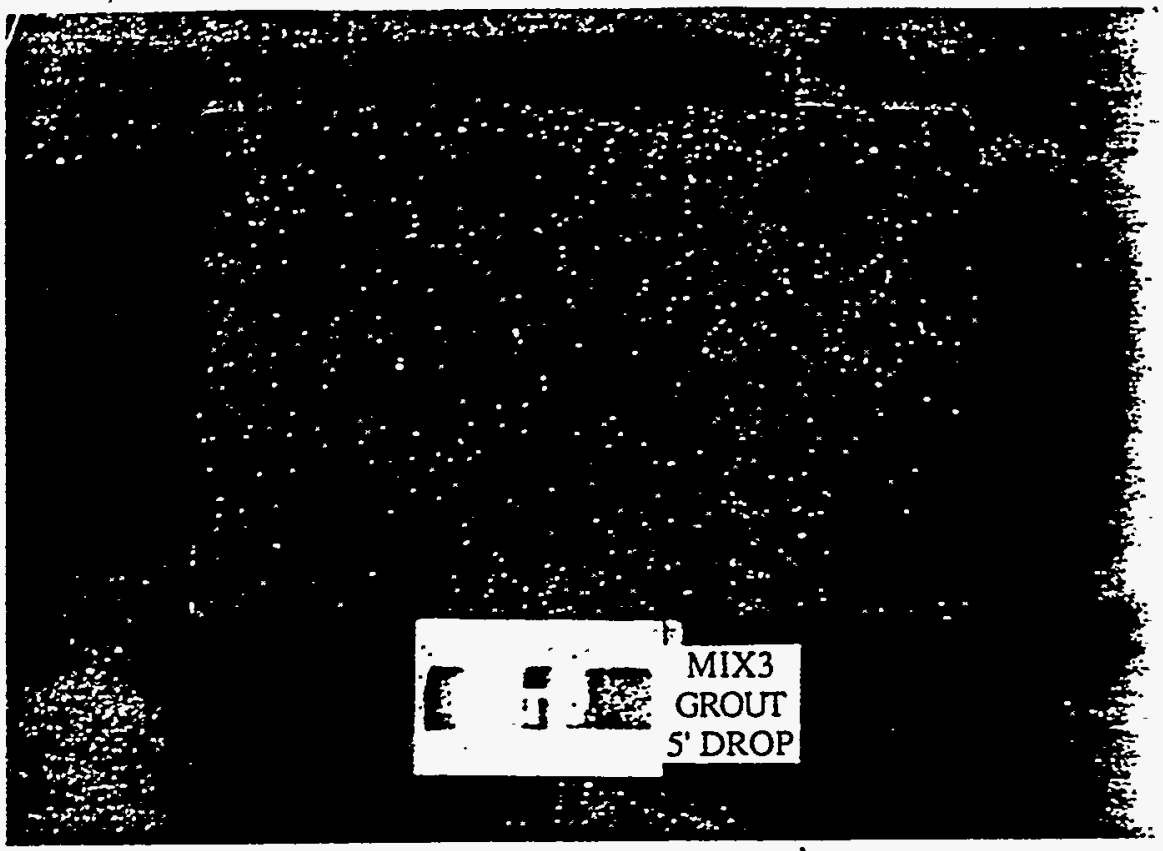

MIX 3 GROUT 5' DROP 2: The constituents are uniformly distributed with only minor local variations in paste volume and air content mostly limited to the top and bottom 0.2 in. No microcracks are observed

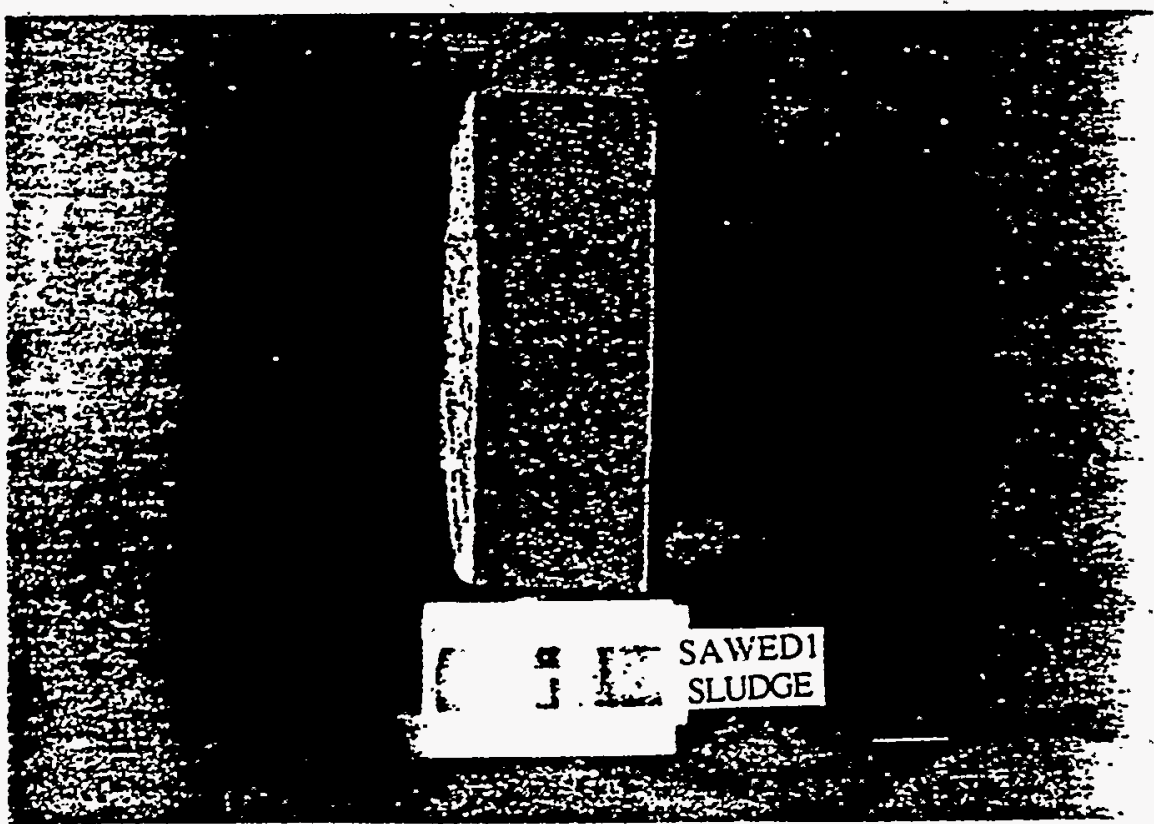

SAKED I SLUDGE: The constituents of the grout are generally uniformly distributed with minor local variations in paste volume and air content. $A$ band of air bubbles occurs at a depth of 0.1 in. from the top surface. A band of dark gray paste occurs at a depth of 0.15 to $0.20 \mathrm{in}$. from the top surface. Sic microcracks are observed. Sludge does not appear to have been incorporated. 


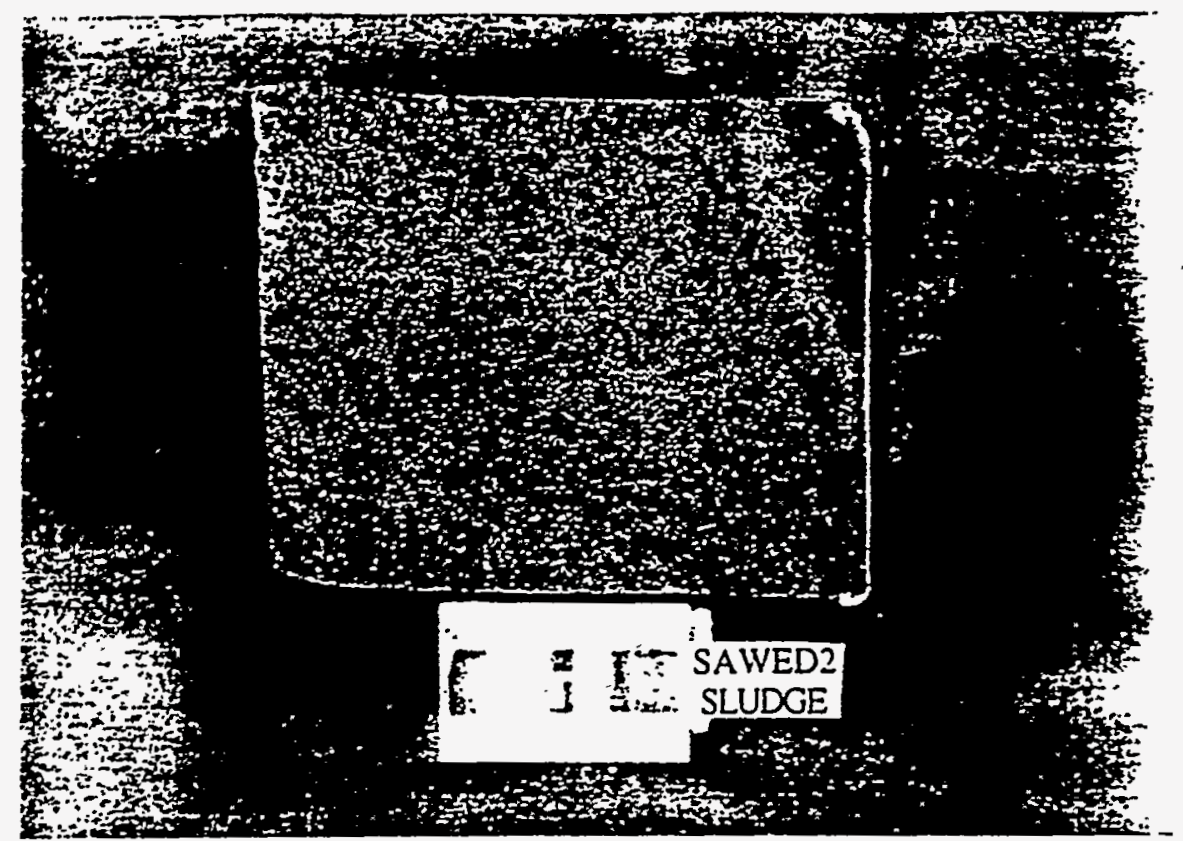

SAWED 2 SLUDGE: The constituents of the grout are uniformly distributed with only minor local variations in paste volume and air content. A paste-rich band occurs across a portion of the bottom surface. Minor incorporation of sludge along botrom. No microcracks were observed.

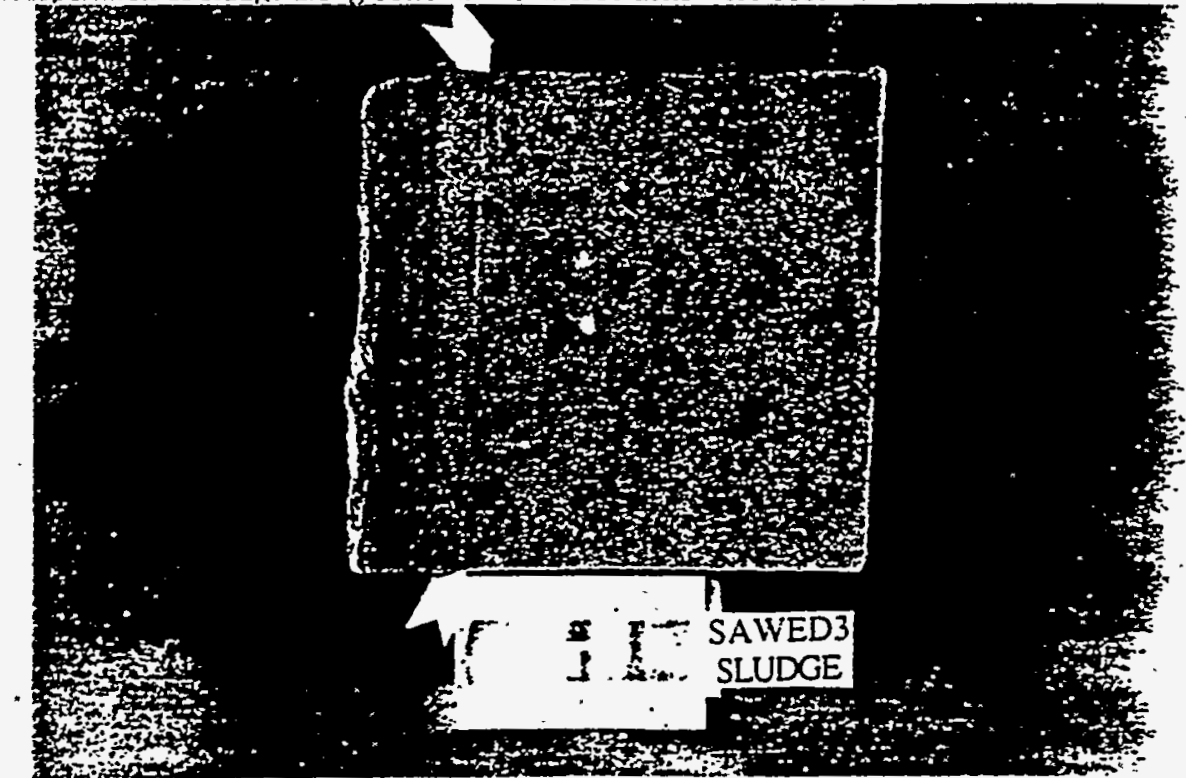

SAWED 3 SLCDGE: The constituents of the grout are uniformly distributed except in the upper 0.7 in. of the core. Sludge appears to be incorporated mainly in a band in the upper 0.10 to $0.15 \mathrm{in}$. Below the sludge band, the grout exhibits horizontal, paste-rich bands. The lowermost band, at a depth of 0.7 in., contains only paste and a single line of small air voids. A horizontal microcrack passes through the center of this band. A few short vertical microcracks are observed in the lower paste band. 


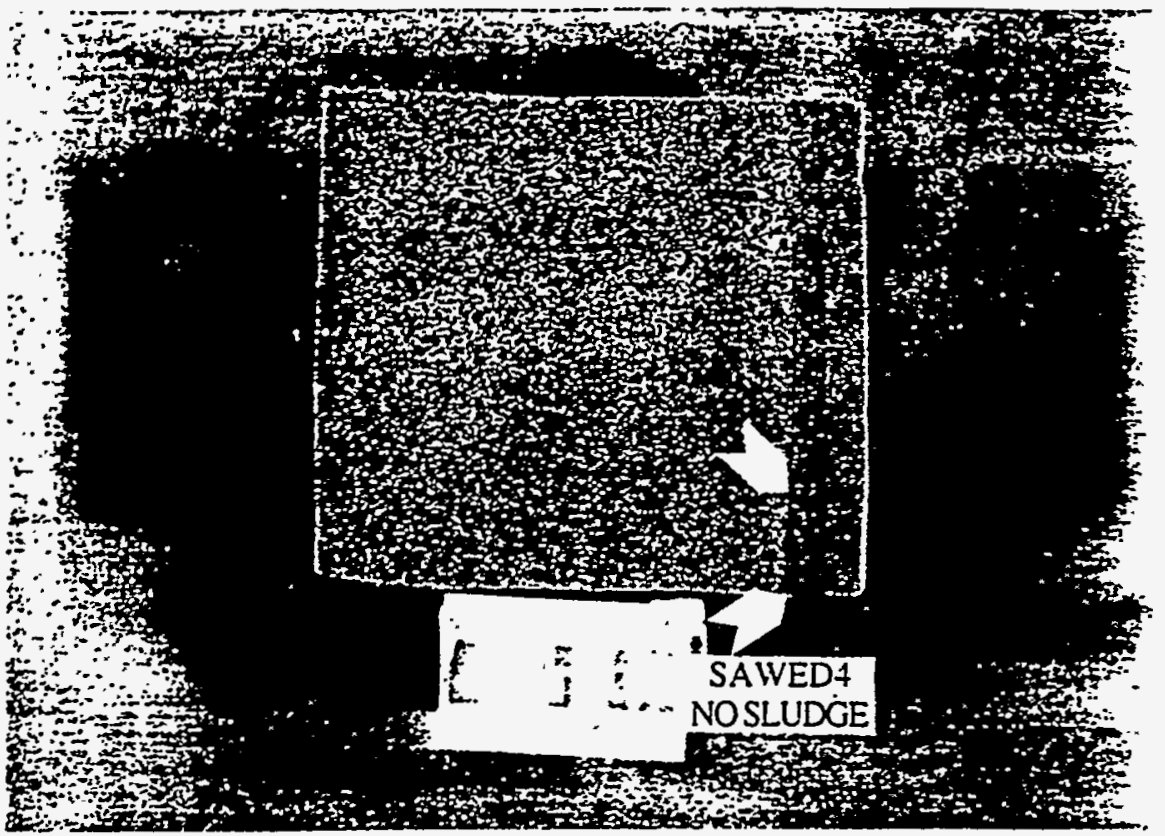

SAWED 4 NO SLUDGE: The constituents of the grout are uniformly distributed except in the lower 0.45 to $0.50 \mathrm{in}$. where horizontal paste-rich bands are present. The uppermost band contains only dark paste and, locally, clusters of tiny air voids (arrow). A horizontal microcrack passes through the center of the band.

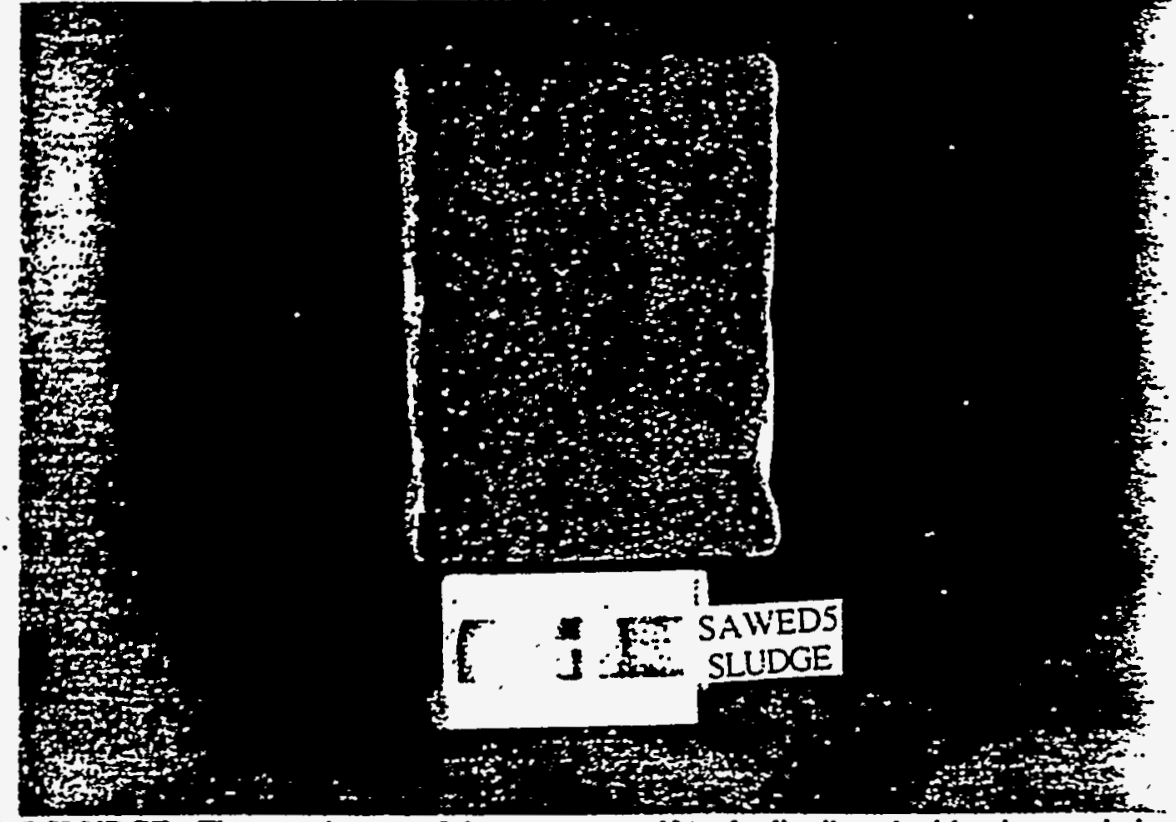

SAKED 5 SLLDGE: The constinents of the grout are uniformly distributed with minor variations in paste volume and air content. locally. The top and bottom 0.1 to 0.2 in. are paste rich. Sludge appears to be incorporated below the top surface. A few vertical microcracks are present. These extent up to 0.3 in. from the bottom surface. 
$3:$

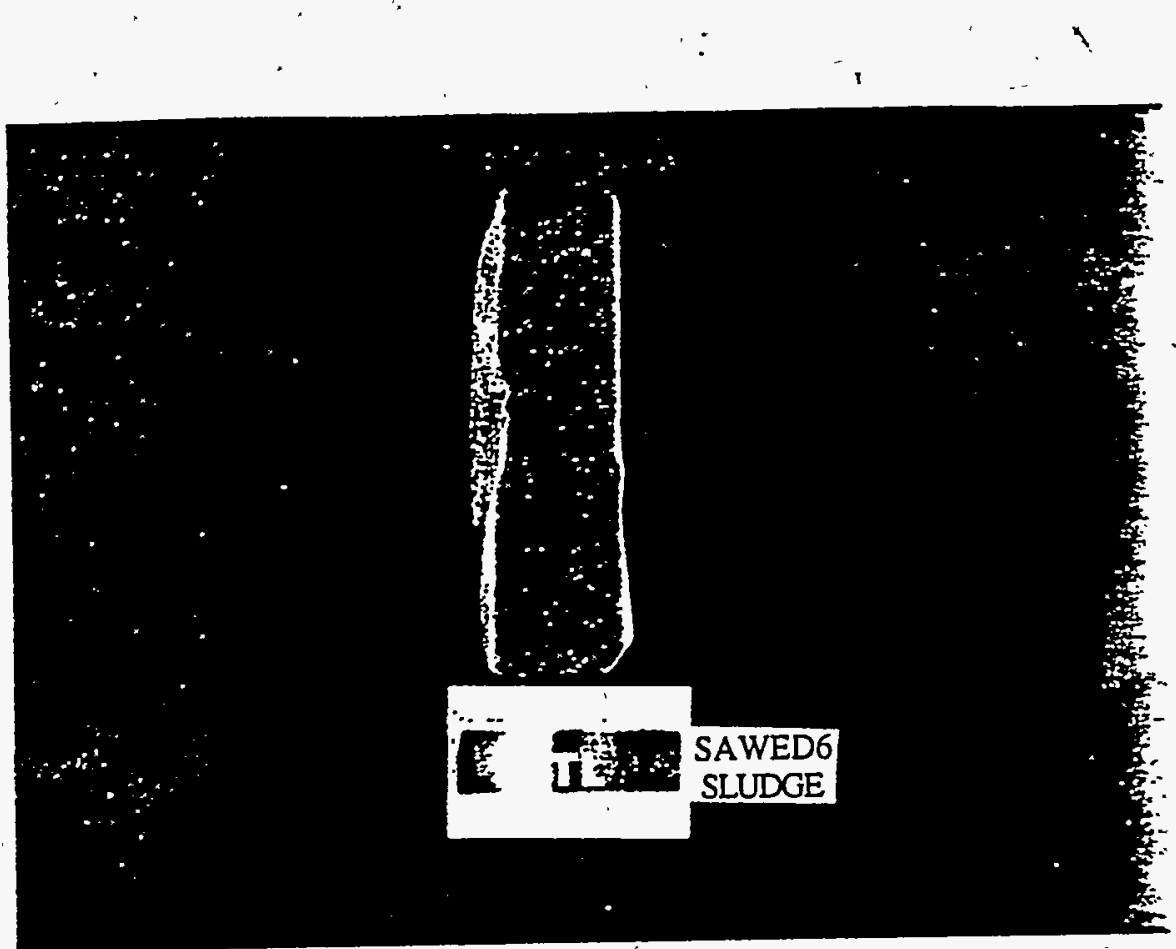

SAWED 6 SLUDGE: The constituents of the grout are uniformly distributed with only minor variations in paste volume and air content. Sludge appears to be incorporated in a layer at the upper surface. No microctacks are observed. 


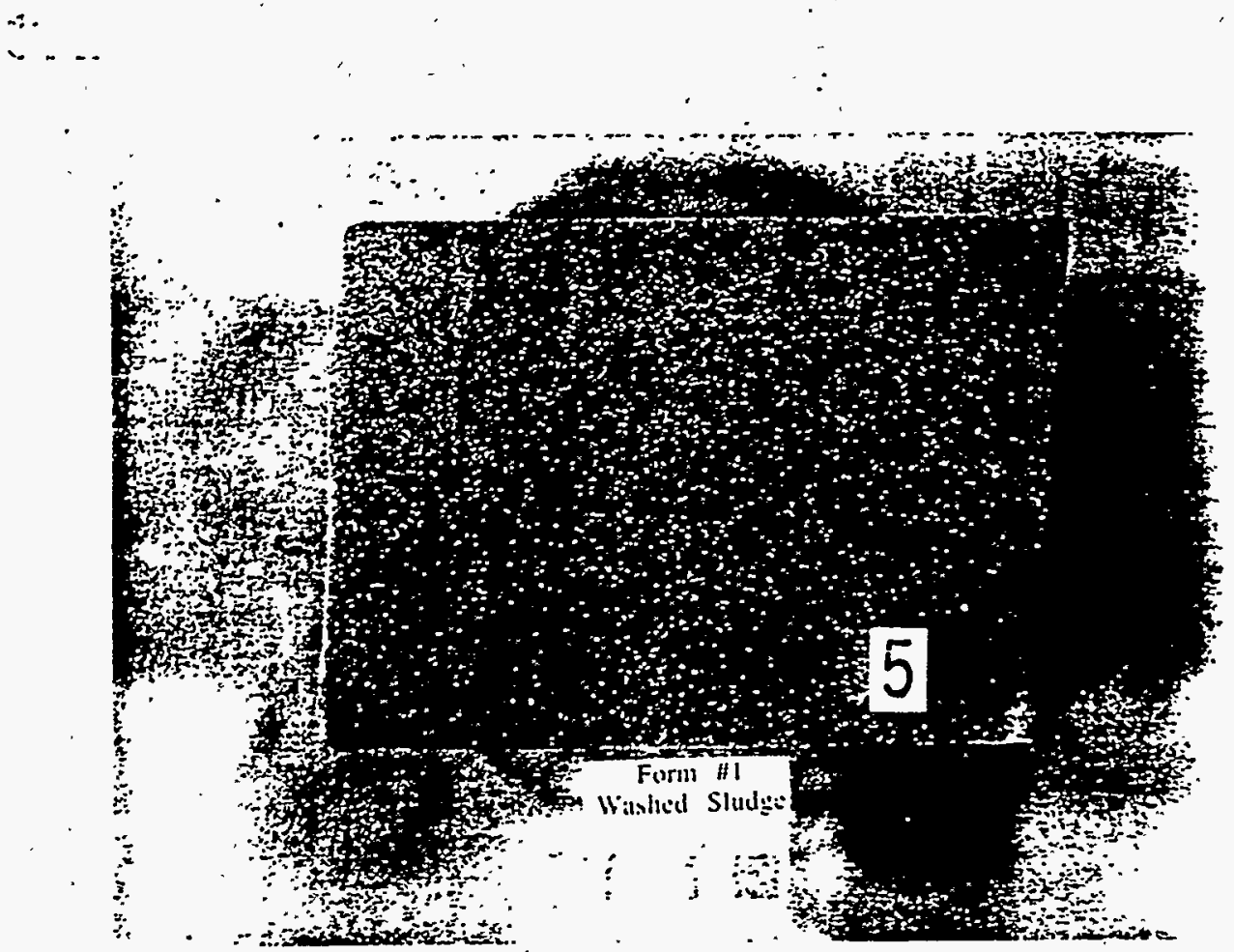

FORM 1, \#5 WASHED SLUDGE: Grout constituents show minor local variations with paste-rich streaks in the upper 1.5 in. and lower 0.3 in. Air void distribution is fairly uniform and the voids are small. A narrow, horizontal stringer of sludge is incorporated at a depth of 0.8 in. Elsewhere, small clumps of sludge are dispersed. Horizontal and vertical microcracks $\propto c c u r$ throughout the length of the core.

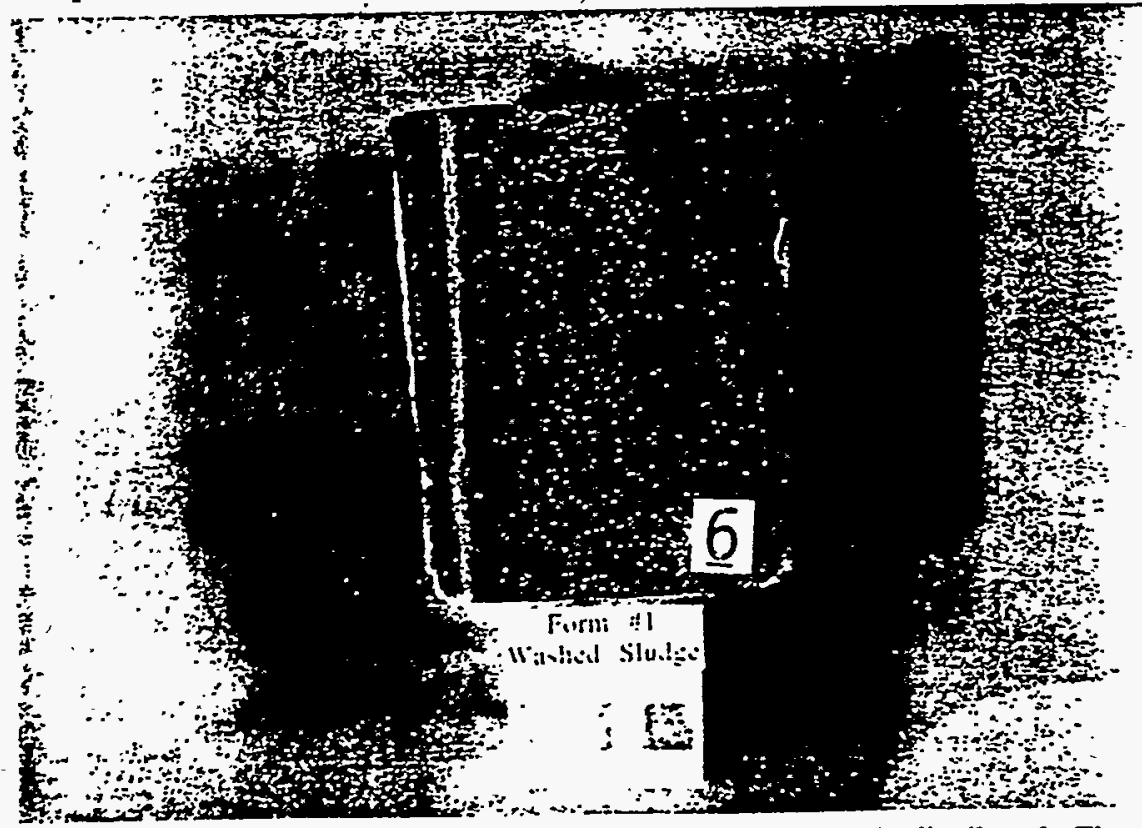

FORM 1, \#6 WASHED SLUDGE: Grout constituents are mostly uniformly distributed. The upper 0.8 in. and the lower 1 in. are somewhat paste rich. A streak of air bubbles and a horizontal microcrask occur at a depth of 0.4 in. from the top surface. Sludge is incorporated in clumps in the top and bottom 0.1 in. 
$\because=$

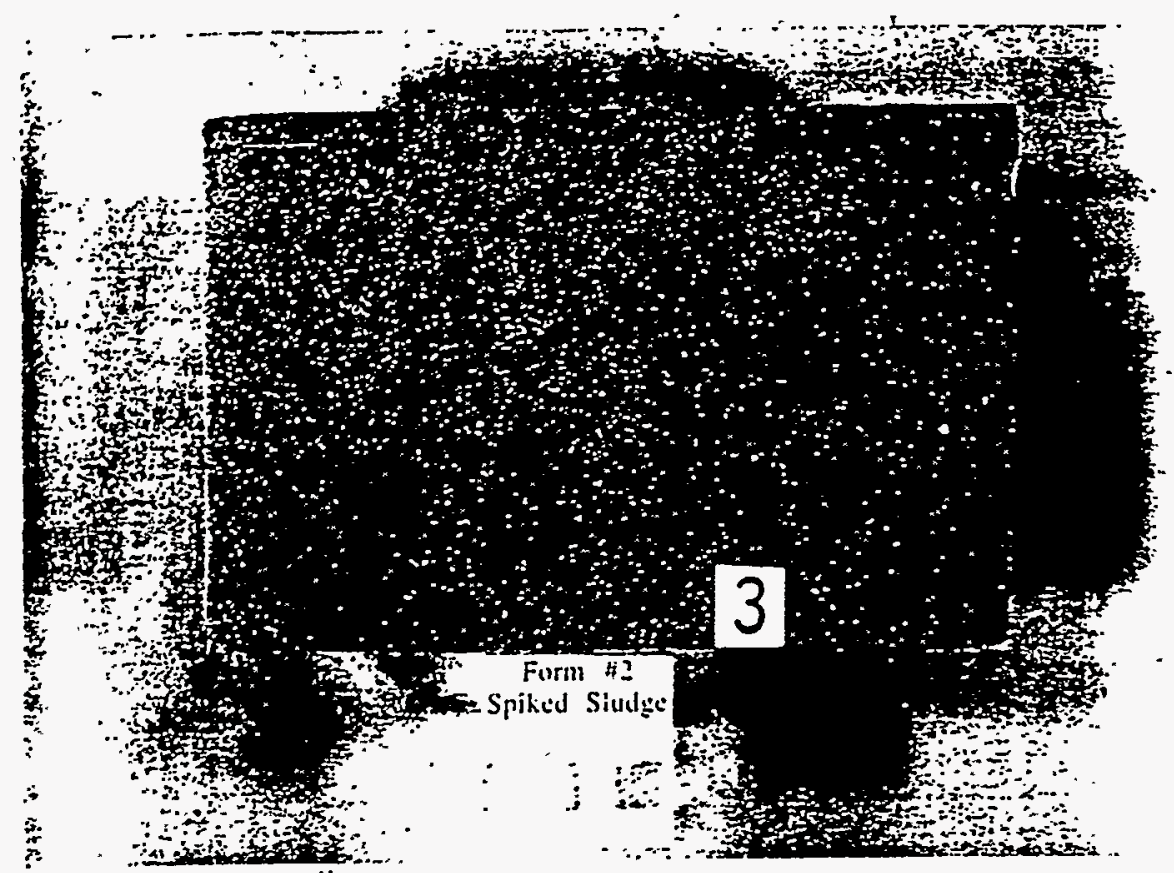

FORM 2, \#3 SPIKED SLUDGE: Grout constituents show minor local variations in distribution; pasterich, horizontal bands. Air voids are small and fairly uniformly distributed. Occasional small clumps and stringers of sludge are present. Horizontal microcracks occur in the bottom 1 in. and a few vertical microcracks extend through the core.

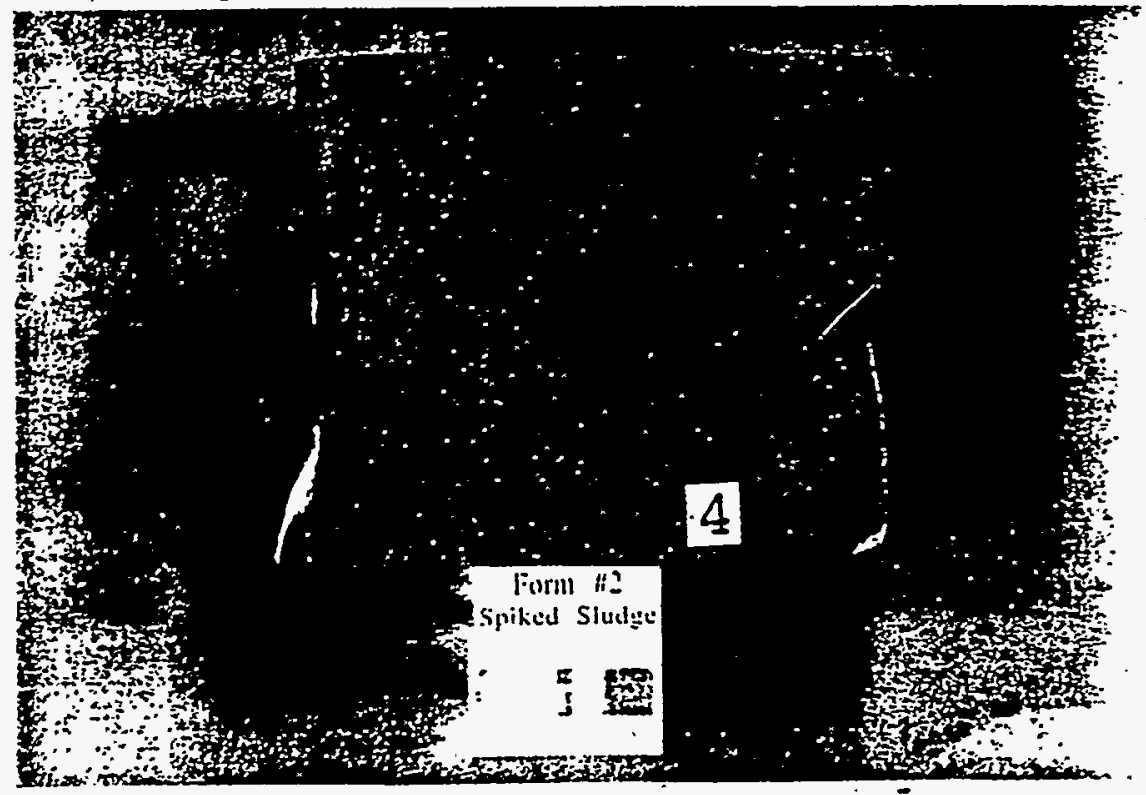

FORM 2,\#4 SPIKED SLUDGE: Grout constituents are fairly uniformly distributed with local variations in paste and air content. Small clumps of sludge occur sporadically in the body of the core and a stringer of sludge is folded into the bottom 1 in. and top 0.5 in. of the core. Horizontal microcracks occur in the upper and lower 0.5 in. and vertical microcracks extend inward up to 2 in. from both the top and bottom surfacis. 
$3 .:$

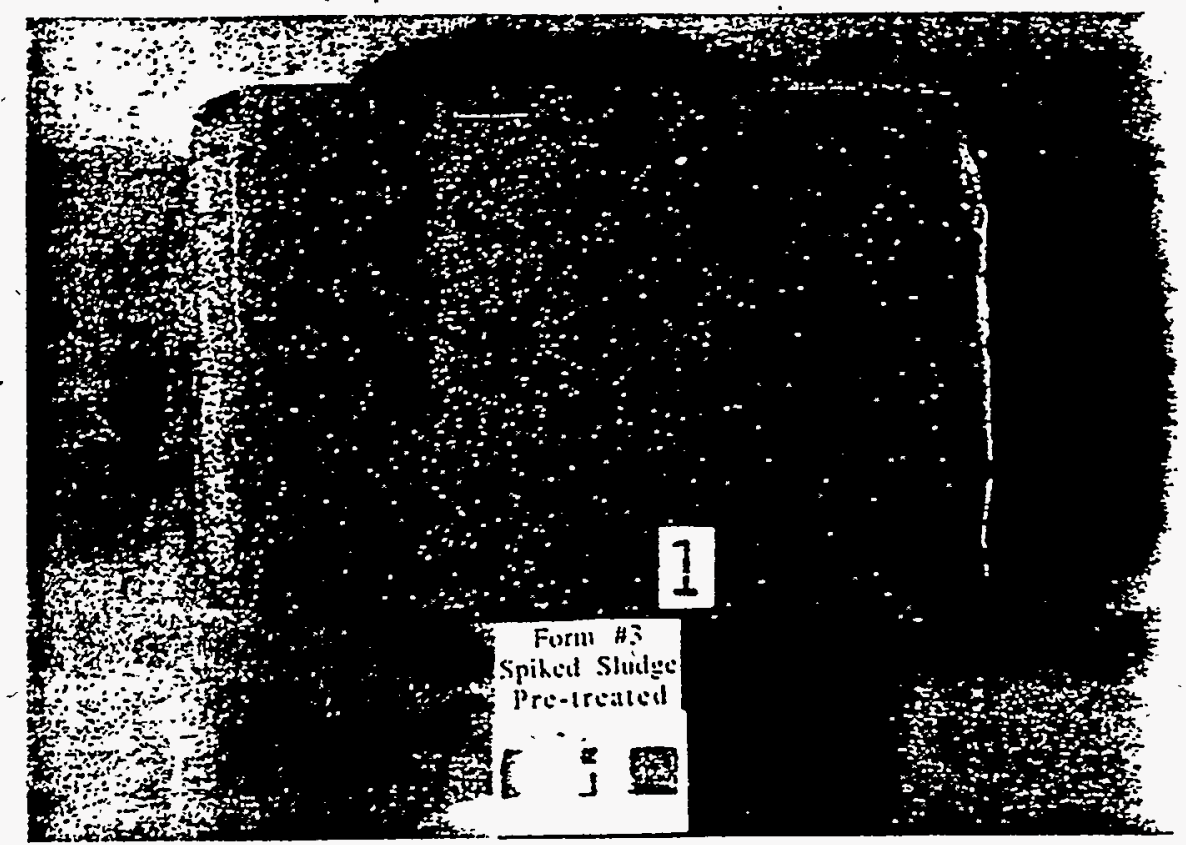

FORM 3, \#1 SPIKED SLUDGE PRETREATED: The grout constituents are fairly uniformily distributed with minos local variations in air content and paste volume. Stringers and small to medium clumps of sludge occur throughout; mostly below the top 1.5 in. Polygonal microcracks occur throughout the core.

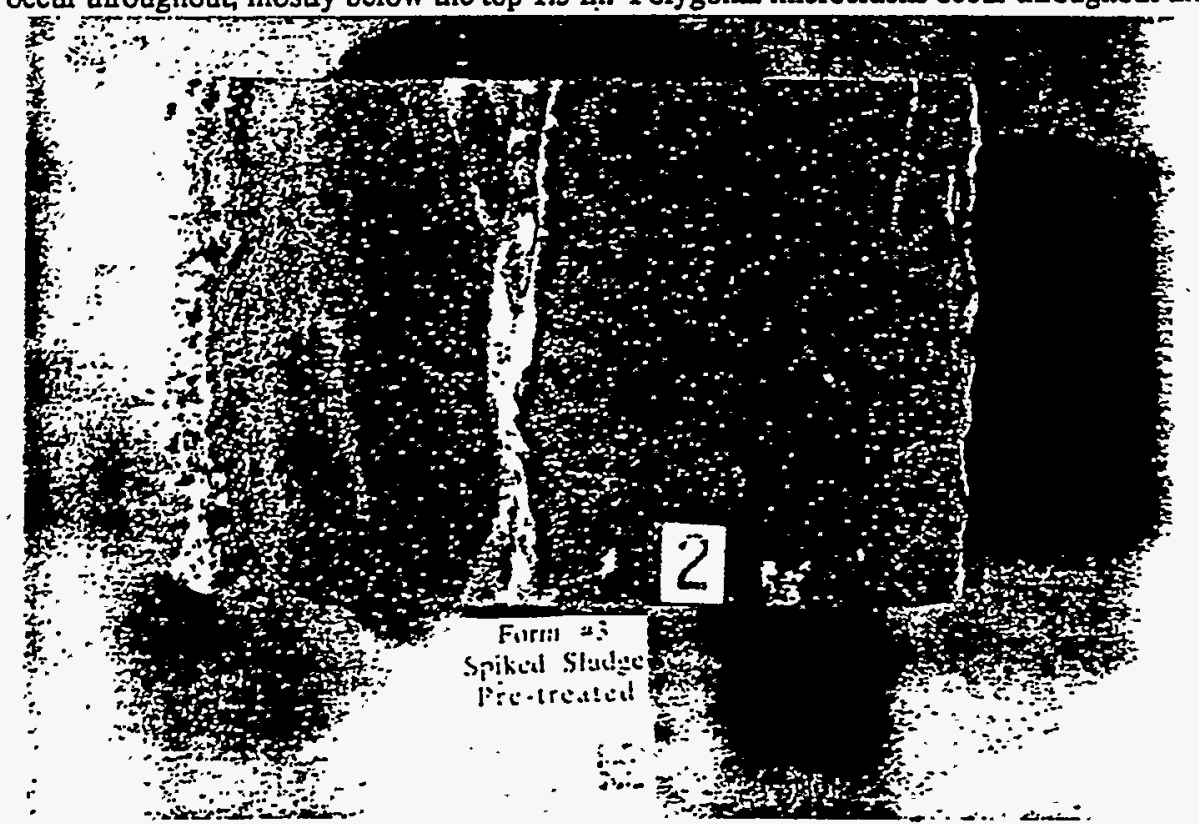

FOR.M 3, \#2 SPIKED SLLDGE PRETREATED: The gtout constituents are generally well distributed except in the top 0.8 in. and between about 2 and 3 in. from the top surface where the paste is white and entrapped air voids are more common. Stringers and clumps of sludge occur throughout. Horizoni:-' microcracks occur in the upper and lower 2 in. Vertical microcracks occur throughout. 


\section{Appendix C \\ Physical Testing Results of Grouts and Grouted Sludges}


Westinghouse / DOE

102875

\section{Grout \#1}

Flow $=6.3$ seconds

U.W. $=1498.8$.

Tare $=733.0$

Cast Monday Aug. 12, 1996

\begin{tabular}{lccc}
\multicolumn{3}{c}{ Compressive Strength, Total Load } \\
1 day & 3 days & 7 days & 14 days \\
6800 & & 12600 & 24200 \\
6500 & 13300 & \\
& & 13900 &
\end{tabular}

\begin{tabular}{cccc}
\multicolumn{5}{c}{ Compressive Strength, psi } \\
1 day & 3 days & 7 days & 14 days \\
1700 & 0 & .3150 & 6050 \\
1625 & 0 & 3325 & 0 \\
0 & 0 & 3475 & 0
\end{tabular}

$\begin{array}{lllll}\text { Avg.: } & 1663 & 0 & 3317 & 6050\end{array}$

Grout \#2

Flow $=7.1$ seconds

U.W. $=1537.0$

Tare $=733.0$

Cast Tuesday Aug. 13, 1996

\section{Grout \#3}

Flow $=5.4$ seconds

U.W. $=1566.0$

Tare $=742.8$

Cast Tuesday Aug. 13, 1996

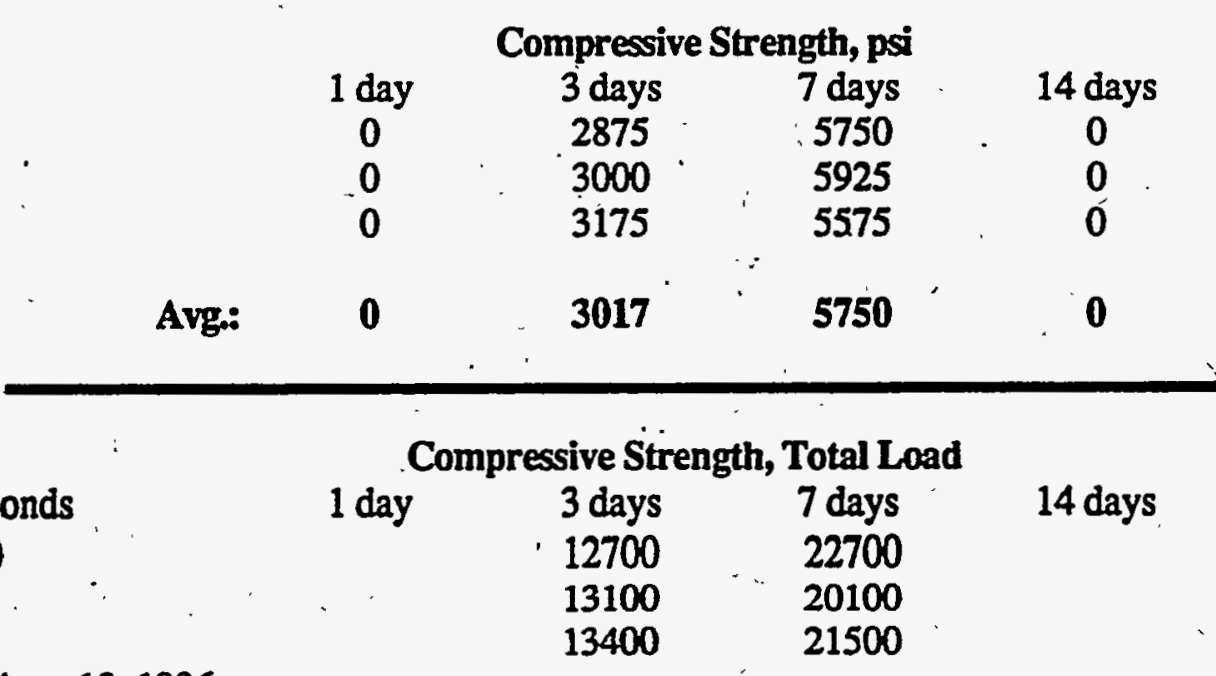

\begin{tabular}{cccc}
\multicolumn{3}{c}{ Compressive Strength, Total Load } \\
1 day & 3 days & 7 days & \\
& 11500 & 23000 & \\
12000 & 23700 & \\
12700 & 22300 &
\end{tabular}

\begin{tabular}{ccccc} 
& \multicolumn{4}{c}{ Compressive Strëngth,psi } \\
& 1 day & 3 days & 7 days & 14 days \\
0 & 3175 & 5675 & 0 \\
0 & 3275 & 5025 & 0 \\
& 0 & 3350 & 5375 & 0 \\
Avg.: & 0 & 3267 & 5358 & 0
\end{tabular}


- Westinghouse/ DOE 102875

\section{Grout \#2}

Flow =

U.W. =

Tare $=$
Compressive Strength, Total Load

$\begin{array}{lll}5 \text { days } & 7 \text { days } & 14 \text { days } \\ 17,800 & 20,900 & 29,000 \\ 17,700 & 21,100 & 28,600 \\ 17,900 & 21,200 & 29,100\end{array}$

Cast Friday, August 2; 1996

These from a mix cast in Structures Lab with large mixer ????

Compressive Strength; psi

$\begin{array}{cccc}1 \text { day } & .3 \text { days } & 7 \text { days } & 14 \text { days } \\ 0 & 4,450 & 5,225 & 7,250 \\ 0 & 4,425 & 5,275 & 7,150 \\ 0 & 4,475 & 5,300 & 7,275\end{array}$

$\begin{array}{llllll}\text { Avg.: } & 0 & 4438 & & 5267 & 7250\end{array}$

Flow $=$ U.W. = Tare $=$

Cast

Flow $=$

U.W. =

Tare $=$

Cast Tuesday Aug. 13, 1996

\section{1 day \\ Compressive Strength, Total Load
3 days
7 days
14 days

$\begin{array}{cccc}\text { Compressive Strength, psi } & : \\ 1 \text { day } & 3 \text { days } & 7 \text { days } & 14 \text { days } \\ 0 . & 0 & 0 & 0 \\ 0 & 0 & 0 & 0 \\ 0 & 0 & 0 & 0\end{array}$

Avg: $0 \quad 0 \quad 0 \quad 0$

\section{Compressive Strength, Total Load}

1 day $\quad 3$ days . 7 days 14 days

0 


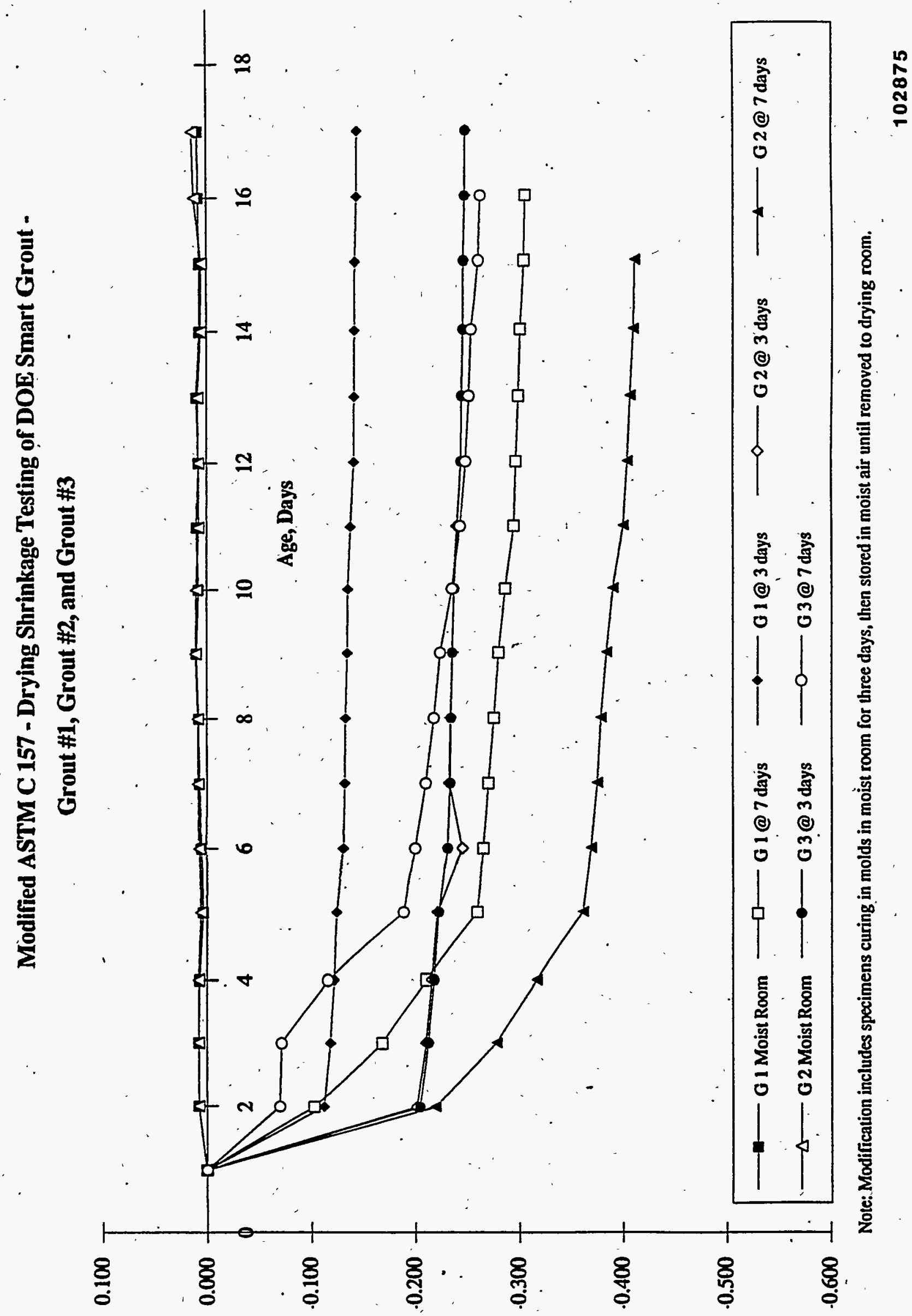




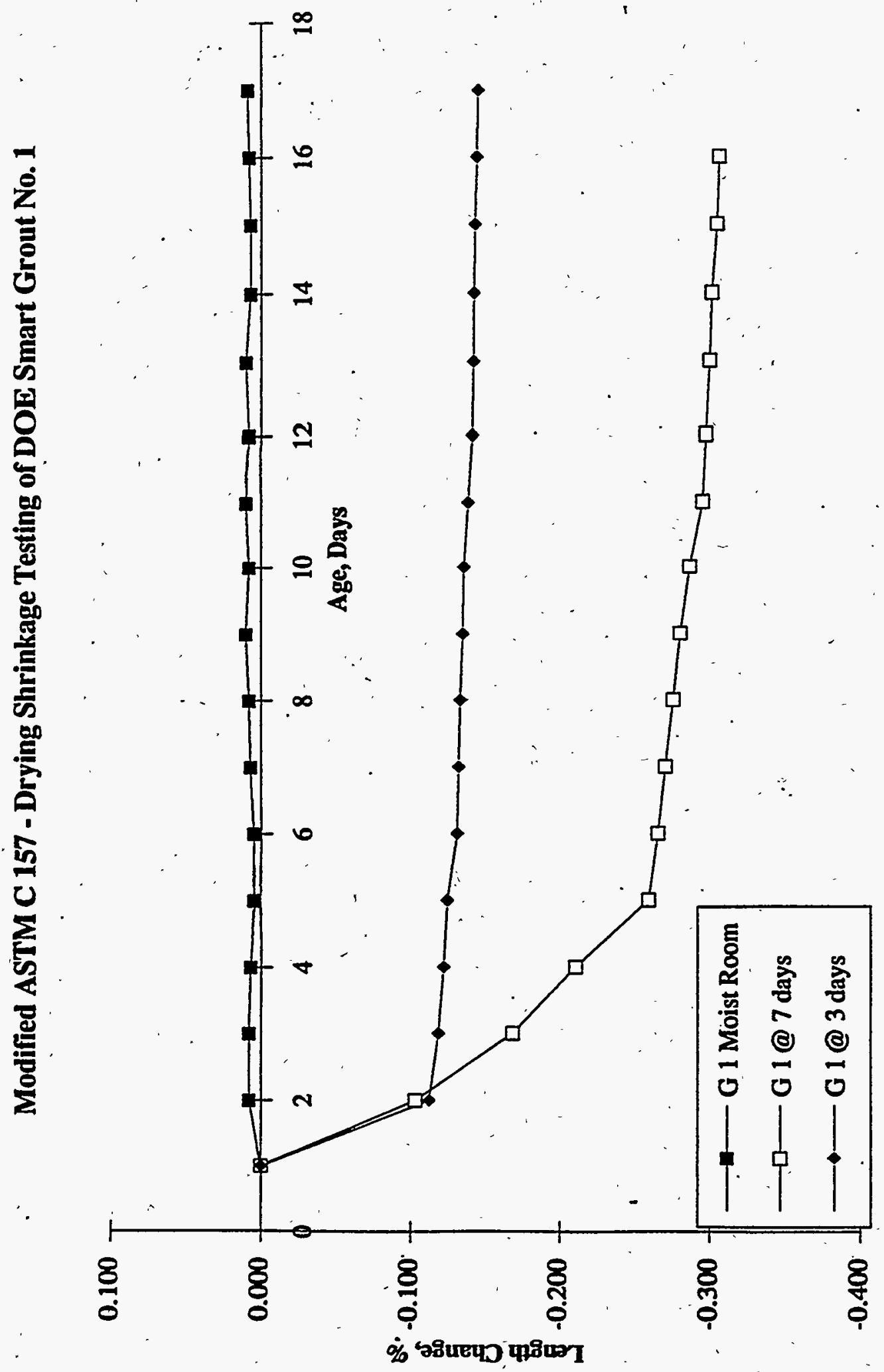


Client: Westinghouse / D.O.E.

Project: Smart Grout

Contact:

Submitter:
CTL Project No.: 102875

CIL Project Mgr.: F. M. Miller

Technician: M. Morrison

Approved: W. Morrison

Date: September 12, 1996

Results of Modified ASTM C 157 - Length Change of Hardened Hydraulic-Cement For a Mixture Identified as

"Grout \#1" After Curing for 3 days in a Moist Room Maintained at $73 \pm 3^{\circ} \mathrm{F}$ and $100 \%$ Relative Humidity

\begin{tabular}{|c|c|c|c|}
\hline \multicolumn{3}{|c|}{$\begin{array}{c}\text { Length Change, } \\
\text { Grout \#1 }\end{array}$} \\
\hline \multirow{2}{*}{ Time } & \multicolumn{2}{|c|}{ Average } \\
\cline { 2 - 3 } & A & B \\
\hline 4 day & -0.002 & -0.223 & -0.112 \\
5 day & -0.002 & -0.235 & -0.119 \\
6 day & -0.002 & -0.242 & -0.122 \\
7 day & -0.002 & -0.247 & -0.125 \\
8 day & -0.002 & -0.260 & -0.131 \\
11 day & -0.002 & -0.262 & -0.132 \\
12 day & -0.002 & -0.264 & -0.133 \\
13 day & -0.002 & -0.267 & -0.135 \\
14 day & -0.002 & -0.269 & -0.136 \\
17 day & -0.002 & -0.274 & -0.138 \\
18 day & -0.003 & -0.280 & -0.141 \\
19 day & -0.003 & -0.281 & -0.142 \\
20 day & -0.003 & -0.282 & -0.142 \\
21 day & -0.003 & -0.283 & -0.143 \\
24 day & -0.003 & -0.286 & -0.144 \\
25 day & -0.003 & -0.287 & -0.145 \\
\hline
\end{tabular}


Client: Westinghouse / D.O.E.

Project: Smart Grout

Contact:

Submitter:
CTL Project No.: 102875

- CTL Project Mgr.: F. M. Miller

Technician: M. Morrison

Approved: W. Morrison

Date: September 12, 1996

- Results of Modified ASTM C 157 - Length Change of Hardened Hydraulic-Cement For a Mixture Idenitified as

"Grout \#1" After Curing for 7 days in a Moist Room

Maintained at $73 \pm 3^{\circ} \mathrm{F}$ and $100 \%$ Relative Humidity

\begin{tabular}{|c|c|c|c|}
\hline \multicolumn{3}{|c|}{$\begin{array}{c}\text { Length Change, } \% \\
\text { Grout \#1 }\end{array}$} \\
\hline \multirow{2}{*}{ Time } & \multicolumn{3}{|c|}{ Average } \\
\cline { 2 - 4 } & A & B & \\
\hline 1 day & -0.104 & -0.102 & -0.103 \\
2 day & -0.168 & -0.169 & -0.169 \\
3 day & -0.209 & -0.212 & -0.211 \\
6 day & -0.257 & -0.262 & -0.260 \\
7 day & -0.263 & -0.268 & -0.266 \\
8 day & -0.267 & -0.274 & -0.271 \\
9 day & -0.273 & -0.278 & -0.276 \\
10 day & -0.277 & -0.283 & -0.280 \\
13 day & -0.284 & -0.289 & -0.287 \\
14 day & -0.292 & -0.298 & -0.295 \\
15 day & -0.294 & -0.300 & -0.297 \\
16 day & -0.297 & -0.302 & -0.300 \\
17 day & -0.298 & -0.304 & -0.301 \\
20 day & -0.302 & -0.307 & -0.305 \\
21 day & -0.303 & -0.309 & -0.306 \\
\hline
\end{tabular}


Client: Westinghouse / D.O.E.

Project: Smart Grout

Contact:.

Submitter: $\therefore$ CTL Project No.: 102875

CTL Project Mgr.: F. M. Miller

Technician: M. Moirison

Approved: W. Morrison

Date: September 12, 1996

Results of Modified ASTM C 157 - Length Change of

Hardened Hydraulic-Cement For a Mixture Identified as

"Grout \#1" Specimens Maintained in Moist Room

Maintained at $73 \pm 3^{\circ} \mathrm{F}$ and $100 \%$ Relative Humidity

for Duration of Test

\begin{tabular}{|c|c|c|c|}
\hline \multicolumn{3}{|c|}{$\begin{array}{l}\text { Length Change, \% } \\
\text { Grout \#1 }\end{array}$} \\
\hline \multirow{2}{*}{ Time } & \multicolumn{2}{|c|}{ Average } \\
\cline { 1 - 4 } & A & B & \\
\hline 4 day & 0.008 & & 0.008 \\
\hline 5 day & 0.008 & & 0.008 \\
6 day & 0.007 & Specimen & 0.007 \\
7 day & 0.004 & Broke & 0.004 \\
8 day & 0.005 & While & 0.005 \\
11 day & 0.007 & Demolding & 0.007 \\
12 day & 0.008 & & 0.008 \\
13 day & 0.010 & & 0.010 \\
14 day & 0.008 & & 0.008 \\
17 day & 0.010 & $\cdots$ & 0.010 \\
18 day & 0.008 & & 0.008 \\
19 day & 0.010 & & 0.010 \\
20 day & 0.007 & & 0.007 \\
21 day & 0.007 & $\ddots$ & 0.007 \\
24 day & 0.008 & & 0.008 \\
25 day & 0.009 & & 0.009 \\
\hline
\end{tabular}


Client: Westinghouse / D.O.E்.

Project: Smart Grout

Contact:

Submitter:
CTL Project No.: 102875

CIL Project Mgr.: F. M. Miller

Technician: M. Morrison

Approved: W. Morrison

Date: September 12, 1996

Results of Modified ASTM C 157 - Length Change of Hardened Hydraulic-Cement For a Mixture Identified as "Grout \#2" After Curing for 7 days in a Moist Room

Maintained at $73 \pm 3^{\circ} \mathrm{F}$ and $100 \%$ Relative Humidity

\begin{tabular}{|c|c|c|c|}
\hline \multicolumn{3}{|c|}{$\begin{array}{c}\text { Length Change, } \% \\
\text { Grout \#1 }\end{array}$} \\
\hline \multirow{2}{*}{ Time } & \multicolumn{3}{|c|}{ Average } \\
\cline { 2 - 4 } & A & \multicolumn{1}{|c|}{ B } \\
\hline 1 day & & -0.219 & -0.219 \\
2 day & & -0.278 & -0.278 \\
3 day & Specimen & -0.317 & -0.317 \\
6 day & Broke & -0.361 & -0.361 \\
7 day & While & -0.369 & -0.369 \\
8 day & Demolding & -0.375 & -0.375 \\
9 day & & -0.379 & -0.379 \\
10 day & & -0.384 & -0.384 \\
13 day & & -0.390 & -0.390 \\
14 day & & -0.400 & -0.400 \\
15 day & & -0.404 & -0.404 \\
16 day & & -0.407 & -0.407 \\
17 day & & -0.410 & -0.410 \\
20 day & & -0.411 & -0.411 \\
\hline
\end{tabular}


Client: Westinghouse / D.O.E.

Project: Smart Grout

Contact:

Submitter: $\therefore$ CTL Project No.: 102875

CTL Project Mgr.: F. M. Miller

Technician: M. Morrison

Approved: W. Morrison

Date: September 12, 1996

Results of Modified ASTM C 157 - Length Change of

Hardened Hydraulic-Cement For a Mixture Identified as

"Grout \#2" Specimens Maintained in Moist Room

Maintained at $73 \pm 3^{\circ} \mathrm{F}$ and $100 \%$ Relative Humidity

for Duration of Test.

\begin{tabular}{|c|c|c|c|}
\hline \multicolumn{3}{|c|}{$\begin{array}{c}\text { Length Change, \% } \\
\text { Grout \#1 }\end{array}$} \\
\hline \multirow{2}{*}{ Time } & \multicolumn{2}{|c|}{ Average } \\
\cline { 2 - 4 } & A & B & \\
\hline 4 day & 0.008 & & 0.008 \\
\hline 5 day & 0.008 & & 0.008 \\
6 day & 0.008 & Specimen & 0.008 \\
7 day & 0.006 & Broke & 0.006 \\
8 day & 0.007 & While & 0.007 \\
11 day & 0.009 & Demolding & 0.009 \\
12 day & 0.009 & & 0.009 \\
13 day & 0.011 & & 0.011 \\
14 day & 0.010 & & 0.010 \\
17 day & 0.008 & & 0.008 \\
18 day & 0.008 & & 0.008 \\
19 day & 0.009 & & 0.009 \\
20 day & 0.006 & & 0.006 \\
21 day & 0.005 & & 0.005 \\
24 day & 0.012 & & 0.012 \\
25 day & 0.014 & & 0.014 \\
\hline
\end{tabular}


Client: Westinghouse / D.O.E.

Project: Smart Grout

Contact:

Submitter:
CTL Project No.: 102875

CTL Project Mgr.: F. M. Miller .

Technician: M. Morrison

Approved: W. Morrison

Date: September 17, 1996

Results of Modified ASTM C 157 - Length Change of Hardened Hydraulic-Cement For a Mixture Identified as

"Grout \#3" After Curing for 3 days in a Moist Room

Maintained at $73 \pm 3^{\circ} \mathrm{F}$ and $100 \%$ Relative Humidity

\begin{tabular}{|c|c|c|c|}
\hline \multicolumn{3}{|c|}{ Length Change, \% } \\
Grout \#1 \\
\hline \multirow{2}{*}{ Time } & \multicolumn{2}{|c|}{ Average } \\
\cline { 2 - 3 } & \multicolumn{1}{|c|}{ A } & B & \\
\hline 4 day & -0.003 & -0.406 & -0.205 \\
5 day & -0.003 & -0.422 & -0.213 \\
6 day & -0.003 & -0.432 & -0.218 \\
7 day & -0.004 & -0.441 & -0.222 \\
8 day & -0.004 & -0.458 & -0.231 \\
11 day & -0.004 & -0.463 & -0.233 \\
12 day & -0.004 & -0.465 & -0.234 \\
13 day & -0.004 & -0.467 & -0.235 \\
14 day & -0.004 & -0.471 & -0.237 \\
17 day & -0.004 & -0.478 & -0.241 \\
\hline 18 day & -0.004 & -0.484 & -0.244 \\
19 day & -0.004 & -0.486 & -0.245 \\
20 day & -0.004 & -0.488 & -0.246 \\
21 day & -0.004 & -0.489 & -0.247 \\
24 day & -0.004 & -0.492 & -0.248 \\
25 day & -0.004 & -0.493 & -0.249 \\
\hline
\end{tabular}


Client: Westinghouse / D.O.E.

Project: Smart Grout

Contact:

Submitter:
CTL Project No.: 102875

CTL Project Mgr.: F. M. Miller

Technician: M. Morrison

Approved: W. Morrison

Date: September 17, 1996

Results of Modified ASTM C 157 - Length Change of Hardened Hydraulic-Cement For a Mixture Identified as "Grout \#3" After Curing for 7 days in a Moist Room Maintained at $73 \pm 3^{\circ} \mathrm{F}$ and $100 \%$ Relative Humidity

\begin{tabular}{|c|c|c|c|}
\hline \multicolumn{4}{|c|}{$\begin{array}{c}\text { Length Change, \% } \\
\text { Grout \#1 }\end{array}$} \\
\hline \multirow{2}{*}{ Time } & \multicolumn{2}{c|}{ Average } \\
\cline { 2 - 3 } & A & B \\
\hline 1 day & -0.072 & -0.068 & -0.070 \\
2 day & -0.073 & -0.070 & -0.071 \\
3 day & -0.118 & -0.114 & -0.116 \\
6 day & -0.194 & -0.184 & -0.189 \\
7 day & -0.205 & -0.195 & -0.200 \\
8 day & -0.216 & -0.204 & -0.210 \\
9 day & -0.224 & -0.212 & -0.218 \\
10 day & -0.229 & -0.219 & -0.224 \\
13 day & -0.238 & -0.233 & -0.236 \\
14 day & -0.247 & -0.240 & -0.244 \\
15 day & -0.253 & -0.244 & -0.249 \\
16 day. & -0.255 & -0.249 & -0.252 \\
17 day & -0.256 & -0.252 & -0.254 \\
20 day & -0.265 & -0.257 & -0.261 \\
\hline & & & \\
\hline
\end{tabular}


Client: Westinghouse / D.O.E.

Project: Smart Grout

Contact:

Submitter:
CTL Project No.: 102875

CTL Project Mgr.: F. M. Miller

Technician: M. Morrison

Approved: W. Morrison

Date: September 17, 1996

Results of Modified ASTM C 157 - Length Change of Hardened Hydraulic-Cement For a Mixture Identified as "Grout \#3" Specimens Maintained in Moist Room

Maintained at $73 \pm 3^{\circ} \mathrm{F}$ and $100 \%$ Relative Humidity for Duration of Test

\begin{tabular}{|c|c|c|c|}
\hline \multicolumn{3}{|c|}{$\begin{array}{c}\text { Length Change, } \\
\text { Grout \#1 }\end{array}$} \\
\hline \multirow{2}{*}{ Time } & \multicolumn{2}{|c|}{ Average } \\
\cline { 2 - 3 } & \multicolumn{2}{|c|}{ A } & B \\
\hline 4 day & 0.008 & 0.003 & 0.005 \\
\hline 5 day & 0.008 & 0.003 & 0.005 \\
\hline 6 day & 0.008 & 0.003 & 0.005 \\
\hline 7 day & 0.006 & 0.003 & 0.005 \\
\hline 8 day & 0.007 & 0.003 & 0.005 \\
\hline 11 day & 0.010 & 0.005 & 0.008 \\
\hline 12 day & 0.011 & 0.005 & 0.008 \\
\hline 13 day & 0.011 & 0.008 & 0.010 \\
14 day & 0.009 & 0.006 & 0.008 \\
\hline 17 day & 0.009 & 0.006 & 0.008 \\
18 day & 0.009 & 0.006 & 0.008 \\
19 day & 0.009 & 0.006 & 0.008 \\
\hline 20 day & 0.010 & 0.006 & 0.008 \\
\hline
\end{tabular}




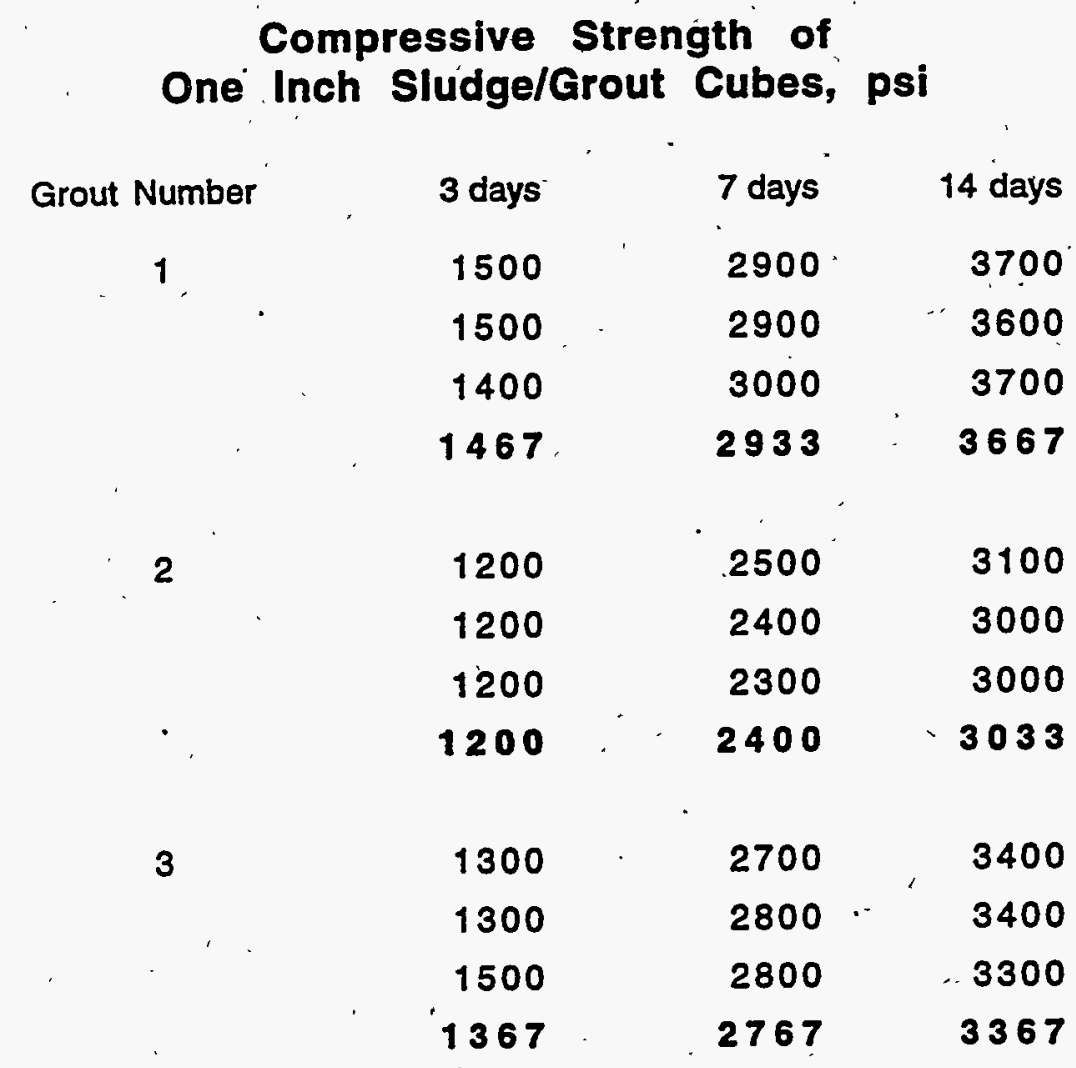




\section{Appendix D}

Graphs from Leaching Tests of Sludge and Grouted Sludges 
WSRC-TR-97-0102

APPENDIX "A"

Revision 0

CTL Tank 20 Reducing Grout Report

Page 95

\section{Appendix D-Results of Sludge Leaching and Sequential Batch Leaching of Grout}

The treated sludge, with added calcium hydroxide and calcium sulfide, and the grouted $s^{\text {'! }}$ dges, after curing for 14 days, were subjected to batch leaching using water, in the case of the sludge, and simulated acid rain or $0.1 \mathrm{M}$ acetic acid, in the case of the grouted sludges. The discussion of the results follows.

\section{Sludge Leaching Test (Reducing Eh and high $\mathbf{p H}$ )}

It is known that the grouts will provide a high $\mathrm{pH}$ and a low $\mathrm{E}_{\mathrm{h}}$ to the system, if they are in intimate contact with the sludge. In an effort to discover the leachability of the elements of interest from the sludge, assuming no incorporation of sludge in the grout, and assuming only that a high $\mathrm{pH}$ and a low $\mathrm{E}_{\mathrm{h}}$ can be maintained, the spiked sludge was subjected to sequential batch leaching using deionized water spiked with calcium hydroxide and calcium sulfide, to simulate the actual species expected to be present in a leachate from the grout. The amount of calcium hydroxide and calcium sulfide added were sufficient to achieve very high $\mathrm{pH}$ values and low $\mathrm{E}_{\mathrm{h}}$ values. By comparison to the leachabilities from the grouted sludges, the leachabilities from the sludge alone were therefore inclined to be biased low, since the actual $\mathrm{E}_{\mathrm{h}}$ and $\mathrm{pH}$ values in the solutions derived from batch leaching of the grouted sludges, especially those leached with acetic acid, were less favorable (lower $\mathrm{pH}$, higher $E_{h}$ ). The procedure for determining $E_{h}$ and $\mathrm{pH}$ is shown in Appendix A. All graphs for the sludge and grout leaching results can be found in Appendix D.The values for $\mathrm{E}_{\mathrm{h}}$ and $\mathrm{pH}$ from the sludge as a function of leach cycle are shown in Fig.1S. The leaching of uranium from the sludge, as an example, is shown in Fig. 2S; the big jump is attributable to an increase in $\mathrm{E}_{\mathrm{h}}$, as can be seen in Fig. 3S.

\section{Sequential Batch Leach Test}

The procedure for this test is described in Appendix A. It involves the preparation of wellmixed specimens of grout and spiked sludge, curing of these specimens for fourteen days, and leaching of the crushed $(-9.5 \mathrm{~mm})$ samples with either $0.1 \mathrm{M}$ acetic acid, which simulates EPA's Toxic Characteristic Leach Procedure (TCLP), or with pH 5 simulated acid rain, which is believed to simulate the groundwater in the Savannah River area. It should be pointed out that 14 days is a very short curing time, and the stabilization of metals is thus probably much less effective than if the system had been allowed to cure for a longer period of time.

There were two separate reasons for the batch leach test. First, it simulated the "best-case" mixing conditions, in that the sludge and grout were deliberately homogenized in a mortar mixer. It would enable the determination of that level of leach protection which might be achievable from such mixing. Secondly, it gave a "worst-case" weathering scenario, in which the pH of the system was allowed to be reduced essentially to that of the soil (or lower), to determine what leaching protection the decomposition products of the grout still might afford.

In addition to analyzing the extracts for their content of the metals and anions. of interest, each leachate was tested for $E_{h}$ and $\mathrm{pH}$. The $E_{h}$ results for the three grouted sludges subjected to simulated acid rain (SAR) leach are shown in Fig. $1\left(\mathrm{E}_{\mathrm{h}} / \mathrm{pH}\right)$. The comparable data for acetic acid leaching are shown in Fig. $2\left(\mathrm{E}_{\mathrm{h}} / \mathrm{pH}\right)$. Figs. $3\left(\mathrm{E}_{\mathrm{h}} / \mathrm{pH}\right)$ and $4\left(\mathrm{E}_{\mathrm{h}} / \mathrm{pH}\right)$ show the comparable data for $\mathrm{pH}$. The initial testing evaluating the leaching of the sludge alone revealed that, of the elements of interest, cesium, selenium, and thenium were very easily leached. Unfortunately, the grouts did not provide much protection against leaching of these two elements. The results are not surprising for cesium, as it is always present as 
WSRC-TR-9̣7-0102

$\mathrm{Cs}^{1+}$ and is not amenable to chemical reduction, nor is its hydroxide insoluble. Selenium is present as an oxyanion, which would be expected to be fairly soluble at high $\mathrm{pH}$ unless stabilized. The high Re solubility was more surprising. On the basis of the reduction potential for perrhenate ion, it is surmised that the heptavalent $(+7) \operatorname{Re}$ was not reduced by the calcium sulfide added to produce a low $\mathrm{E}_{\mathrm{h}}$ sludge, nor by the sodium thiosulfate ar,jitive. In this respect, $\operatorname{Re}$ was found to be a poor surrogate for $\mathrm{Tc}$, since pertechnetate is known to be amenable to reduction by blast fumace slag (Langton, 1987 and Bostick et al., 1988).

The leaching of the relatively insoluble metals from the sludge vs leach cycle is shown in Fig. 4S, and for the soluble metals, in Fig. 5S. Uranium and cerium, the two surrogates for plutonium, are both very insoluble from the sludge. The uranium becomes slightly more soluble in the later leaching stages. Cerium remains almost completely insoluble. Molybdenum has intermediate solubility, and so is shown by itself, in Fig. 6S. The strong dependence of Mo leachability on $\mathrm{E}_{\mathrm{h}}$ is documented in Fig. 7S.

\section{Simulated Acid Rain Leaches}

In the simulated acid rain leaching studies, Cs was rapidly leached (Fig. 1GS), as is $\operatorname{Re}$ (Fig. 2GS), although by comparison to the sludge alone, the grouts seem to reduce leachability slightly. The grouts reduce Sr leachability significantly (Fig. 4GS).

Dependence of $\mathrm{Sr}$ leachability on $\mathrm{E}_{\mathrm{h}}$ would not be expected, as the divalent state is the only oxidation state of interest for Sr. $\mathrm{pH}$ dependence, on the other hand, would be anticipated, and is observed. The two elements used as surrogates for plutonium, uraniúm and cerium, showed very low leachability in the simulated acid rain experiments The uranium was significantly better stabilized in the grout than simply in the $\mathrm{pH} / \mathrm{E}_{\mathrm{h}}$ adjusted sludge (Fig. SGS). However, it did show some leachability dependence on $\mathrm{E}_{\mathrm{h}}$. Uranium is more difficult to reduce than is plutonium, so plutonium's $\mathrm{E}_{\mathrm{h}}$ sensitivity may be less marked. Cerium was well stabilized in grouted sludge and in adjusted sludge (Fig. 6GS).

Presumably, the cerium is maintained in its trivalent state, which has low solubility.

The situation with molybdenum and selenium is very interesting. Molybidenum's leachability is strongly dependent on $\mathrm{E}_{\mathrm{h}}$, as well as on $\mathrm{pH}$ (Fig. 7GS). The fact that molydenum was better retained in the sludge than in the grouted sludges is almost certainly a function of the lower $E_{h}$ in the sludge. In the case of selenium, the grouts significantly reduce the leachability relative to the sludge alone (Fig. 3GS). This finding is consistent with the known ability of selenium to substitute for sulfur in ettringite-like compounds. However, again $E_{h}$ is a strong factor in the solubility. It appears that Mo and Se are fairly easily oxidized, and the oxidized forms are more soluble.

Iron, nickel, manganese, and silver are well retained at high $\mathrm{pH}$ in sludge or in grouted sludge. Mercury is far better retained in grouted sludge.

\section{Leachabilities with Acetic.Acid}

In the case of the acetic acid leaching, the $\mathrm{pH}$ became quite acidic in the latter stages of leaching. As anticipated, most of the metals were poorly retained when the $\mathrm{pH}$ became low. The leachability of cerium, molybdenum, selenium, and uranium vs milliequivalents of acetic acid added are shown in Figs.8GS-11GS. $E_{h}$ is also plotted on these graphs, and it is striking how well the curves track one another. Re is not as well immobilized, but its leachability still tracks $E_{h}$; as shown in Fig. 15GS. The single electrode potential comparison reveals that, as compared to Tc, Re is simply rather hard to reduce to the 
tetravalent state, and easily re-oxidized to the heptavalent state. Mo is again mụch more readily leached at higher values of $\mathrm{E}_{\mathrm{h}}$.

\section{Summary}

F.specially for the earlier leaching steps, the results reveal that all grouts perform approximately equivalently in stabilization of the radionuclides of concem. Uranium and selenium, as.well as strontium, are far better retained in grouts than in sludges.with controlled $\mathrm{pH}$ and Eh. Cerium is well retained in all high $\mathrm{pH}$, low $\mathrm{E}_{\mathrm{h}}$ systems. When present in the heptavalent oxidation state, rhenium is not well retained in any of the systems studied, and molybdenum is also rather mobile, although better stabilized at low $\mathrm{E}_{\mathrm{h}}$.. These results are in part attributable to the short curing period. Cesium retention is minimal, and probably some grout compositional modifications would be necessary to improve retention of this element. 


\section{Progression of $\mathrm{pH}$ and Eh on Leached} Sludge with added $\mathrm{Ca}(\mathrm{OH}) 2$ and $\mathrm{CaS}$

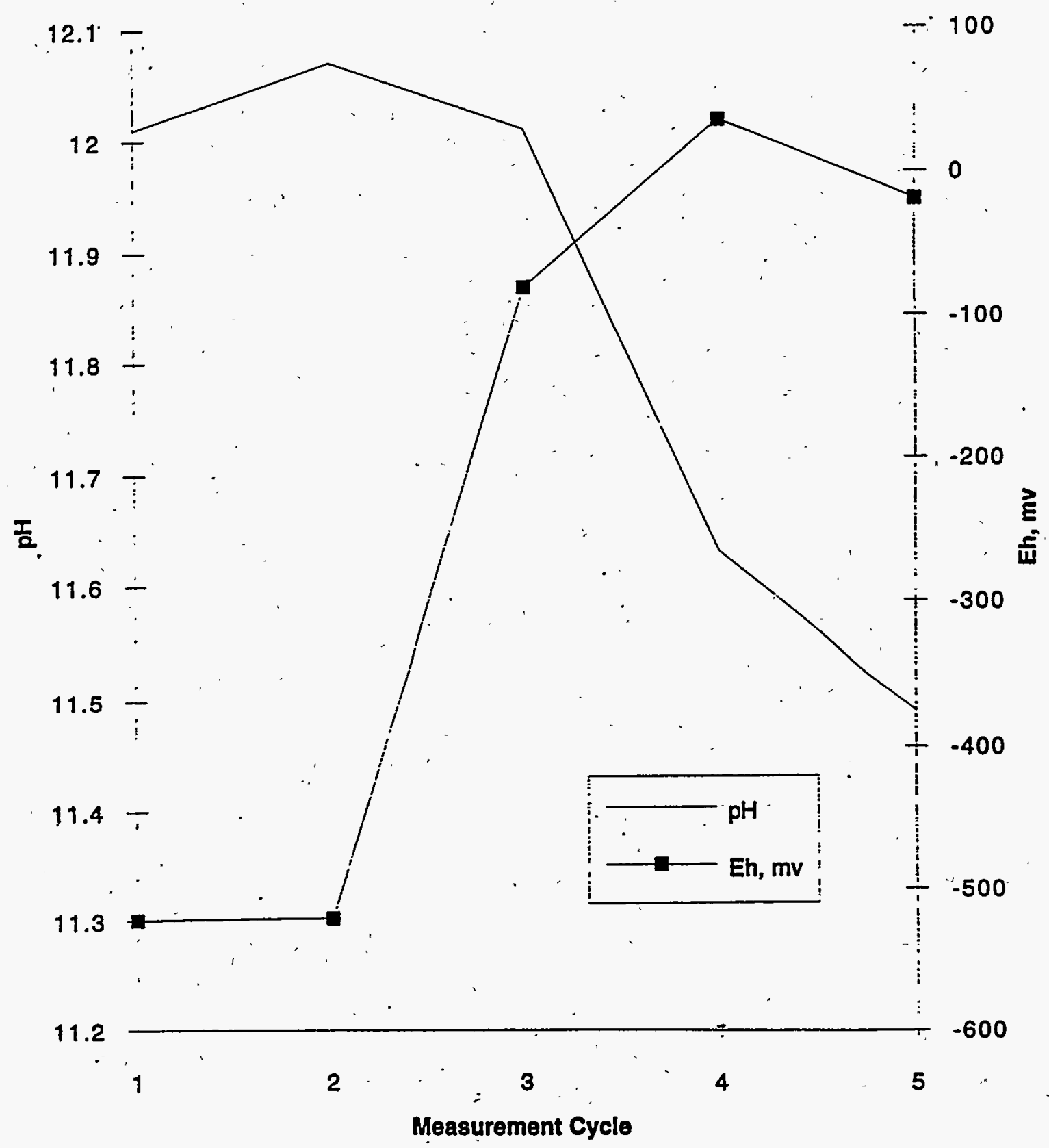




\section{Leaching of Uranium from Spiked Sludge at High pH and Low Eh}

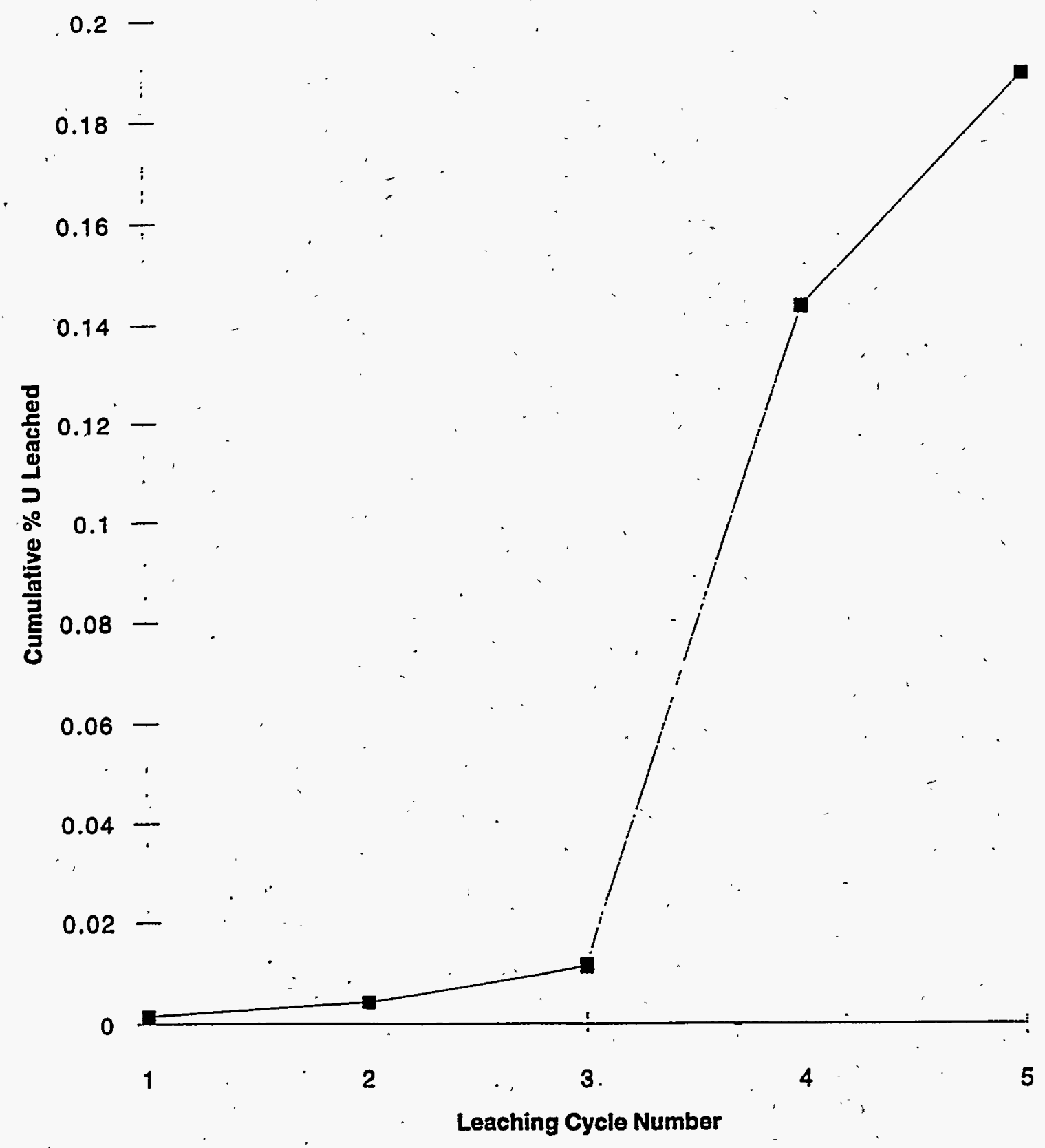

$\therefore$ Figure 2S 


\section{Sludge- U Leach vs Eh}

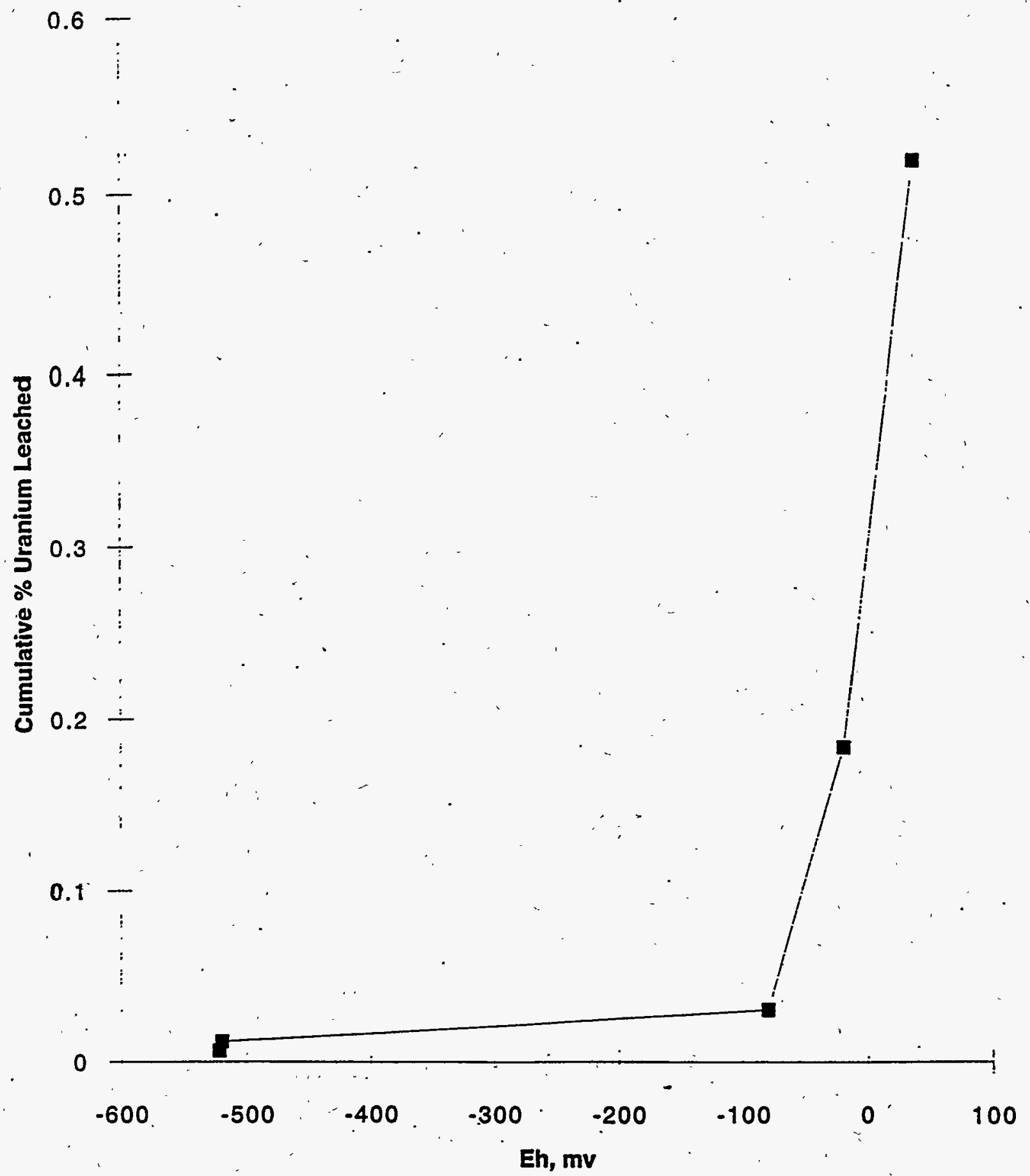

Figure 35 


\section{Maintenance of Eh, Grouted Sludges with Acid Rain}

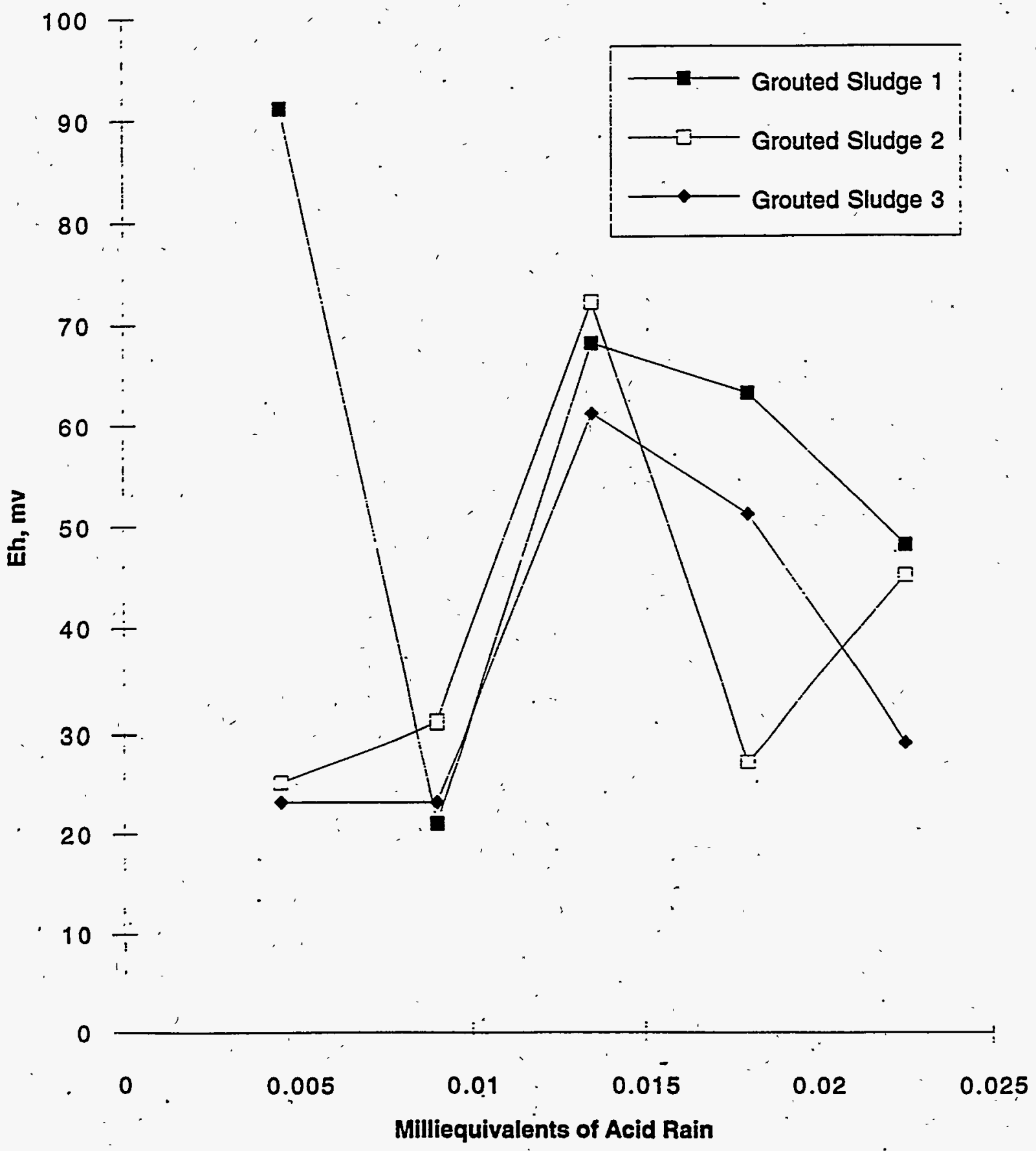




\section{Maintenance of Reducing Capability} Acetic Acid Sequential Leaching

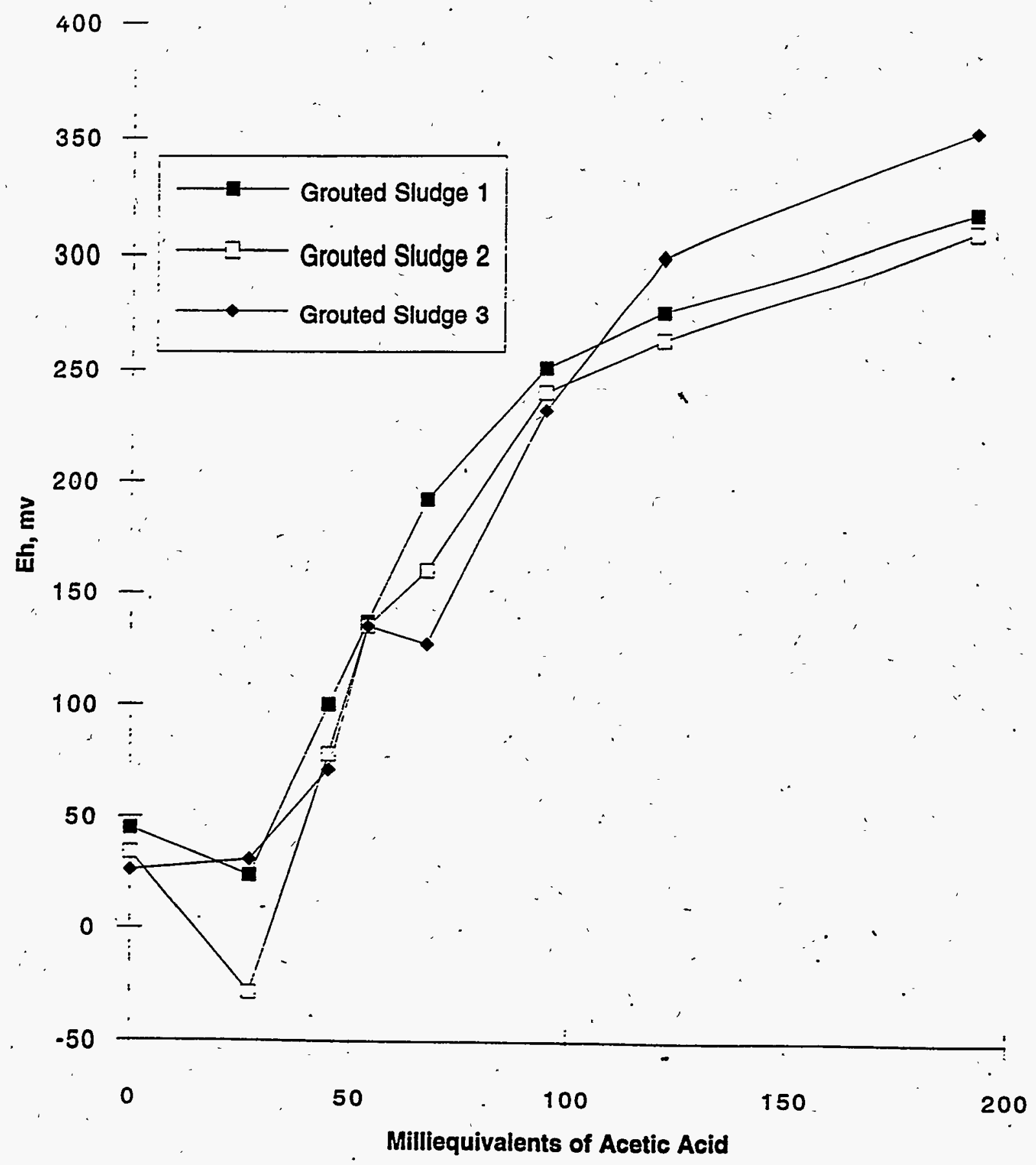

Figure $2(\mathrm{Eh} / \mathrm{pH})$ 


\section{Maintenance of $\mathrm{pH}$, Grouted Sludges with Acid Rain}

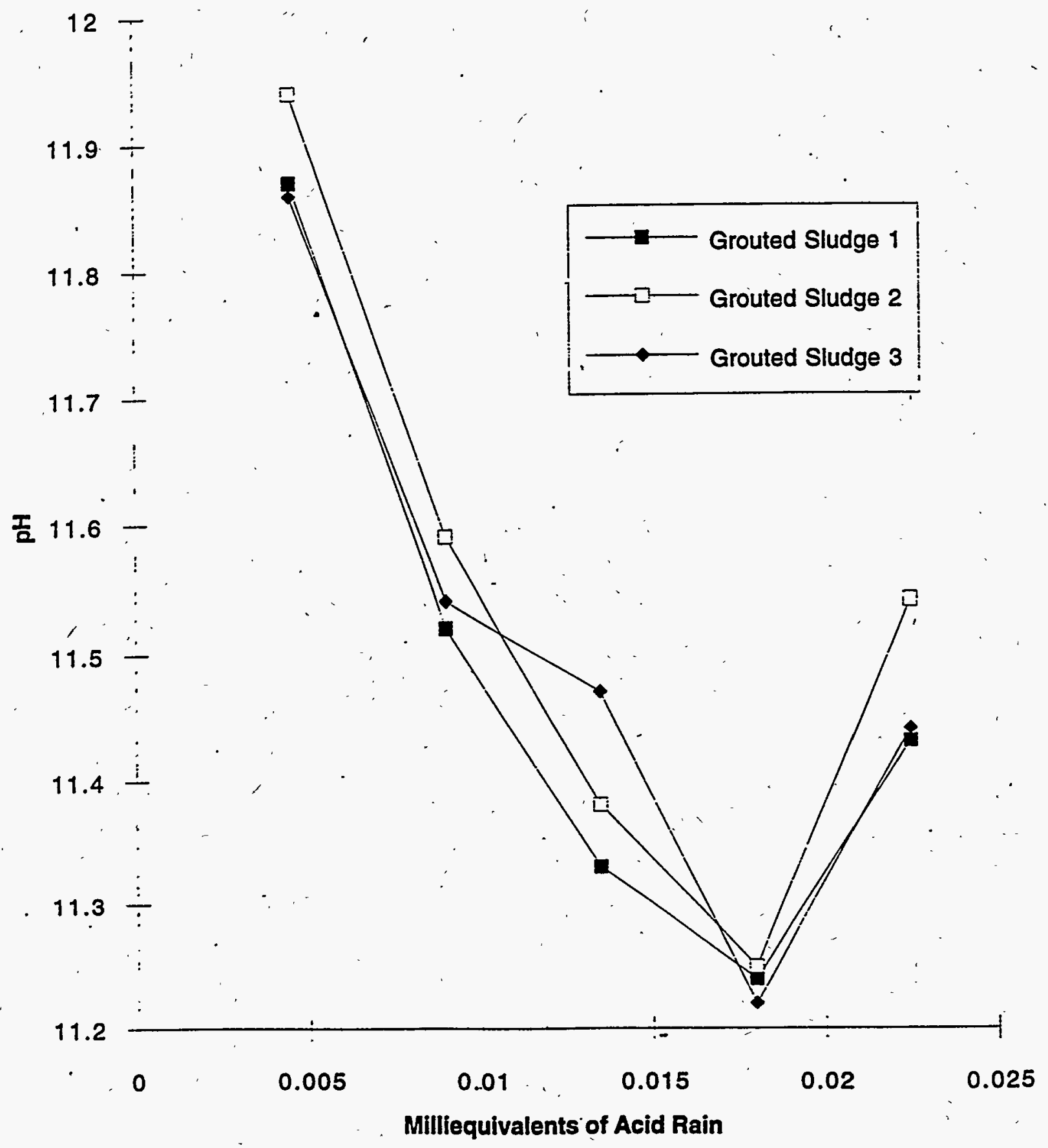

Figure $3(\mathrm{Eh} / \mathrm{pH})$ 


\section{Maintenance of $\mathrm{pH}$, \\ Grouted Sludges with Acetic Acid}

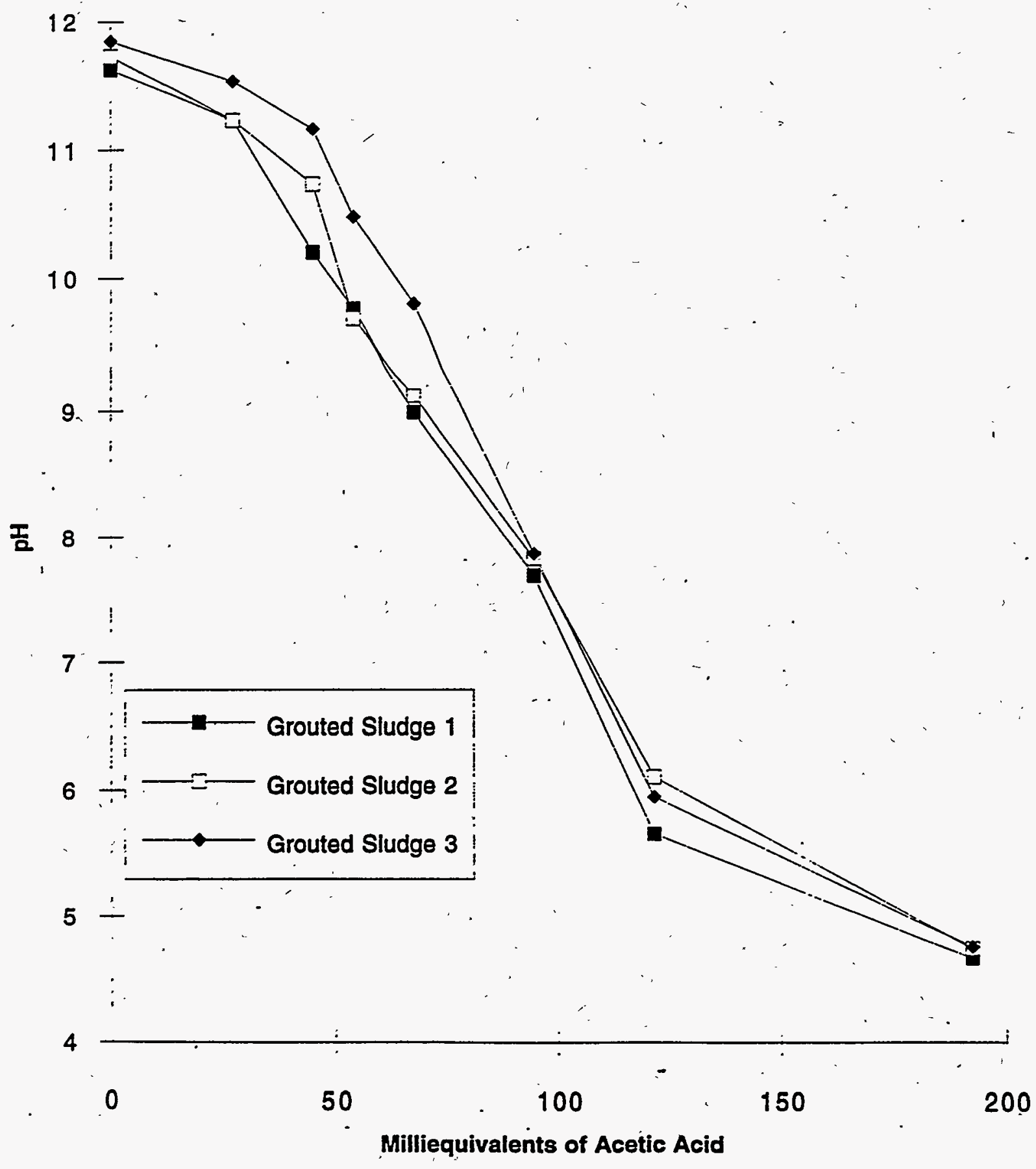

Figure. $4(\mathrm{Eh} / \mathrm{pH})$ 


\section{Leaching of Relatively Insoluble Metals} From Spiked Sludge at Low Eh, High pH

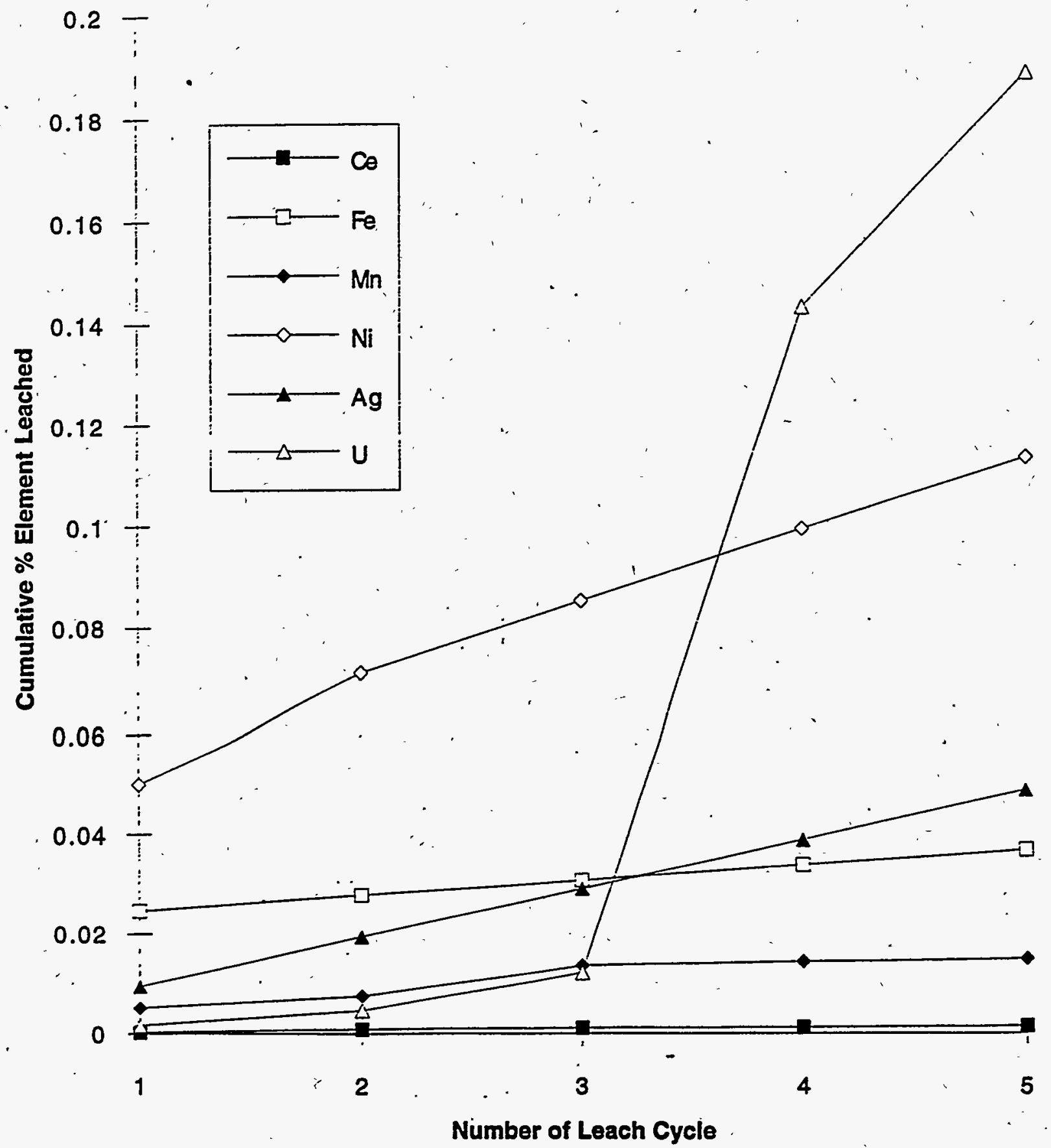

$\therefore \quad$ Figure 45 


\section{Leaching of Soluble Metals from Spiked Slùdge at Low Eh, High pH}

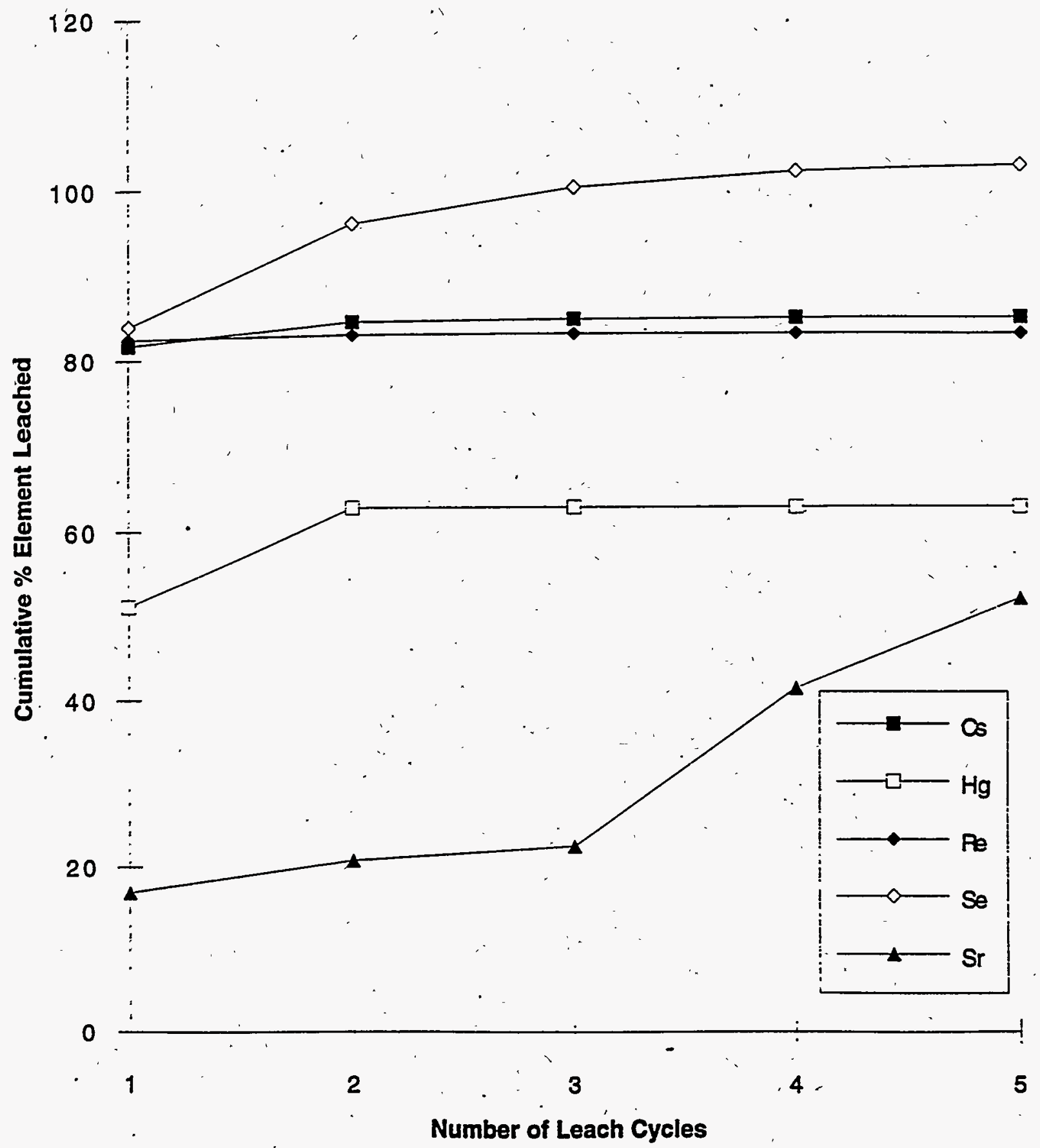

Figure 5S 


\section{Leaching of Mo from Spiked \\ Sludge at Low Eh, High pH}

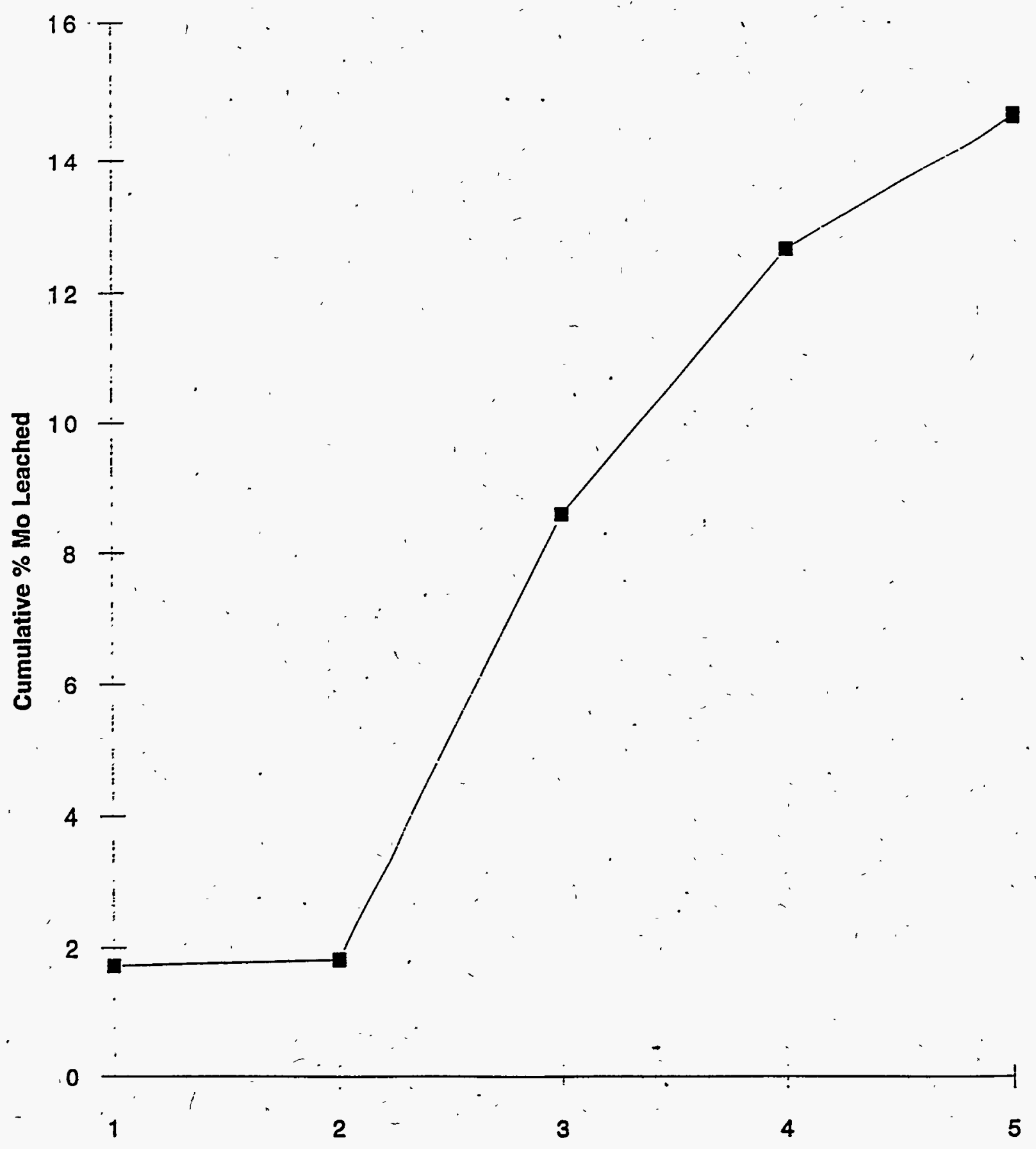




\section{Relationship Between Eh and Mo Leachability from Spiked Sludge}

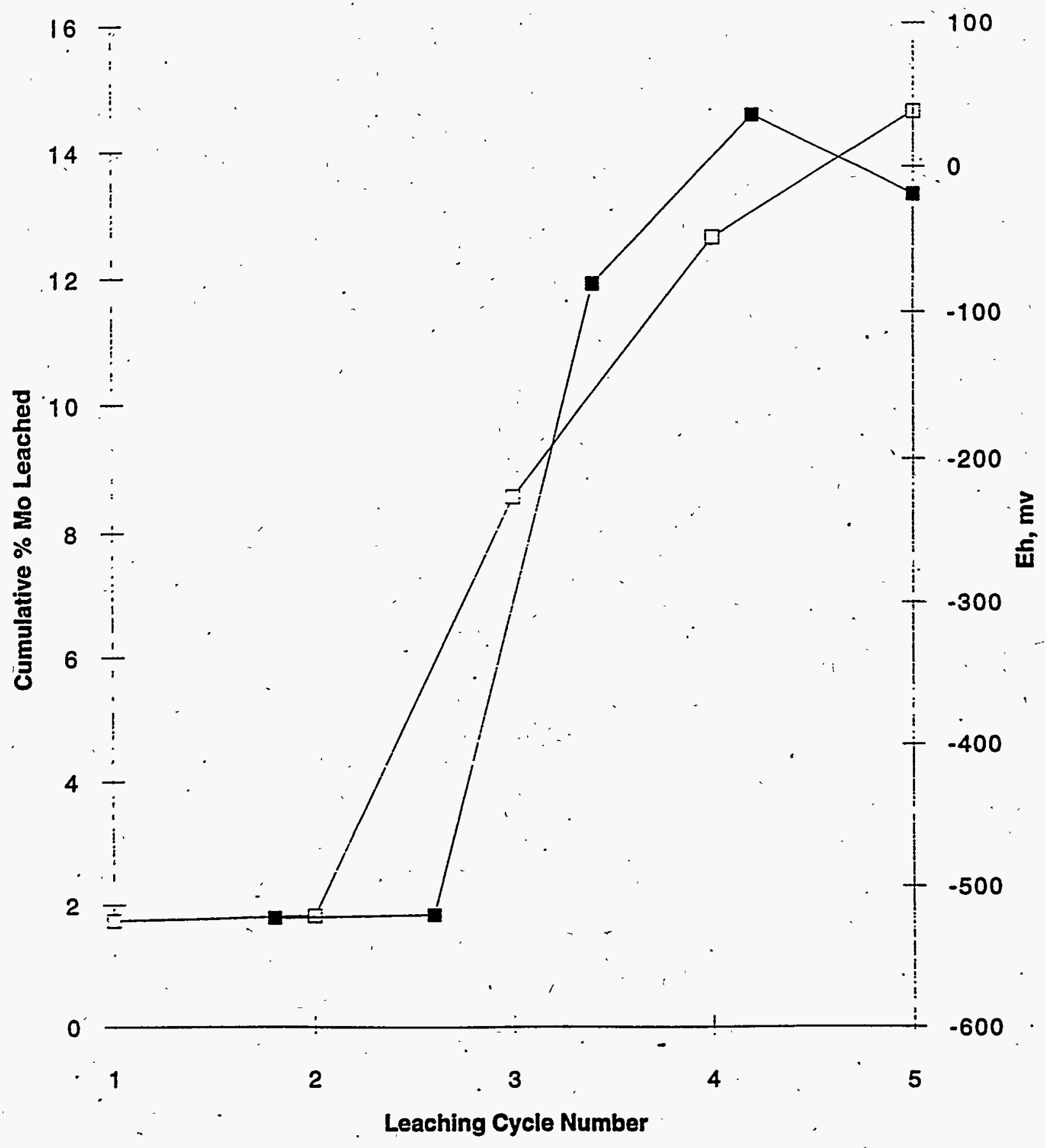




\section{Leaching of Cs with Simulated Acid Rain}

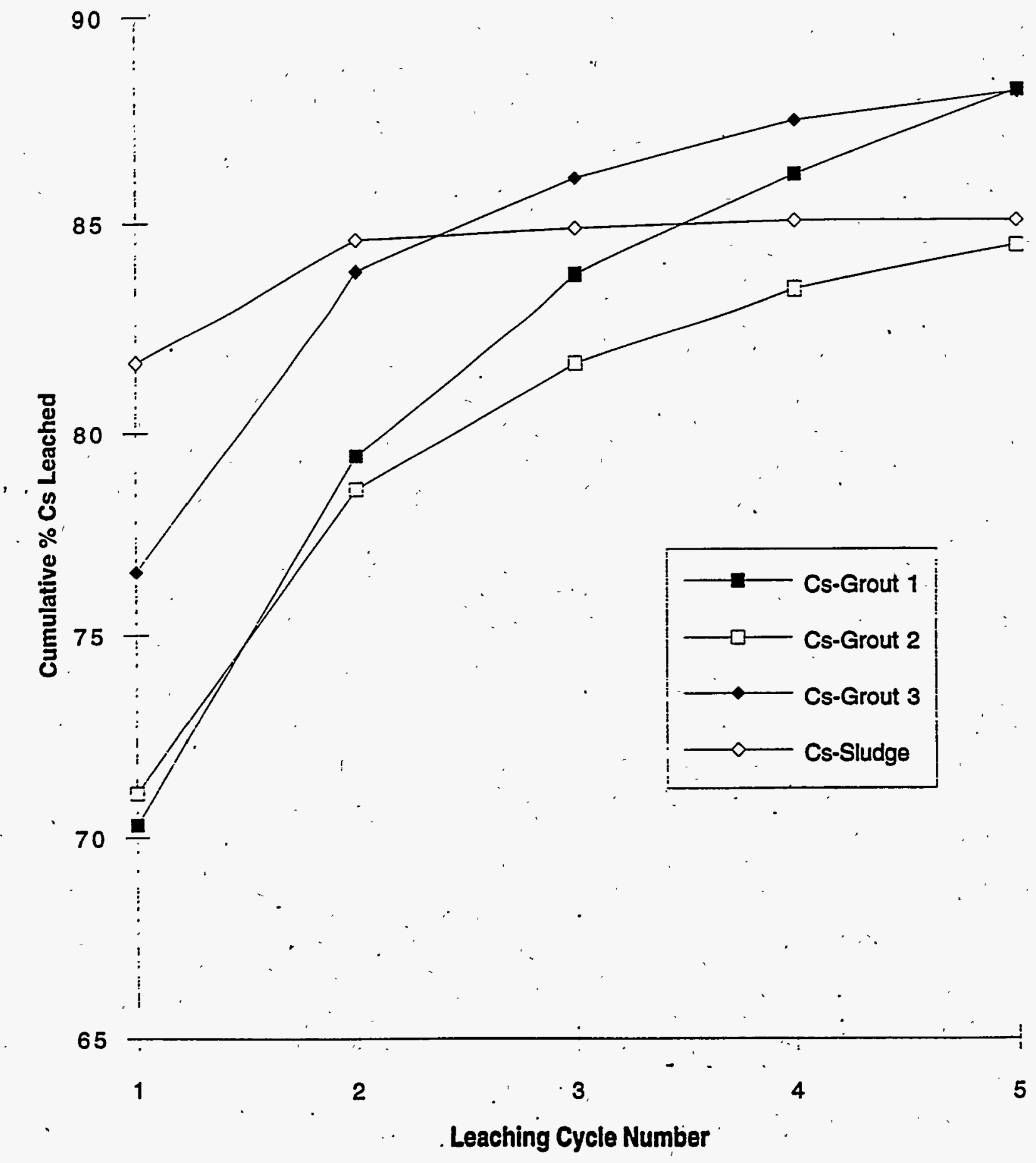

$\therefore \quad$ Figure 1GS 


\section{Leaching of Re with Simulated Acid Rain}

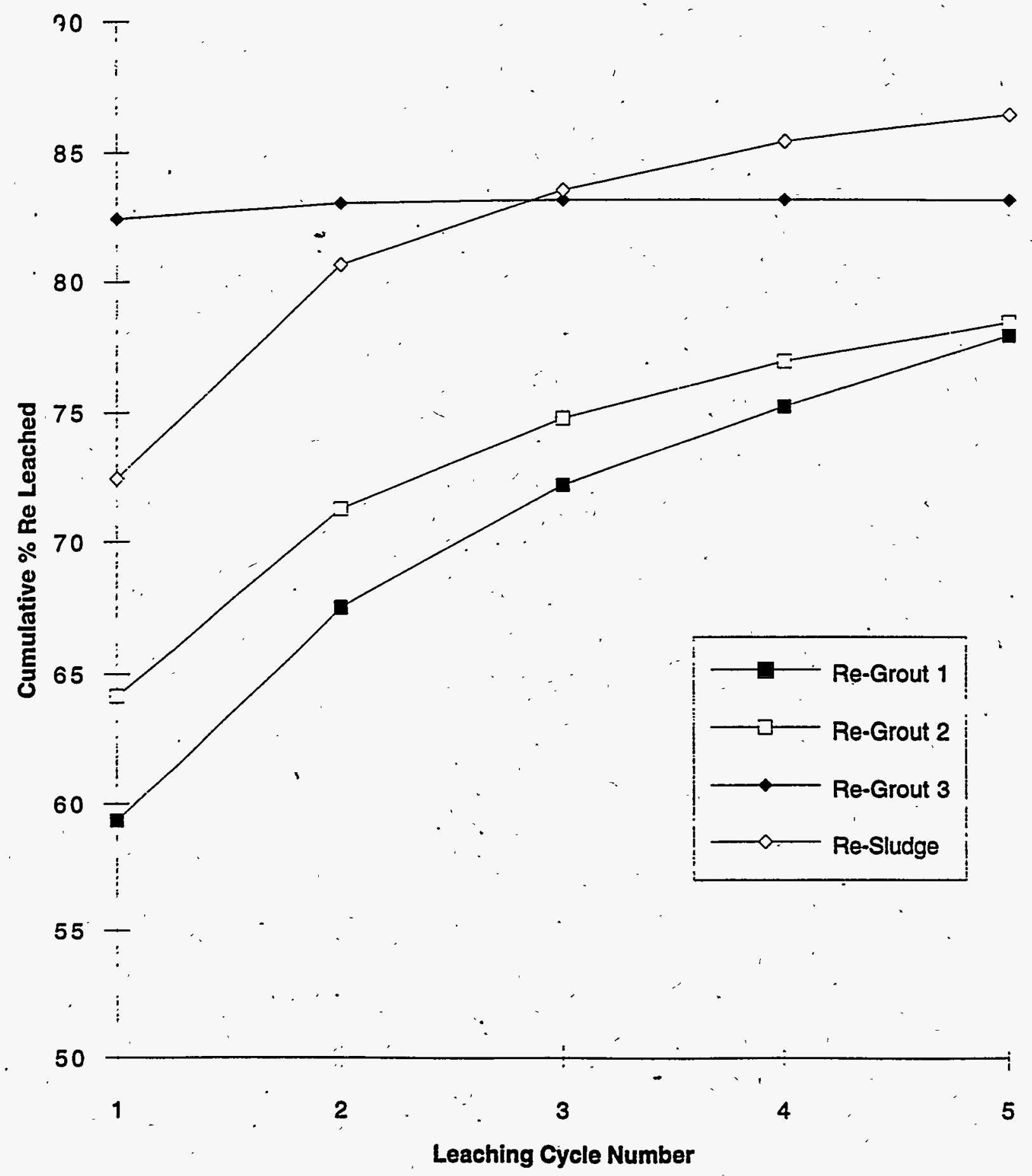

Figure 2GS 


\section{Leaching of Se with Simulated Acid Rain}

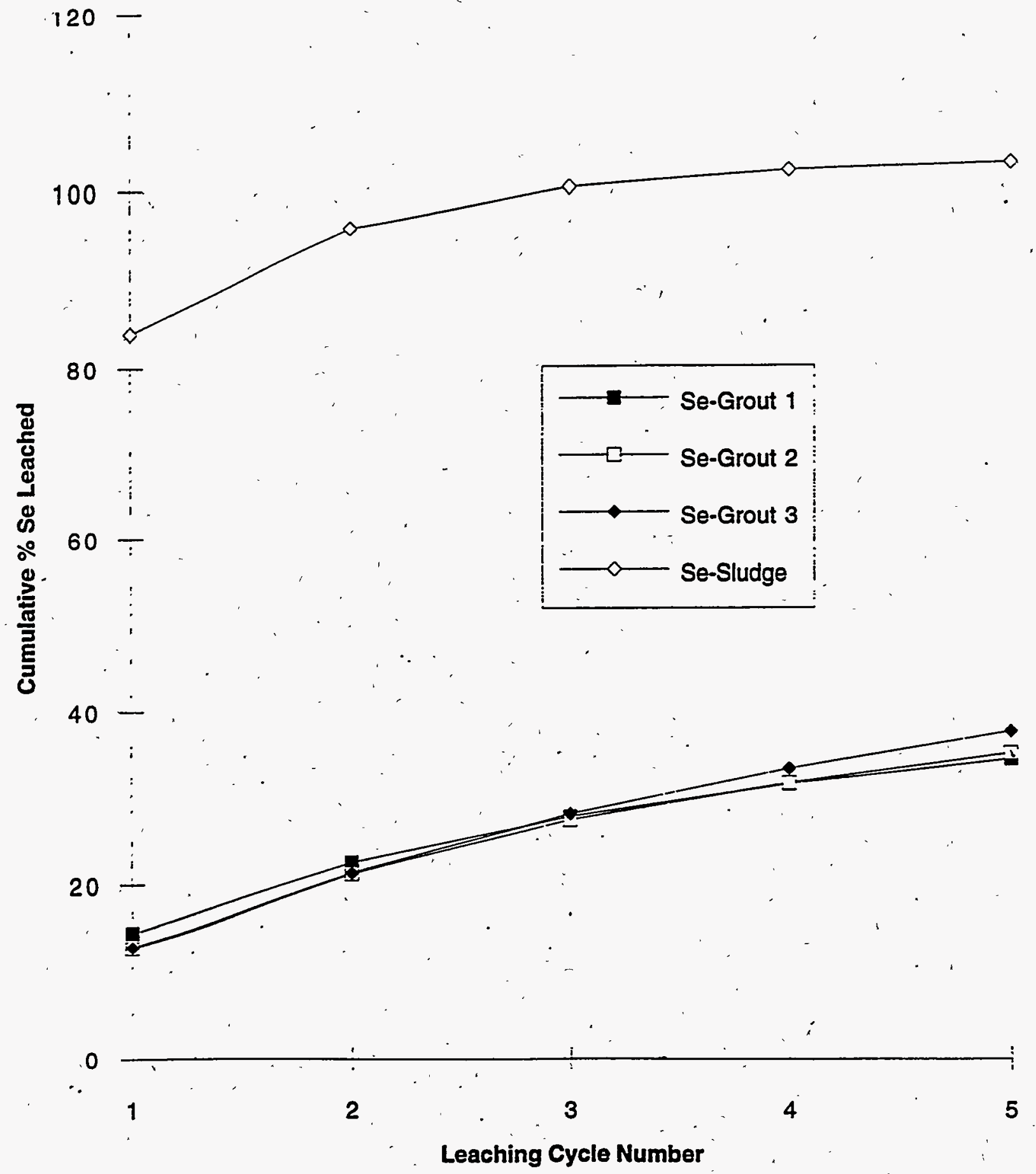

Figure 3GS 


\section{Leaching of Sr with Simulated Acid Rain}

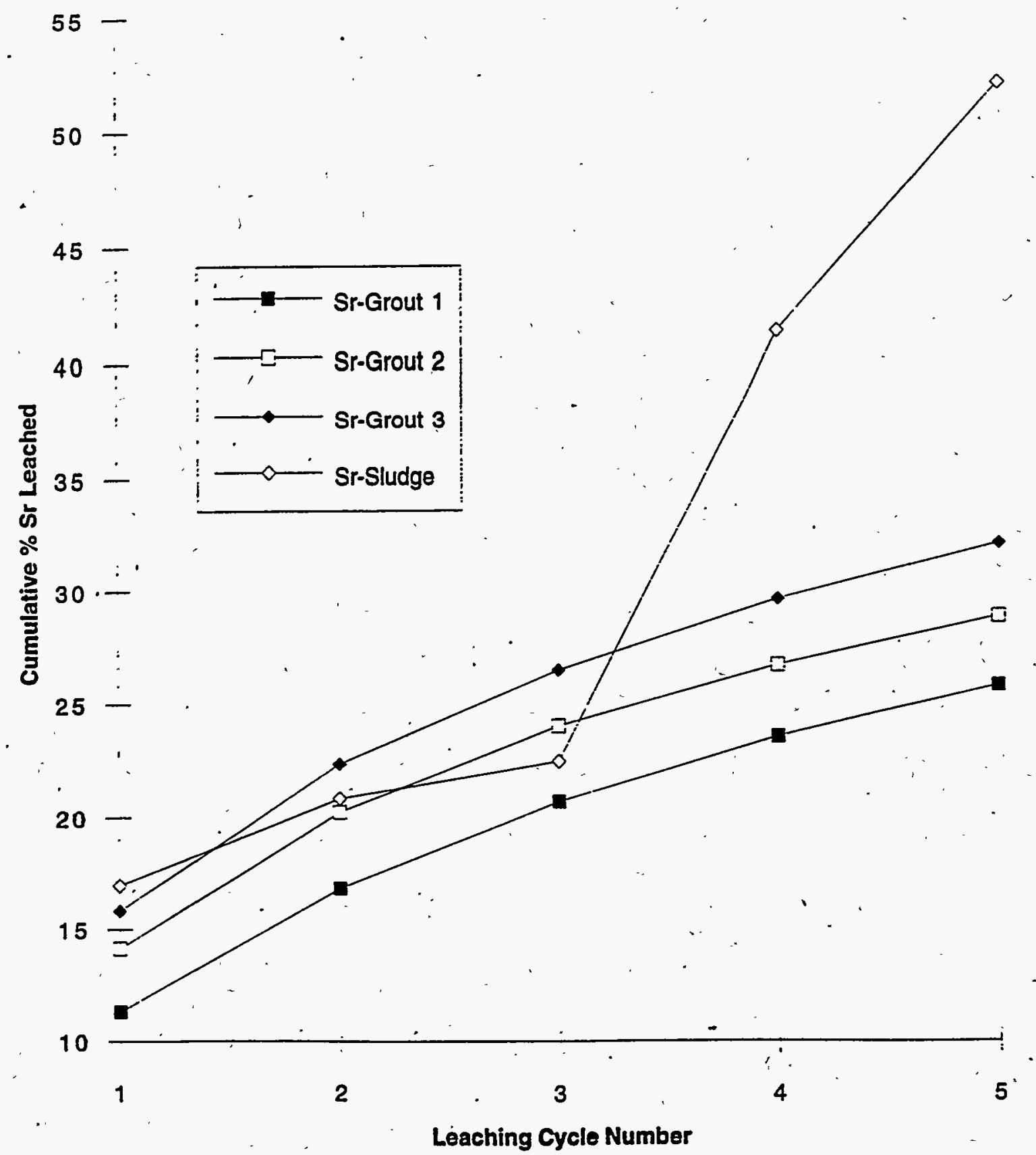


WSRC-TR-97-0102

APPENDIX "A"

CTL Tank 20 Reducing Grout Report
Revision 0

Page 113

Leaching of $U$ with Simulated Acid Rain

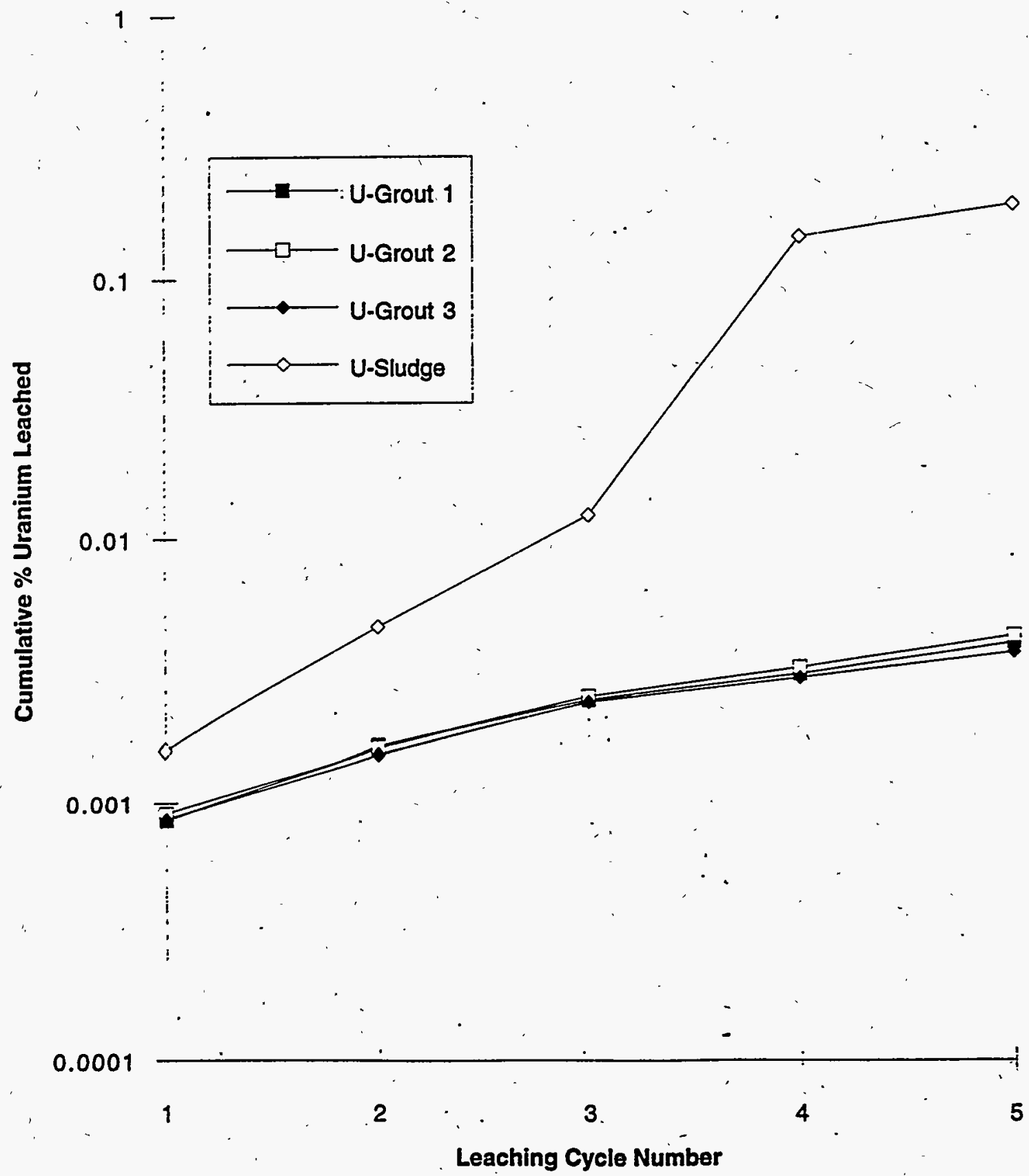

Leaching Cycle Number

Figure 5GS 


\section{Leaching of Ce with Simulated Acid Rain}

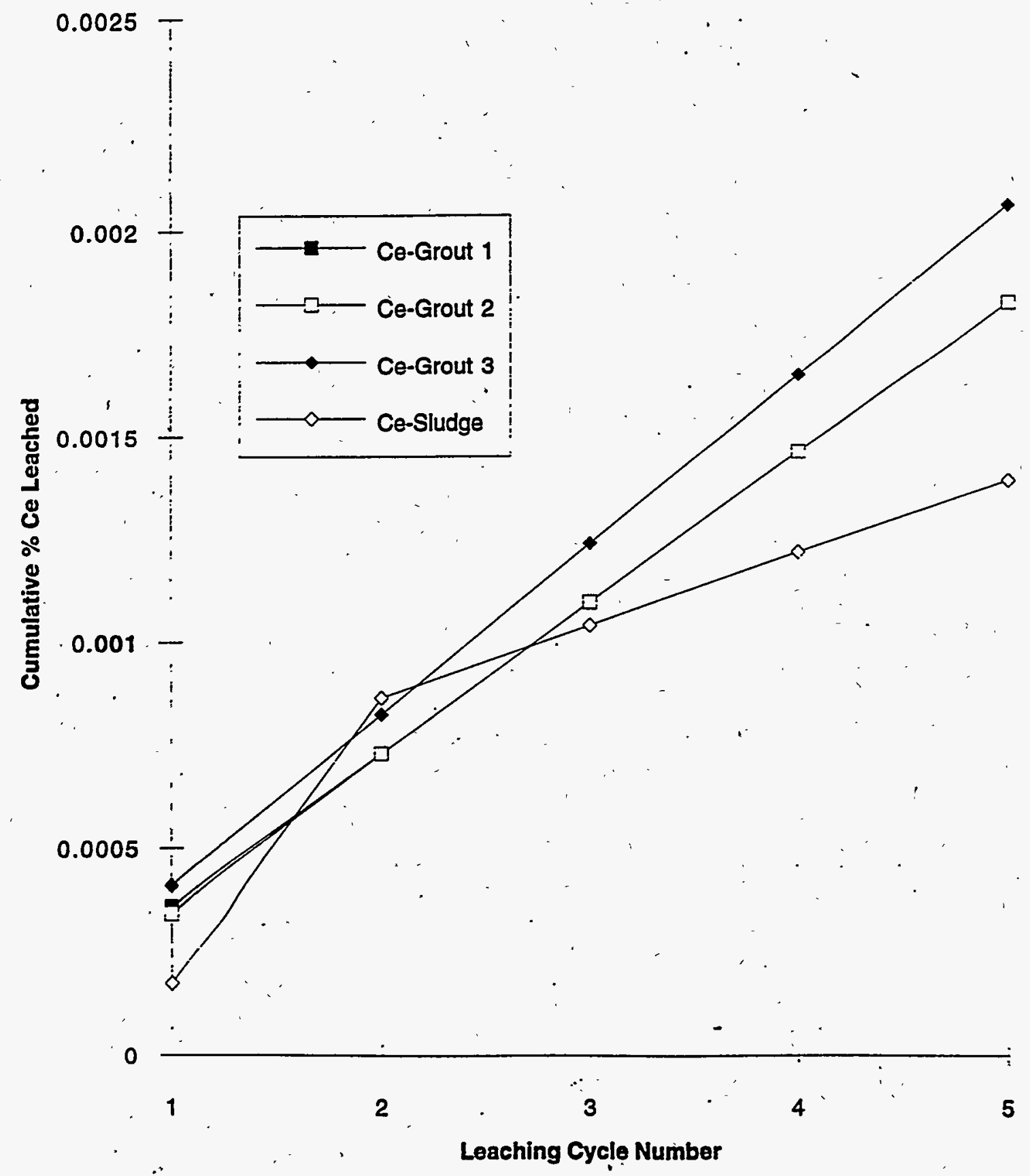

Figure 6GS 
WSRC-TR-97-0102

APPENDIX "A"

CTL Tank 20 Reducing Grout Report
Revision 0

Page 115

Leaching of Mo with Simulated Acid Rain

$45-$

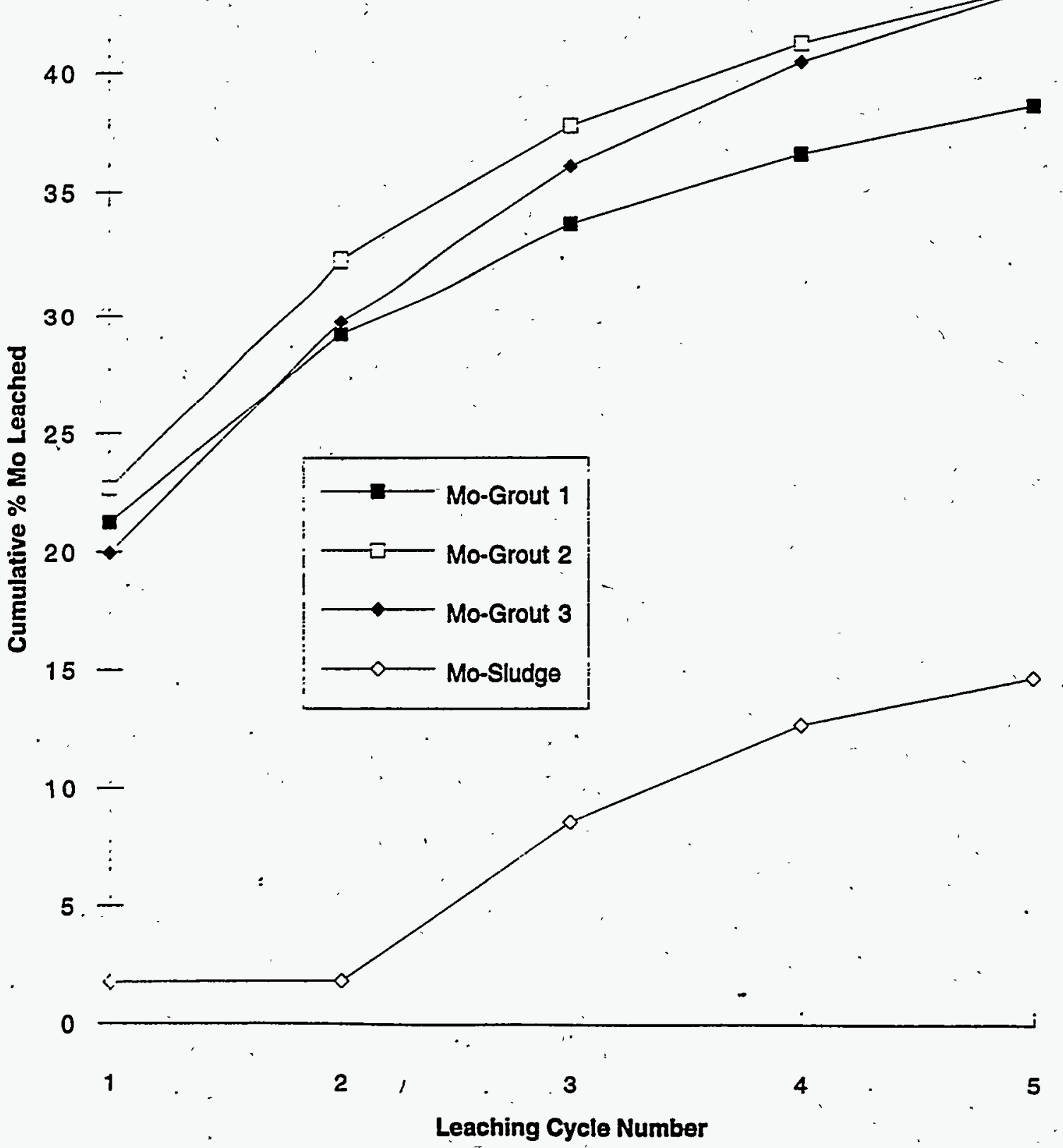

Figure 9Ğs 


\section{Leaching of Mo with Simulated Acid Rain}

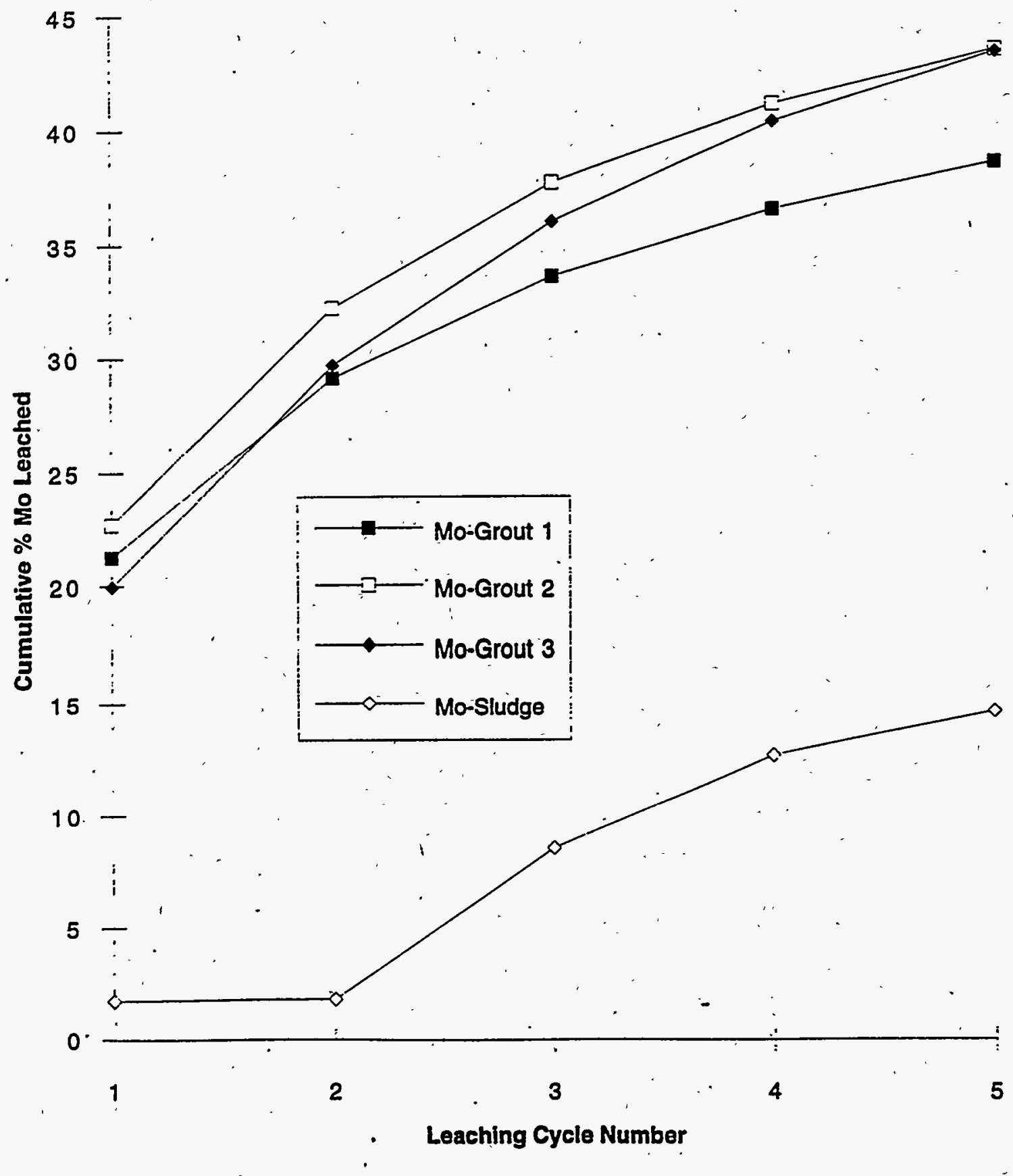




\section{Leaching of Ce.with Acetic Acid Effect of Total Acid and Eh}

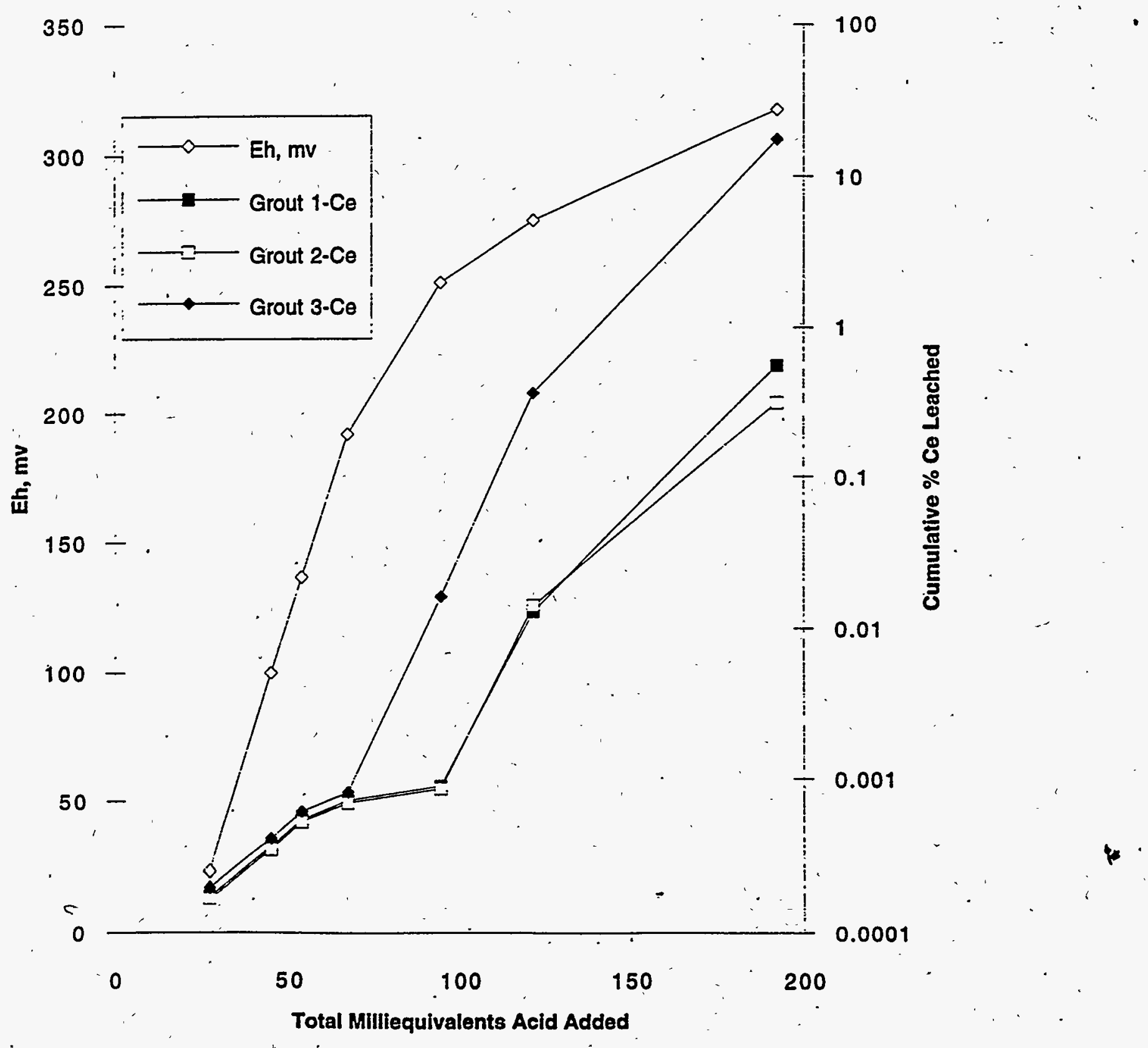




\section{Leaching of Mo with Acetic Acid} r. Effect of Total Acid and Eh

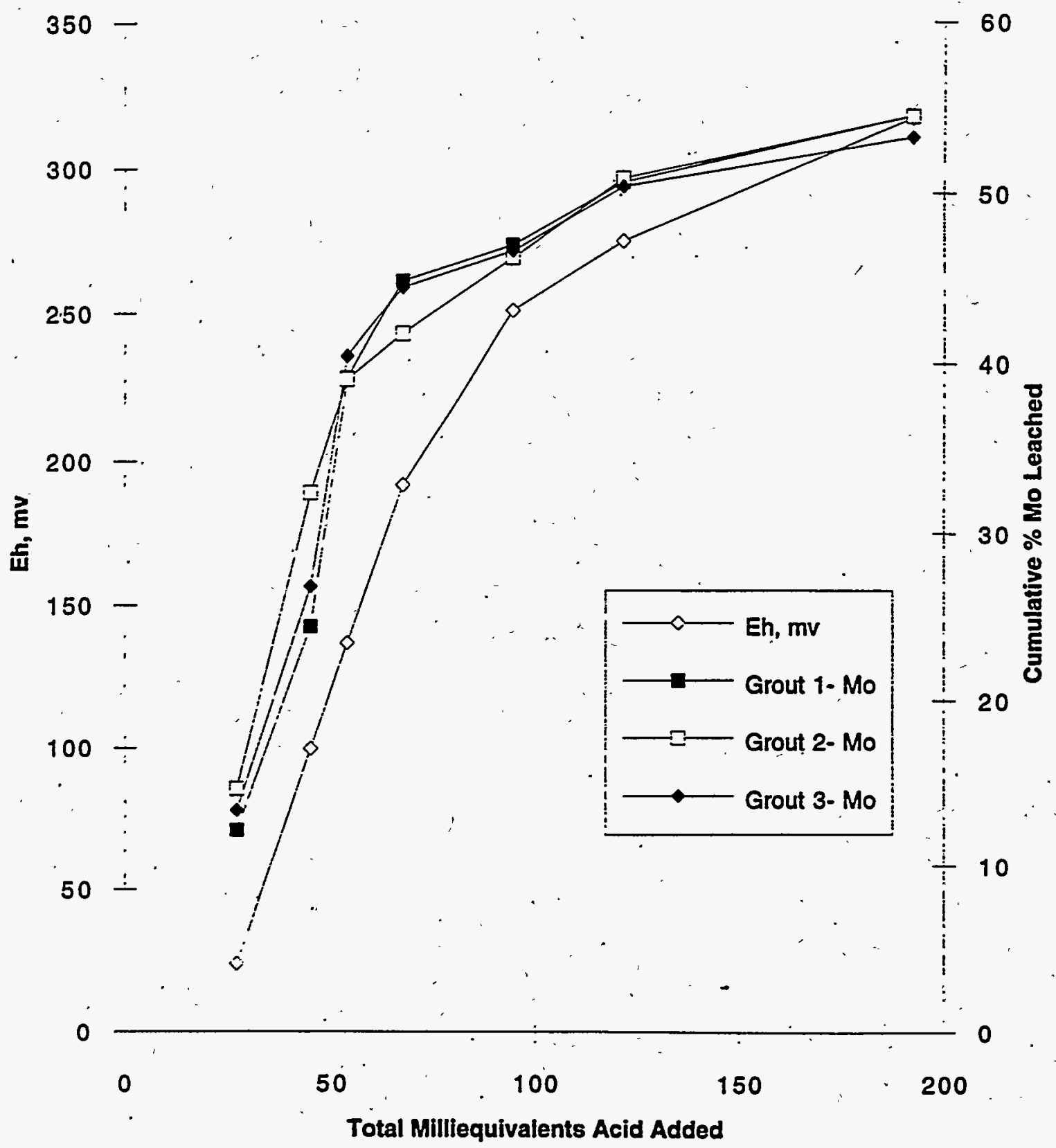




\section{Leaching of Se with Acetic Acid} Effect of Total Acid and Eh

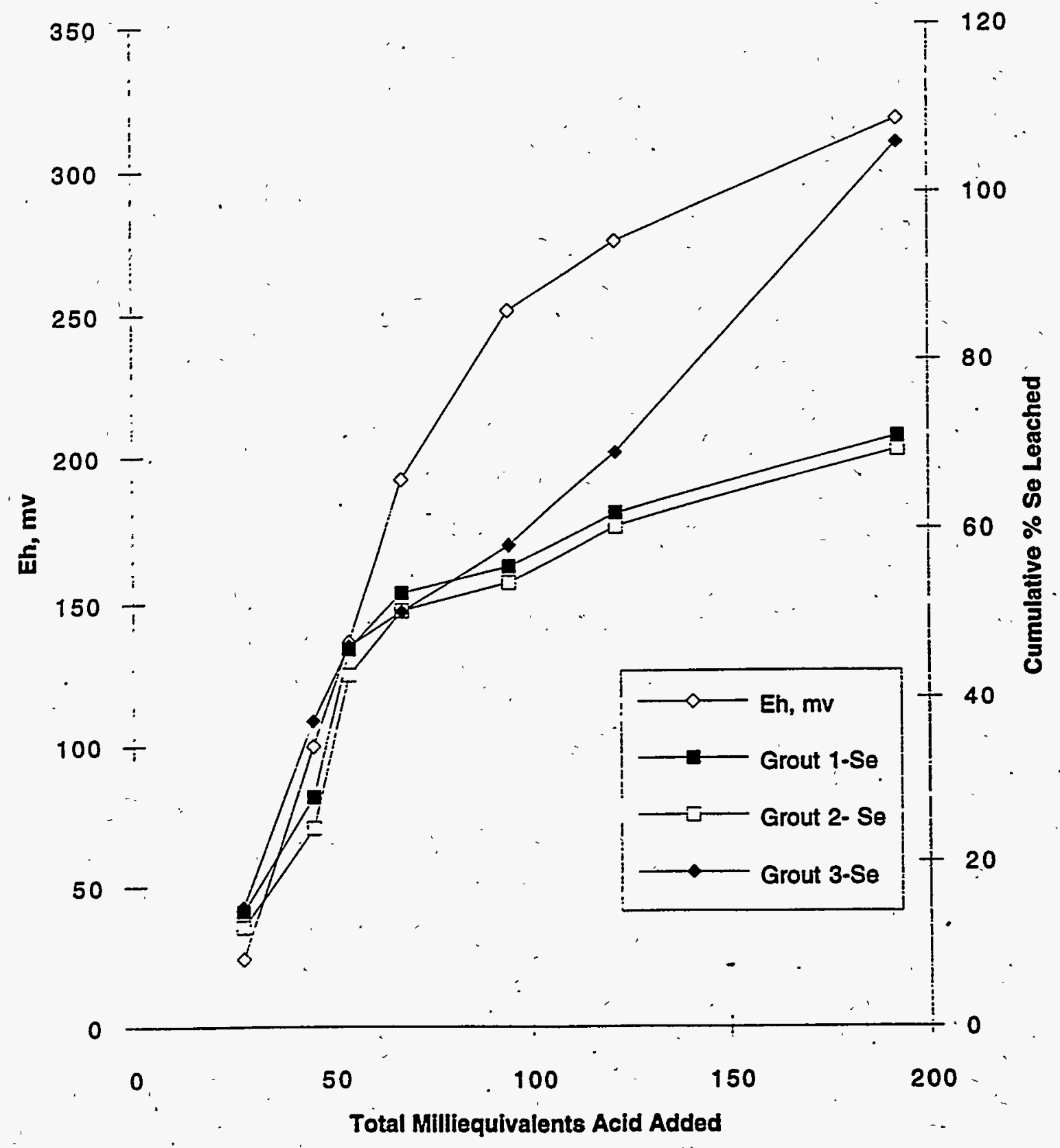




\section{Leaching of $U$ with Acetic Acid \\ Effect of Total Acid and Eh}

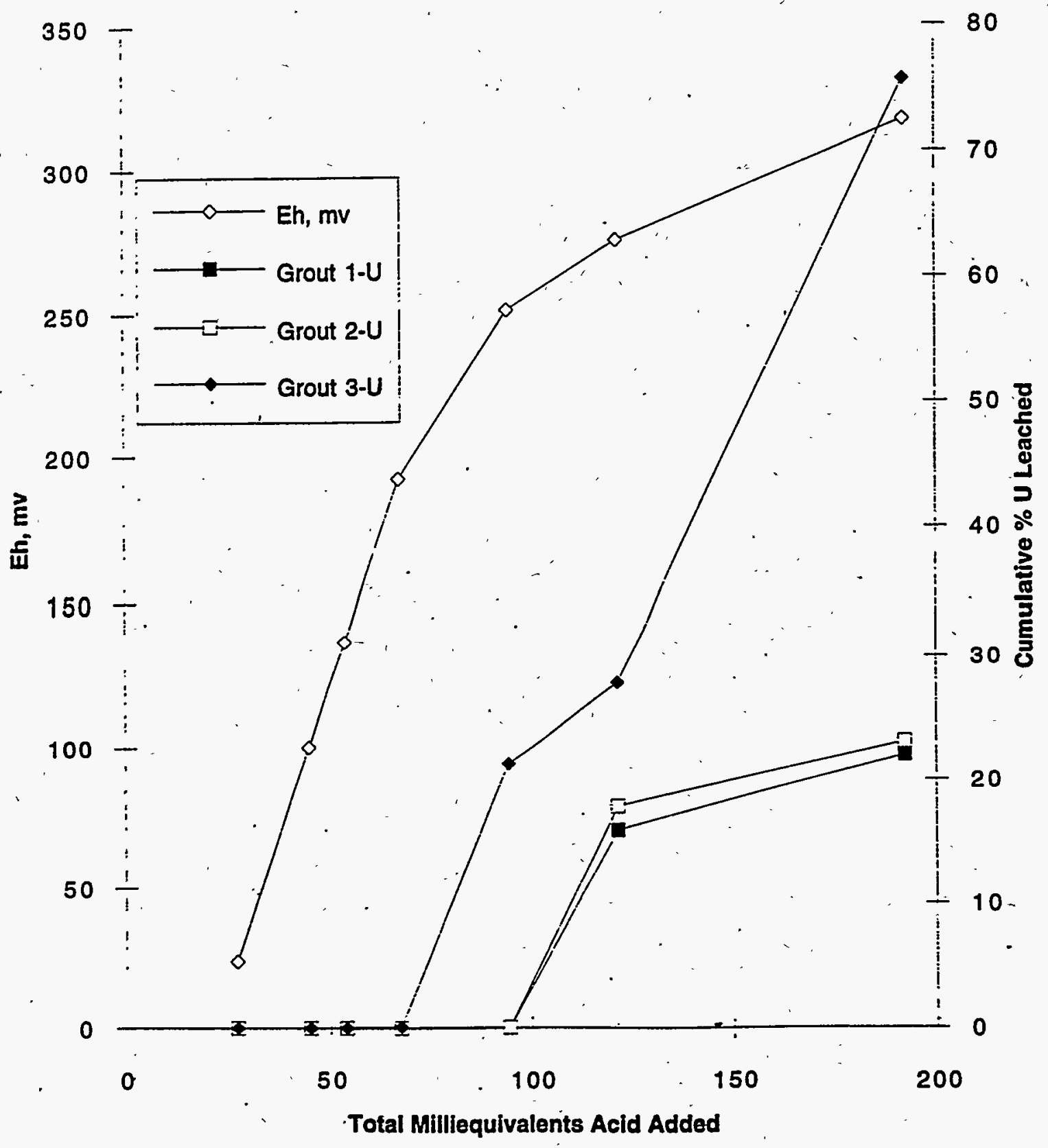

Figure 11GS 


\section{Leaching of Re with Acetic Acid}

Effect of Total Acid and Eh

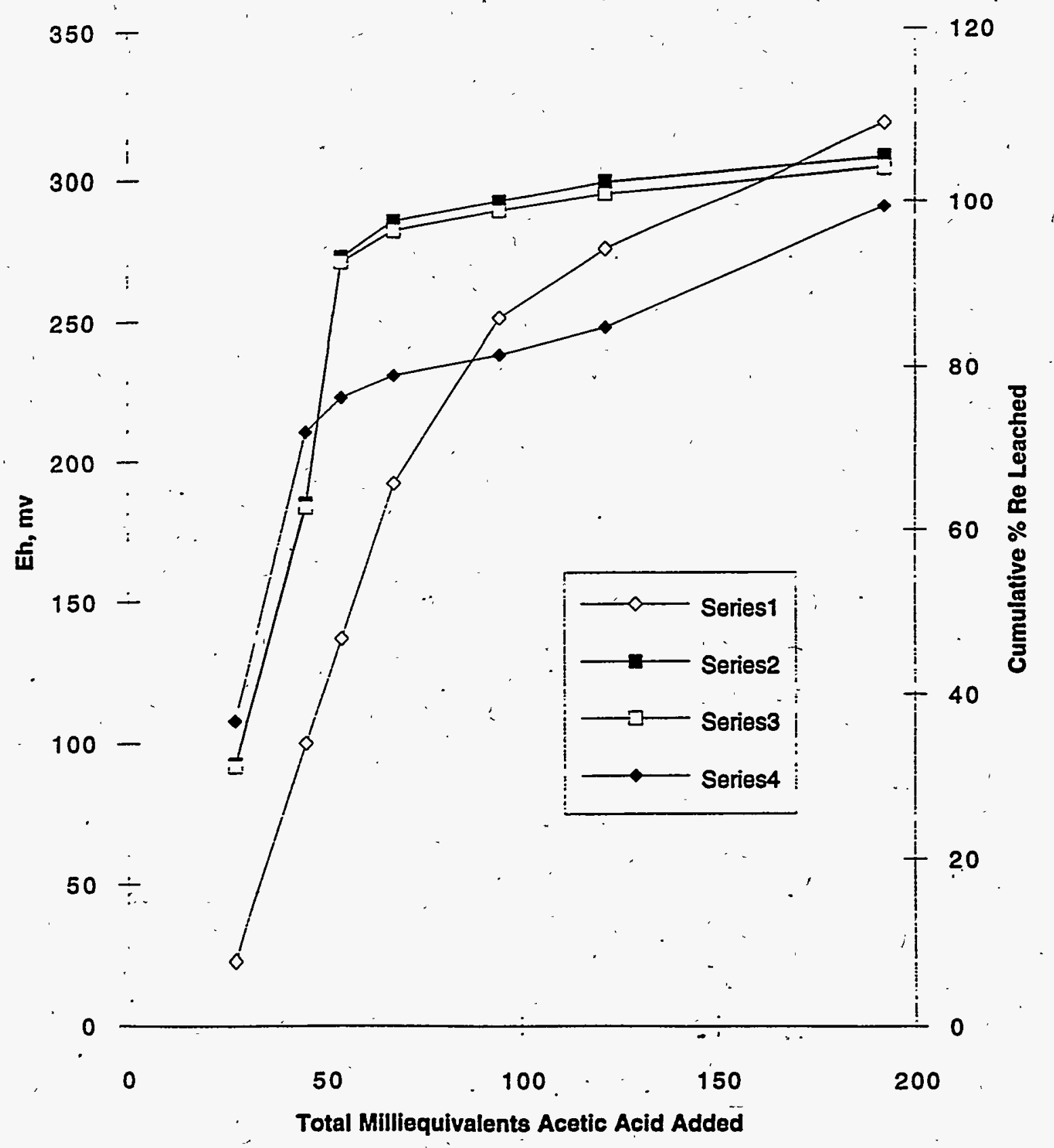




\section{Appendix E \\ Scanning Electron Microscopy/Energy \\ Dispersive X-ray Analysis}




\section{Appendix E-Diffusion of Sludge Components}

\section{Preparation of specimens}

Tr.e mix proportions of the three grouts used in the test program were as shown in the following table. Note that the sodium thiosulfate $\left(\mathrm{Na}_{2} \mathrm{~S}_{2} \mathrm{O}_{3}\right)$ was omitted from these grouts, as it was expected to have no effect on the microstructure or diffusion properties.

Table 1E-Grout Mix Designs

\begin{tabular}{|l|c|c|c|}
\hline & Grout 1 & Grout 2 & Grout 3 \\
\hline Type I Cement, g & 596 & 760 & - \\
\hline Type K Cement, g & - & 165 & - \\
\hline Type V Cement, g & - & - & 1384 \\
\hline Slag, g & 110 & 165 & 110 \\
\hline Silica Fume, g & 80 & 90 & 80 \\
\hline Masonry Sand, g & 1440 & 1440 & 1440 \\
\hline Water, g & 350 & 522 & 639 \\
\hline Retarder, mL & 4 & 4.5 & 4 \\
\hline Superplasticizer, $\mathrm{mL}$ & 20 & 27 & 11 \\
\hline
\end{tabular}

Each grout was mixed according to the following sequence: The cementitious materials . were thoroughly mixed in the dry state in a separate pan. The water and chemical admixtures (retarder and superplasticizer) were poured into the bowl of the Hobart mixer, after which the cementitious materials were added. The materials were mixed at speed 3 (fastest speed) for one minute. The mixer was then stopped to allow time to scrape down the sides and bottom of the bowl with a rubber scraper to dislodge any dry material adhering to the bowl. The mixer was then restarted at speed 3 and the sand added in a steady stream; mixing continued for two minutes. The mixer was stopped to allow time to scrape the sides and bottom of the bowl. The mixer was restarted at speed 3; mixing continued for an additional minute.

Grouts were then cast into $400 \mathrm{ml}$ beakers to a level of approximately $250 \mathrm{ml}$. The beakers were covered with parafilm to prevent moisture loss and then placed into the laboratory oven, which had been preheated to $48^{\circ} \mathrm{C}$. After at least four hours of curing at $48^{\circ} \mathrm{C}$, approximately $50 \mathrm{ml}$ of spiked sludge was carefully poured onto the top of each grout to avoid disturbing the grout surface. In the case of Grout 1 only, the retardation of set was such that the grout had not set; thus some mixing of grout and sludge was unavoidable. The beakers were again covered with parafilm and returned to the oven.

The grouts were left to cure at $48^{\circ} \mathrm{C}$ for 14 days with the sludge in place. At age 14 days, the loose sludge was removed from the specimens and discarded in accordance with accepted environmentally sound procedures. The grout was removed from the beaker. Two specimens of approximately $1 \mathrm{~cm}^{3}$ were sawcut from each grout sample: one at the surface and one in the interior for comparison purposes. All cutting and polishing was done without the use of aqueous coolants or lubricants in order to avoid the dissolution of the materials to be examined.

One surface of each cube, chosen from those that were originally perpendicular to the grout surface, was polished using a series of successively finer polishing grits to form a smooth surface that would not interfere with the collection of accurate X-ray data. The polished surface of each specimen was then sputter-coated with carbon to conduct electrons away 
from the surface, thus preventing charging (which interferes with the data collection). Carbon was selected in preference to gold coating because it causes less interference in the detection of elements of lower atomic mass.

\section{Scanning electron microscopy}

Backscattered electron imaging. Backscattered electron images of the top surface samples of the three grouts were examined at several magnifications. As can be seen from the notations on the photomicrographs, the microscope was operated at an accelerating voltage of $15 \mathrm{kV}$. The microscope used thas a maximum accelerating voltage of $25 \mathrm{kV}$. The choice of accelerating voltage represents a compromise between resolution and contrast: higher voltages give greater contrast, but reduce the resolution because the electron beam penetrates further into the specimen. Observation of X-ray spectra (discussed below) of these specimens made it clear that little if any diffusion or capillary suction of the elements from the sludge into the grout had taken place; thus it was not necessary to examine the specimens taken from the interior portions of the grouts.

Backscattered electron images of polished specimens depict the various phases as gray levels ranging from bright white (highest mean atomic mass) to black (lowest mean atomic , mass). In these samples the brightest material is the slag due to its iron content.' The unhydrated cement particles appear light gray; the hydration products darker gray; and the sand particles, cracks, and air voids black. (If it were necessary to distinguish between sand particles and voids by gray level; the microscope's accelerating voltage, brightness, and contrast could be adjusted accordingly.)

Due to the short time of exposure to the sludge, little or no diffusion into the grout could be expected. However, capillary action was a distinct possibility given the previously observed tendency of the grouts to desiccate the sludge. Thus after a quick overview of the entire specimen, the examination concentrated on the material near the cracks perpendicular to the top surface. While there was some randomly oriented microcracking in the specimens, many of the cracks were more or less perpendicular to the top surface and emanated from it, as shown for. Grout 1 in Fig. 1. In this figure the top surface is near the right edge of the photomicrograph. Note that near the surface the concentration of the sand grains is reduced, an indication of slight bleeding and segregation of the grout. Because preparation of the specimens involves drying, some of the cracks could have been induced during the preparation process. However, such cracks would tend to begin at any surface, not the top surface in particular. Thus it is likely that at least some of the cracks emanating from the top surface initiated during the curing stage. Evidence for this is shown in Fig. 2, which contains a crack with deposits inside. Figure 3 also provides evidence of early cracking, since the crack has gone around, not through, the slag and cement particles. Since cracks choose the path of least energy, they will avoid material that is stronger in preference to weak material. As hydration proceeds the hydration products gain strength and are no longer significantly weaker than the unhydrated slag and cement particles.

Figures 4-6 show the microstructure of Grout 2 near the top surface (on the right in these photomicrographs) at increasing magnifications. These are similar to those of Grout 1 in showing evidence of slight bleeding, though less than in Grout 1. This is consistent with the observed retardation in the setting of Grout 1 as compared to the other grouts. Here, too, most of the cracks emanated from the top surface and were oriented more or less perpendicular to it. Figures 5 and 6 show the crack path around the slag particles. Figure 7 shows a view of Grout 3 . In this case the crack may have formed during the specimen preparation process, as it passes through a slag particle, indicating that the surrounding material had gained some strength before the crack propagated through it. 


\section{$X$-ray analysis.}

$\mathrm{X}$-ray microanalyses were performed on the polished specimens as a first step in mapping select elements to determine the depth of penetration of the sludge into the grouts. Elyments for mapping were selected from analyses of grout constituents and sludge. The $\%$.ray microanalysis field was on the order of $1 \mathrm{~mm}^{2}$. Analyses were performed on each specimen at or near the surface of the grout which was in contact with the sludge. Analyses were typically performed at microcracks perpendicular to the top surface to determine the degree of penetration of the elements from the sludge due to capillary suction.

In all cases, the major elements found in the analyses were those of the original grout materials. High concentrations of calcium, silicon, and aluminum were noted, as expected. These elements are attributed to the constituents of the grout. Additional elements were also identified, as indicated in Fig. 8. Figure 8 is an X-ray spectrum of a $1 \mathrm{~mm}^{2}$ area near the top surface of grout 3.

Figure 8 also indicates that some elements have multiple peaks and that many elements have peaks of similar energy. An example of multiple peaks is calcium which has peaks at 0.35 and $3.6 \mathrm{kV}$. Silicon and tantalum are examples of overlapping peaks. These peaks overlap in Fig. 8 at $1.75 \mathrm{kV}$. Each element has a unique fingerprint of multiple energy peaks referred to as the $K, L$, and $M$ lines (corresponding to their atomic structure). Incident electrons of different energy levels are required to produce the $K, L$, and $M$ lines. As an example, incident electrons with a minimum energy of $125 \mathrm{kV}, 18 \mathrm{kV}$, and $3 \mathrm{kV}$ are required to produce $K, L$, and $M$ lines (respectively) of mercury. Since the SEM used in this study was operated at $15 \mathrm{kV}$, only the M-lines of mercury could be produced. Other elements may also have similar energy peaks. For example, bromine, tungsten, and rhenium all have L-line energies similar to the L-line energy for mercury. Many elements have one or more peaks with minimum energy levels exceeding $15 \mathrm{kV}$, therefore could not be observed with this microscope.

\section{Elemental Mapping}

Elemental mapping was performed to détermine the location and relative concentration of elements from the sludge within the grout matrix. Mapping assisted in evaluating whether the elements of minor concentration are trace elements in the grout constituents or were leached and/or diffused from the sludge. Mapping also assisted in evaluating the method of movement of elements within the grout (via diffusion or capillary suction) and whether the elements were preferentially attracted to a particular component of the grout. Table 2E presents the mapped elements, their associated energy lines, and possible overlapping elements or interest. Note that a number of elements presented in Table $2 E$ overlap. For this reason it is important to interpret the element maps along with the corresponding backscattered images and to possess a knowledge of the grout composition. 
Table 2E-Energy Lines and Overlaps of Mapped Elements

\begin{tabular}{|c|c|c|}
\hline Element & Energy Line & $\begin{array}{l}\text { Overlapping } \\
\text { Elements }\end{array}$ \\
\hline Aluminum & $\mathrm{K}$ & \\
\hline Calcium & $\mathrm{K}$ & \\
\hline Calcium & $L$ & $C$ \\
\hline Cerium & $L$ & $\mathrm{Ba}$ \\
\hline Cesium & $L$ & \\
\hline Chromium & $\bar{K}$ & $\mathrm{Mn}$ \\
\hline Cobalt & $\mathrm{K}$ & $\mathrm{Fe}, \mathrm{Ni}$ \\
\hline Copper & $\mathrm{K}$ & \\
\hline Copper & $L$ & $C$ \\
\hline lodine & $L$ & $\mathrm{Ba}$ \\
\hline Iron & $\mathrm{K}$ & \\
\hline Manganese & $\mathrm{K}$ & $\mathrm{Cr}$ \\
\hline Mercury & $M$ & S, Mo \\
\hline Molybdenum & $L$ & $\mathrm{~S}, \mathrm{Hg}$ \\
\hline Nickel & $L$ & $\mathrm{Co}, \mathrm{Ce}$ \\
\hline Rhenium & $M$ & $\mathrm{Si}, \mathrm{Sr}$ \\
\hline Selenium & $L$ & \\
\hline Silicon & K & Sr, Re \\
\hline Silver & $L$ & $\mathrm{~S}, \mathrm{Hg}$ \\
\hline Sodium & $\mathrm{K}$ & Zn \\
\hline Strontium & $L$ & Si, Re \\
\hline Sulfur & K & $\mathrm{Mo}, \mathrm{Hg}$ \\
\hline Uranium & $M$ & $\mathrm{~K}, \mathrm{Ag}$ \\
\hline Zine & $L$ & $\mathrm{Na}$ \\
\hline
\end{tabular}

Elemental mapping of the grouts was primarily concentrated at cracks perpendicular to and emanating from the top surface of the grout, where capillary suction could draw sludge water and solids into the grout. A photomicrograph of the mapped area of Grout 2 is presented in Fig. 9. The left side of the photo is approximately $1 \mathrm{~mm}$ below the surface of the grout. A large crack runs from the top surface to the center of the grout (left to right in the figure). Several large pores are clearly visible, as well as sand particles. Figure 10 presents the element map image. Colors of the individual elements were arbitrarily selected. For each element, darker shades of color indicate lower concentrations, while brighter shades indicate higher concentrations.

Upon initial examination, the sand particles in Fig. 10 are made up of aluminum, rhenium, siliçon, and strontium. As discussed above, overlap of the characteristic element energies, reveals that rhenium, silicon, and strontium all have overlapping characteristic energies. Therefore, the sand particles are most likely aluminum and silicon. Within the detection limits of the method ${ }^{*}$, diffusion of sludge elements such as cesium, cerium, selenium, etc. has apparently not occurred as indicated by the lack of a concentration gradient from the top surface of the grout (left to right in the figure). Capillary suction apparently did not

\footnotetext{
- Minimum detection limits are increased by the presence of overlapping elements. Diffusion concentration gradients or concentrations along cracks, if in exisitence, would be detected if there had been significant infiltration of the sludge constituents.
} 
conduct sludge solids into the grout. Trace amounts of copper, manganese and iron appear to be present in the grout constituents.

Similar findings are observed in Grout 3, presented in Figs. 11 and 12. The top surface of ine grout (in contact with the sludge) is approximately $1 \mathrm{~mm}$ below the bottom of the ligures.

The crystals noted in Grout 1 (Fig. 2) were also mapped and are presented in Fig. 12. The crystal growths are most likely sodium, potassium, and silicon due to the bulk of the specimen being grout. 


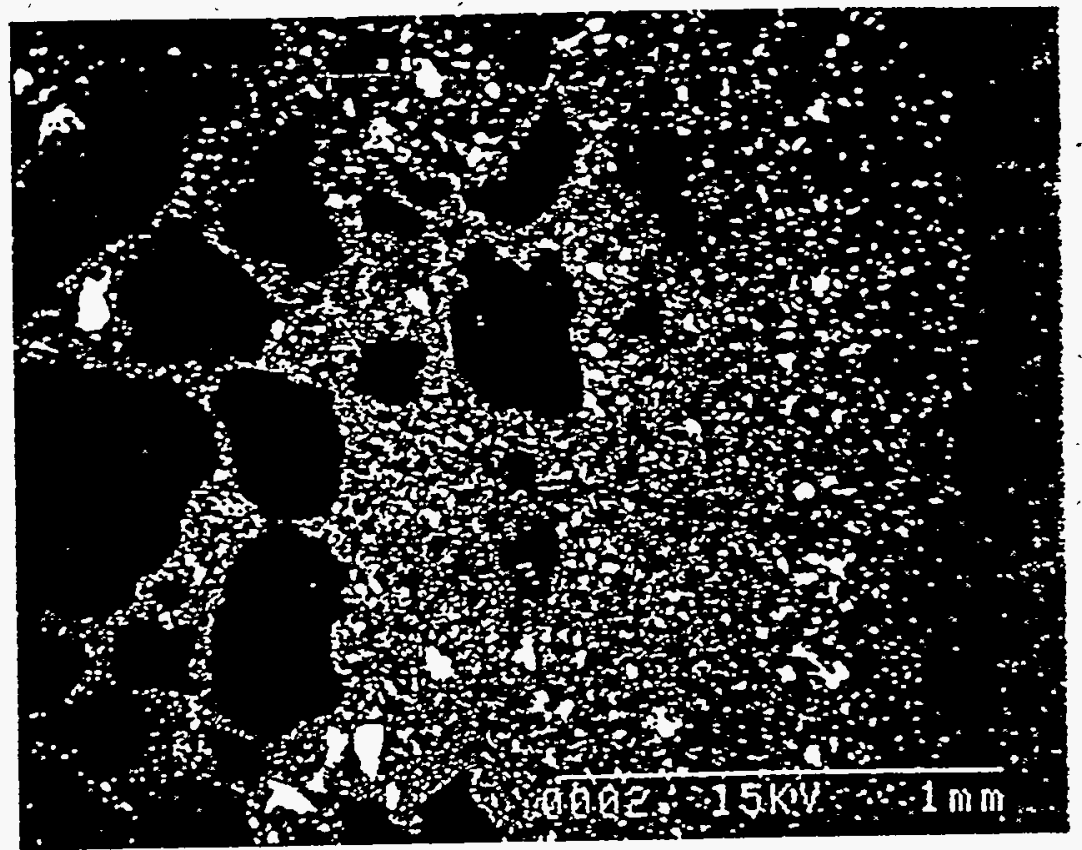

Figure 1 - Grout 1 top.

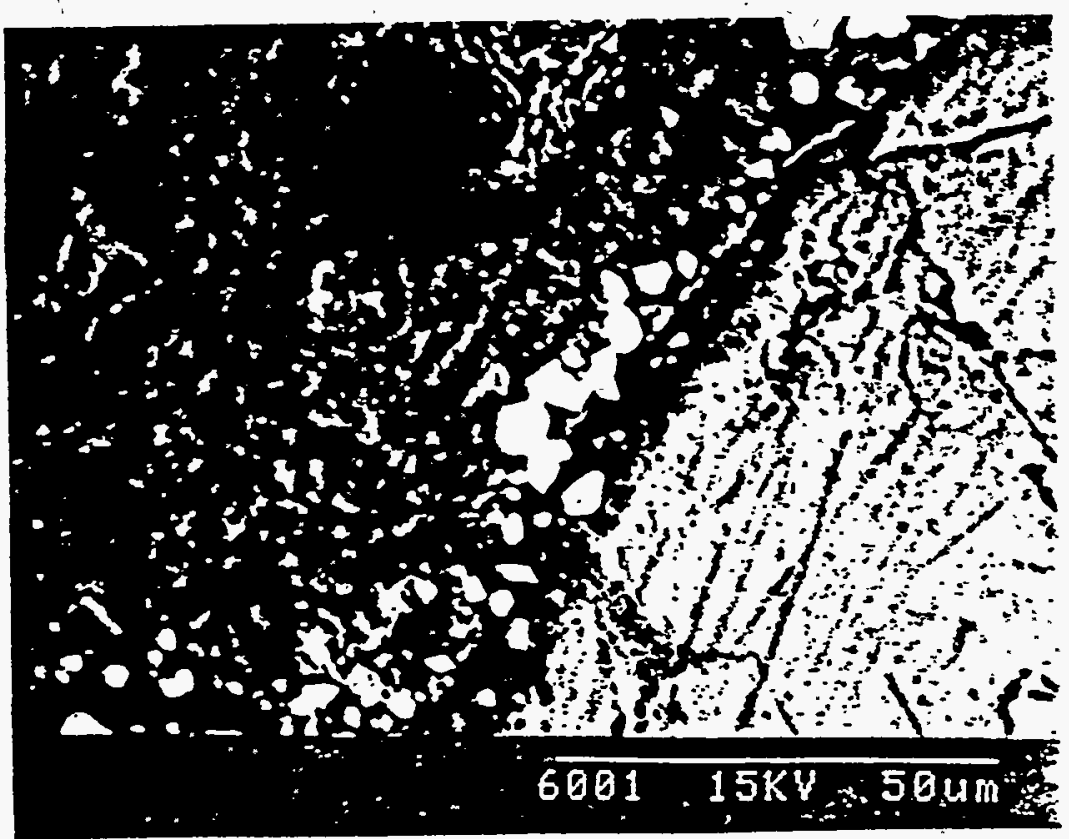

- Figure 2 - Crystal growths in Grout 1 near top. 


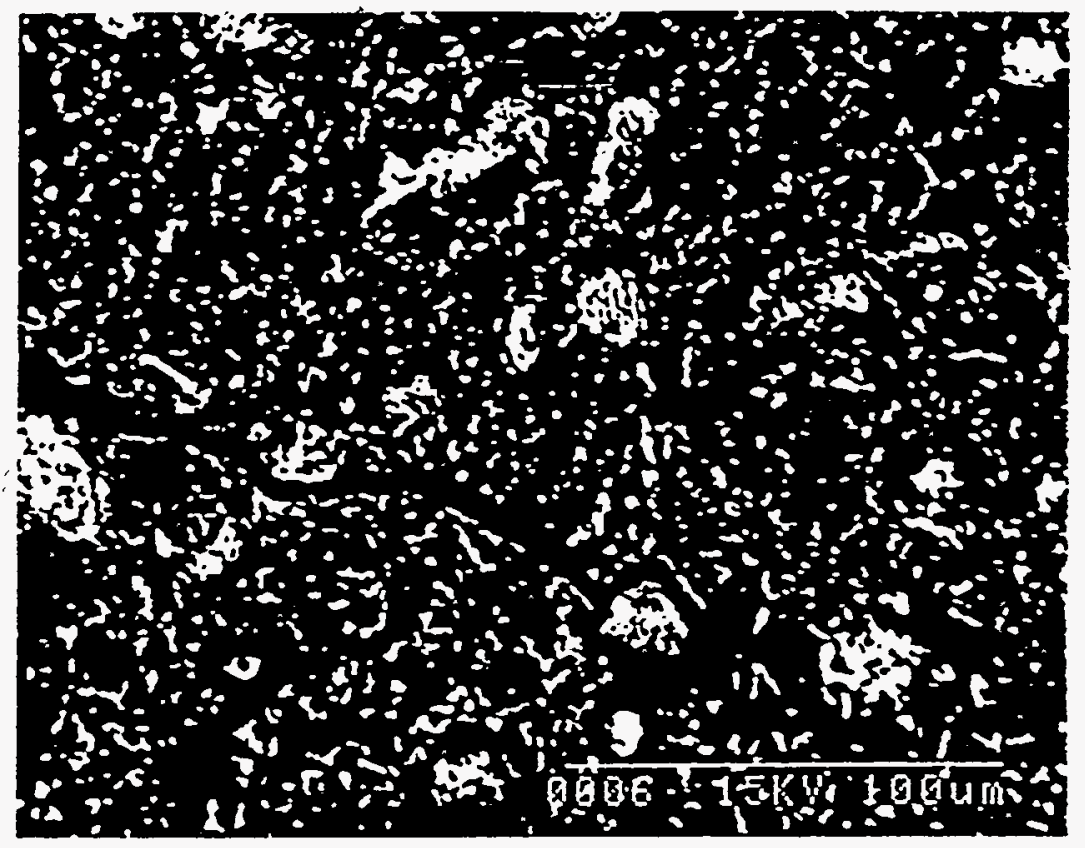

Figure 3 - Grout 1 top.

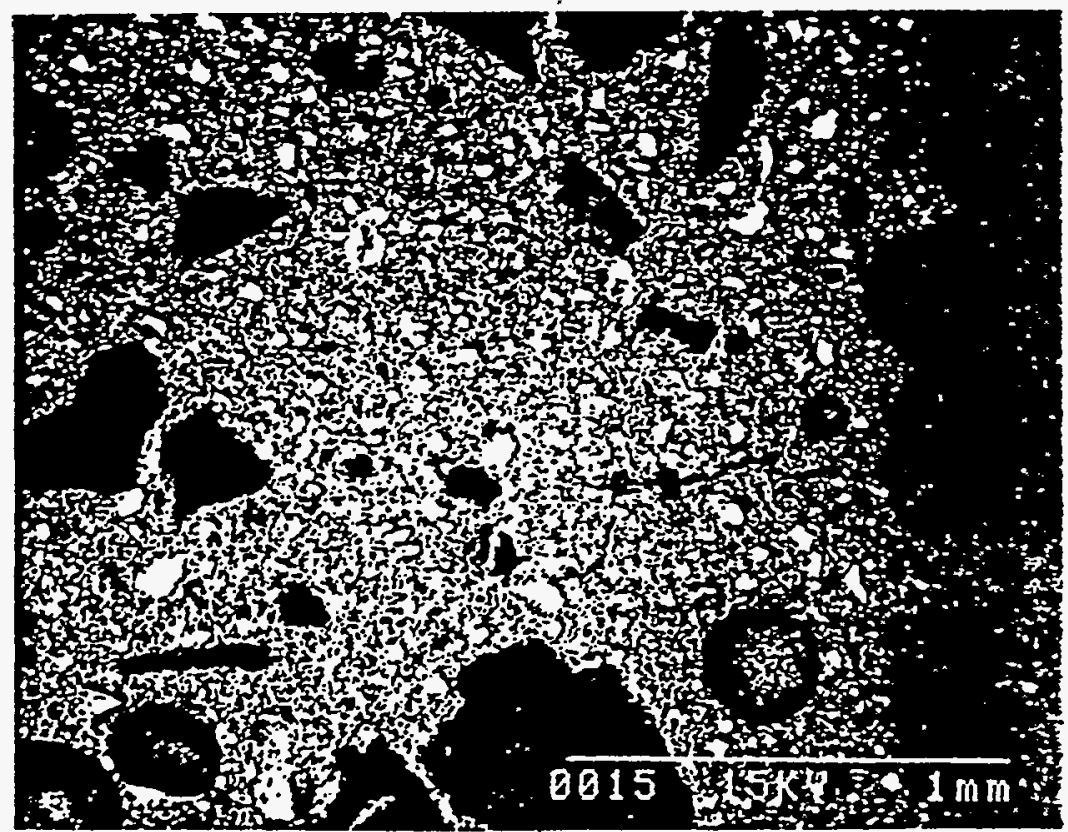

Figure 4 - Grout 2 top. 
WSRC-TR-97-0102

APPENDIX "A"

Revision 0

CTL Tank 20 Reducing Grout Repórt

Page 130

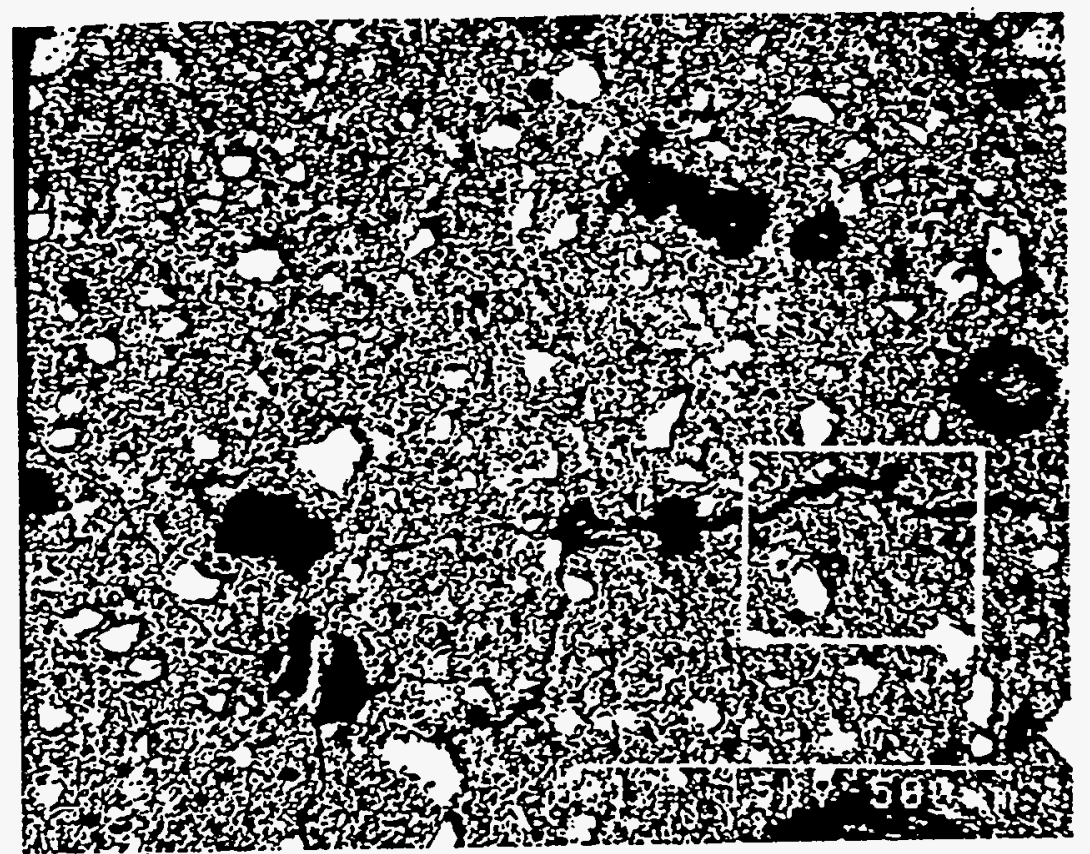

Figure 5 - Grout 2 top.

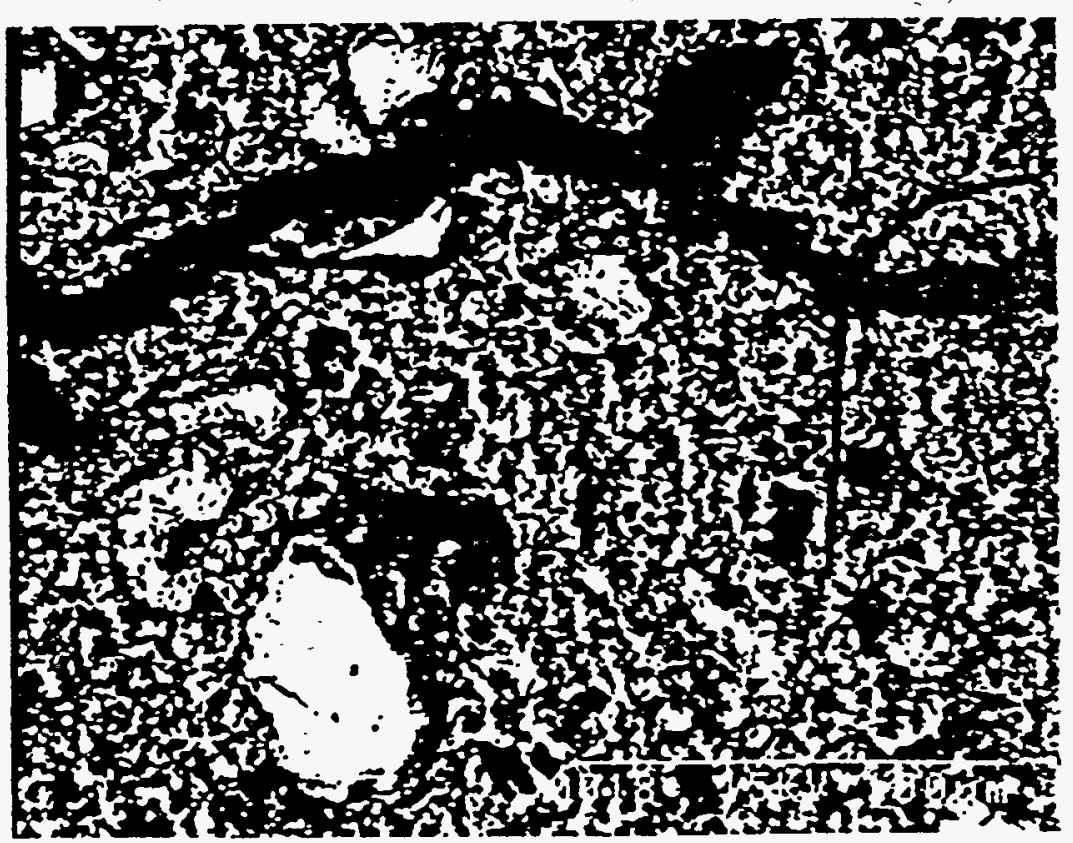

Figure 6 - Grout 2 top. 


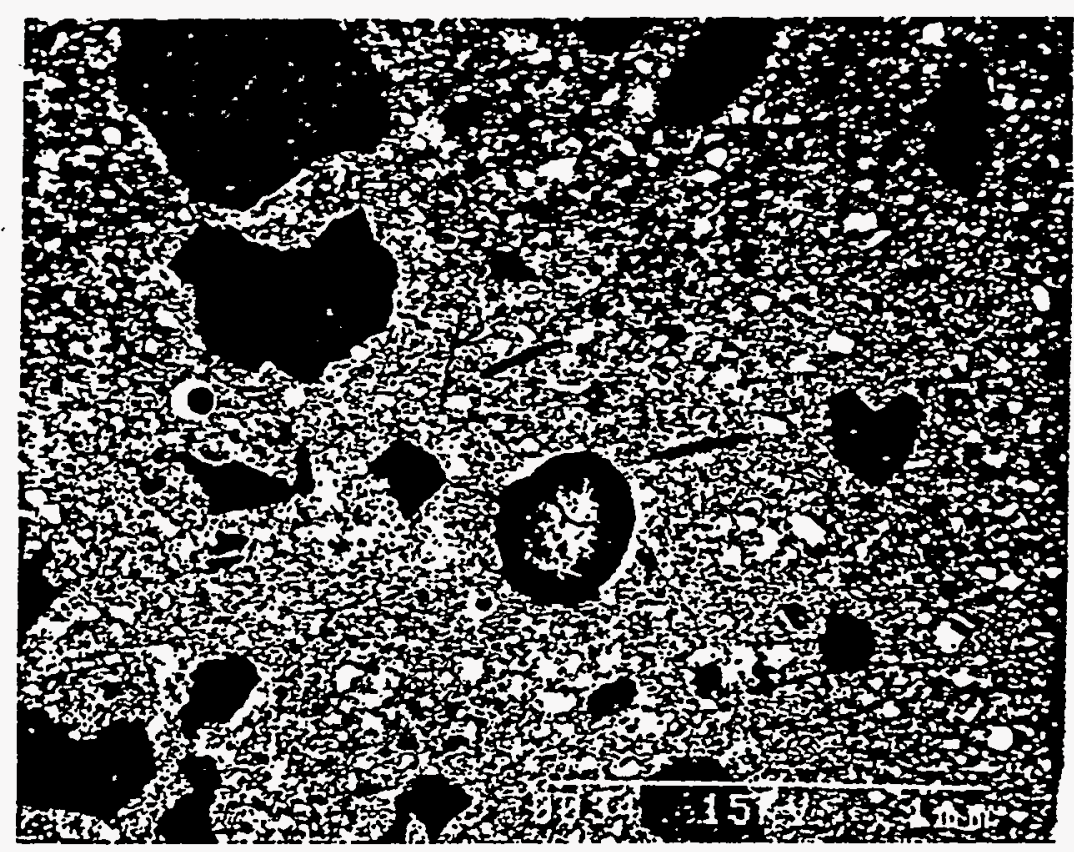

Figure 7 - Grout 3 top. 


\section{Mapped Elements:}

$\mathrm{Na}, \mathrm{Al}, \mathrm{Si}, \mathrm{S}, \mathrm{Ca}, \mathrm{Cr}, \mathrm{Mn}, \mathrm{Fe}, \mathrm{Co}, \mathrm{Ni}$,

$\mathrm{Cu}, \mathrm{Zn}, \mathrm{Se}, \mathrm{Sr}, \mathrm{Zr}, \mathrm{Mo}, \mathrm{Ag}, \mathrm{I}, \mathrm{Cs}, \mathrm{Ba}$,

$\mathrm{Ta}, \mathrm{Re}, \mathrm{Hg}, \mathrm{Ce}, \mathrm{U}$

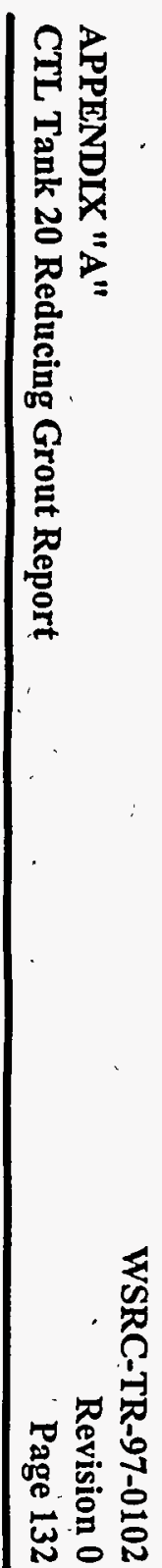

Figure 8 - X-ray Analysis of Grout 3. 


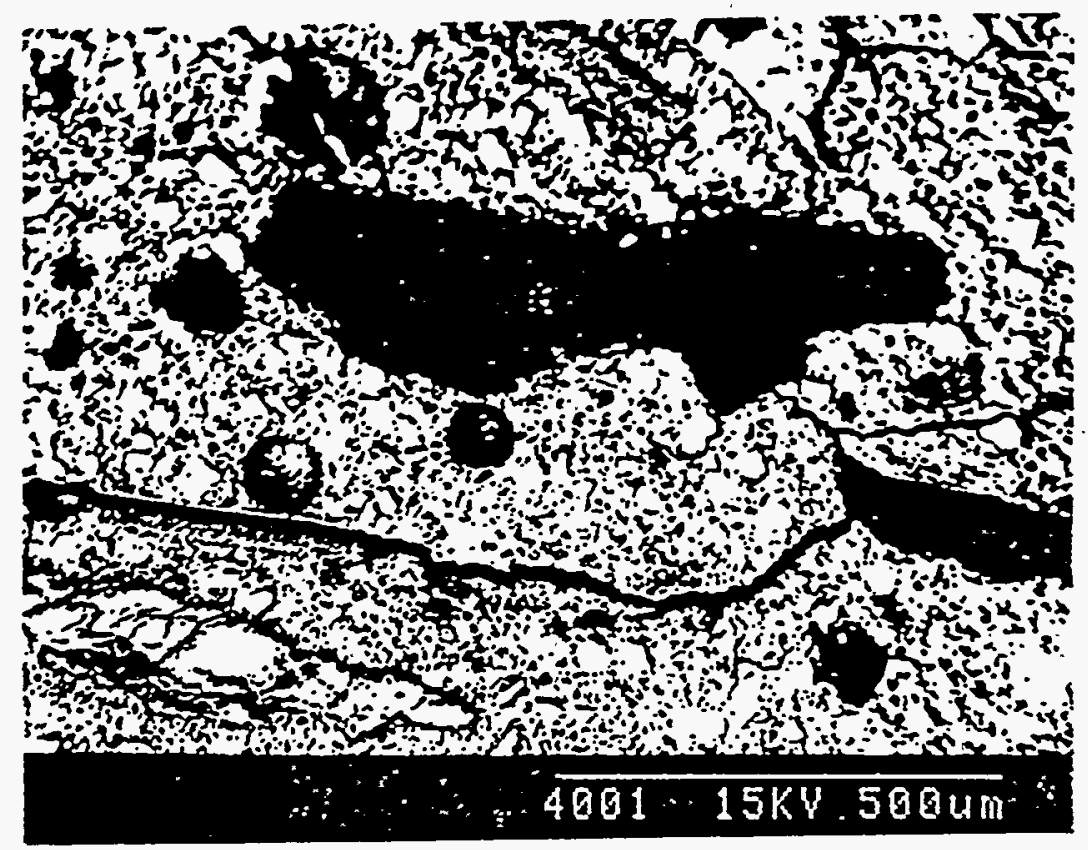

Figure 9 - Grout 2 top. 
APPENDIX "A"

WSRC-TR-97-0102

CTL Tank 20 Reducing Grout Report

Revision 0

Page 134

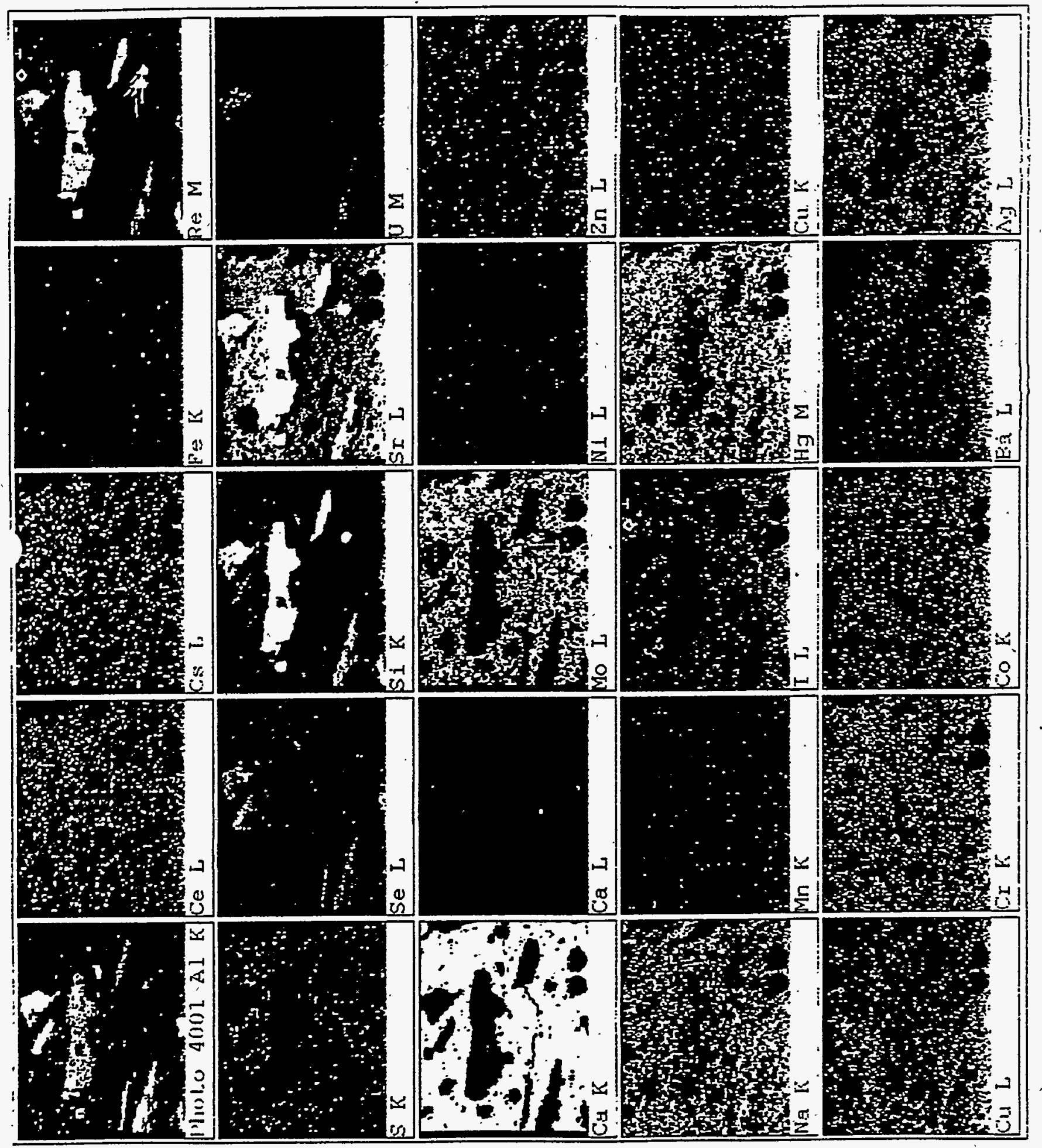




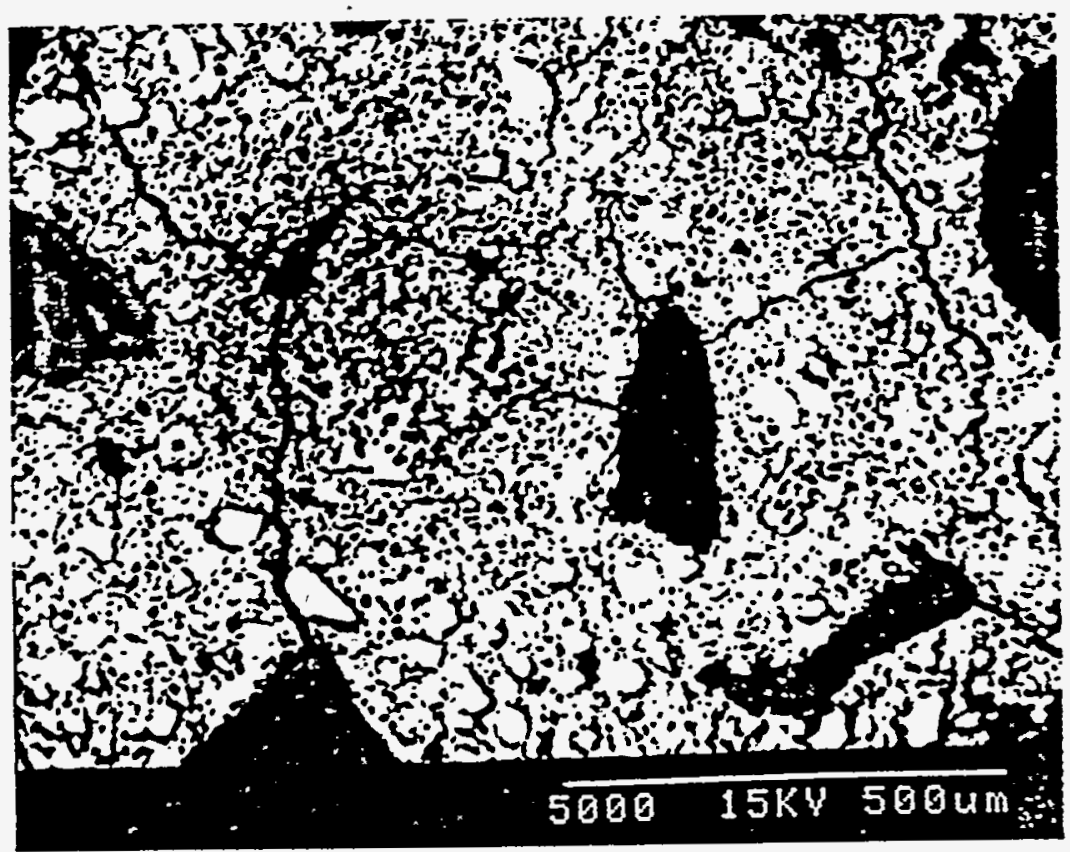

Figure 11 - Grout 3 top. 
WSRC-TR-97-0102

APPENDIX "A"

Revision 0

CTL Tank 20 Reducing Grout Report

Page 136

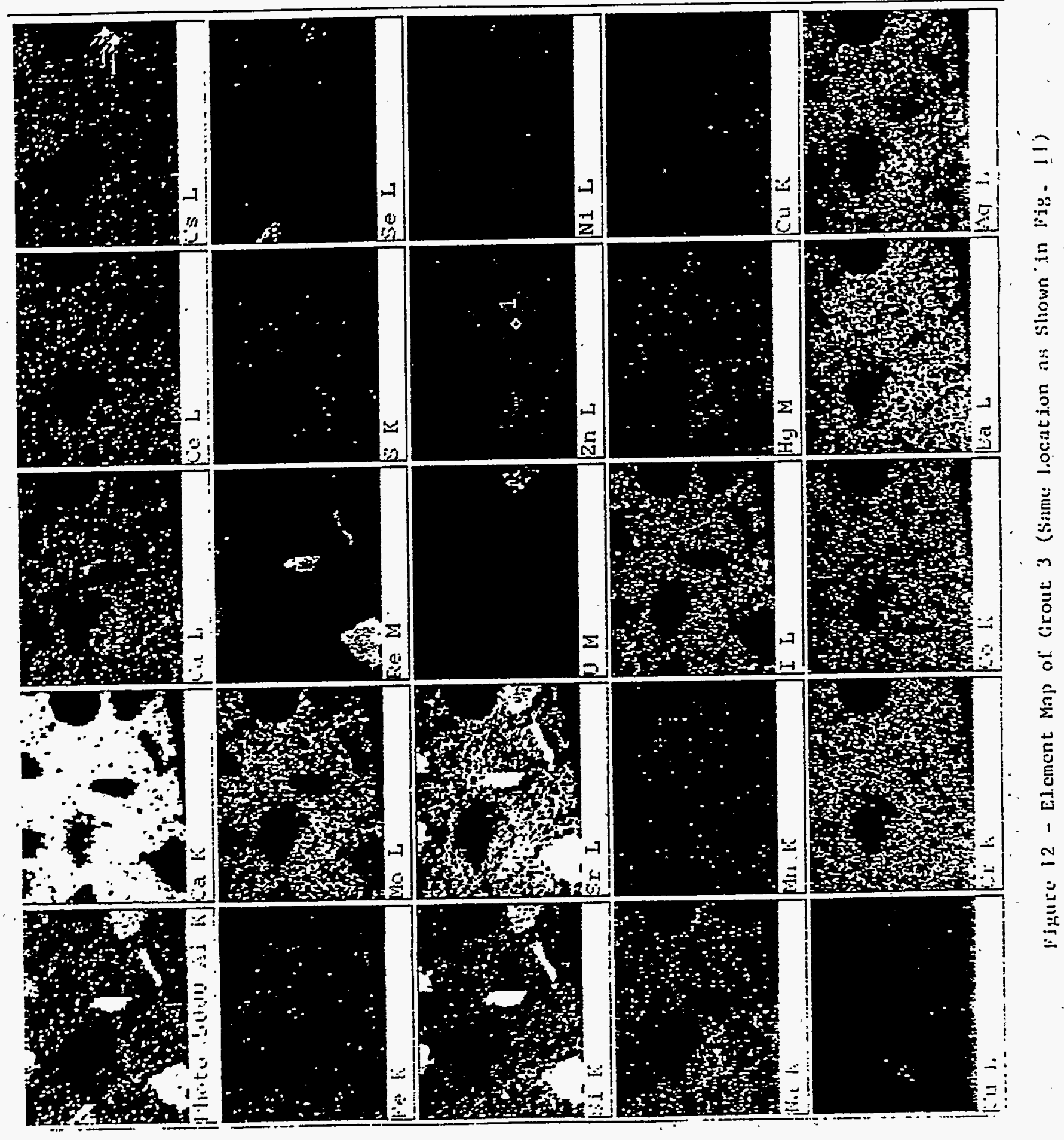


WSRC-TR-97-0102

APPENDIX "A"

Revision 0

CTL Tank 20 Reducing Grout Report

Page 137

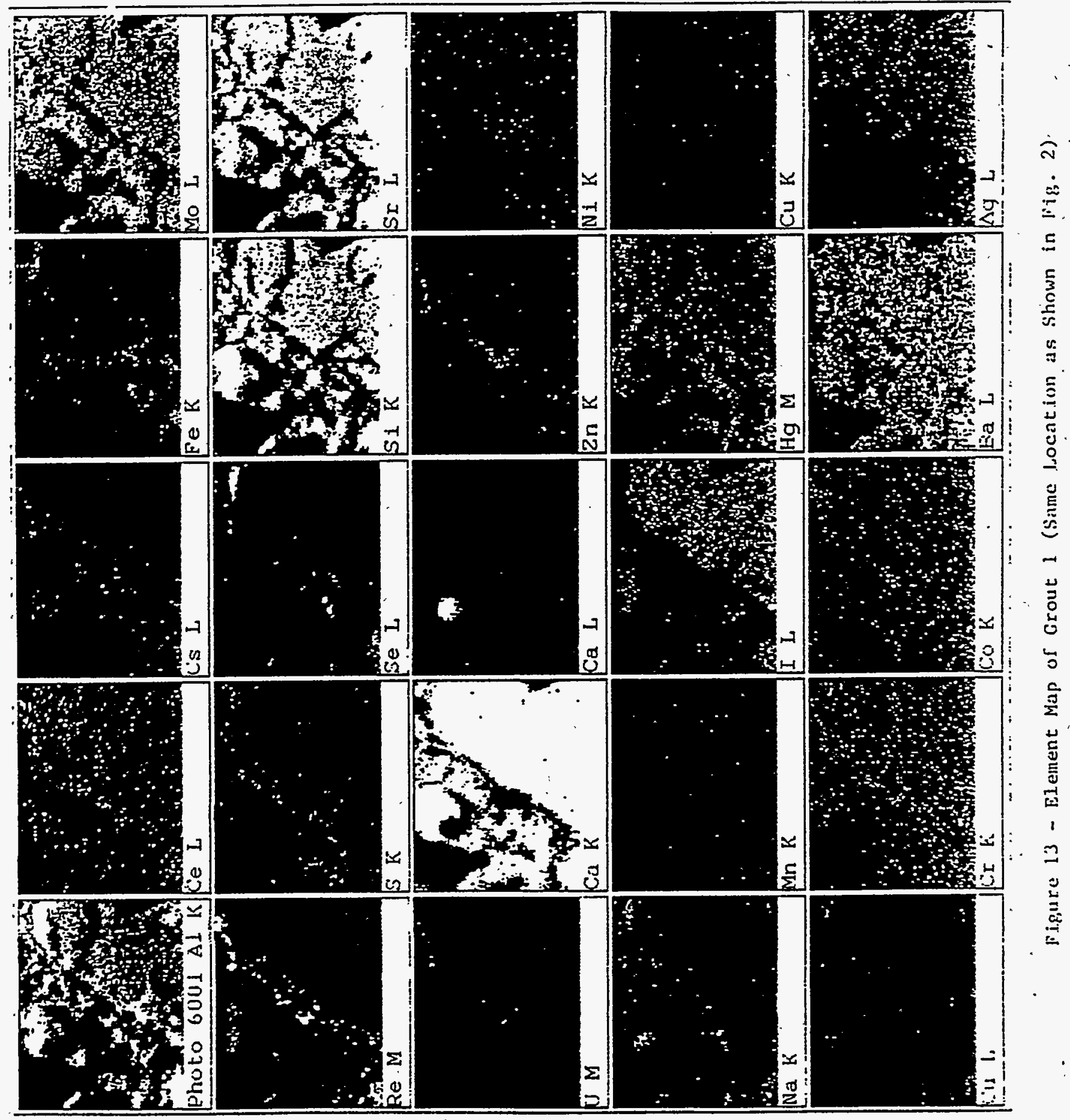




\section{Appendix F}

Thermal Considerations, Hydration of Grouts and

Grouted Sludges 


\section{Analyses to Evaluate the Heat Generation and Dissipation in Grout and Grout/Sludge Mixes}

Construction Technology Laboratories, Inc. (CTL) has performed simplified calculations to evaluate the heat generation and dissipation of six grout and grout/sludge mixtures for use in the Westinghouse Savannah River (WSR) underground radioactive waste storage tanks (USTs). These analyses used data measured at CTL and data from CTL's WSR contacts.

\section{SUMMARY AND CONCLUSIONS}

Simplified one-dimensional calculations were performed to predict. the maximum temperatures within the grout for three mix designs, with and without intermixing of the sludge material. These analyses assumed the grout was placed in three lifts, with each lift approximately $1 \mathrm{ft}$ high. Lifts were placed at 3 day intervals (at times 0,72 , and 144 hours).

Calculated maximum temperatures are based on the lift thickness, heat generation of the grout, and assumed soil, air, and grout temperatures during placement. At the request of CTL's WSR contacts, the temperature of the air in the UST, the temperature of the UST, the temperature of the soil beneath the UST, and the deep soil temperature were assumed to be $70^{\circ} \mathrm{F}$. Calculations utilized measured heat of hydration data and estimated thermal properties of the grout mixtures.

The grout temperature during placement in the UST was assumed to be 75,85 , or $95^{\circ} \mathrm{F}$. Results indicate the grout placement temperature has a small effect on the ultimate maximum temperature within the grout. The 1-ft thick layer of grout generally cools to ambient temperature (approximately $70^{\circ} \mathrm{F}$ ) before significant heat is generated by the cementitious materials in the grout. However, the grout must meet project flow cone requirements at the placement temperature.

The maximum temperatures for Grout No. 1,2, and 3 and Grout Nos. 1, 2, and 3 with slurdge, respectively, were approximately $130,115,110,105,115$, and $125^{\circ} \mathrm{F}$. The highest temperatures are experienced with Grout No. 1 because of its delayed heat generation compared to the other grouts.

It is important to note that calculation assumptions may not replicate field conditions. Calculations assume the air temperature within the UST remains at $70^{\circ} \mathrm{F}$ regardless of the heat generated by the grout. If the air temperature rises significantly, or the thickness of the grout layers is increased, the grout will not cool as predicted. Calculations also assume the rate of heat evolution from cement hydration is identical at 75,85 , and $95^{\circ} \mathrm{F}$ placement temperatures, which is a simplification commonly performed using this calculation method. The calculated peak temperature and time of occurrence are generally not significantly affected by this assumption. 


\section{STRUCTURE AND MATERIALS}

Information recęived from WSR indicated that the USTs are steel-lined single-shelled, reinforced concrete tanks with approximate dimensions of $85 \mathrm{ft}$ in diameter and $30 \mathrm{ft}$ in height. The USTs are buried under approximately $15 \mathrm{ft}$ of soil. The USTs are vented, therefore the air temperature (within the UST) is similar to that of the ambient air temperature (above ground). Approximately 2 to 3 in. of "sludge" remains at the bottom of the USTs, which will be intermixed/encapsulated within the grout.

Grout mix designs and measured heat of hydration data at $73.4^{\circ} \mathrm{F}$ for the cementitious portion of the grout and grout/sludge mixtures are presented in the main body of this report. The grout with sludge was assumed to contain $17 \%$ sludge. Grout mix designs were identified as Nos. 1,2, and 3 . This nomenclature corresponds to that used in the main body of this report.

Dr. Miller of CTL indicated that grout will be placed in one-foot thick lifts at 3-day intervals.

\section{CALCULATION TO PREDICT CONCRETE TEMPERATURES}

\section{Assumptions}

Calculations were performed to predict the maximum temperature within the grout. Heat of hydration of the cementitious portions (without sand) of Grout Nos. 1,2, and 3 with and without sludge are presented in the main body of this report. Results are also presented in Fig. 1. Results were provided in joules per gram per hour of cementitious material with and without sludge for a period of approximately 3 days. The heat generated for the grouts with sludge occurred earlier and over a shorter time period than that without sludge. If data were available for cement hydration at 85 and $95^{\circ} \mathrm{F}$, it most probably would also show heat generation occuring earlier and over a shorter time period than that at $73.4^{\circ} \mathrm{F}$.

Temperature rise of the grout under adiabatic conditions was calculated using the heat of hydration data, grout mix design, and the equation on page 189 in Chapter 15 of Design and Control of Concrete Mixtures, Portland Cement Association (PCA) Publication EB001. The specific heat of the grout was assumed to be $0.24 \mathrm{Btu} / \mathrm{lb} \cdot{ }^{\circ} \mathrm{F}$.

One-dimensional heat dissipation of the grout elements were calculated in accordance with American Concrete Institute (ACI).Standard Practice on Mass Concrete, ACI 207.1R-87, "Mass Concrete". This finite difference method had 0.20-ft thick grout elements and temperatures were caleulated at approximately 30 minute intervals. Thermal diffusivity of the grout was assumed to be $1.0 \mathrm{ft}^{2} / \mathrm{day}$. This value is recommended in Section 5.3 .4 of $\mathrm{ACI}$ 207.1R-87 when actual thermal diffusivity is not known. Concrete thermal diffusivities presented in this reference range from 0.77 to $1.39 \mathrm{ft}^{2} / \mathrm{day}$.

At the request of CTL's WSR contacts, the temperature of the air in the UST, the temperature of the UST, the temperature of the soil beneath the UST, and the deep soil temperature were assumed to be $70^{\circ} \mathrm{F}$. The temperature of the air in the UST was assumed to remain at $70^{\circ} \mathrm{F}$ regardless of the heat generated by the grout. The temperature of the soil beneath the UST was allowed to gain heat as a result of the heat generated by the grout. 


\section{Results}

The grout temperature during placement in the UST was assumed to be 75,85 , or $95^{\circ} \mathrm{F}$. Maximum grout temperatures during the first 12 days after placement are presented for the three grouts with and without sludge in Figs. 2 through 19. Results indicate the grout placement temperature has a small effect on the ultimate maximum temperature within the grout. The 1 -ft thick layer of grout generally cools to ambient temperature (approximately $70^{\circ} \mathrm{F}$ ) before significant heat is generated by the cementitious materials in the grout.

However, the grout must meet project flow cone requirements at the placement temperature.

The maximum temperatures for Grout Nos. 1, 2, and 3 and Grout Nos. 1, 2, and 3 with sludge, respectively, were approximately $130,115,110,105,115$, and $125^{\circ} \mathrm{F}$. The highest temperatures are experienced with Grout No. 1 because of its delayed heat generation compared to the other grouts.

The highest maximum grout temperatures occur at the $95^{\circ} \mathrm{F}$ placement temperature for Grout No. 1 and the Grout No. 3 with sludge mixture. Maximum temperature differences between the center and surface of the grouts are presented in Figs. 20 and 21. The maximum temperature differentials are $57^{\circ} \mathrm{F}$ and $53^{\circ} \mathrm{F}$ for Grout No. 1 and the Grout No. 3 with sludge mixture, respectively. Figures 22 and 23 present the calculated maximum grout temperatures within individual lifts and at lift interfaces. The difference in the number of peaks in these figures is due to the delayed heat of hydration of Grout No. 1 in comparison to that of the Grout No. 3 and sludge mixture.

The results of these analyses are based on the heat of hydration measurements presented in Fig. 1. These measurements were performed at $73.4^{\circ} \mathrm{F}$. If the temperature during the time of placement is increased, the heat may be generated sooner and with a higher peak. Due to the rapid heat dissipation which occurs in the $1 \mathrm{ft}$ thick lifts, the maximum grout temperatures of the first lift may increase, however, the overall maximum grout temperature (which occurs after placement of the third lift) would most likely decrease or remain the same.

\section{Importance of Assumptions}

It is important to note that calculation assumptions may not replicate field conditions. The use of heat of hydration data obtained at $73.4^{\circ} \mathrm{F}$ but applied to all placement temperature cases is anticipated to only slightly change the calculated maximum temperatures as noted above. Calculations assume the air temperature within the UST remains at $70^{\circ} \mathrm{F}$ regardless of the heat generated by the grout. If the air temperature rises significantly the grout will not cool as predicted. 


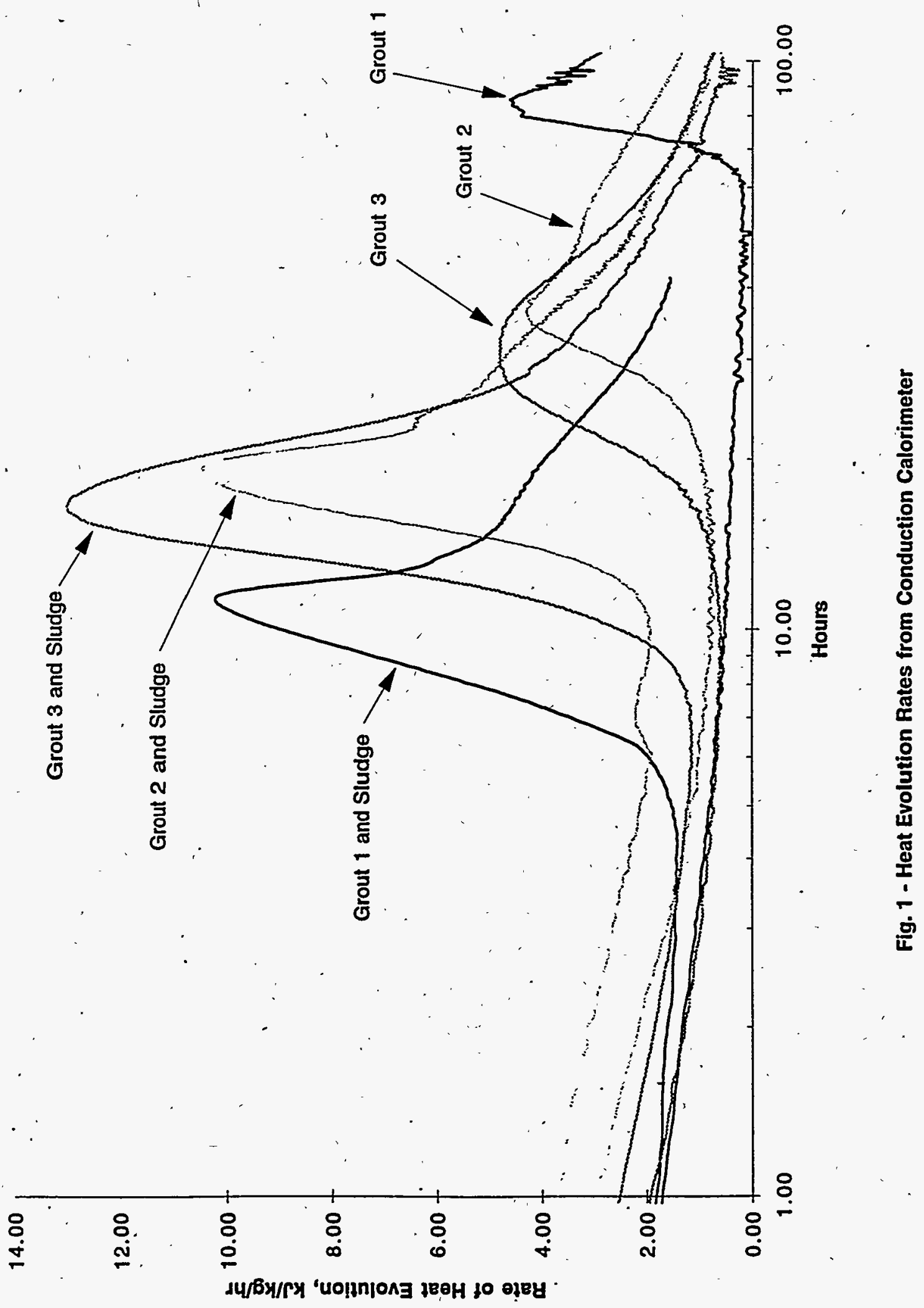




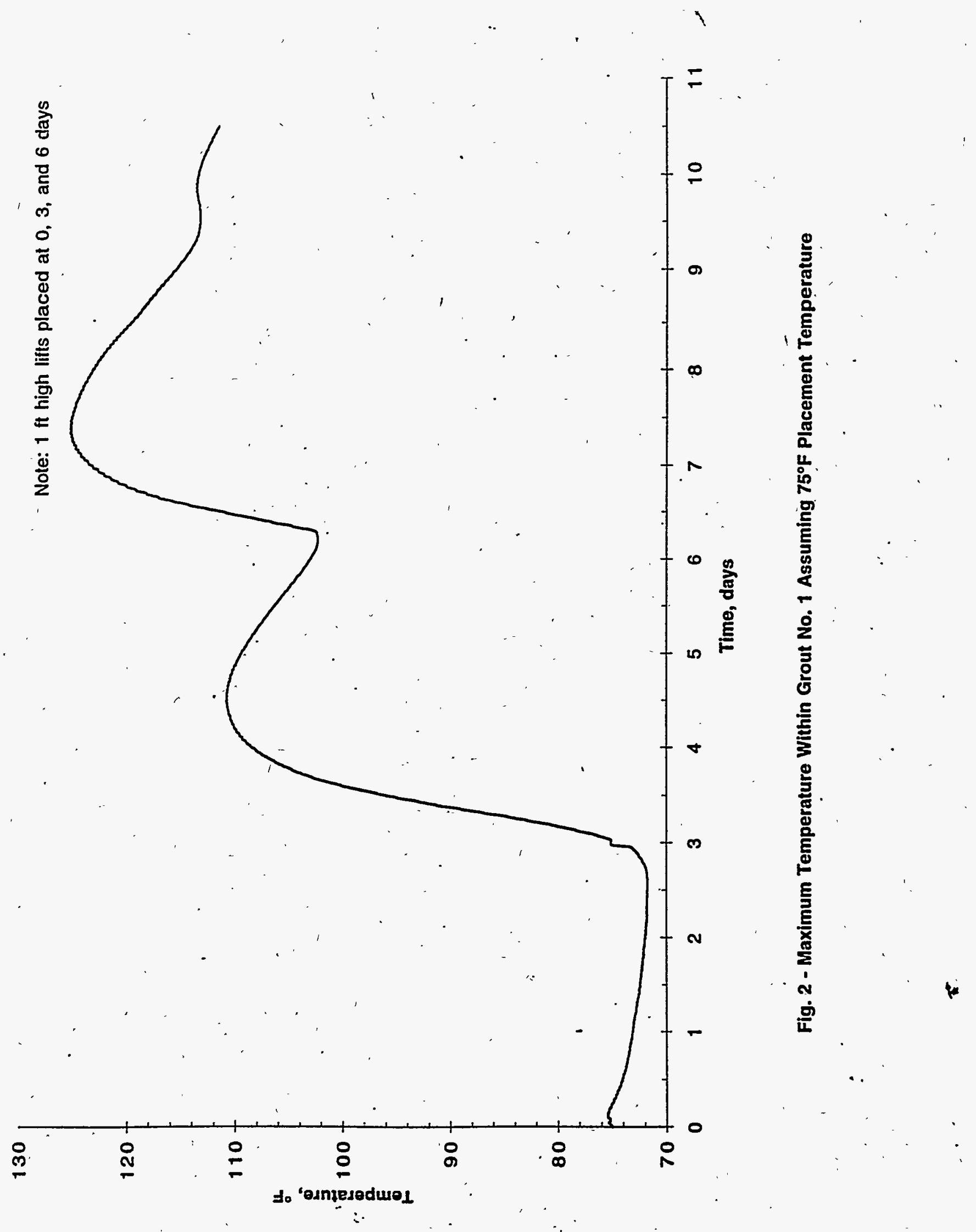




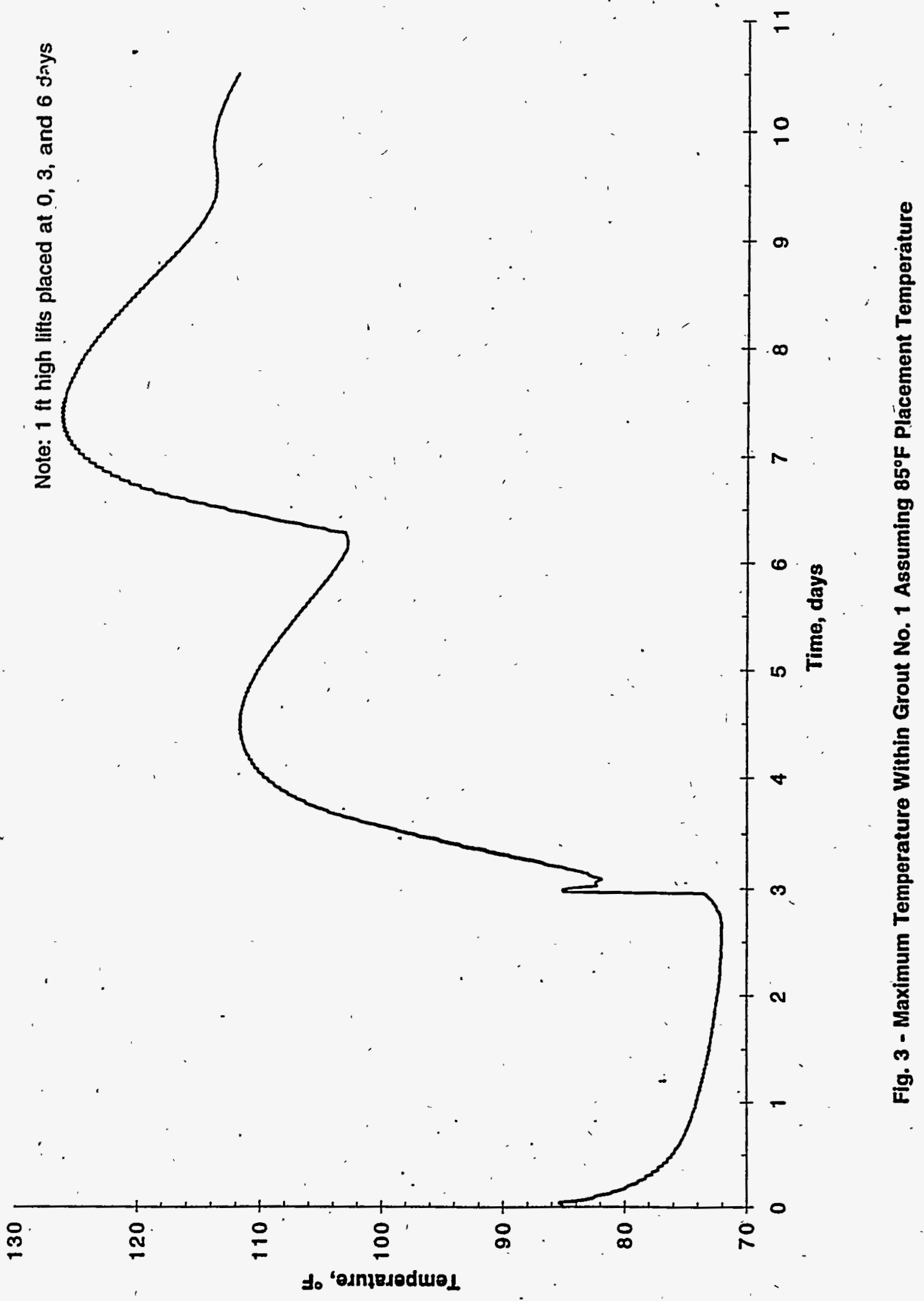




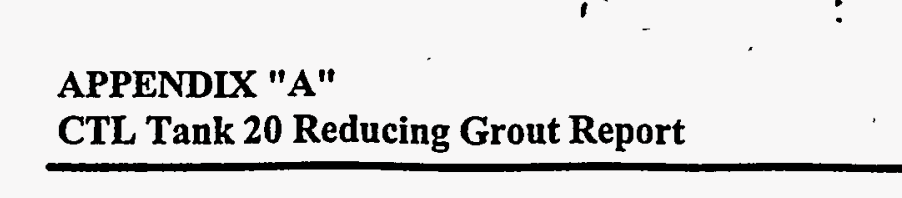

WSRC-TR-97-0102

Revision 0

Page 145

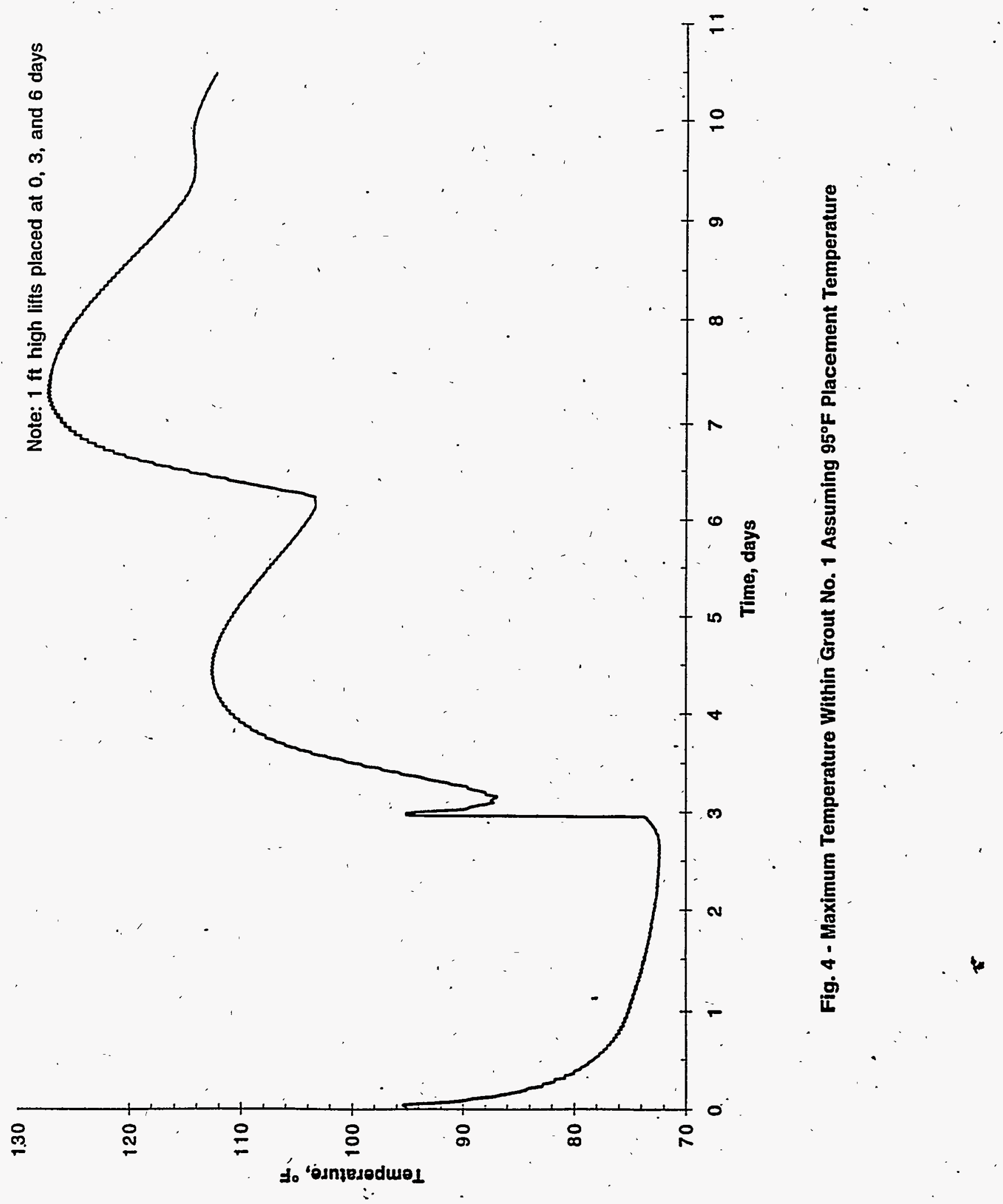




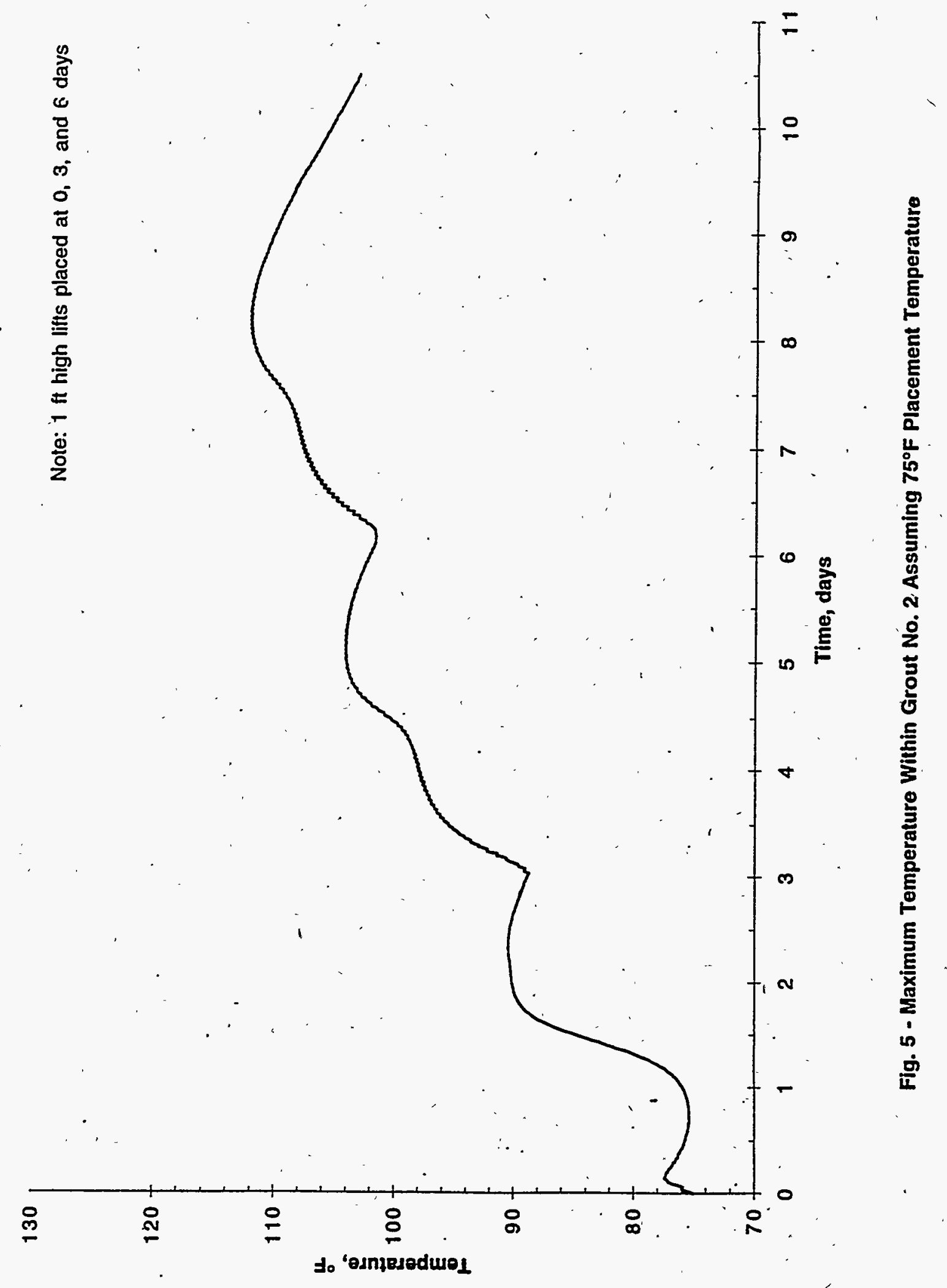




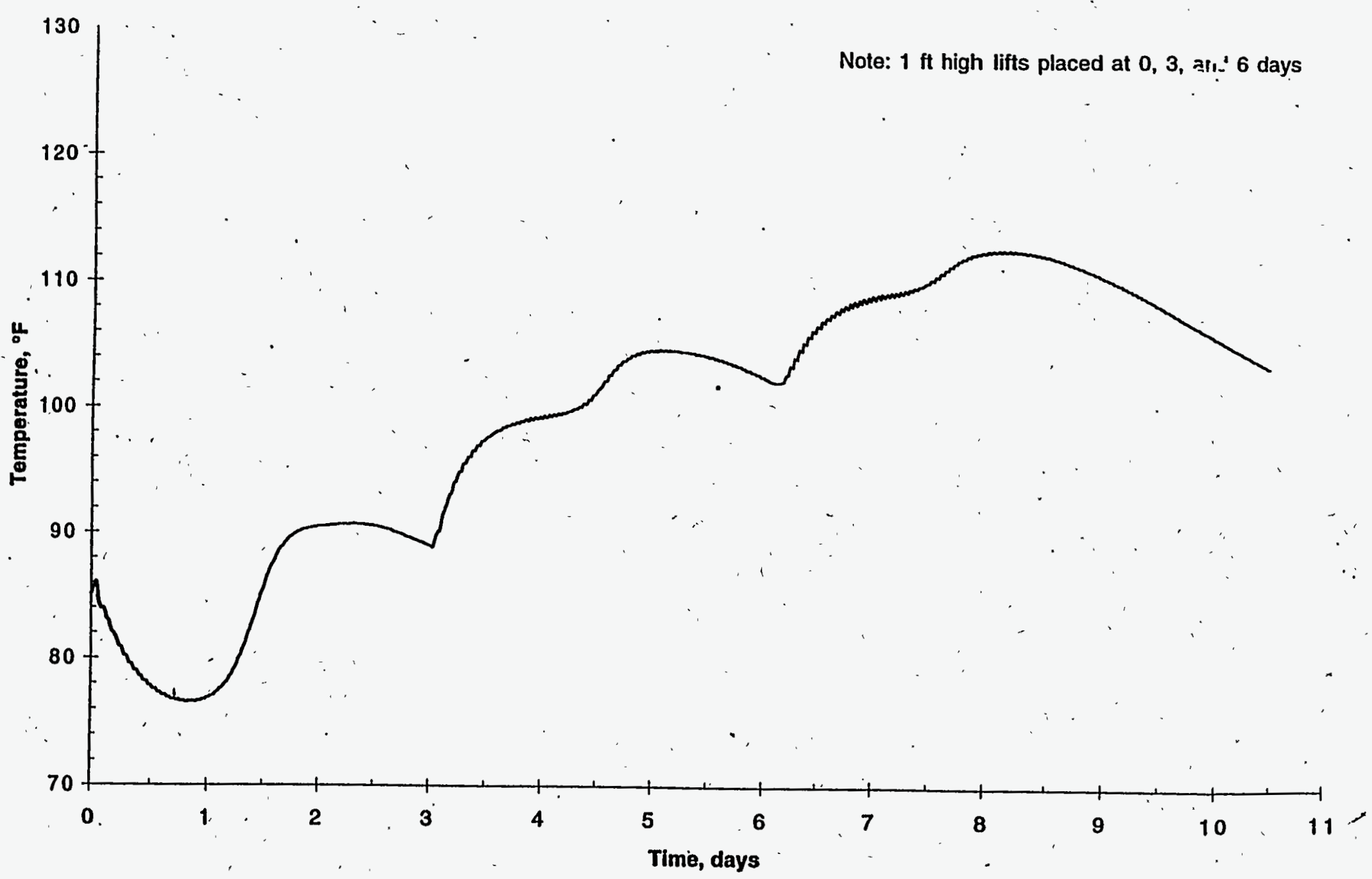

Fig. 6 - Maximum Temperature Within Grout No. 2 Assuming 85F Placement Temperature 


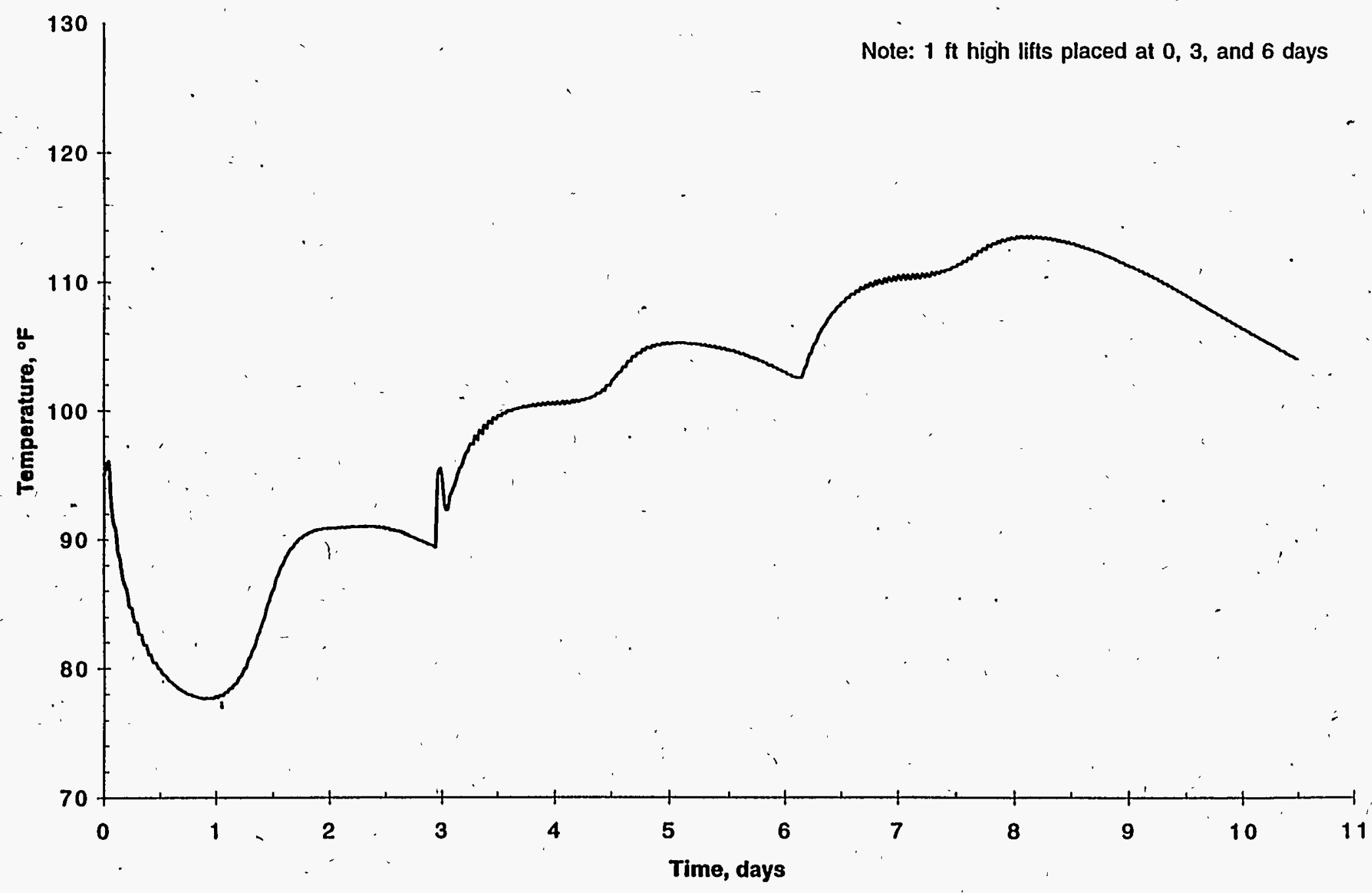

Fig. 7 - Maximum Temperature Within Grout No. 2 Assuming 95F Placement Temperature

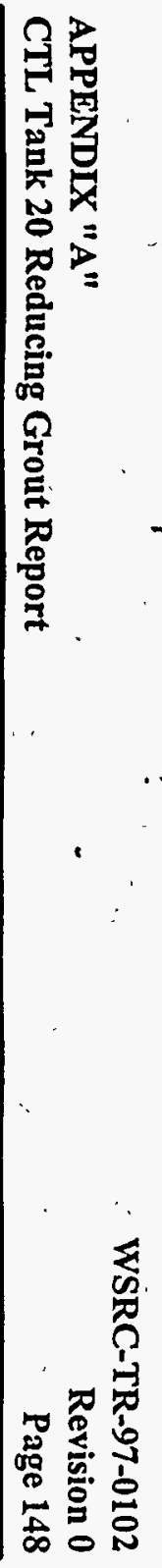




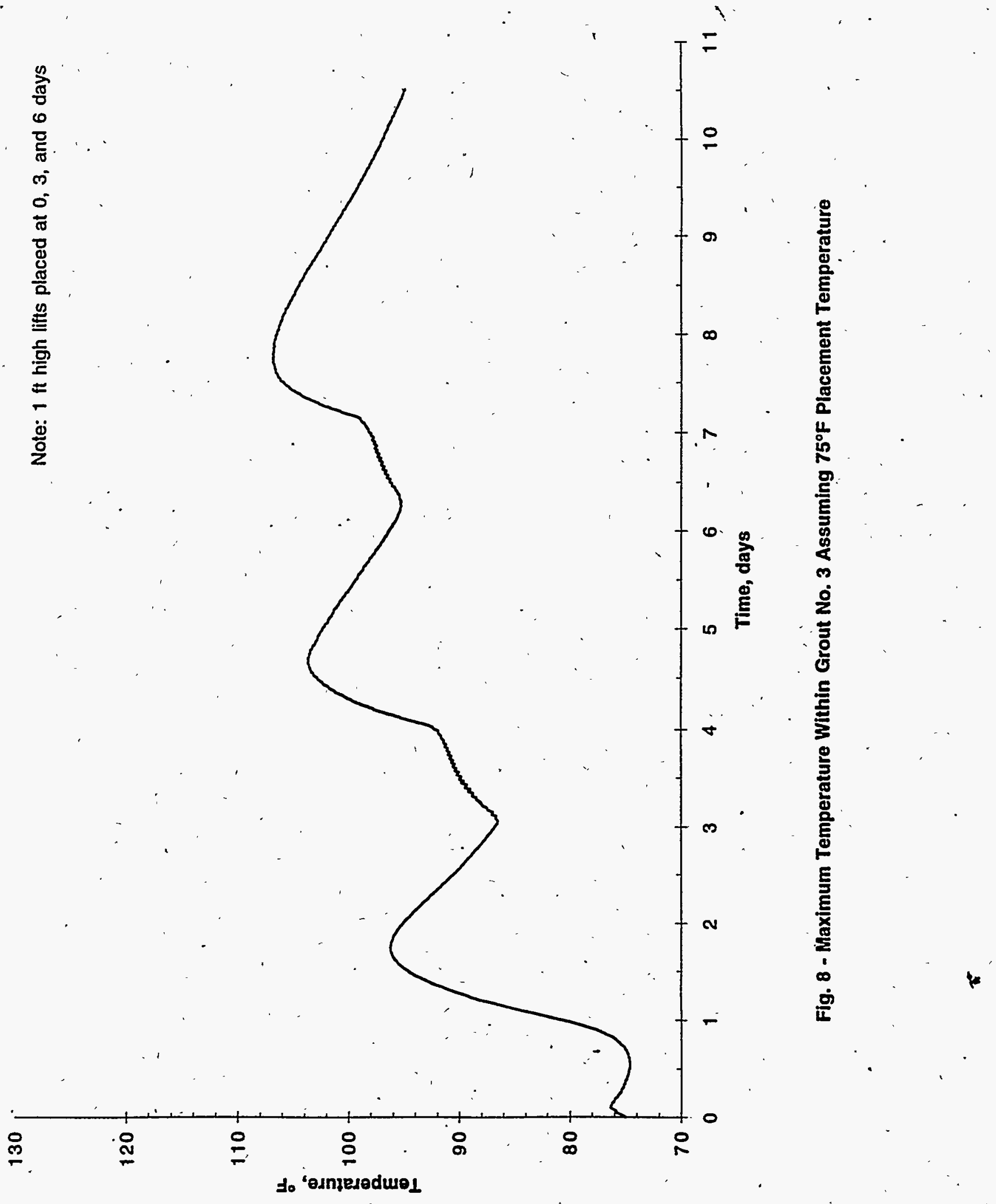




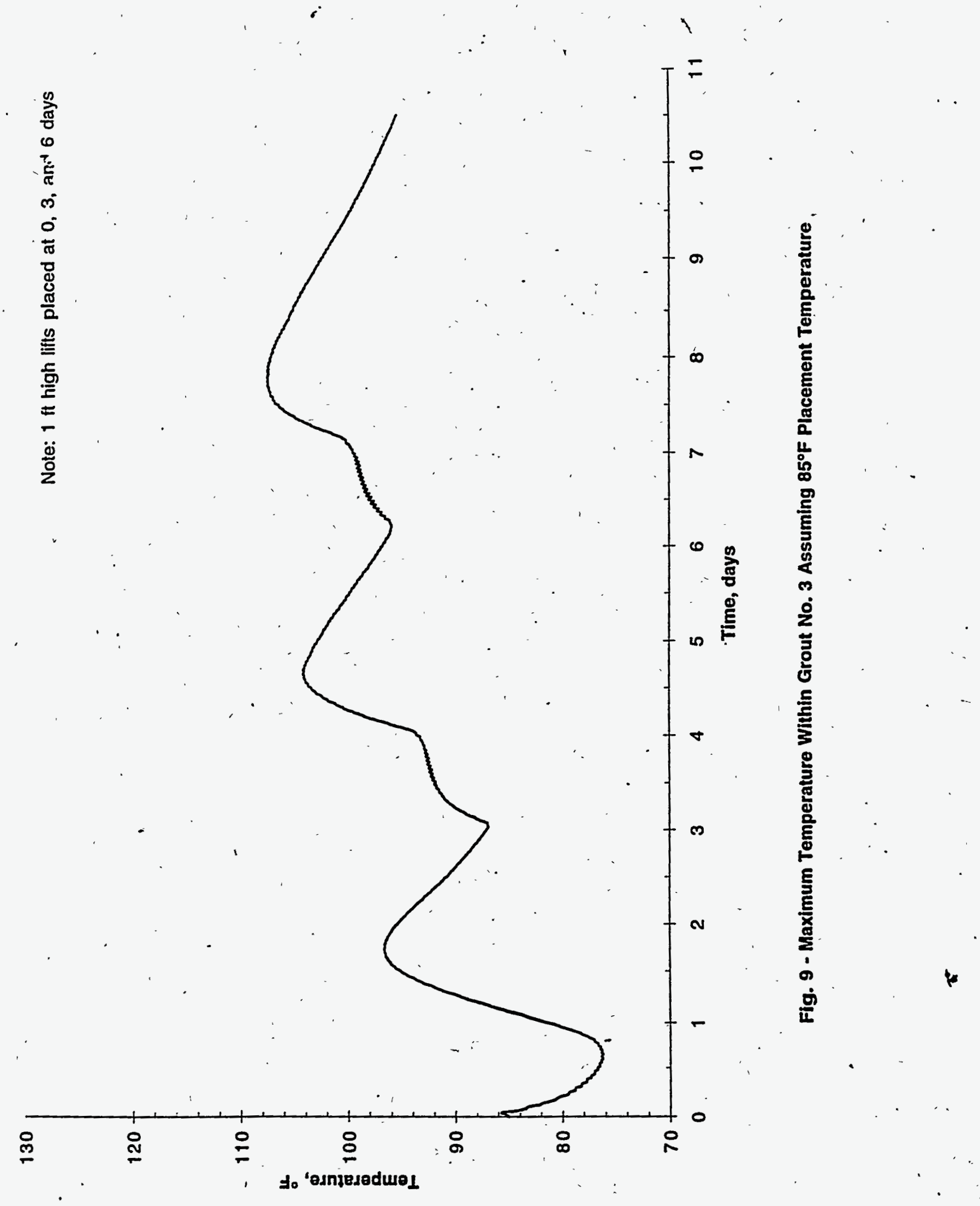


APPENDIX "A"

CTL Tank 20 Reducing Grout Report

WSRC-TR-97-0102

Revision 0

Page 151

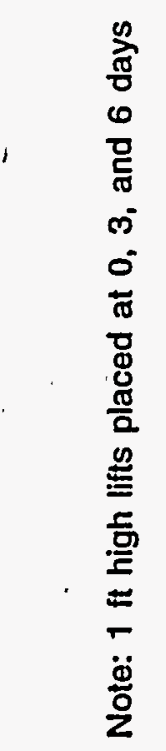

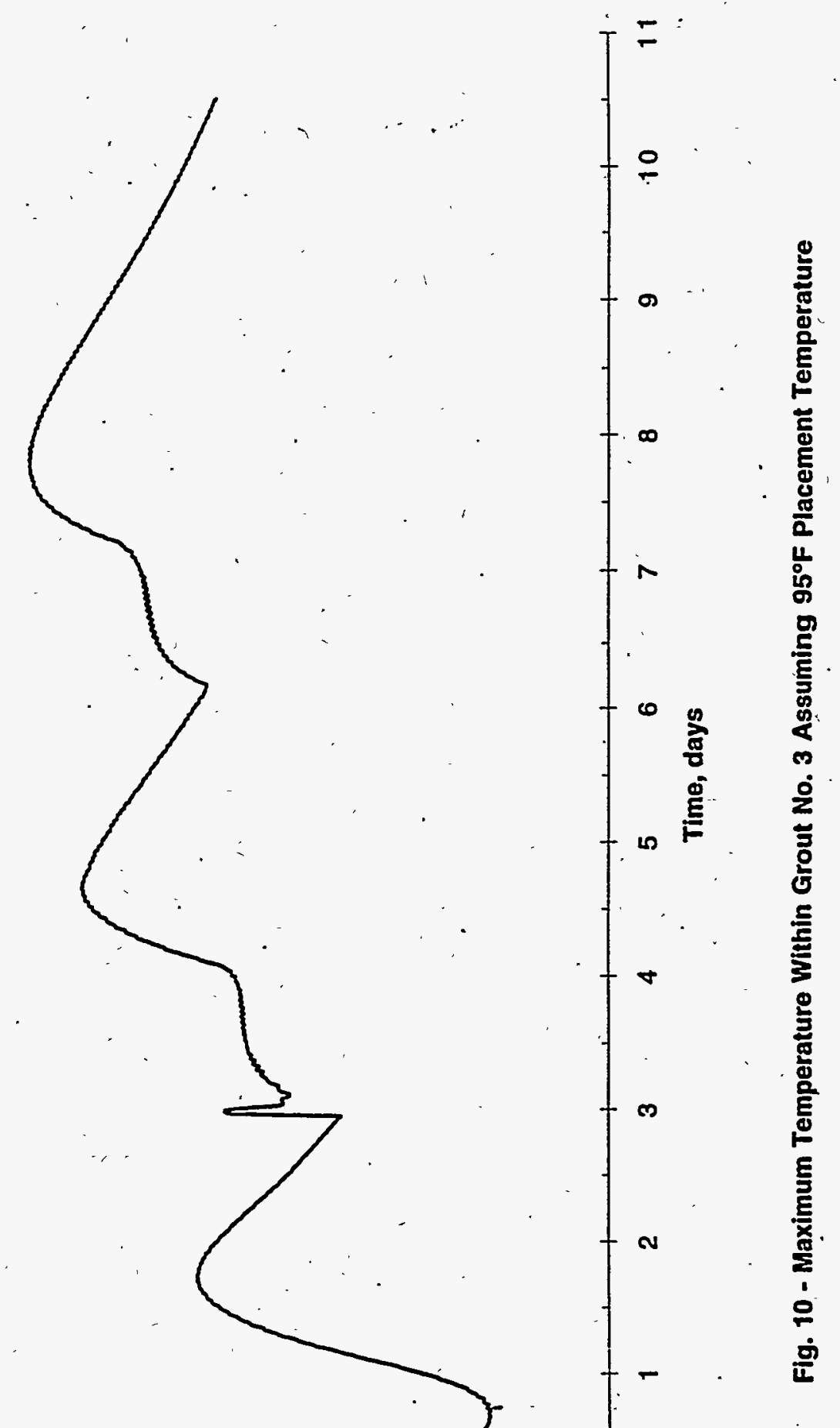

욤

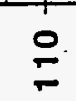

。

jo 'osnzesedwal 
WSRC-TR-97-0102

APPENDIX "A".

CTL Tank 20 Reducing Grout Report

Revision 0

Page 152

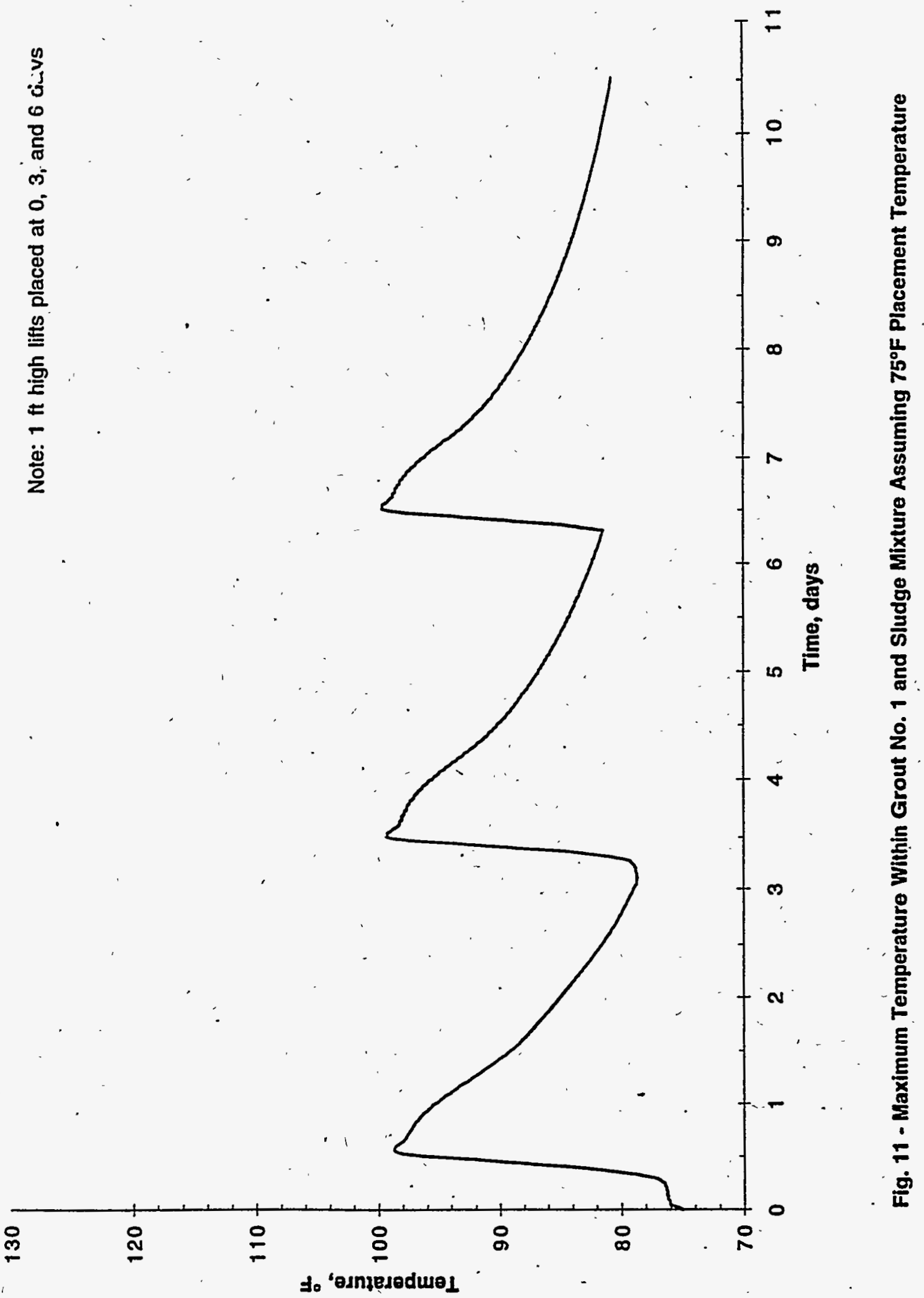


APPENDIX "A"

CTL Tank 20 Reducing Grout Report
WSRC-TR-97-0102

Revision 0

Page 153

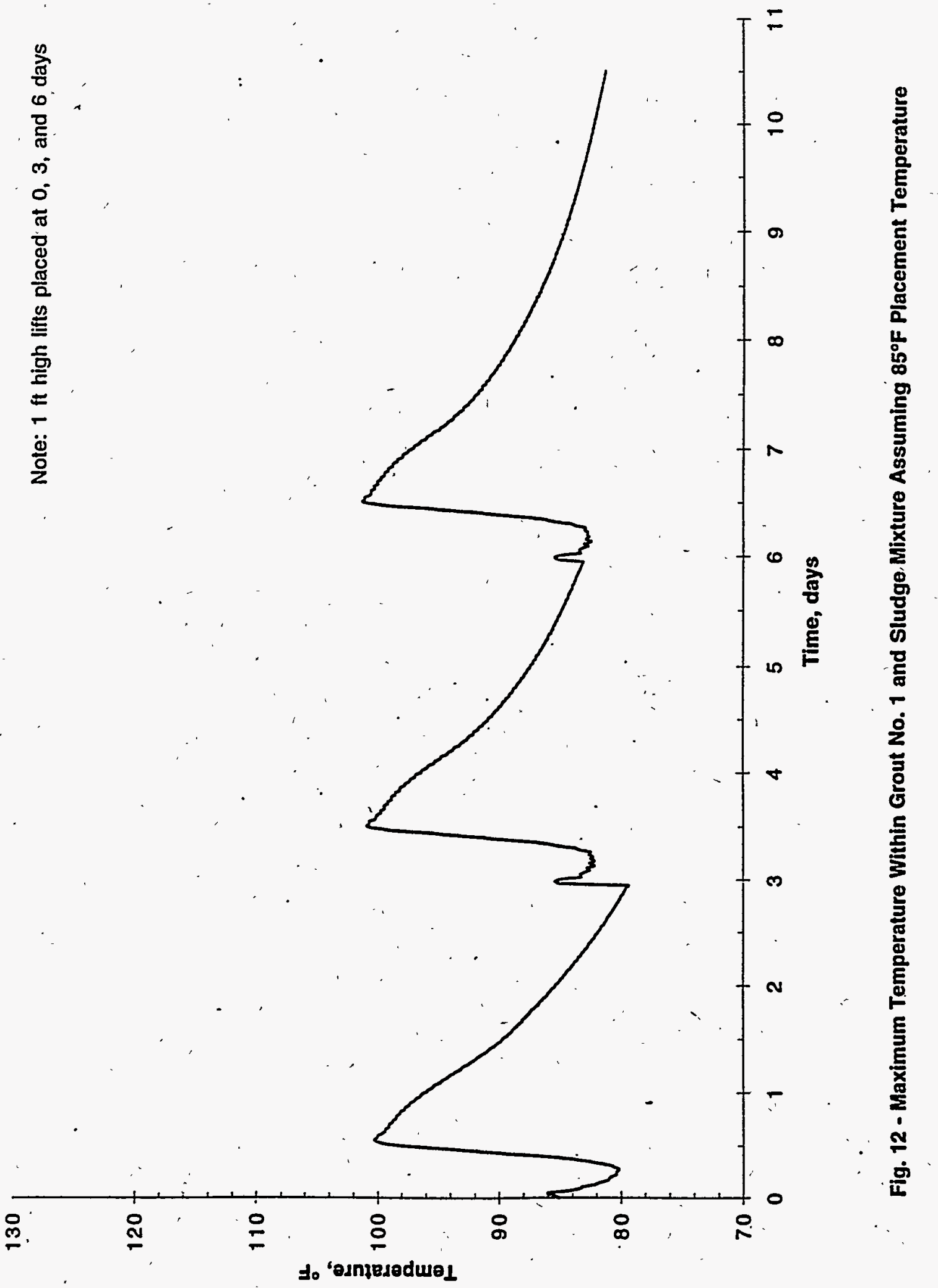




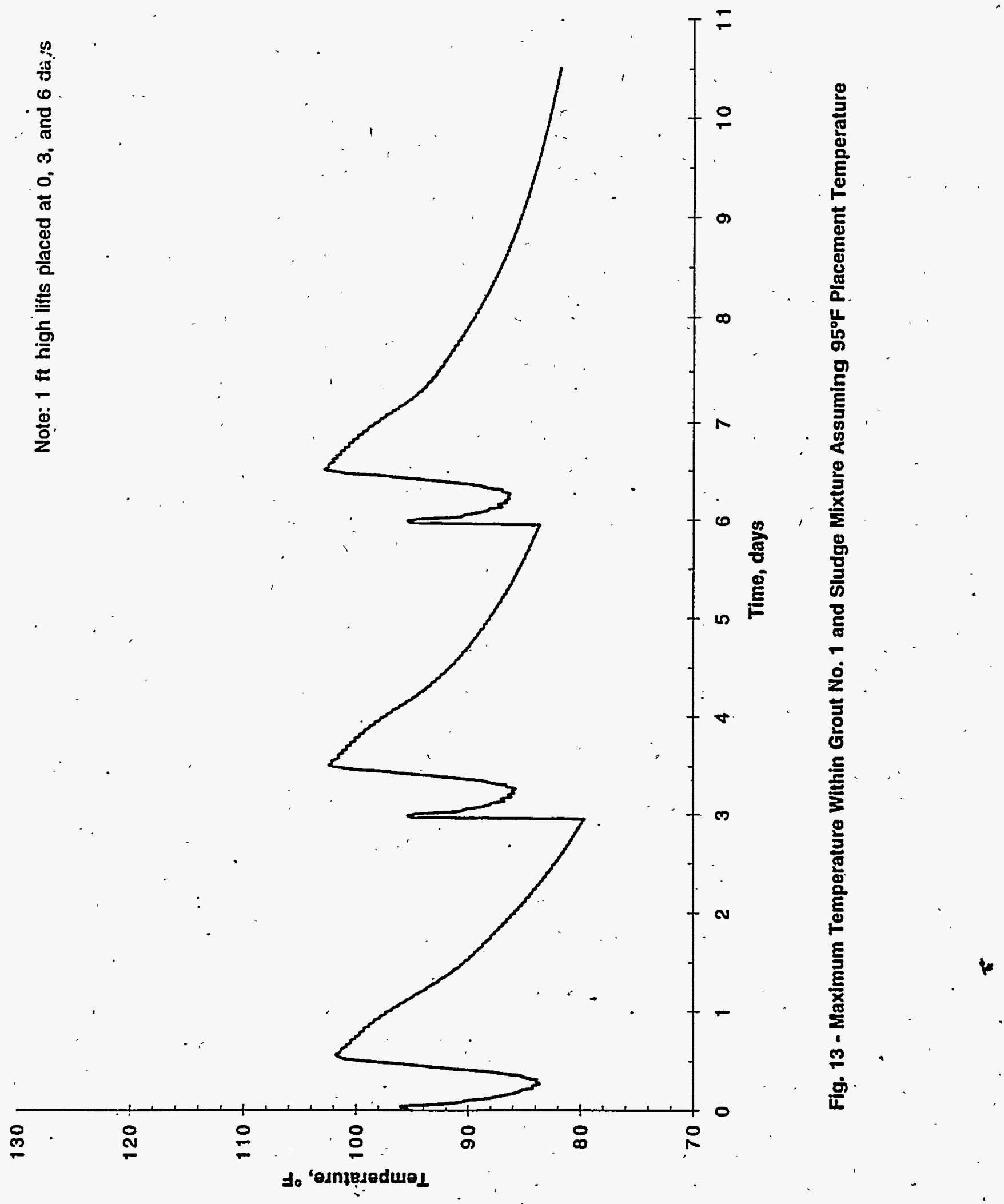




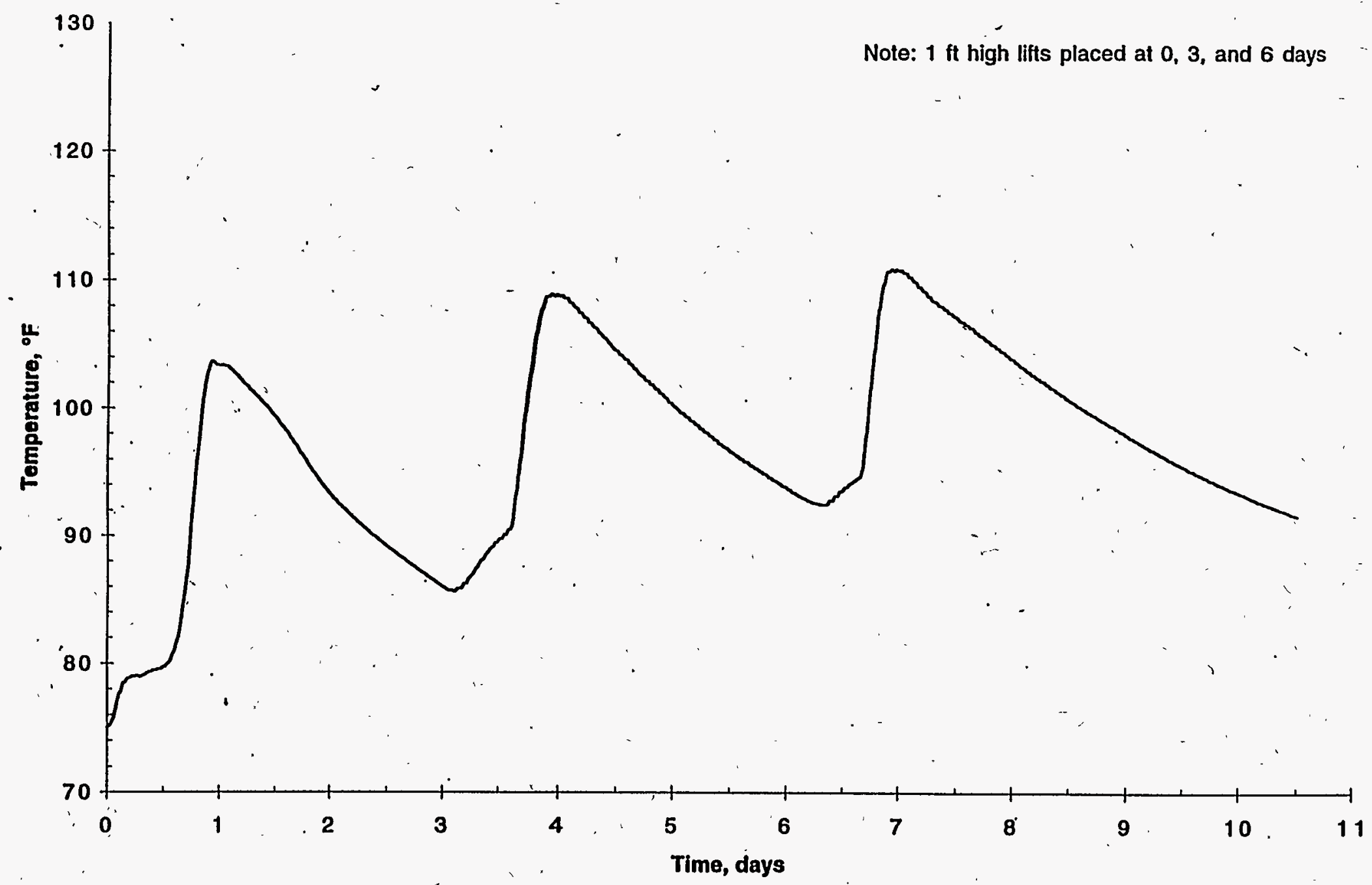

Fig. 14 - Maximum Temperature Within Grout No. 2 and Sludgé Mixture Assuming 75F Placement Temperature 
APPENDIX "A"

CTL Tank 20 Reducing Grout Report
WSRC-TR-97-0102

Revision 0

Page 156

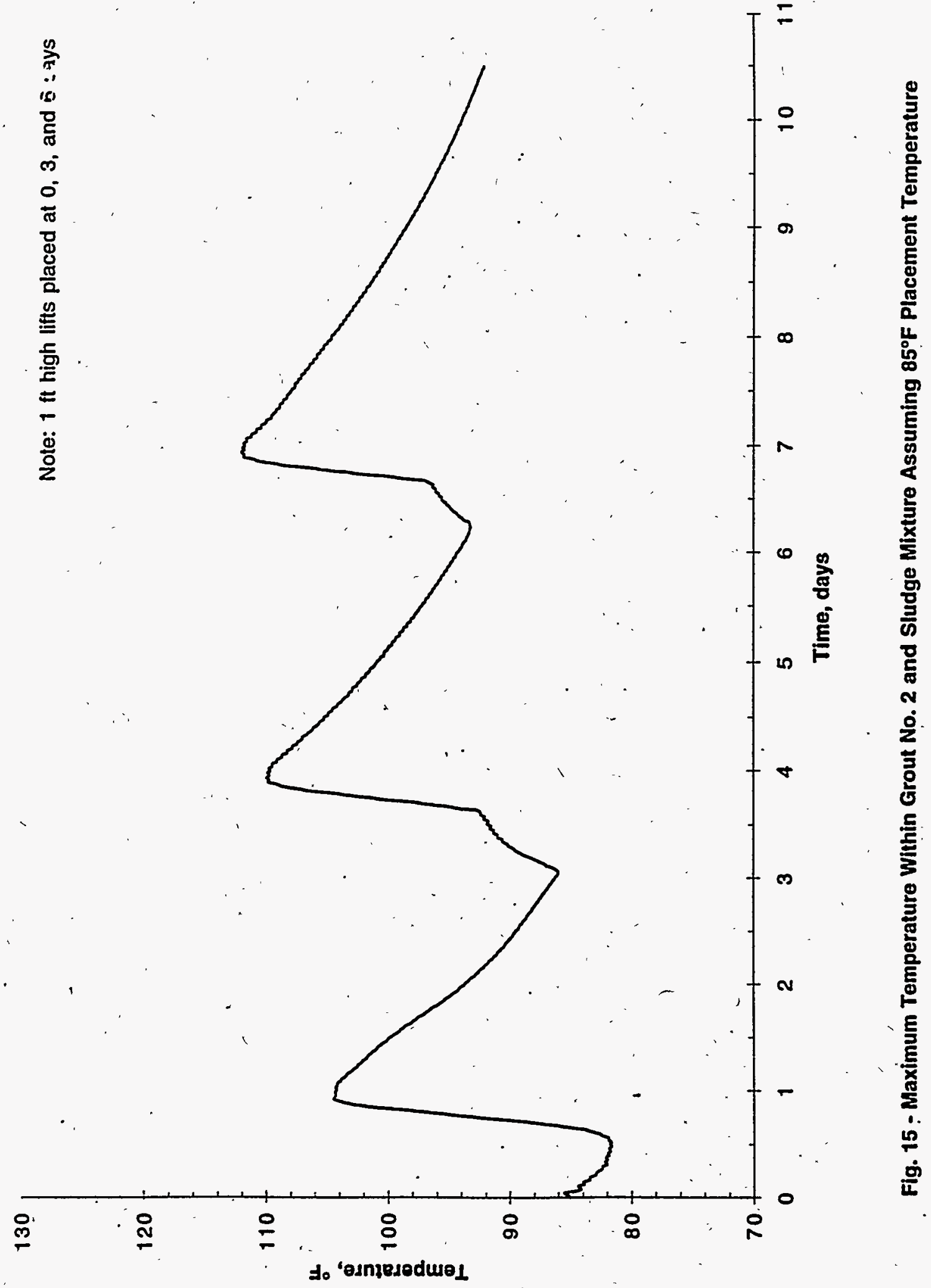


APPENDIX "A"

CTL Tank 20 Reducing Grout Report
. WSRC-TR-97-0102

Revision 0

Page 157

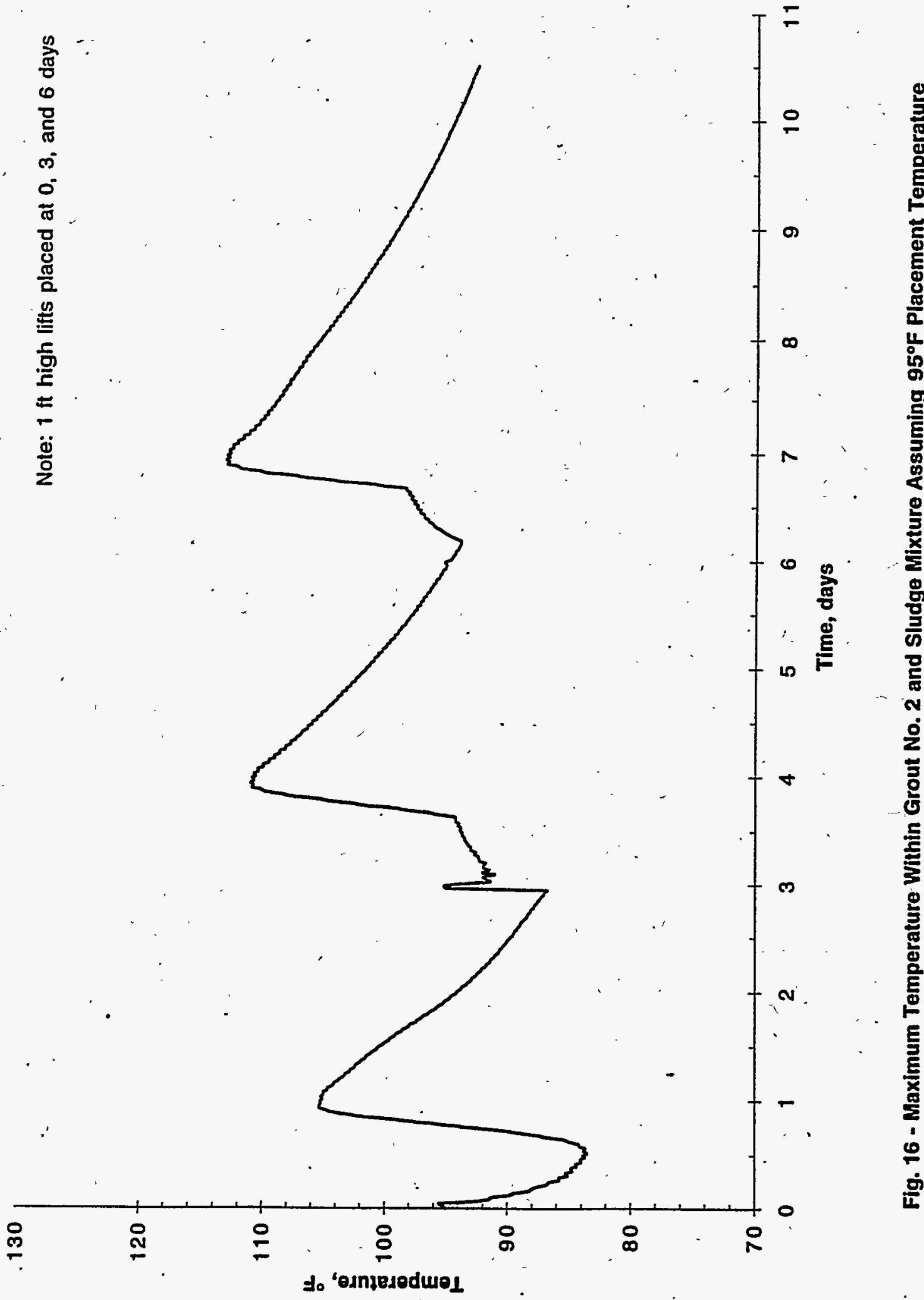




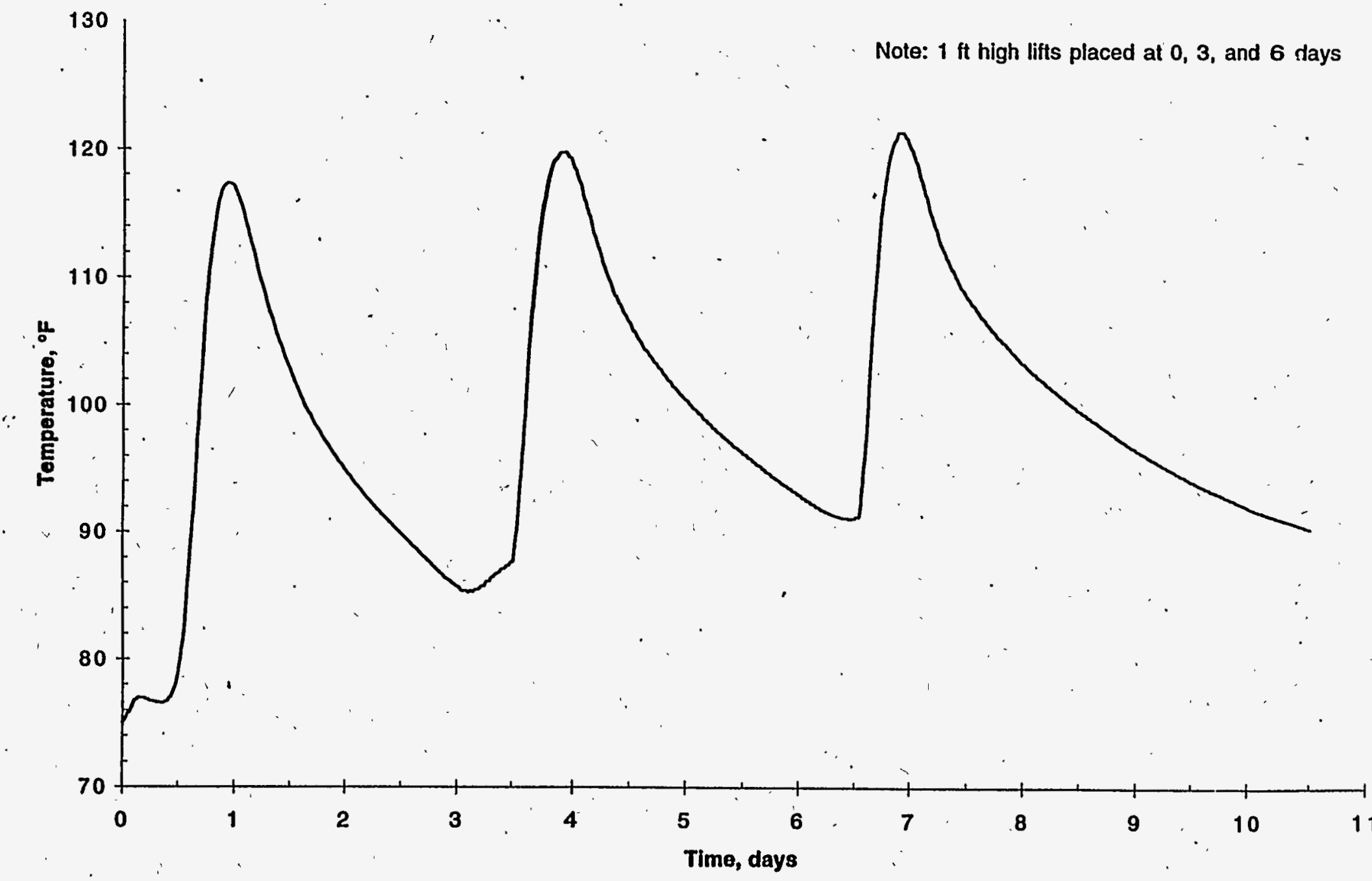

Fig. 17 - Maximum Temperature Within Grout No. 3 and Sludge Mixture Assuming $75^{\circ}$ F Placement Temperature

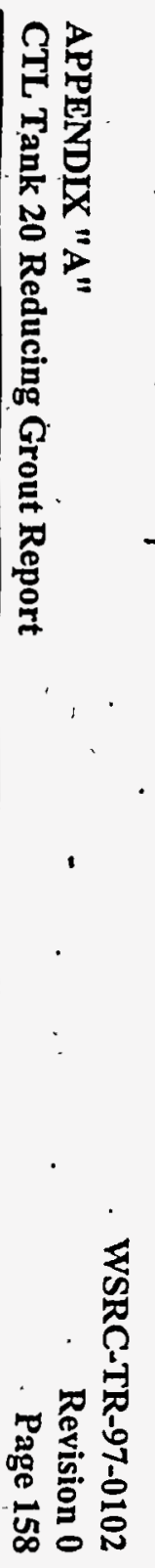




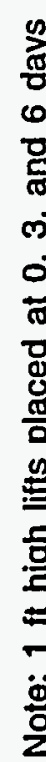
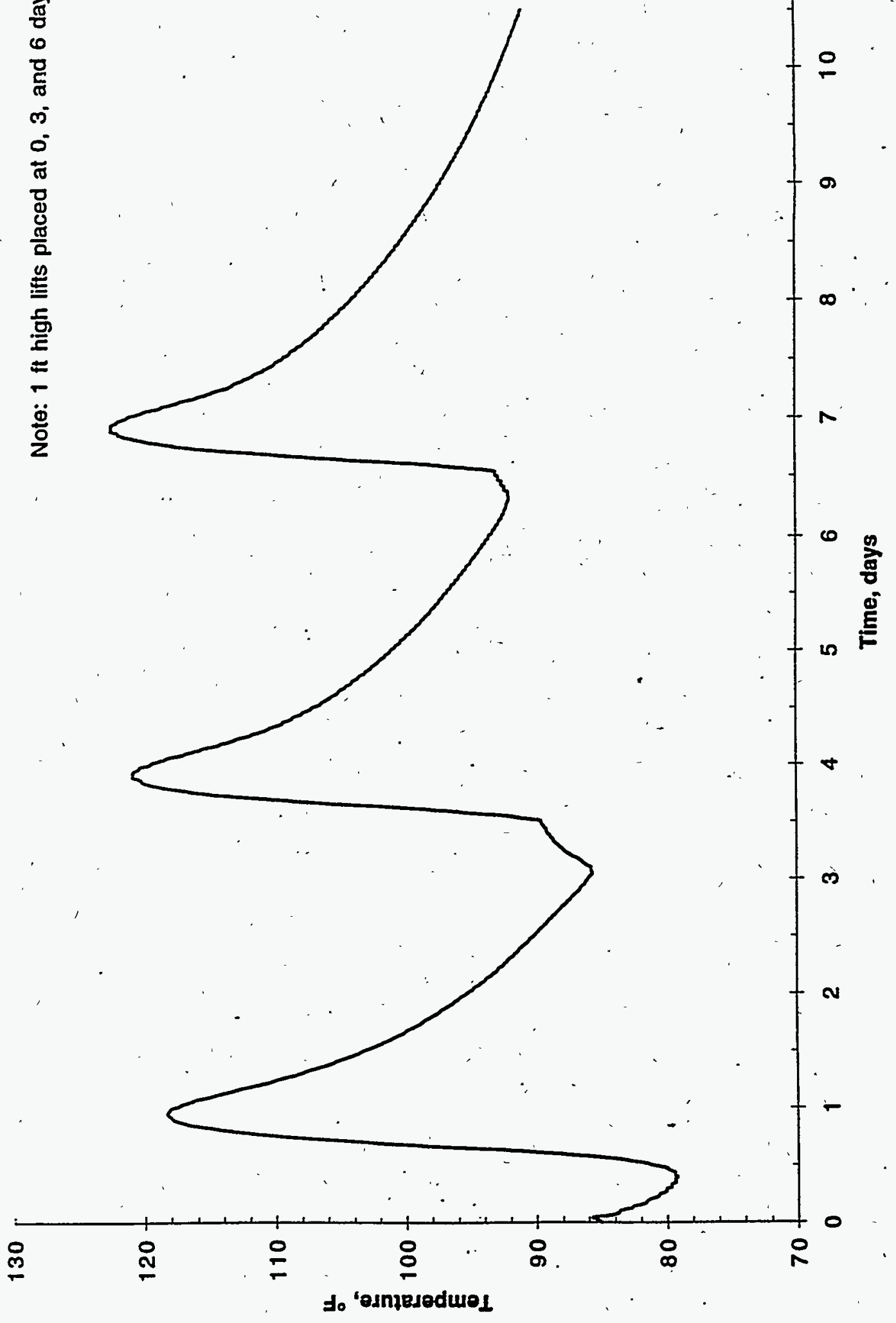


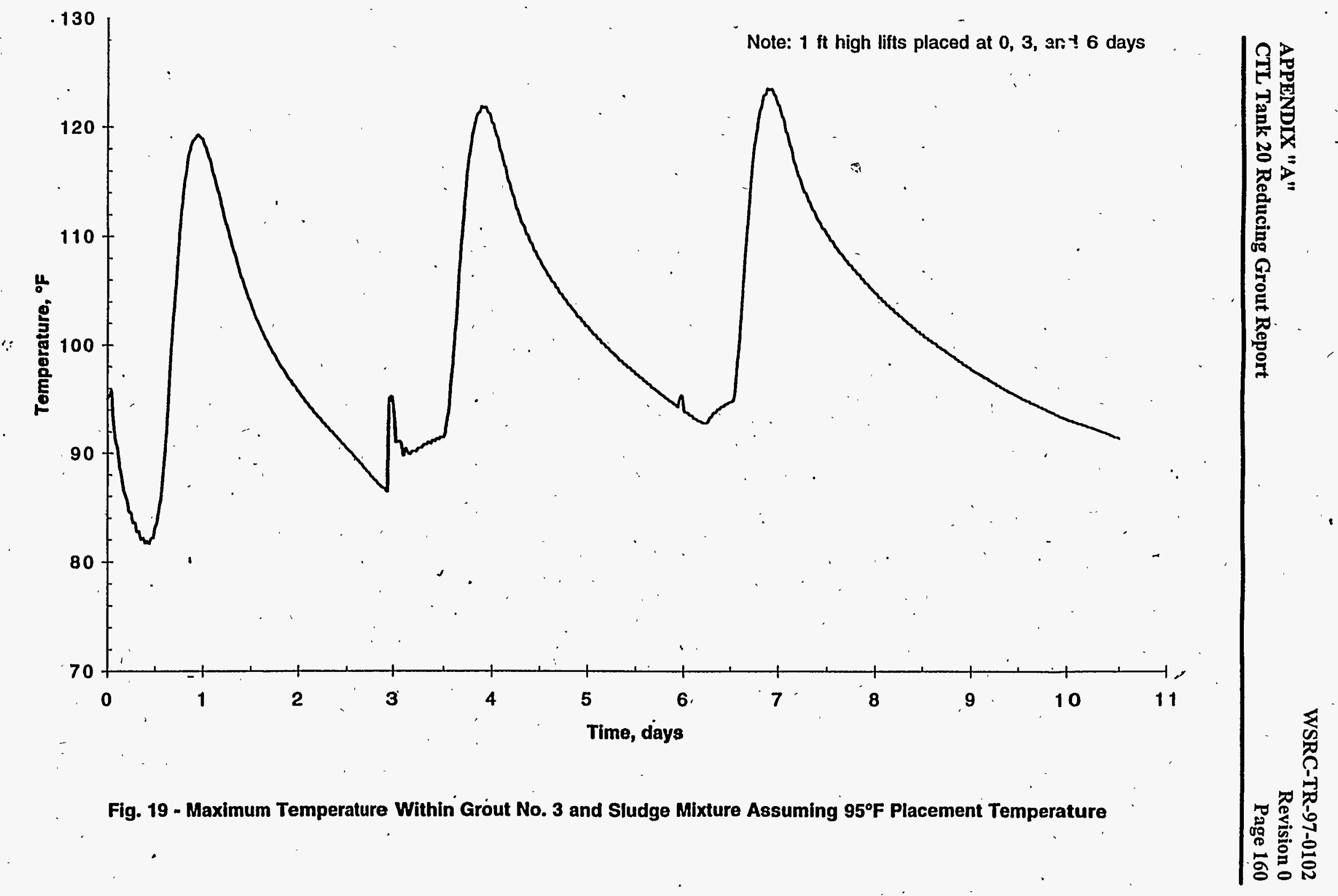




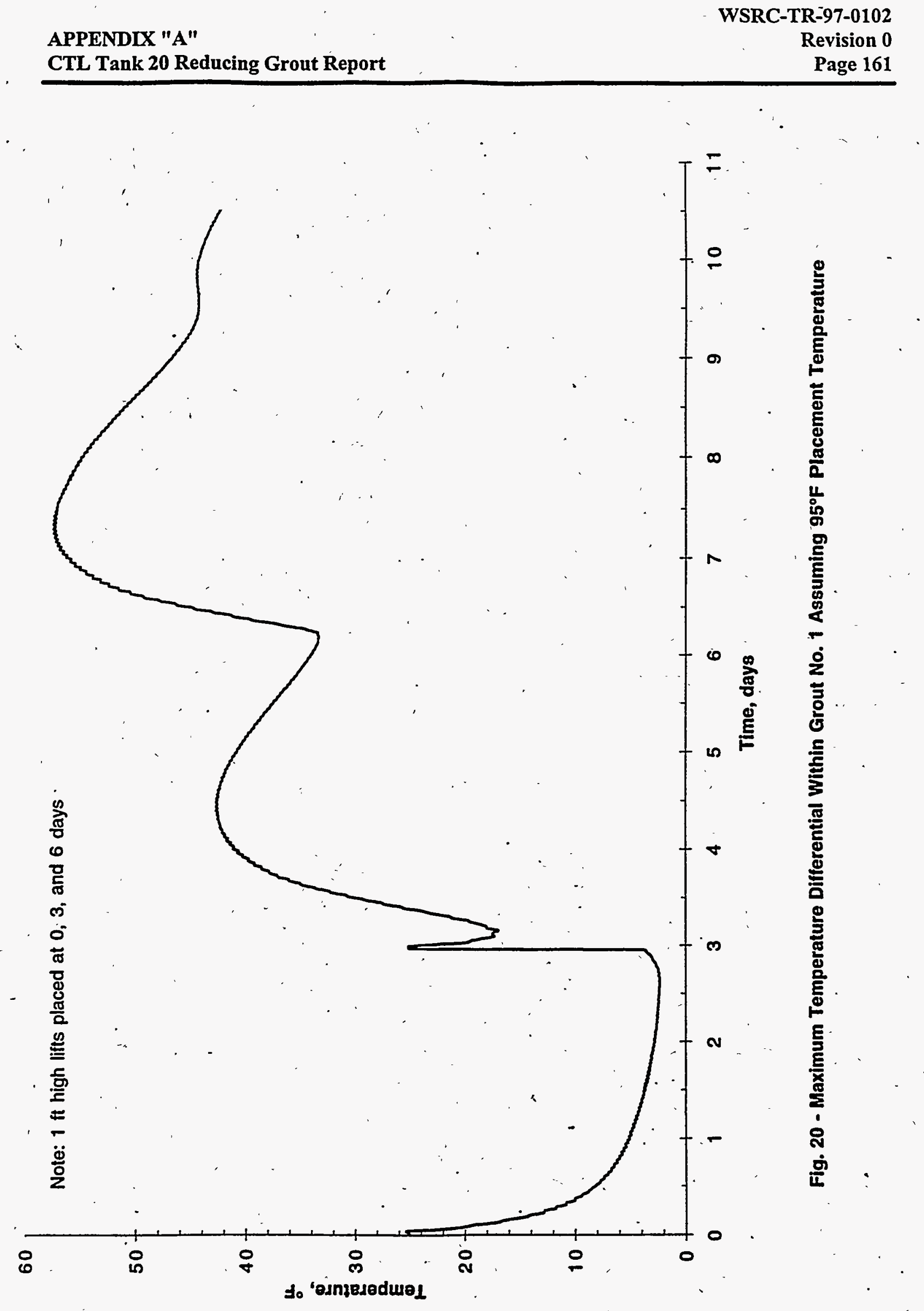




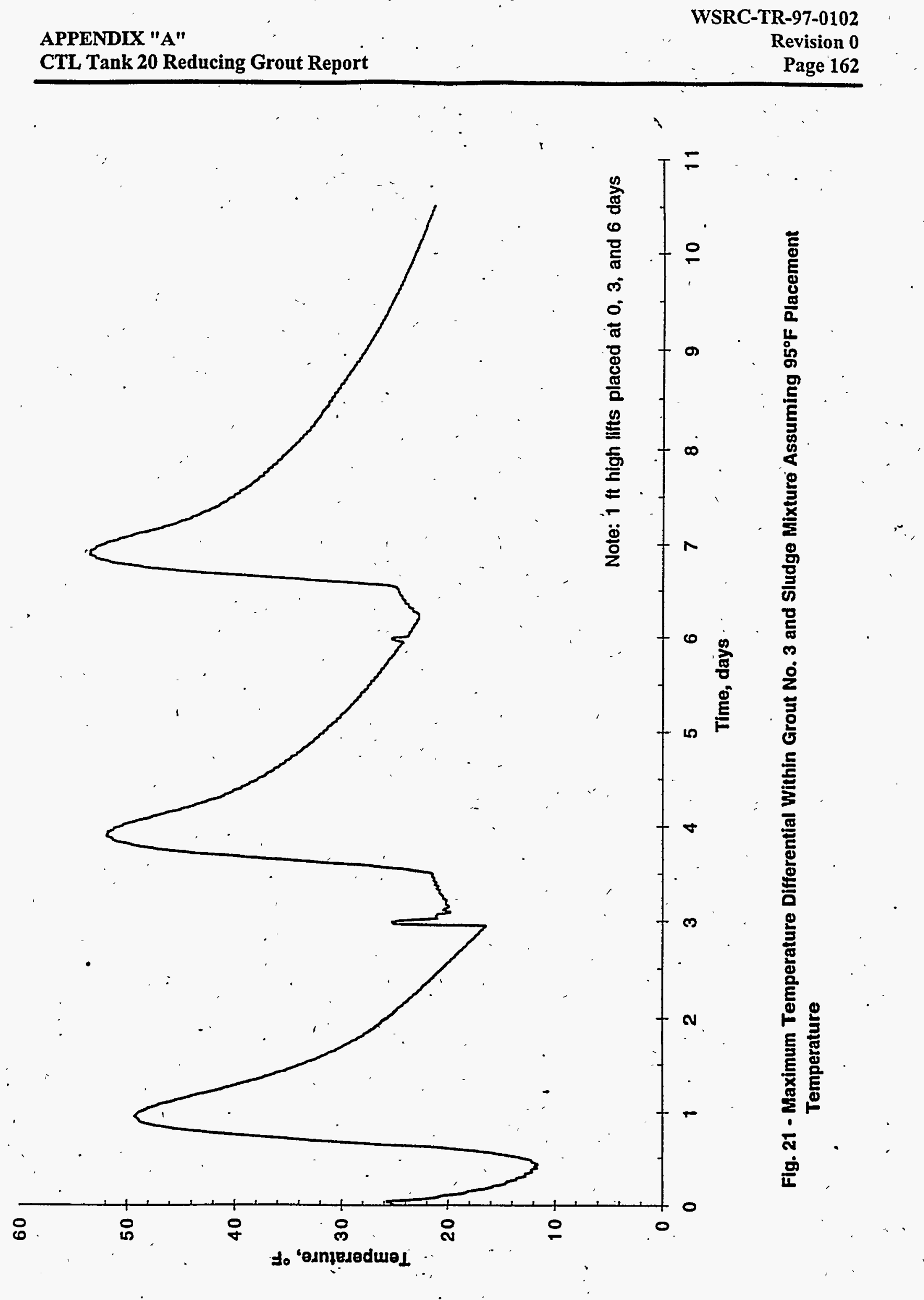




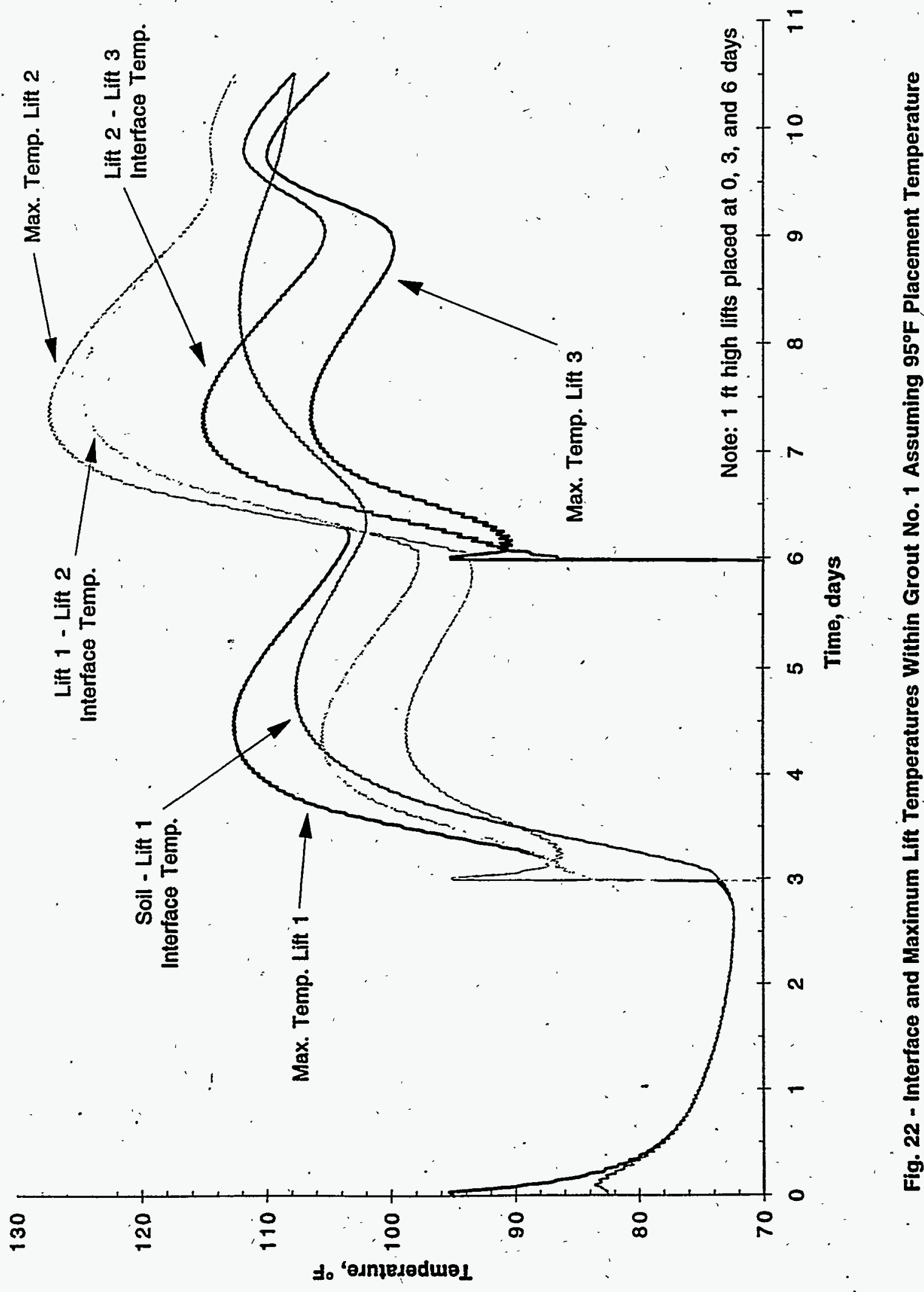




\begin{tabular}{lr} 
APPENDIX "A" & WSRC-TR-97-0102 \\
CTL Tank 20 Reducing Grout Report & $\begin{array}{r}\text { Revision } 0 \\
\text { Page 164 }\end{array}$ \\
\hline
\end{tabular}

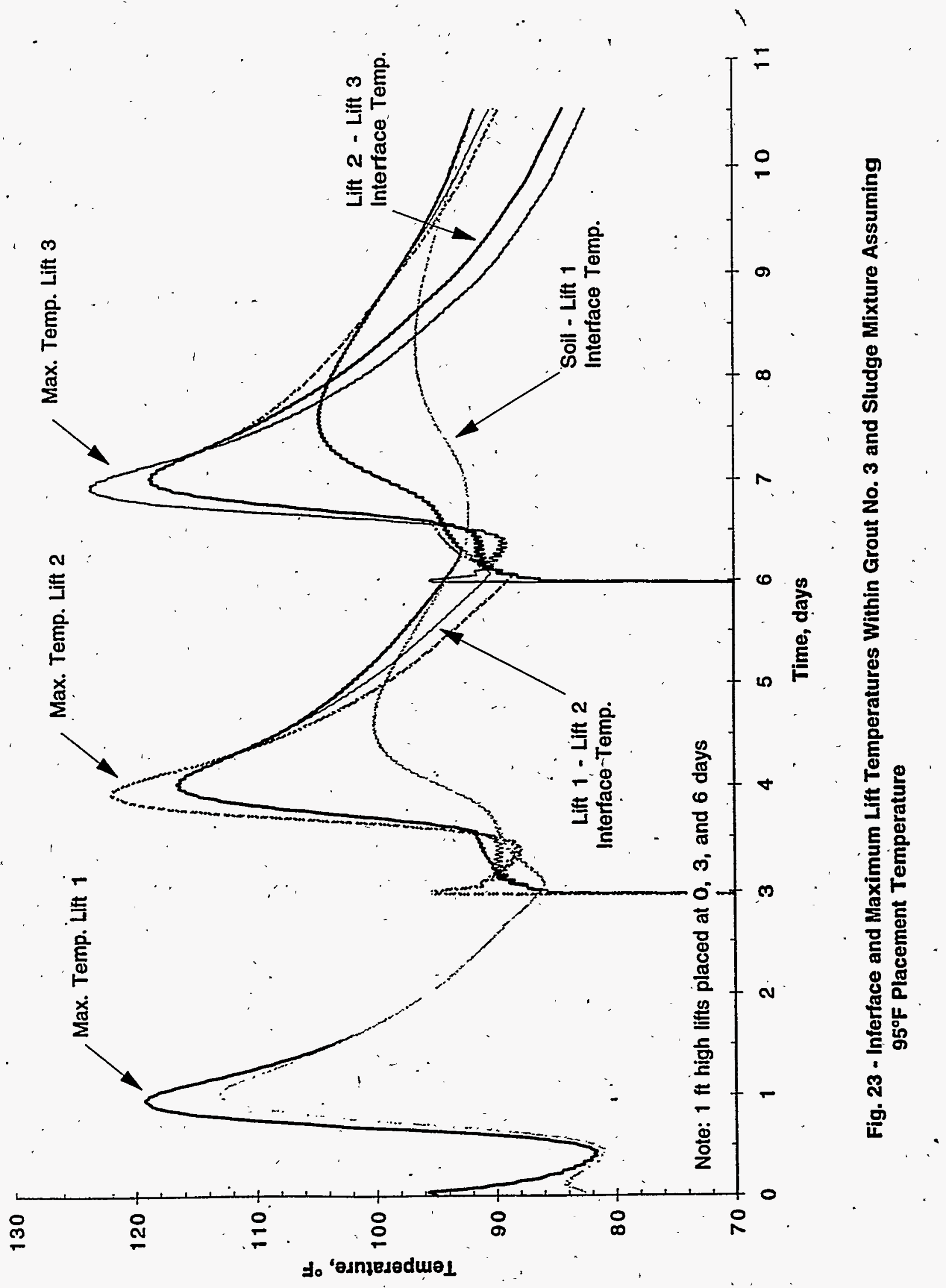




\section{Appendix G}

Heat of Hydration by Conduction Calorimetry 


\section{Appendix G - Heat of Hydration by Conduction Calorimetry}

Zieat of hydration is obtained by conduction calorimetry, which is described, in general terms, in the body of the report in the section titled "Thermal Considerations and Heat of Hydration Tests". The specific details are described in Appendix A, "Procedure for the Conduction Calorimetry Measurement of Heat of Hydration".

The results of the tests showing the rate of heat evolution versus the time in hours on a linear scale are shown in this Appendix. Data for Grout \#1 with and without sludge are shown in Fig. 1, for Grout \#2 with and without sludge in Fig. 2, and for Grout \#3 with and without sludge in Fig. 3. The results indicated all three grouts are substantially retarded with the earliest maximum heat generation occurring for Grout \#3 and the latest for Grout \#1. Complete mixing of sludge and grout accelerated the reaction significantly with the strongest interaction between sludge and Grout \#1. When mixed with sludge, the earliest maximum heat generation occurred with Grout \#1 and sludge and the latest for Grout \#2 and sludge. The details described below are most easily followed by refering to the following figures.

Grout \#1 was dormant for 62 hours during which $23.2 \mathrm{~kJ} / \mathrm{kg}$ heat evolved; maximum heat evolution of $4.54 \mathrm{~kJ} / \mathrm{kg} / \mathrm{hr}$ occurred at 83.9 hours when total heat evolved was $70.3 \mathrm{~kJ} / \mathrm{kg}$. After 112 hours, only $164 \mathrm{~kJ} / \mathrm{kg}$ heat had been generated by hydration. This is in sharp contrast to grout \#1 and sludge which was dormant about 5 hours having released 6.23 $\mathrm{kJ} / \mathrm{kg}$, then the rate increased rapidly to $10.26 \mathrm{~kJ} / \mathrm{kg} / \mathrm{hr}$ at 11.4 hours with cumulative heat release of $45 \mathrm{~kJ} / \mathrm{kg}$. Heat released through 112 hours is roughly estimated as $204 \mathrm{~kJ} / \mathrm{kg}$.

. The data for Grout \#1 are shown in Fig. 1.

Grout $\# 2$ had a dormant period of 16 hours which decreased to 10 hours with sludge; heat evolved up to these times was 19.0 and $22.9 \mathrm{~kJ} / \mathrm{kg}$. Maximum heat evolution occurred at 37.3 hours without sludge at a rate of $4.37 \mathrm{~kJ} / \mathrm{kg} / \mathrm{hr}$ and with sludge at $10.8 \mathrm{~kJ} / \mathrm{kg} / \mathrm{hr}$ after 20.4 hours of hydration. The total amount of heat evolved when the maximum rate occurred was $62.3 \mathrm{~kJ} / \mathrm{kg}$ for the case with no sludge and $79.2 \mathrm{~kJ} / \mathrm{kg}$ with sludge. After 112 hours, the total heat evolved for Grout \#2 alone was $240 \mathrm{~kJ} / \mathrm{kg}$ and it is estimated that $292 \mathrm{~kJ} / \mathrm{kg}$ would evolve for this grout mixed with sludge after 112 hours. Data for Grout \#2 with and without sludge are shown in Fig. 2.

Grout \#3 was dormant for 10 hours during which $9.7 \mathrm{~kJ} / \mathrm{kg}$ of heat was generated and the maximum rate of heat evolution was $4.9 \mathrm{~kJ} / \mathrm{kg} / \mathrm{hr}$ at 32 hours; cumulative heat evolved at this time was $64.1 \mathrm{~kJ} / \mathrm{kg}$. Cumulative heat of hydration after 112 hours was $219.2 \mathrm{~kJ} / \mathrm{kg}$. Heat was normalized to cementitious material and a greater percentage of this mix was cement than in the other grouts (see Table 2). The higher cumulative heat, in part, is due to the higher cement content. When mixed with sludge, Grout \#3 was dormant 7 hours during which $10.7 \mathrm{~kJ} / \mathrm{kg}$ heat had evolved. The rate of heat generated increased quickly to $13.1 \mathrm{~kJ} / \mathrm{kg} / \mathrm{hr}$ at 17.7 hours; the heat evolved during this time was $71.6 \mathrm{~kJ} / \mathrm{kg}$. It is estimated that $289 \mathrm{~kJ} / \mathrm{kg}$ heat would be evolved after 112 hours by the hydration reactions of Grout \#3 mixed with sludge. These data for Grout \#3 are shown in Fig. 3.

The findings were used in calculating the temperature profile in the tank as a function of time, for all three grouts and for all three grouts perfectly intermixed with sludge. These findings are given in Appendix $F$. 


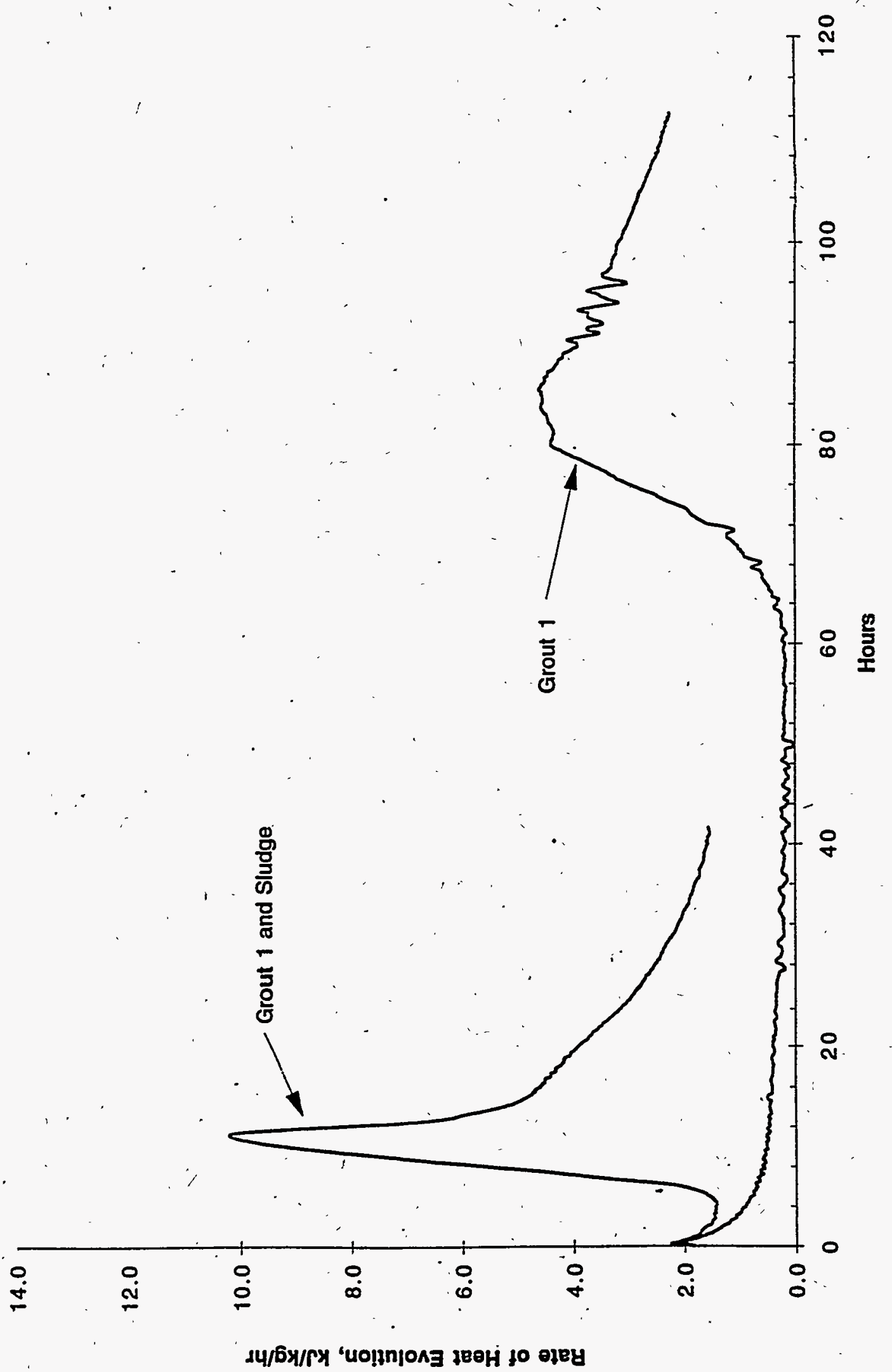

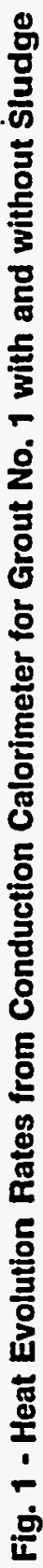




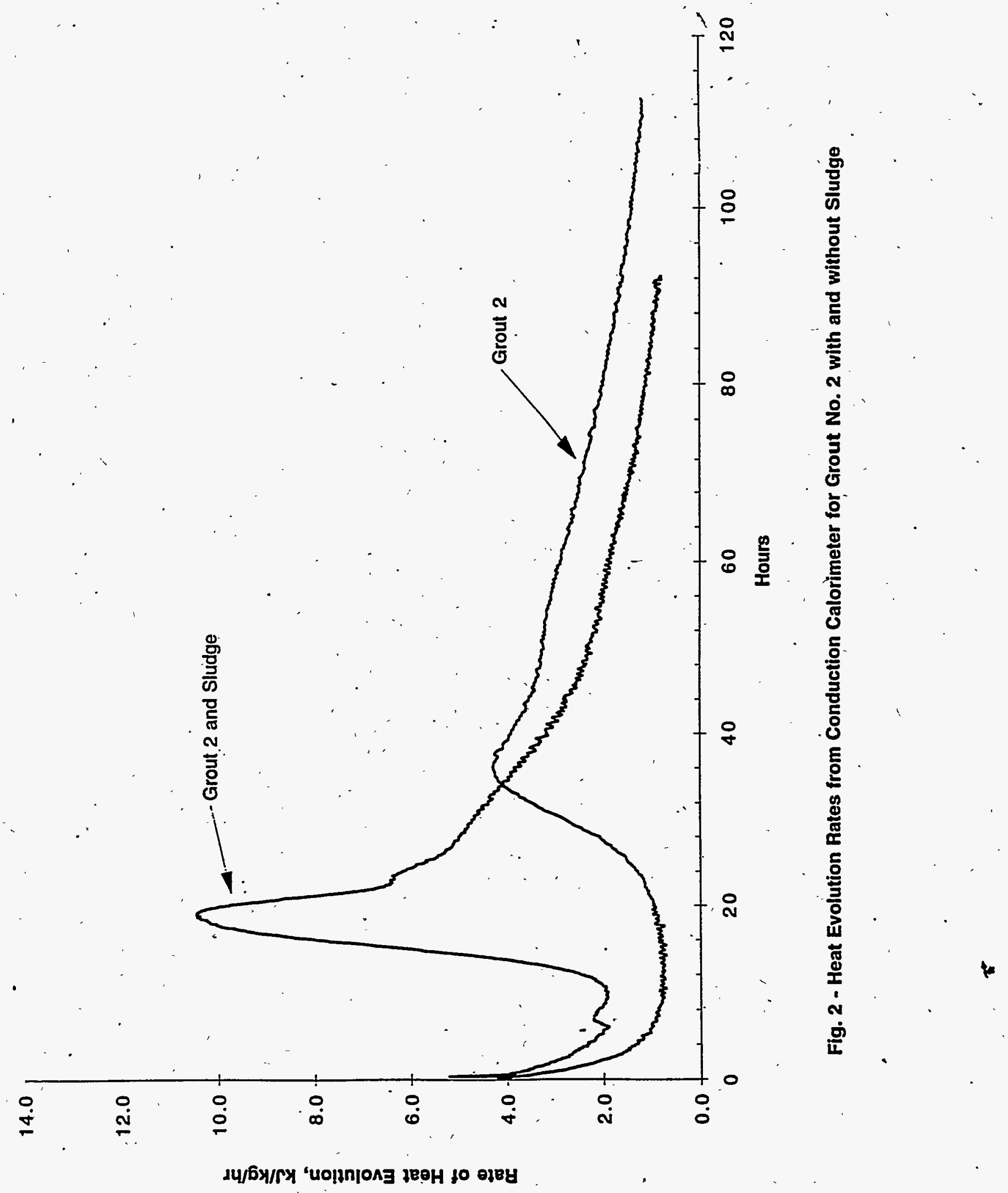




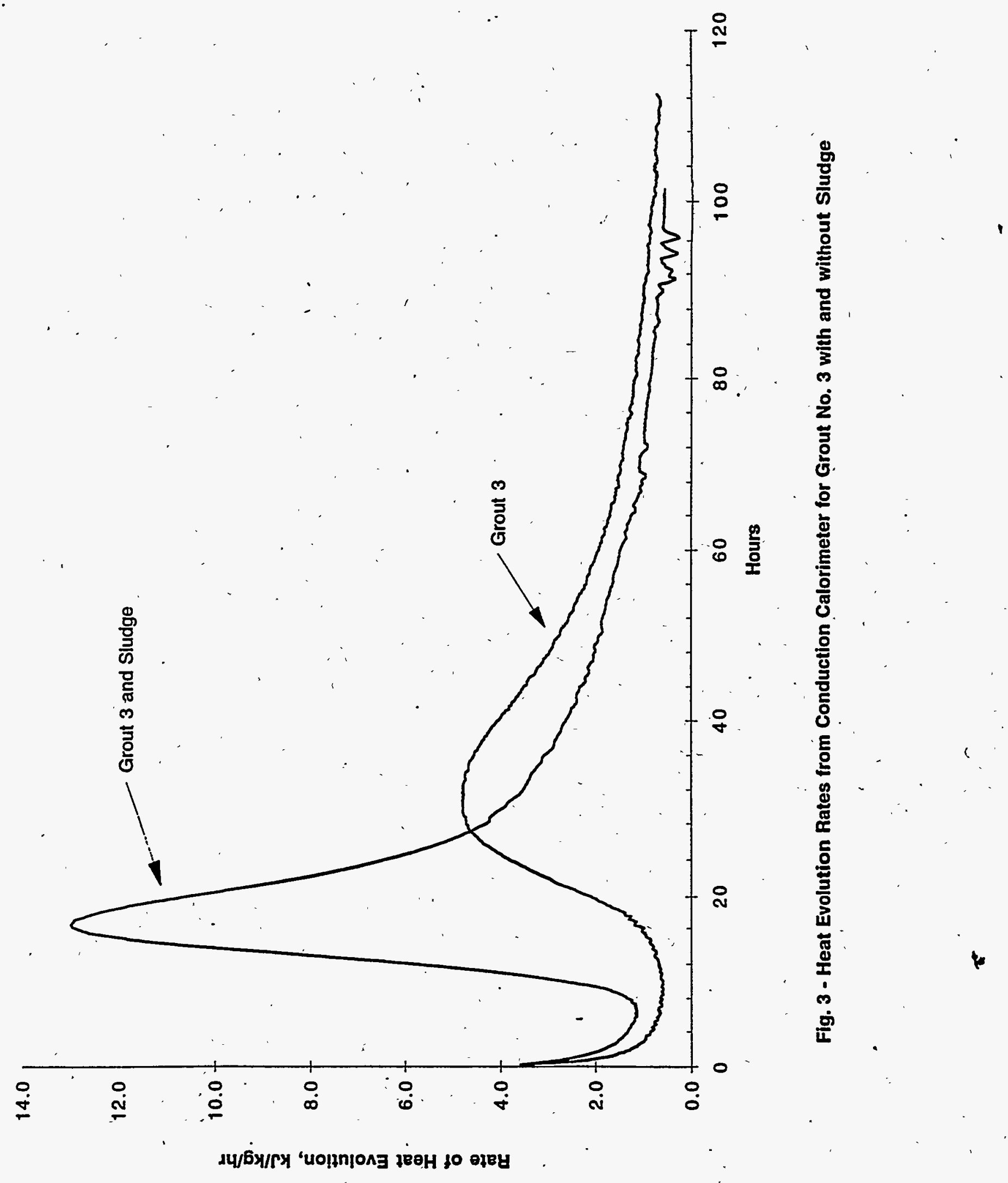


Appendix $\mathrm{H}$

Literature Review, Stabilization of Radionuclides 


\title{
USE OF CEMENTITIOUS SYSTEMS FOR STABILIZING RADIOACTIVE WASTES: A LITERATURE OVERVIEW
}

by

Javed I. Bhatty and F. M. Miller

Construction Technology Laboratories, Inc

Skokie, Ilinois 60077

\begin{abstract}
This report summarizes the findings from literature investigations on the stabilization of commonly known radionuclides in cementitious systems. The cementitious systems studied are pastes, slurries, grouts, mortars, and concretes. The topics covered in the report are the formulations of the cement-based systems,' and the mechanism of stabilization, in terms of the metal interaction with the hydration products calcium silicate hydrate (C-S-H), calcium hydroxide ( $\mathrm{C}-\mathrm{H})$, and ettringite, and in terms of modifications in pore solution chemistry. The degree of stabilization is discussed in terms of metal leachability from the stabilized mass as a function of matrix composition, metal dosage, curing time, nature of leachant, $\mathrm{pH}$, and environmental changes. Selected examples have also been cited as practical scenarios. The impact of interaction of cement and its hydration products with the wastes in the near-field conditions, are also discussed. Particular emphasis is placed on the radionuclides of concern for the present situation and of their surrogates, i.e., $\mathrm{Tc}, \mathrm{Se}, \mathrm{Cs}, \mathrm{Sr}, \mathrm{Pu}, \mathrm{U}, \mathrm{Ce}$, etc.
\end{abstract}

\section{Summary}

The radioactive elements are stabilized in cement matrices by: 1) forming stable hydroxides due to high $\mathrm{pH}$, and 2) incorporation into the calcium silicate hydrate through substitution, , adsorption, or precipitation during hydration. The microstructure of C-S-H gel and its modifications immobilize radioactive species by substituting for $\mathrm{Ca}$ into the lattice.

Several formulations that have been designed to.immobilize commonly found radioactive species, are based on ordinary portland cement (Type I/I), fly ash, and clays, and selected modifying additives. When tested for $\mathrm{Cs}, \mathrm{Cm}, \mathrm{Pu}$, and $\mathrm{Sr}$ leachabifity, the grouts were comparable to the borosilicate glasses. 
Additions of blast furmace slag in cement-clay based grouts has shown improvements in the retention of $\mathrm{Cs}$ and $\mathrm{Tc}$. The selective effect of slag on Tc retention, is its ability to reduce $\mathrm{Tc}(\mathrm{VM})$ to less soluble $\mathrm{Tc}(\mathrm{IV})$ due to the presence of $\mathrm{Fe}^{2+}$ and $\mathrm{Mn}$ in slag. .

Use of other additives such as silica fume, activated carbon, and hydrated lime in the cementbased grouts has also been reported.

When used to contain multiple radioactive species such as $\mathrm{Cs}$, $\mathrm{Sr}$, and $\mathrm{Tc}$, grouts composed of slag cement and portland cement, with bentonite or silica fume behaved independently. Lower liquid-to-cement ratio appeared beneficial. Bentonite improved the retardation of Cs significantly, but silica fume acted adversely.

Addition of hydraulic lime in a slag-based grouts activates "gelation" or setting of the mixes. Addition of lime to slag-fly ash grouts reportedly improved Tc retention.

In certain situations ordinary portland cement and fly ash grouts were marginally acceptable for retention of ${ }^{99} \mathrm{Tc}$. Addition of slag reduced the leachability of Tc by several orders of magnitude.

A summary of the findings on grout formulations, their ability to stabilize various radionuclides in terms of leaching and structural durability of the matrix, reported in this review is given in Table 15.

\section{General Introduction}

Nuclear wastes are generally solidified in cementitious systems prior to disposal in a subsurface environment. The radionuclides contained in the wastes are tied up in the cement system either in the hydration products that are stable at high $\mathrm{pH}$, or they are physicochemically incorporated in the solid matrix via adsorption and precipitation, or by forming other products such as phosphates or carbonates, dependent upon the environment as the system ages. The degree of stability of these species is dependent upon the solubility of the product and the complexation of the radionuclides, and the nature of the environment. The report deals with published work on the subject of cement-based systems used in stabilizing radionuclides, their stability, and leaching habits as the environment changes. The formulations of pastes, grouts, mortars, and concretes used in stabilizing various elements, and data obtained on stability and leachability are used for elucidation of the mechanism of stabilization. 
Cement has not only become a generally accepted primary matrix in stabilizing radioactive wastes, but is also considered for use in other aspects' of repository constructions. Glasser [199?] has reviewed the progress on the use of portland cement and the addition of other cementitious materials in immobilizing radioactive wastes. Supplementary cementitious materials.such as fly ash, blast furnace slag, and silica fume are frequently used to improve the initial packing and fluidity, and reduce permeability, of the stabilizing matrices. Silica fume, however, generally requires a viscosity-reducing admixture to attain acceptable fluidity. The amount of these materials may range up to $70 \%$ for certain fly ashes, $90 \%$ for blast furnace slag, and about $10 \%$ for silica fume for appropriate application. Conditioning aids such as sodium silicates to precipitate heavy metals and to reduce permeability, and organic polymers as "getters" to incorporate tritium are also used as matrix modifiers. Details on the types of supplementary cementitious materials, conditioning aids, and "getters" commonly employed in radioactive waste stabilization, and their primary roles are summarized in Table 1.

\section{Table 1: Supplementary cementitious materials, conditioning} aids, and getters [Glasser, 1992]

\begin{tabular}{|l|l|}
\hline Materials & Applications \\
\hline Fly ash & $\begin{array}{l}\text { Reduces permeability, increases mix } \\
\text { fluidity, reduces initial heat evolution }\end{array}$ \\
\hline Blast furnace slag & $\begin{array}{l}\text { Reduces permeability, increases mix } \\
\text { fluidity, reduces initial heat evolution, } \\
\text { lowers internal Eh }\end{array}$ \\
\hline Silica fume & $\begin{array}{l}\text { Reduces permeability, increases sorption, } \\
\text { reduce segregation, reduces leaching of } \\
\text { calcium }\end{array}$ \\
\hline Superplasticizers & $\begin{array}{l}\text { Reduces water demand, and permeability, } \\
\text { improves flowability }\end{array}$ \\
\hline $\begin{array}{l}\text { Calcium hydroxide and sodium } \\
\text { hydroxide }\end{array}$ & $\begin{array}{l}\text { Conditions borate waste and ensures set, } \\
\text { maintains high pH }\end{array}$ \\
\hline Sodium silicate & $\begin{array}{l}\text { Precipitates heavy metals, reduces } \\
\text { permeability, accelerates hardening }\end{array}$ \\
\hline $\begin{array}{l}\text { Miscellaneous "getters": chemical and } \\
\text { structural }\end{array}$ & $\begin{array}{l}\text { Reduce solubility of specific radioactive } \\
\text { waste species (e.g: Ag for iodine } \\
\text { conditioning) }\end{array}$ \\
\hline Organic polymers & \begin{tabular}{l} 
Reduce permeability, "getter" for tritium \\
\hline
\end{tabular} \\
\hline
\end{tabular}

According to Glasser [1992], the chemical factors associated with cementitious systems in stabilizing wastes become more important at later ages. Cements fumish a matrix that arises from the C-S-H micropore network and its concomitant high surface area. C-S-H gel and 
$\mathrm{Ca}(\mathrm{OH})_{2}$ dominate the chemical properties of the aqueous phase in cement and its blends with cementitious materials. Both $\mathrm{C}-\mathrm{S}-\mathrm{H}$ gel and $\mathrm{Ca}(\mathrm{OH})_{2}$ can undergo microstructural modi?ication when exposed to high temperature environments, which can lead to changes in their properties. Low level wastes are unlikely to emit sufficient radiation to cause significant changes in matrix properties. Moderate-to-high level radiation causes radiolysis in the aqueous phase in the micropores, that can lead to gas evolution causing microstructural stress and eventual degradation of the matrix. Such microcracks probably have very little effect on leaching, because hydrated cement normally contains flaws in the form of microcracks. However, the larger cracks act as channels and promote movement as well as leaching of radioactive wastes.

The role of calcium silicate hydrate, and its modifications in particular, in immobilization of radioactive species was studied by McCulloch et al [1985]. They assessed the immobility of the species by relating to the mineralogy of the calcium silicate hydrates. For instance, tobermorite and xonotlite were studied, because these minerals result from hydrothermal treatment of calcium silicates and are probably thermodynamically stable in cement matrices. Clinoptilolite was studied because of its considerable ion-exchange capacity and high selectivity for radioactive ions difficult to immobilize, such as $\mathrm{Cs}$ and Sr. Portland cement and high alumina cement (HAC) blends with fly ash and blast fumace slag were also studied for comparison. Slags and fly ash did not adsorb Cs to the same extent as clinoptilolite but their reaction with $\mathrm{Ca}(\mathrm{OH})_{2}$ was slower. This property was considered advantageous especially in the HAC-fly ash/slag blends, where the release of $\mathrm{Cs}$ bound in $\mathrm{Ca}(\mathrm{OH})_{2}$ could be effectively suppressed in the pore system. Tobermorite and xonotlite appeared stable in the cement matrix to potentially improve $\mathrm{Cs}$ immobilization by substituting for $\mathrm{Ca}$ into the lattice.

\section{Formulations of Cementitious Matrices}

The design of a durable radioactive waste system is considered at the fabrication stage. The raw materials: cement, supplementary cementitious materials, matrix modifiers, "getters", and the aggregates, need to be properly selected; specified, and formulated specific to any particular application. The potential impact of waste stream constituents, active as well as inactive, needs to be assessed for appropriate application and peak performance. There are several reports that deal with the design and formulation of cement-based systems to stabilize the radioactive species. 
Moore et al. [1976] have evaluated the formulation of a cementitious grout to immobilize a number of nuclides including $\mathrm{Cs}, \mathrm{Cm}, \mathrm{Pu}$, and $\mathrm{Sr}$ contained in a waste. The grout was prepi..ed by combining the predetermined amounts of dry solids with desired volumes of wastes. The solids consisted of a mixture of of Type I portland cement, fly ash, and clay (Attapulgite-150 and Grundite). Modifying additives such as sugar (delta gluconolactone or CFR-1) as a retarder, and tributylphosphate (TBP) for easy release of air and to prevent foaming, were also added. The grout composition is given in Table 2, as follows:

Table 2.: Grouts containing cement, fly ash, clays, retarder, and and anti-foaming additive for stabilizing $\mathrm{Cs}, \mathrm{Pu}$, and $\mathrm{Sr}$ (Moore et al, 1976)

\begin{tabular}{|c|c|}
\hline Components & Mass (\%) \\
\hline Cement & 15.33 \\
\hline Fly ash & 15.33 \\
\hline Attapulgite-150* & 6.13 \\
\hline Grundite** & 3.07 \\
\hline CFR-1 (sugar) & 0.02 \\
\hline TBP (tributylphosphate) & 0.03 \\
\hline Waste salts (containing Cs, Cm, Pu, and Sr) & 6.11 \\
\hline H $\mathrm{H}_{2} \mathrm{O}$ & 53.62 \\
\hline
\end{tabular}

* Attapulgite-150 is a trade name of a clay product from polygroskite group of clay minerals. ** Grundite is also a trade name of a clay product from the illite group of clay minerals from Grundy County, Illinois.

The grout was placed, cured, and tested for $\mathrm{Cs}, \mathrm{Cm}, \mathrm{Pu}$, and Sr leachability. The leachability performance was found comparable to those of borosilicate glasses. However, with proper adjustments of the mix formulations, it was possible to further improve the desired properties.

Brodda [1988] designed a number of cement-based slurries to stabilize medium level wastes containing Tc using portland cement (OPC), blast furnace siag cement (BFSC), and high alumina cement (HAC) with and without the use of bentonite and microsilica. In the first trial, cements-only slurries were used. Separately, $5 \%$ bentonite was added to all cements, and $15 \%$ and 30\% microsilica was added to portland cement and high alumina cements only. The compositions of the slurries are shown in Table 3. A quinary brine solution (referred as $\mathrm{Q}$ brine) and distilled water were used as leachants. The Q-brine was composed of $\mathrm{NaCl}-1.5 \%$, 
$\mathrm{KCl}-3.6 \%, \mathrm{MgCl}_{2}-24.6 \%, \mathrm{MgSO}_{4}-2.3 \%$, and $\mathrm{H}_{2} \mathrm{O}-68.0 \%$ by weight. The-water-to cement ratio was adjusted to 0.47 .

- Tible 3. Slurries containing cement, alumina cement, slag, clay, and microsilica to stabilize Tc (Brodda, 1988)

\begin{tabular}{|c|c|c|c|c|}
\hline \multicolumn{5}{|c|}{ Combination by Mass \% } \\
\hline Components & $\begin{array}{c}\text { OPC or BFSC } \\
\text { or HAC }\end{array}$ & $\begin{array}{c}\text { OPC or BFSC } \\
\text { or HAC }\end{array}$ & OPC or HAC & OPC or HAC \\
\hline Cements & 68 & 64.5 & 57.8 & 47.6 \\
\hline Bentonite & - & 5 & - & - \\
\hline Microsilica & - & - & 15 & 30 \\
\hline $\begin{array}{c}\text { Waste solution } \\
\text { containing Tc }\end{array}$ & 32 & 30.4 & 27.2 & 22.4 \\
\hline
\end{tabular}

The leachability of $\mathrm{Tc}$ was investigated. Data on ${ }^{137} \mathrm{Cs}$ and ${ }^{36} \mathrm{Cl}$ were used for comparative studies. With high alumina cement-bentonite slurry gave unfavorable results. High alumina cement itself performed somewhat better than the high alumina cement-bentonite slurry. Portland cement with or without bentonite showed a medium leachability. The best results were obtained with the blast furnace slag cement where the leachability was below $0.1 \%$.

In subsequent studies, Brodda and Mingxia [1989] used cementitious systems composed of blast furnace slag cement, portland cement, with bentonite or Microsilica (see Table 4), to.

Table 4. Cement slurries containing slag/cement, clay/microsilica, acrylic resin, and sulfides for Cs, Sr, and Tc stabilization [Brodda and Mingxia, 1989]

\begin{tabular}{|c|c|c|c|c|c|c|}
\hline \multicolumn{7}{|c|}{ Compositions, mass \% } \\
\hline Components & Slurry 1 & Slurry 2 & Slurry 3 & Slurry 4 & Slurry 5 & Slurry 6 \\
\hline Slag or cement & 68.0 & 66.3 & 64.6 & 64.6 & 63.6 & 69.0 \\
\hline $\begin{array}{c}\text { Waste solution or } \\
\text { water }\end{array}$ & 32.0 & 31.2 & 30.4 & 30.2 & 30.0 & 24.1 \\
\hline $\begin{array}{c}\text { Bentonite or } \\
\text { Microsilica }\end{array}$ & - & 2.5 & 5.0 & 5.0 & & \\
\hline Sulfide ion & - & - & & 0.17 & - & - \\
\hline PLEXILITH 850 & - & 6 & 5 & - & 6.4 & 6.9 \\
\hline $\begin{array}{c}\text { Liquid/cement } \\
\text { ratios }\end{array}$ & 0.47 & 0.47 & 0.47 & 0.47 & 0.47 & 0.35 \\
\hline
\end{tabular}


immobilize chlorine, cesium, strontium, and technetium from intermediate level liquid waste (ILLW). Acrylic resin (PLEXILITH 850) and $\mathrm{Na}_{2} \mathrm{~S}$ used as additives.' In some cases, portl: . 1d cement was also used. The liquid-to-cement ratio was mostly 0.47 except for one slurry where the liquid-to-cement ratio was 0.35 .

Bentonite reduced the rate of leaching of $\mathrm{Cs}$ significantly, but had no significant effect on $\mathrm{Cl}$, Sr and Tc. Microsilica hindered the stabilization of $\mathrm{Cs}$, but has no effect on $\mathrm{Cl}, \mathrm{Sr}$, and $\mathrm{Tc}$, release. Sulfide was expected to reduce the leachability of $\mathrm{Tc}$ by forming insoluble $\mathrm{Tc}_{2} \mathrm{~S}_{7}$. However, no significant effect was observed, because either $\mathrm{Tc}_{2} \mathrm{~S}_{7}$ did not form at the $\mathrm{pH}$ of the slurry or, because of the solubility competition, insoluble Tc also formed in the absence of sulfide ions. Acrylic resin did not reduce the leachability of $\mathrm{Cs}$ significantly. A liquid-tocement ratio of 0.35 , instead of 0.47 , improved the retention of $C s$ by a factor of $1.5-4$, which may be due to a reduction of porosity in the specimen. Leachability behavior of the nuclides is discussed later in the leaching section of this report.

Gilliam et al [1990] used cement-based grouts to stabilize mixed low-level radioactive and chemical hazardous wastes. Ordinary portland cement and fly ash grouts were marginally acceptable for retention of radioactive ${ }^{99} \mathrm{Tc}$, which was present in the waste as the highly. mobile pertechnetate anion. Examples of grout compositions are given in Table 5.

Table 5. Grouts containing fly ash and blast furnace slag for stabilizing Tc (Gilliam, 1990)

\begin{tabular}{|c|c|c|c|}
\hline Components & \multicolumn{3}{|c|}{ Mass \% } \\
\hline Sludge containing Tc & .13 .9 & 40.0 (wet) & 30.0 \\
\hline Water & 36.1 & - & 20.0 \\
\hline Portland cement (Type I/I) & 24.0 & 20.0 & 24.6 \\
\hline Fly ash (Class F). & 24.0 & 20.0 & 24.6 \\
\hline Blast furnace slag & - & 20.0 & - \\
\hline Reducing additive & $2.0\left(\mathrm{FeSO}_{4}\right)$ & - & $.0 .9\left(\mathrm{Na}_{2} \mathrm{~S}\right)$ \\
\hline
\end{tabular}

The addition of ground blast furnace slag to the grout reduced the leachability of Tc by several orders of magnitude. The selective effect of slag is believed to be due to its ability to reduce 
$\mathrm{Tc}$ (VII) to the less soluble $\mathrm{Tc}(\mathrm{IV})$ species. The use of other reducing additives (e.g., $\mathrm{Na} 2 \mathrm{~S}$, $\mathrm{Fe}^{2+}$, etc.) also improved the $\mathrm{Tcc}$ retention.

In earlier similar studies, Bostick et al [1988] also used ground slag in cement-based grouts to stabilize $\mathrm{Tc}$ from toxic wastes that also contained $\mathrm{Pb}, \mathrm{Cd}, \mathrm{U}$, and $\mathrm{Ni} .{ }^{99} \mathrm{Tc}$ was present in the waste as the highly mobile pertechnetate anion. By increasing the proportion of slag, the effective diffusivity of $\mathrm{Tc}$ from the grout was significantly reduced. The slag reduces $\mathrm{Tc}(\mathrm{VII})$ to the less soluble Tc(IV) species. Other reducing admixtures such as $\mathrm{Na}_{2} \mathrm{~S}, \mathrm{Fe}^{2+}$, and powdered Fe, also improved Tc retention. Bums et.al [1991], also emphasized the importance of slag addition in stabilizing $\mathrm{Tc}(\mathrm{VII})$ in the presence of gamma radiolysis of $\mathrm{Np}(\mathrm{IV})$. Solutions of $\mathrm{Tc}(\mathrm{VII})$ are reduced to $\mathrm{Tc}$ (IV) by gamma irradiation when in contact with slag-portland cement mixture under an inert atmosphere, but not when in contact with fly ashportland cement mix.

Langton [1987] evaluated a slag-based waste form to stabilize low level salt solutions containing ${ }^{90} \mathrm{Sr},{ }^{99} \mathrm{Tc}$, and ${ }^{137} \mathrm{Cs}$. Lime or cement was added to activate gelation or setting of the mixes. As a result of improved microstructure, the blend gave reduced leaching as compared to portland cement-based mixes. Pumpable slurry could also be made that solidifies after emplacement through an engineered vault. $\mathrm{Cr}$ and $\mathrm{Tc}$ were less leachable from slag.mixes than cement-based waste form because they were chemically reduced to a lower valence state by the presence of $\mathrm{Fe}^{2+}$ or $\mathrm{Mn}^{2+}$ in the slag and precipitated as relatively insoluble phases, such as $\mathrm{Cr}(\mathrm{OH})_{3}$ and $\mathrm{TcO}_{2}$. The composition of the slag-based form, also known as the saltstone, is given in Table 6 .

Table 6. Slag-based form containing fly ash, and lime or cement for stabilizing Sr, Tc, and Cs (Langton, 1987).

\begin{tabular}{|l|l|}
\hline Components & Mass \% \\
\hline Slag & 25 \\
\hline Fly ash (Class F) & 25 \\
\hline Hydraulic lime or portland cement & 4 \\
\hline Salt solution & 46 \\
\hline Water & 31.4 \\
\hline
\end{tabular}


Tallent et al [1988] immobilized $\mathrm{Tc}$ and nitrate in cement-based grouts. The grounds were mixed with $\mathrm{Tc}$ laden simulated wastes, cured at $60^{\circ} \mathrm{C}$ under moist conditions for 28 days and testec for Tc post-wash leachability. The grouts used in the investigations are given in Table 7.

Table 7. Grouts containing cements, slag, fly ash, lime and clay to stabilize Tc (Tallent et al, 1988)

\begin{tabular}{|c|c|c|c|c|}
\hline B.F. Slag & $\begin{array}{c}\text { Type I/I } \\
\text { Cement }\end{array}$ & $\begin{array}{c}\text { Class F fly } \\
\text { Ash }\end{array}$ & $\begin{array}{c}\text { Lime } \\
\text { Ca(OH) } 2\end{array}$ & $\begin{array}{c}\text { Pottery } \\
\text { Clay }\end{array}$ \\
\hline 70 & 25 & - & - & 5 \\
\hline 49.8 & 43.2 & - & - & 7 \\
\hline 75 & 20 & - & - & 5 \\
\hline 100 & - & - & - & - \\
\hline 90 & 10 & - & - & - \\
\hline 95 & - & - & 5 & - \\
\hline 88 & - & - & 5 & 7 \\
\hline 47.5 & - & 47.5 & 5 & - \\
\hline 47.5 & - & 5 & 5 & 7 \\
\hline 38 & 10 & 47 & 5 & - \\
\hline 38 & 10 & 40 & 5 & 7 \\
\hline
\end{tabular}

In general, Tc post-wash leachability decreased with grout fluid density, blended ground slag content and increased mix ratio. Blends with $100 \%$ slag, and $47.5 \%$ slag: $47.5 \%$ fly ash:5\% lime gave the best results as their Tc leachability indices were $>9.0$ and 8.6 to 9.4 respectively.

Siegrist et al [1996] conducted a full-scale field demonstration to evaluate a grout for in situ solidification of a RCRA land treatment site. The substrate silt and clay deposits were contaminated not only with $500 \mathrm{ppm}$ of trichloroethylene and other halocarbons, but also with low levels of $\mathrm{Pb}, \mathrm{Cr},{ }^{235} \mathrm{U}$, and ${ }^{99} \mathrm{Tc}$. The composition of the grout is given in Table 8 . 
Table 8. Grouts containing cement, fly ash, activated carbon, and retarder for stabilizing U, Tc, etc. (Siegrist et al, 1996)

\begin{tabular}{|c|c|}
\hline Components & Mass \% \\
\hline Type I portland cement & 41.3 \\
\hline Fly ash & 10.4 \\
\hline Activated carbon & 17.0 \\
\hline Retarder & $<0.10$ \\
\hline Water & 31.4 \\
\hline
\end{tabular}

Some difficulties were realized in subsurface injection to attain uniform grout distribution in the test region. Solidification occurred rapidly, though strength differed within the region because of volume expansion. Leaching was non-detectable to acceptable low levels for all metals.

Morgan and Bostick [1992] evaluated a series of grout formulations to encapsulate organic resins containing radioactive impurities. The formulations are shown in Table 9 . The grouts incorporated the resins with a moderate waste loading (approximately 40\%) and showed good integrity, as judged by freezing/thawing and immersion testing.

Table 9. Grouts containing slag, clay, amorphous silica, fly ash, and silica fume combinations (Morgan and Bostick, 1992)

\begin{tabular}{|c|c|c|c|c|c|c|c|}
\hline \multicolumn{9}{|c|}{$\cdot$} & \multicolumn{7}{c|}{ Blend Compositions, mass \% } \\
\hline Components & $\# 1$ & $\# 2$ & $\# 3$ & $\# 4$ & $\# 5$ & $\# 6$ & $\# 7$ \\
\hline Blast furnace slag & 75 & 69 & 70 & 75 & 69 & 84.5 & 90 \\
\hline Type I/II cement & 10 & 10 & 10 & 10 & 10 & 9.5 & 10 \\
\hline Bentonite clay & 15 & 15 & - & - & 15 & - & - \\
\hline Attapulgite clay & - & - & 15 & 15 & - & - & - \\
\hline Amorphous silica & - & 6 & 5 & - & - &.- & - \\
\hline Class F fly ash & - & - & - & - & 6 & - & - \\
\hline Silica fume & - & - & - & - & - & 6 & - \\
\hline
\end{tabular}

Allan and Kukacka [1996] also tested a number of grouts for in situ application as barriers for hazardous wastes containing $\mathrm{Pb}, \mathrm{Cr},{ }^{235} \mathrm{U}$, and ${ }^{99} \mathrm{Tc}$ (see Table 10 ). 
Table 10. Grouts with clay and silica fume (Allan and Kukacka, 1996)

\begin{tabular}{|c|c|c|c|c|}
\hline \multicolumn{5}{|c|}{ Grout Compositions, $\mathbf{~ k g} / \mathrm{m}^{3}$} \\
\hline Somponents & Grout 1 & Grout 2 & Grout 3 & Grout 4 \\
\hline Cement & 769 & 832 & 749 & 1361 \\
\hline Bentonite clay & 19 & 20 & 17 & 12 \\
\hline Silica fúme & - & - & 83 & - \\
\hline Sand & 922 & 832 & 832 & - \\
\hline Water & 384 & 399 & 416 & 544 \\
\hline
\end{tabular}

Optimization of the physical and mechanical properties of these grouts in terms of permeability, leach resistance, strength, and shrinkage crácking was achieved using various mix proportions. This paper emphasized the physical properties of the grouts, as opposed to leachability criteria.

Henson et al [1991] tested two grouts containing blast furmace slag, ordinary portland cement, and clays to encapsulate Tc-laden beaded ion exchange resin. The formulations are given in Table 11.

Table 11. Grouts containing slag, cement, and clays to stabilize Tc (Henson et al, 1991)

\begin{tabular}{|c|c|c|}
\hline Components & Grout 1 (mass \%) & Grout 2 (mass \%) \\
\hline Blast furnace slag & 75 & 75 \\
\hline Portland cement & 10 & 10 \\
\hline Bentonite clay & 15 & - \\
\hline Attapulgite clay & - & 15 \\
\hline
\end{tabular}

The grout mixture containing $75 \%$ blast furnace slag, $10 \%$ ordinary portland cement and $15 \%$ Bentonite clay showed poor wetting-drying durability behavior. However, the grout with similar formulation but containing 15\% Attapulgite clay exhibited good performance.

Vejmelka et al [1990] optimized formulation of cement-based slurries to prepare waste forms for cementing low- and intermediate-level wastes. The investigations included the dependence of viscosity, bleeding, setting time, and hydration heat on the waste cement slurry. composition. From the process requirements, portland cements gave the best mixtures for cementation. Mixtures with cement showed a lower tendency to bleed and lower viscosity than 
did the mixtures with blast furnace slag cement or pozzolanic cement. Higher heat of hydration helped in enhanced cementation as compared to slag-based mixtures. The studies on the interaction of the waste forms with aqueous solutions included the determination of the Cs or $\mathrm{Sr}$ reicase, corrosion resistance, and the release of actinides as a function of cement type, additives, overall composition setting time, and sample size.

Benischek et al [1993] reported the use of clay materials as fillers in the repository to determine the $\mathrm{K}_{\mathrm{d}}$ values for safety analysis in site studies. Two Austrian clays and various types of naturally occurring and activated bentonites were used to test the sorption behavior for ${ }^{137} \mathrm{Cs}$ and ${ }^{85} \mathrm{Sr}$. The $\mathrm{Cs}$ and $\mathrm{Sr}$ concentrations were varied between $10^{-3}$ and $10^{-5} \mathrm{M}$ in experiments with the Austrian clays to determine the effects of the concentrations.

Barnes et al [1986] made use of both ordinary portland and high alumina cements and their modifications by adding amorphous silica to make composites for nuclear waste forms. The silica-adjusted composites were chemically more stable than those made with as-received cements. Leach rates were lower in the case of the adjusted cements for $\mathrm{Rb}, \mathrm{Cs}, \mathrm{Ca}, \mathrm{Sr}, \mathrm{Ba}$, $\mathrm{La}, \mathrm{Ce}, \mathrm{Nd}, \mathrm{Gd}, \mathrm{Al}$, and $\mathrm{Si}$. Only $\mathrm{Na}$, in the case of both portland and calcium aluminate cements, and $\mathrm{Mg}$ and $\mathrm{U}$ in the case of calcium aluminate cements, had greater leach rates in adjusted cements.

Aattbek et al [1992] pointed out the importance of sand grain distribution on the required properties of mortars such as fluidity, homogeneity, compaction, and shrinkage. A smaller sand-void ratio required reduced cement paste resulting in lower heat of hydration, reduced shrinkage and less cracking, lower water-to-cement ratio and consequently lower permeability. It also increased point-to-point contact and improved material homogeneity.

\section{Stabilizing Mechanism}

Various researchers have come up with different explanations as to the mechanism of radionuclide stabilization in cementitious matrices. Their conclusions are based on the systems they studied; the composition of matrices, experimental parameters, and the curing conditions they used. Generally, the radioactive elements such as $\mathrm{Th}, \mathrm{U}, \mathrm{Np}, \mathrm{Pu}, \mathrm{Am}, \mathrm{Tc}, \mathrm{Nb}, \mathrm{Sr}, \mathrm{Cs}$ etc, are stabilized in cement matrices by: 1) forming discrete hydroxides due to high pH caused by portlandite, 2) incorporation into a solid matrix (most likely the calcium silicate hydrate) through a combination of precipitation, adsorption, or substitution during cement hydration, or 
3) forming a variety of other solid products such as phosphates and carbonates depending upon the environments as the hydration proceeds [Serne et al, 1996].

Bames et al [1986], demonstrated that the hydration products, calcium silicate hydrate (C-S-H) gel or C-S-H gel + silica, and tobermorite are responsible for the encapsulation and reduced leachabilities of radionuclides. The point was made by making use of both portland and calcium aluminate cements and their modifications with amorphous silica additions. The silicaadjusted composites were chemically more stable than the as-received cement. In the case of portland cement, the amorphous silica reacted with excess portlandite to produce C-S-H gel or C-S-H gel + silica at low temperatures, and to obtain tobermorite at equilibrium at temperatures above ambient. In the case of high alumina cement, the objective was to be in equilibrium with more silica-rich phases. As previously noted, the adjusted cements gave lower leach rates for most elements. Only $\mathrm{Na}$, in the case of both portland and high alumina cements, and $\mathrm{Mg}$ and $U$ in the case of high alumina cement, had greater leach rates in adjusted cements.

Atkins et al [1990] also demonstrated the adsorption of U onto the C-S-H as the uranyl ion. However, higher loadings (corresponding to uranium/calcium ratios of 0.75 to 2) adversely affected the formation of $\mathrm{C}-\mathrm{S}-\mathrm{H}$ or exceeded its immobilization capacity. Two phases can be solubility-limiting for uranium: uranophane $\left[\mathrm{Ca}\left(\mathrm{UO}_{2}\right)_{2}\left(\mathrm{SiO}_{2}\right)(\mathrm{OH})_{2} .5 \mathrm{H}_{2} \mathrm{O}\right]$ and hydrated calcium uranyl oxide [ $\left.\mathrm{Ca}_{2} \mathrm{UO}_{5} \cdot(1.2-1.7) \mathrm{H}_{2} \mathrm{O}\right]$. At high free $\mathrm{Ca}\left(\mathrm{OH}_{2}\right.$ contents, the formation of becquerelite $\left[\mathrm{CaO} .6 \mathrm{UO}_{3} .11 \mathrm{H}_{2} \mathrm{O}\right]$ also occurred.

According to Wu et al [1991], Cs partially replaces Ca in the C-S-H gel. Shi Caijun et al [1991] reported that a variety of strontium silicate and strontium silicate hydrates are formed when $\mathrm{Sr}$ is stabilized in cement matrices. $\mathrm{SrO} \cdot \mathrm{SiO}_{2}, \mathrm{SrO} \cdot \mathrm{SiO}_{2} \cdot 0.5 \mathrm{H}_{2} \mathrm{O}, 3 \mathrm{SrO} \cdot \mathrm{SiO}_{2} \cdot 2 \mathrm{H}_{2} \mathrm{O}$, and $3 \mathrm{SrO}^{2} \cdot 2 \mathrm{SiO}_{2} \cdot 3 \mathrm{H}_{2} \mathrm{O}$ could form at $4230 \mathrm{~K}$ by hydrothermal reaction at different molar ratios of $\mathrm{SrO} / \mathrm{SiO}_{2}$ and depending upon the type of $\mathrm{SiO}_{2}$ used. Sr could also replace $\mathrm{Ca}$ in $\mathrm{C}-\mathrm{S}-\mathrm{H}$. Merz et al [1986], found that the fixation of $\mathrm{Cs}$ and $\mathrm{Sr}$ in cement-based systems results from their uniform distribution in the gelatinous-filled pore spaces and the degree of sorption on selected additives, and more importantly on the porosity of the cementitious products.

Sorption and leaching of Cs in a system containing fly ash, blast furnace slag, tobermorite, xonolite, and clinoptilolite differs with different additives [McCulloch et al, 1985]. Fly ash and blast furnace slag do not sorb $C$ s to the same extent as clinoptilolite. While slags, fly ash, and clinoptilolite undergo reactions at different rates, tobermorite and xonolite are stable in cement. Nishi et al [1992] examined active silica for stabilizing Cs and compared the results with those 
for slag cement, silica fume, crushed cement-glass, and synthetic zeolite. Active silica showed. pozzolanic activity in the saturated $\mathrm{Ca}(\mathrm{OH})_{2}$ solution similar to that of silica fume, and formed C-S- $-\mathrm{S}$ that fixes $\mathrm{Cs}$, and reduces $\mathrm{Cs}$ leaching ratio to below $1 / 10$ of that without reactive silica.

Morgan et al [1987] determined that the actinides U, Np, Pu and Am sorbed extensively on cements as compared to bentonites and polyester resin. The sorptive behavior was investigated under air-saturated conditions by batch sorption experiments. The sorption was 10-100 times . greater for the cements studied than the bentonite or the resin. Desorption studies identified bentonite as an ion-exchanger whereas some of the cements and the polyester resin may sorb by irreversible chemisorption.

Hoeglund et al [1986] illustrated the effects of cement matrix composition on the sorption behavior of the radionuclides. The sorption of actinides was high in all the concrete systems studied. Generally, the sorption of calcium was low, due to the low exchange capacity of the cement and the high concentration of competing cations in the pore water. The differences among the various concrete systems were generally minor in terms of their sorbing capacities.

According to Lanza et al [1985], resistance to the release of a radioactive element in a waste form is limited not by the waste matrix degradation, but by the solubility limit of the different species containing such an element. The most important parameters seemed to be the concentration of complexing agents in the water surrounding the waste form, the $E_{h}$ of the solution, and the $\mathrm{pH}$. The predominate species of $\mathrm{U}$ in equilibrium with $\mathrm{UO}_{2}$ were $\mathrm{UO}_{2}\left(\mathrm{CO}_{3}\right)_{3}$ and $\mathrm{U}(\mathrm{OH})_{5}$. As reported by Atkins et al [1990], U(VI) appeared stable as the hydrous oxide, $\mathrm{UO}_{3} \cdot \mathrm{nH}_{2} \mathrm{O}$, in alkaline solution. But in the presence of $\mathrm{Ca}$ and $\mathrm{Si}$, as in cement, a series of uranium solubility limiting phases developed. These appeared to be uranophane, $\mathrm{Ca}\left(\mathrm{UO}_{2}\right)_{2}\left(\mathrm{SiO}_{3}\right)_{2}(\mathrm{OH})_{2} .5 \mathrm{H}_{2} \mathrm{O}$, and a hydrated calcium uranyl oxide, $\mathrm{Ca}_{2} \mathrm{UO}_{5}(1.2-1.7) \cdot \mathrm{H}_{2} \mathrm{O}$. At high free $\mathrm{Ca}(\mathrm{OH})_{2}$, becquerelite $\left(\mathrm{CaO} \cdot 6 \mathrm{UO}_{3} \cdot 11 \mathrm{H}_{2} \mathrm{O}\right)$ was also noted. Other as-yet-incompletely characterized phases may also occur because of high $\mathrm{pH}$. Uranium may also be reduced to its lower valency states $\left(U^{4+}, U^{5+}\right)$ if reducing conditions prevail due to the presence of blast furnace slag-cement blends or steel reinforcement.

Given that the cement hydrates are regarded as the sole products for encapsulating the 'radioactive waste species, Grutzeck et al [1984] studied the chemistry of calcium aluminate hydrates and Stratling's compound as the common cement hydrates as low-temperature, inexpensive host phases for isolating radioactive-waste species. An I-containing analog of calcium monosulfoaluminate hydrate $\left(\mathrm{C}_{3} \mathrm{~A} \cdot \mathrm{CaI}_{2} \cdot \mathrm{xH}_{2} \mathrm{O}\right)$ was also identified as a possible host 
phase. $\mathrm{CsOH}$ was added to formulations in the neighborhood of Stratling's compound, in order to establish phase relations and identify the fixation ability of Stratling's compound and its assiciated hydrates.

Barnes et al [1982] demonstrated the stability of $\mathrm{Sr}$ and $\mathrm{I}$ to be a combination of dissolution and diffusion mechanism in a cement-based system. The Sr radiophase was Sr-powellite and the I radiophase was I-sodalite. Sr-powellite leached incongruently indicating a combination of dissolution and diffusion-controlled exchange of $\mathrm{Ca}$ for Sr. I-sodalite leaching data indicated diffusion as dominant at short times and dissolution as dominant at long times.

Atkins et al [1990] reviewed the predictive capability of cement-based composites for radioactive waste stabilization. Considerable progress has been made in modeling of cementbased systems in terms of $\mathrm{pH}, \mathrm{E}_{\mathbf{h}}$, and of element partition between solid and aqueous phases. The behavior of model radioactive waste elements $(I$ and $U$ ) indicates that both sorption and precipitation occur, where U(VI) forms solubility-limiting compounds, e.g., uranophane. Still, the present data are inadequate to predict many cement-waste stream interactions. Future progress is likely to rely heavily on additional data base. Progress is underway to predict the impact of $\mathrm{CO}_{2}$, a common groundwater component, on the performance of cement systems. Also, the repository environment will condition chemical exchanges in cement-based systems.

Brownsword et al [1990] studied the solubility of uranium (IV) in a number of simulated pore waters from repository backfill concretes, and compared it to solubilities in solutions of $\mathrm{Ca}(\mathrm{OH})_{2}$ and $\mathrm{NaOH}$. The sorption of uranium was also studied on a portland cement with a slag filler. The same cement was hydrothermally treated to simulate the temperature conditions in the repository and the product used for comparative studies. The aqueous concentration of uranium over the uranates formed in the presence of $\mathrm{Ca}(\mathrm{OH})_{2}$ and $\mathrm{NaOH}$ was constant above pH 7 at $3 \times 10^{-6} \mathrm{M}$. In the concrete pore waters the solubility of uranium was equal to or lower than this value. The distribution coefficient for the sorption of uranium onto the slag cement was $2.5 \times 10^{4} \mathrm{~mL} / \mathrm{g}$, and was increased by a factor of two after hydrothermal treatment.

Atkinson et al [1990] measured the diffusion and gas transport in a variety of cementitious materials including both structural concretes and cementitious backfills as possible repository construction materials. Measurements were made using aqueous $\mathrm{I}, \mathrm{Sr}$, and $\mathrm{Cs}$ ions and tritiated water as diffusants. The results show that the diffusion of tritiated water is more rapid than that of other species, whereas the transport of $\mathrm{Sr}$ and $\mathrm{Cs}$ is hindered by sorption, particularly in materials containing blast furnace slag. The transport of gas in these materials 
was very sensitive to water saturation and was extremely low-in fully saturated structural concretes. However, the cementitious backfills showed appreciable gas transport even when almo:: water saturated.

Bayliss et al [1992] reviewed the recent data on the solubility and sorption under a cementitious environment, along with that of the resuits from the thermochemical and sorption modeling. Under conditions similar to those expected in the repository, the predicted solubility of Se is approximately $3 \times 10^{-8} \mathrm{M}$. Experimental measurements confirm that at low redox potential the solubility of Se was substantially less than that previously observed under an air atmosphere and was closer to the predictions of the thermochemical modeling. The solubility of sodium stannate was studied after heating solutions at 50,80 , and $200 \% \mathrm{~K}$. Crystalline Sn solids were formed at all temperatures. For solutions at $200^{\circ} \mathrm{K}$ the solids were identified as cassiterite. The solubilities of all of the crystalline solids were $10^{-6}-10^{-9} \mathrm{M}$, which are at least 5-fold lower than that of the original sodium stannate. Distribution ratios $\left(R_{d}\right)$ between $1 \times 10^{3}$ and $5 \times 10^{3}$ $\mathrm{mL} / \mathrm{g}$ were measured for the sorption of tetravalent $\mathrm{Tc}$ onto a cementitious material. Preliminary results from an in-diffusion experiment involving Am and an intact cement sample agreed well (at $1 \times 10^{4} \mathrm{~mL} / \mathrm{g}$ ) with $R_{d}$ values determined from previously reported batch sorption experiments.

\section{Leaching Characteristics of Radionuclides}

Barnes et al [1986] studied the leachabilities of $\mathrm{Rb}, \mathrm{Cs}, \mathrm{Sr}, \mathrm{La}, \mathrm{Ce}, \mathrm{Nd}, \mathrm{Gd}$, and U from "supercalcine with U added", SPC-2 + U, and "Savannah River sludge", SRP, waste forms. Both ordinary portland cement (OPC) and high alumina cement (HAC) and their modifications with amorphous silica were used as the stabilizing matrices. The silica-adjusted composites were chemically more stable than those made with as-received cement. See Table 12 for the leaching rates of different metals. 
Table 12. Leach rates of different ions (G. $m^{2}$.day ${ }^{-1}$ ) at $25^{\circ} \mathrm{C}$ on 25th day in normal and silica adjusted cements (Barnes et al, 1986)

\begin{tabular}{|c|c|c|c|c|}
\hline Ion; & $\begin{array}{c}\text { OPC + SPC-2 } \\
+\mathrm{U}\end{array}$ & $\begin{array}{c}\text { OPC adjusted } \\
+ \text { SPC-2 }+\mathbf{U}\end{array}$ & HAC + SRP & $\begin{array}{c}\text { HAC adjusted } \\
+ \text { SRP }\end{array}$ \\
\hline $\mathrm{Rb}$ & 3.7 & 3.6 & $<1$ & $<1$ \\
\hline $\mathrm{Cs}$ & 2.6 & 0.9 & & $<1$ \\
\hline $\mathrm{Sr}$ & 8.6 & 3.6 & 1 & $<1$ \\
\hline $\mathrm{La}$ & 0.4 & $<0.1$ & 1 & $<1$ \\
\hline $\mathrm{Ce}$ & 0.3 & 0.04 & 10 & $<1$ \\
\hline $\mathrm{Nd}$ & 0.1 & 0.05 & 7 & \\
\hline $\mathrm{Gd}$ & 0.03 & 0.008 & & 0.086 \\
\hline $\mathrm{U}$ & & & 0.036 & \\
\hline
\end{tabular}

Leach rates for all ions, except $U$, were lower in the case of the adjusted cements. Only $U$, in the case of calcium aluminate cements, had greater leach rates in adjusted cements. Adjusting the composition of cements with silica appeared beneficial to encapsulate nuclear waste forms.

Brodda and Mingxia [1989] studied the leaching of ${ }^{36} \mathrm{Cl},{ }^{137} \mathrm{Cs}$, ${ }^{90} \mathrm{Sr}$, and ${ }^{99} \mathrm{Tc}$ from intermediate level liquid wastes (ILLW) stabilized with blast furnace slag cement using bentonite, Microsilica, acrylic resin, and $\mathrm{Na}_{2} \mathrm{~S}$ as additives. The paste specimens were made with either ILLW or water. The solution containing the respective radionuclides was used when the $\mathrm{pH}$ was adjusted to 8 . The samples were cured in desiccators for more than 90 days over the liquids respectively used for their preparation at room temperature. The samples were leached with distilled water and Q-brine. After 250 days the sequence of leachability from additive-free specimen in Q-brine was $\mathrm{Cl}>\mathrm{Cs}>\mathrm{Sr}>\mathrm{Tc}$, and $\mathrm{Cs}>\mathrm{Cl}>\mathrm{Sr}>\mathrm{Tc}$ in water. $\mathrm{Cl}$ and $\mathrm{Cs}$ leaching is diffusion-controlled, whereas $\mathrm{Sr}$ and $\mathrm{Tc}$ leaching is chemically controlled. Bentonite reduced the the leachability of Cs significantly, but had no significant effect on $\mathrm{Cl}, \mathrm{Sr}$ and Tc. Microsilica adversely effected the leachability of $\mathrm{Cs}$, but had no effect on $\mathrm{Cl}, \mathrm{Sr}$, and $\mathrm{Tc}$ release. Figures 1 show the leaching behaviors of $\mathrm{Sr}, \mathrm{Tc}, \mathrm{Cs}$ ions from the additive-free blast furmace slag cement prepared with $I L W W$ and water respectively, and using Q-brine and distilled water as leachants. Figure 2 shows leaching from the additive-containing blast furnace slag cement prepared with $I L L W$ and using Q-brine as the leachant. 
$\mathrm{Na}_{2} \mathrm{~S}$ was added to check whether $\mathrm{Tc}$ leachability could further be reduced by precipitation of insoluble $\mathrm{Tc}_{2} \mathrm{~S}_{7} . \mathrm{Na}_{2} \mathrm{~S}$ was added after adjusting $\mathrm{pH}$ at 8 to precipitate all insoluble sulfides. No significant effect was observed with $\mathrm{Na}_{2} \mathrm{~S}$ addition. Although sulfide was expected to reduce $\mathrm{Tc}$ leachability by forming stable $\mathrm{Tc}_{2} \mathrm{~S}_{7}$, the $\mathrm{pH}$ level of the cement slurry did not appear favorable, as no data are available for the stability of $\mathrm{Tc}_{2} \mathrm{~S}_{7}$ at $\mathrm{pH} 8$ or above. Table 13 shows the accumulated $\mathrm{Tc}$ fraction leached from the cementitious matrices containing sulfides.

Table 13. Total Tc leached from the blast furnace slag cements matrices containing additives with and without sulfides

\begin{tabular}{|c|c|}
\hline Additives & \% Tc leached \\
\hline Bentonite & 0.032 \\
\hline Bentonite + Sulfide & 0.033 \\
\hline Microsilica & 0.025 \\
\hline Microsilica + Sulfide & 0.050 \\
\hline
\end{tabular}

Moore et al [1977] evaluated the leaching of $\mathrm{Sr}, \mathrm{Cs}, \mathrm{Pu}$, and $\mathrm{Cm}$ from a hydrofracture grout using the International Atomic Energy Agency test method or its modification. The leaching varied with the square root of time if the leachant was replaced more than once per day, but was inhibited when the replacement was made less often. The leaching of Sr or Cs from the grout varied directly with drying while curing and inversely with the time of curing. In general the leach rate followed the order $\mathrm{Cs}>\mathrm{Sr}>\mathrm{Cm}>\mathrm{Pu}$ as shown in Figure 3. The amount of leaching as a function of time was also dependent on the leachant type and varied in the order. distilled water $>$ tap water $>$ grout water.

The grout provided leach rates comparable to those obtained for wastes incorporated into borosilicate glass. For instance, the data showed that at short times the fraction of Cs leached from the glass was slightly less than the grouts. At long durations, the trend reversed.

Comparison of Cs leaching from the grout and borosilicate glasses is shown in Figure 4. The credibility of laboratory results with simulated waste was substantiated by a short-term continuous leach test made on a fragment of a core sample of hydrofracture grout. The modified effective diffusivities of $10^{-11}$ to $10^{-10} \mathrm{~cm}^{2} / \mathrm{s}$ (equivalent to a leach rate of the order of $10^{-7} \mathrm{~g} / \mathrm{cm}^{2}$ day) for Sr and Cs were comparable to the laboratory data.

In an earlier study, Moore et al [1976] used Grundite clay in hydrofracture grout for improved Cs retention. Grundite (while satisfactory) was least effective. However, the leach rate for Cs 
was decreased by the addition of Grundite, pottery clay, or locally available Conasauga shale. These additives were in the order of increasing effectiveness with respect to Cs retention.

Godbee et al (1975) used a derived modified effective diffusivities, $D_{e}$, in comparing the the amounts leached from a 55-gal drum of grout assuming two different forms for the drum to simulate a semi-infinite and a finite medium respectively. The calculations showed that the drum approximated a semi-infinite medium for a few years if the $D_{e}$ was approximately $1 \times 10^{-9} \mathrm{~cm}^{2} / \mathrm{sec}$ and for $>3000$ years if the $D_{e}$ was approximately $6 \times 10^{-18} \mathrm{~cm}_{i}^{2} / \mathrm{sec}$.

Serne et al [1996], determined the leachability of $\mathrm{Nd}, \mathrm{U}, \mathrm{Th}$, and $\mathrm{Sr}$ in cement slurries in a $\mathrm{CO}_{2}$-free atmosphere. The aliquots of the crushed cement samples doped with these ions were equilibrated with deionized water at pch+ (hydrogen ion concentration in molarity units) between 7.5 to 12.5 to predict the leachabilities. Nd concentration level decreased with the increase in $\mathrm{pcH}_{\mathrm{H}}+$ from 7.5 to 9.0 where the $\mathrm{Nd}(\mathrm{OH})_{3}$ appeared to be the controlling solid phase. U concentrations in the aliquot decreased by two orders of magnitude. Data suggests that $\mathrm{CaUO}_{4}$ is the likely controlling solid. The concentration of Th was at or below the detection limit over the entire range of the $\mathrm{pcH}^{+}+$covered, and the likely controlling solid appears to be $\mathrm{ThO}_{2}$. Apparently, $\mathrm{Sr}$ does not enter appreciably into the solid matrix of cement and does not form insoluble compounds in carbonate-free environments.

Scheetz et al [1985] examined the physical properties of cement-based waste forms to evaluate the extent of waste loading that might be feasible and still maintain a leach-resistant, strong, monolithic object. For a minimum compressive strength of $21 \mathrm{MPa}$, waste loadings of 40 to $60 \%$ were possible. With 30 and $70 \%$ waste loading, the leach rates for Cs and Sr were found comparable to those found for glass and ceramic waste forms.

Nishi et al [1992] studied the effect of active silica (a natural acid clay composed of cristobalite and quartz) for its applicability as Cs adsorbent in slag cement-based waste forms containing spent ion exchange resin. Other additives tested for comparison were silica fume, zeolite, and cement glass. Since active silica carried the $\mathrm{Cs}$ exchangeable silanol group (-SiOH) originally, the Cs distribution coefficient was remarkably high $\left(>10^{4}\right)$. It increased in saturated $\mathrm{Ca}(\mathrm{OH})_{2}$ solution due to formation of new silanol groups. As a result, when active silica was added to the forms containing slag cement, the Cs leaching ratio was reduced to below $1 / 10$ th of the value obtained without active silica. A comparison of $\mathrm{Cs}$-leaching between active silica and other additives used is given in Figure 5. 
Wu et al [1991] reported a decrease in Cs leachability when using alkali-activated slag cement (AASC) as compared to the ordinary portland cement (OPC) in waste-forms cured at $2980 \mathrm{~K}$. Unde: identical condition high alumina cement (HAC) performed better than both. When cured at a high temperature of $3430 \mathrm{~K}$, the alkali-activated slag cement was best of them all. However, the leachability of Cs increased with increase in temperature and curing time (see Table 14).

Table 14. \% Leachability of Cs with time (Wu et al, 1991)

\begin{tabular}{|c|c|c|c|c|}
\hline Cements & Temperature & 3-day & 7-day & 28-day \\
\hline AASC & \multirow{2}{*}{$298 \% \mathrm{~K}$} & 3.45 & 4.96 & 7.33 \\
\cline { 1 - 4 } & & 8.57 & 11.3 & 15.6 \\
\cline { 3 - 5 } OPC & & 2.17 & 2.59 & 3.44 \\
\cline { 1 - 4 } HAC & & 8.6 & 11.7 & 14.1 \\
\hline AASC & \multirow{2}{*}{$343 \circ \mathrm{K}$} & 21.7 & 25.5 & 26.5 \\
\hline OPC & & 23.6 & 24.2 & 25.1 \\
\hline
\end{tabular}

The leachability values were calculated using the following equation:

Leachability $(\mathrm{cm})=\left(a_{t} / A\right)(F / V)$, where;

$a_{t}=$ mass $(g)$ of Cs leached at sample time

$A=$ mass $(\mathrm{g})$ of $C s$ in specimen

$\mathrm{F}=$ surface area of the specimen .

$\mathrm{V}=$ volume $\left(\mathrm{cm}^{3}\right)$ of the specimen

Similar leachability trend is also observed with $\mathrm{Sr}$ is leached from AASC waste form under identical curing coriditions [Shen, et al, 1994].

Bostick et al (1988) compared the leachability of Tc in waste sludge using conventional portland cement and fly ash grouts (50:50 mix), and cement, fly ash, and ground blast furnace slag grouts (33:33:33 mix). Slag addition reduced the effective diffusivity of Tc significantly. The effect of slag was attributed to its ability to reduce $\mathrm{Tc}(\mathrm{VII})$ to the less soluble $\mathrm{Tc}(\mathrm{IV})$ species. Leachability indices for $\mathrm{Tc}$ as a function of loading and curing time in both grouts clearly show the stability effect of slag addition (Figure 6). Cumulative leaching of $\mathrm{Tc}$ from a grout that had $40 \%$ Tc containing sludge filtrate, $20 \%$ each of slag, cement, and fly ash, is shown in Figure 7. The plot should be linear for a diffusion-controlled release, but it actually biphasic. The larger Tc release that occurs in the initial 1 to 2 days could be attributed to some kind of surface phenomenon, or, more likely, it may simply be due to two oxidation stages of Tc leaching at different rates. Guppy and Atkinson [1989] correlated the leachability of Tc to 
redox conditions in cement-based stabilizing matrix. Slag cements showed greater reducing capacity than the ordinary portland cement, but naturally the reducing capacity fell as leaching proceeded. However, the oxidation potentials were relatively high and insensitive to leaching, suggesting that the reducing species present were unable to remove contamination. For slag cement, the apparent solubility of Tc was $<10^{-9} \mathrm{~mol} / \mathrm{L}$; but was $>2 \times 10^{-5} \mathrm{~mol} / \mathrm{L}$ for ordinary portland cement.

Amini et al [1993] examined the leaching behavior of $\alpha$-emitting radionuclides ( $U$ and Am) from zeolite-L and the zeotype (SAPO-34) in a Flexcrete-cement matrix by static and dynamic methods. Synthetic groundwater and $0.005 \mathrm{M} \mathrm{CaCl}_{2}$ were used as leachants. The leaching rates of $\mathrm{UO}_{2}{ }^{2+}$ were higher by approximately 10 orders of magnitude than those of $\mathrm{Am}^{3+}$ for both zeolite-L and SAPO-34 in the cement matrix. The static and dynamic leaching rates of $\mathrm{UO}_{2}{ }^{2+}$ for SAPO-34 in $\mathrm{CaCl}_{2}$ and synthetic groundwater were 10 orders of magnitude lower than those for zeolite-L. SAPO-34 showed good selectivity for $\mathrm{U}$ at $\mathrm{pH}$ 2-3.5 and zeolite-L was effective for $\mathrm{Am}^{3+}$. Distribution coefficients of $\mathrm{Am}^{3+}$ and $\mathrm{UO}_{2}{ }^{2+}$ increased with the equilibrium $\mathrm{pH}$. 
Table 15. A summary of grout formulations to immobilize different radionuclides, and their leachability \& durability characteristics

\begin{tabular}{|c|c|c|c|}
\hline Metals & Grout formulations & Leaching/durability & Reference \\
\hline $1:-$ & $\begin{array}{l}\text { 6. Type I cement, fly ash, activated } \\
\text { carbon, retarder } \\
\text { 7. Cement-fly ash; cement-fly ash- } \\
\text { slag } \\
\text { 8. Slag, Type I/II cement, Class F } \\
\text { fly ash, lime, and pottery ash } \\
\text { 9. Slag, Type I/II cement, } \\
\text { bentonite, Attapulgite clay, Class } \\
\text { F fly ash, amorphous silica, } \\
\text { silica fume }\end{array}$ & $\begin{array}{l}\text { 1. Slag-cement blends } \\
\text { reduced Tc leachability } \\
\text { 2. Sulfides did not reduce } \\
\text { Tc leaching } \\
\text { 3. Slag, and reducing } \\
\text { additives reduced Tc } \\
\text { leachability } \\
\text { 4. Reduced Tc leaching } \\
\text { compared to cement- } \\
\text { based mixes } \\
\text { 5. Bentonite reduced the } \\
\text { wetting/ drying durability; } \\
\text { Attapulgite clay improved } \\
\text { it } \\
\text { 6. Reduced Tc leaching to } \\
\text { low and non detectable } \\
\text { levels } \\
\text { 7. Slag reduced Tc } \\
\text { leachability } \\
\text { 8. 100\% slag, and } 47.5 \% \\
\text { slag: } 47.5 \% \text { fly ash: } 5 \% \\
\text { lime reduced Tc } \\
\text { leachability } \\
\text { 9. Improved integrity, } \\
\text { freeze/thaw durability of } \\
\text { the stabilized form }\end{array}$ & $\begin{array}{l}\text { 4. Langton, } \\
1987 \\
\text { 5. Hensen et al., } \\
1991 \\
\text { 6. Siegrist et al, } \\
\text { 1996 } \\
\text { 7. Bostick et al } \\
\text { 1988. } \\
\text { 8. Tallent et al } \\
\text { 1988 } \\
\text { 9. Morgan and } \\
\text { Bostick, } 1992\end{array}$ \\
\hline
\end{tabular}


Table 15. A summary on grout formulations....... (continued)....

\begin{tabular}{|c|c|c|c|}
\hline Metals & Grout Formulations & Leaching/Durability & Reference \\
\hline Cs & $\begin{array}{l}\text { 1. Cement, fly ash, Attapulgite and } \\
\text { Grundite clays, sugar, } \\
\text { tributylphosphate } \\
\text { 2. Slag or cement, bentonite or } \\
\text { microsilica, sulfide, and acrylic } \\
\text { resin. } \\
\text { 3. Slag, Class F fly ash, hydraulic } \\
\text { lime or cement } \\
\text { 4. Alkali activated slag cements } \\
\text { (AASC); portland cements, high } \\
\text { alumina cement (HAC). }\end{array}$ & $\begin{array}{l}\text { 1. Reduced Cs leaching as } \\
\text { comparable to } \\
\text { borosilicates } \\
\text { 2. Bentonite significantly } \\
\text { reduced Sc leachability } \\
\text { 3. Reduced Sc leaching } \\
\text { more than the cement } \\
\text { 4. In reducing Cs leaching } \\
\text { HAC performed better at } \\
\text { 298०K, but AASC was } \\
\text { best at } 343 \circ \mathrm{K}\end{array}$ & $\begin{array}{l}\text { 1. Moore et al. } \\
1970 \\
\text { 2. Brodda and } \\
\text { Mingxia, } 1989 \\
\text { 3. Langton, } \\
\text { 1987 } \\
\text { 4. Wu, et al } \\
\text { 1991. }\end{array}$ \\
\hline$\overline{\mathrm{Sr}}$ & $\begin{array}{l}\text { 1. Cement, fly ash, Attapulgite and } \\
\text { Grundite clays, sugar, } \\
\text { tributylphosphate } \\
\text { 2. Slag or cement, bentonite or } \\
\text { microsilica, sulfide, and acrylic } \\
\text { resin } \\
\text { 3. Slag, Class F fly ash, hydraulic } \\
\text { lime or cement }\end{array}$ & $\begin{array}{l}\text { 1. Reduction in leaching } \\
\text { comparable to } \\
\text { borosilicates } \\
\text { 2. Sr leachability is not } \\
\text { much effected } \\
\text { 3. Reduced Sc leaching } \\
\text { compared to cemint- } \\
\text { based mixes }\end{array}$ & $\begin{array}{l}\text { 1. Moore et al. } \\
1977 \\
\text { 2. Brodda and } \\
\text { Mingxia, 1989 } \\
\text { 3. Langton, } \\
\text { 1987. }\end{array}$ \\
\hline $\mathrm{Pu}$ & $\begin{array}{l}\text { 1. Cement, fly ash, Attapulgite and } \\
\text { Grundite clays, sugar, } \\
\text { tributylphosphate }\end{array}$ & $\begin{array}{l}\text { 1. Reduction in leaching } \\
\text { comparable to } \\
\text { borosilicates }\end{array}$ & $\begin{array}{l}\text { 1. Moore et al. } \\
1977\end{array}$ \\
\hline$\overline{\mathrm{U}}$ & $\begin{array}{l}\text { 1. Type I cement, fly ash, activated } \\
\text { carbon, retarder }\end{array}$ & $\begin{array}{l}\text { 1. Reduced U leaching to } \\
\text { low and non-detectable } \\
\text { levels }\end{array}$ & $\begin{array}{l}\text { 1. Siegrist et al, } \\
1996\end{array}$ \\
\hline$\overline{\mathrm{Cm}}$ & $\begin{array}{l}\text { 1. Cement, fly ash, Attapulgite and } \\
\text { Grundite clays, sugar, } \\
\text { tributylphosphate }\end{array}$ & $\begin{array}{l}\text { 1. Reduced } \mathrm{Cm} \text { leaching as } \\
\text { comparable to } \\
\text { borosilicates }\end{array}$ & $\begin{array}{l}\text { 1. Moore et al., } \\
1970\end{array}$ \\
\hline $\begin{array}{c}\mathrm{Np}, \mathrm{Rb} \\
\mathrm{La}, \mathrm{Nd}, \\
\mathrm{Gd}, \mathrm{Ce}\end{array}$ & $\begin{array}{l}\text { 1. Portland cement, calcium } \\
\text { aluminate cement, modified } \\
\text { calcium aluminate cement }\end{array}$ & $\begin{array}{l}\text { 1. Modified calcium } \\
\text { aluminate cement reduced } \\
\mathrm{Np}, \mathrm{Rb}, \mathrm{La}, \mathrm{Nd}, \mathrm{Gd}, \mathrm{Ce} \\
\text { leaching }\end{array}$ & $\begin{array}{l}\text { 1. Barnes et al, } \\
1986\end{array}$ \\
\hline General & $\begin{array}{l}\text { 1: Portland cement, sand, } \\
\text { bentonite, silica fume }\end{array}$ & $\begin{array}{l}\text { 1. Optimizing of strength, } \\
\text { leach resistance, } \\
\text { shrinkage resistance, } \\
\text { reduced permeability, } \\
\text { were achieved through } \\
\text { varying the mix } \\
\text { proportions }\end{array}$ & $\begin{array}{l}\text { 1. Allan and } \\
\text { Kukacka, } 1996\end{array}$ \\
\hline
\end{tabular}


Q-Brine Leachant
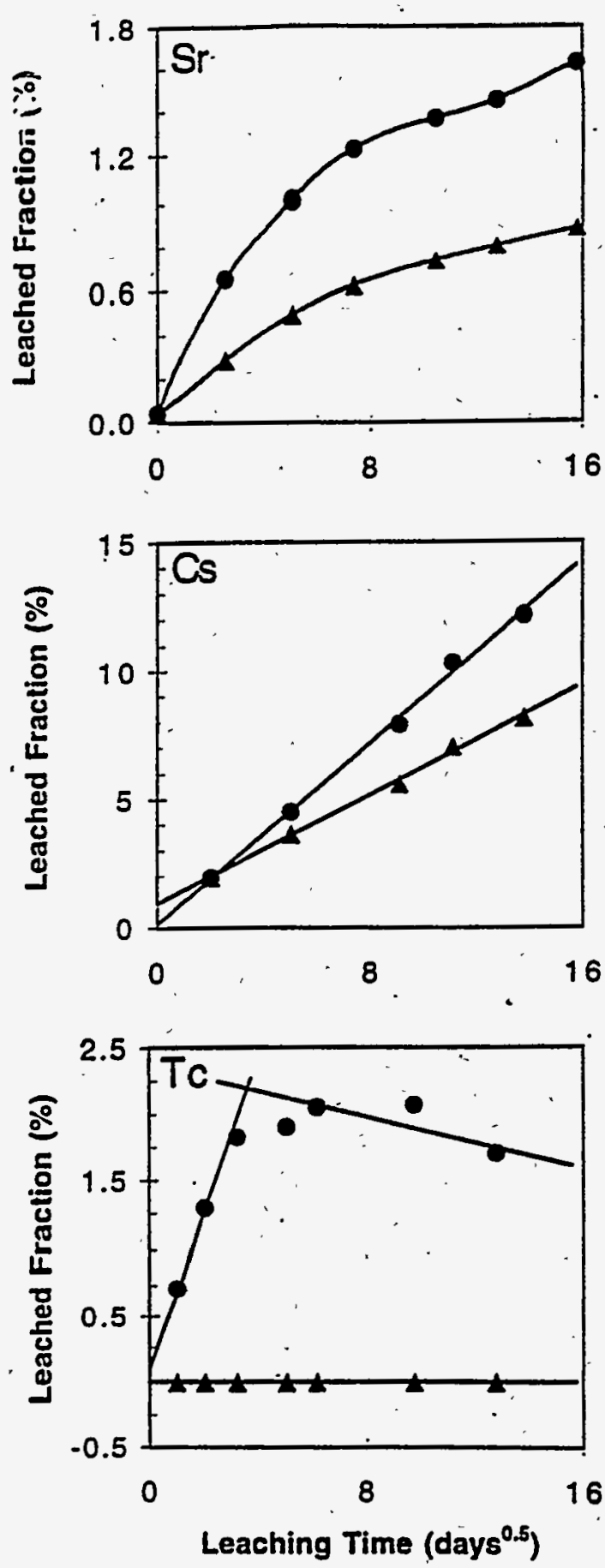

-Prepared with ILLW
: Water Leachant
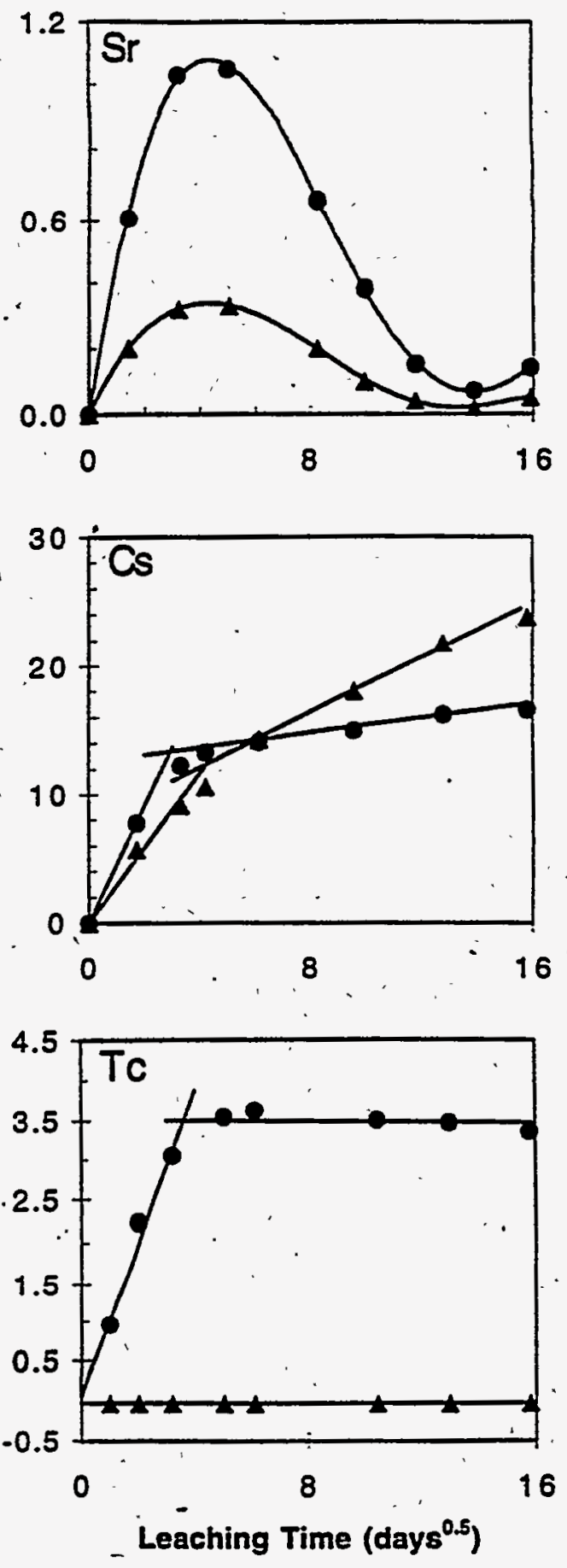

$\rightarrow$ Prepared with Water

Figure 1. Sr, TC, and Cs Leaching from BFC with and without ILLW into Q-Brine and Water (Brodda and Mingxia, 1989). 

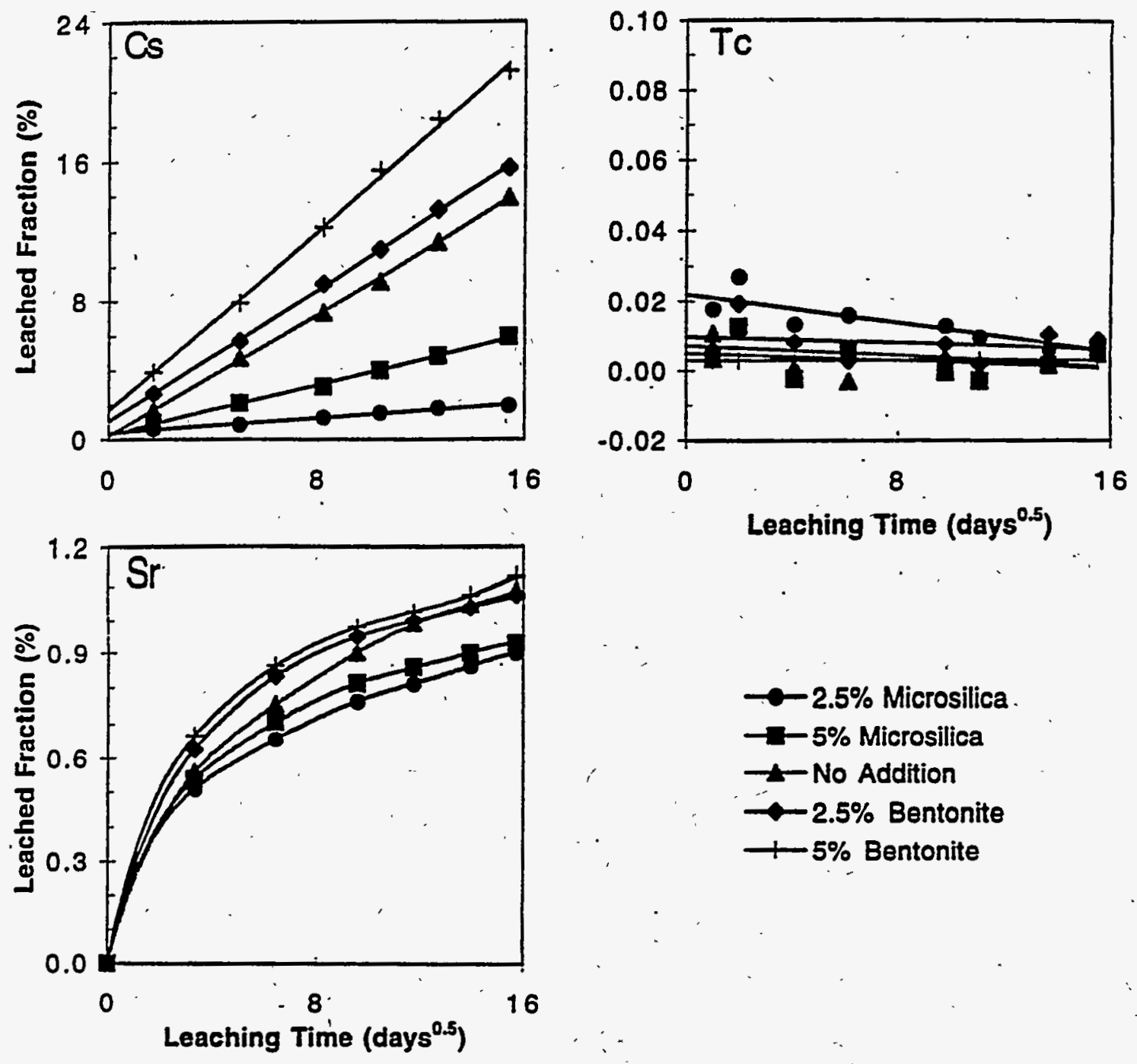

Figure 2. Sr, Tc, and Cs Leaching from BFC with ILLW and Additives in Q-Brine (Brodda and Mingxia, 1989). 


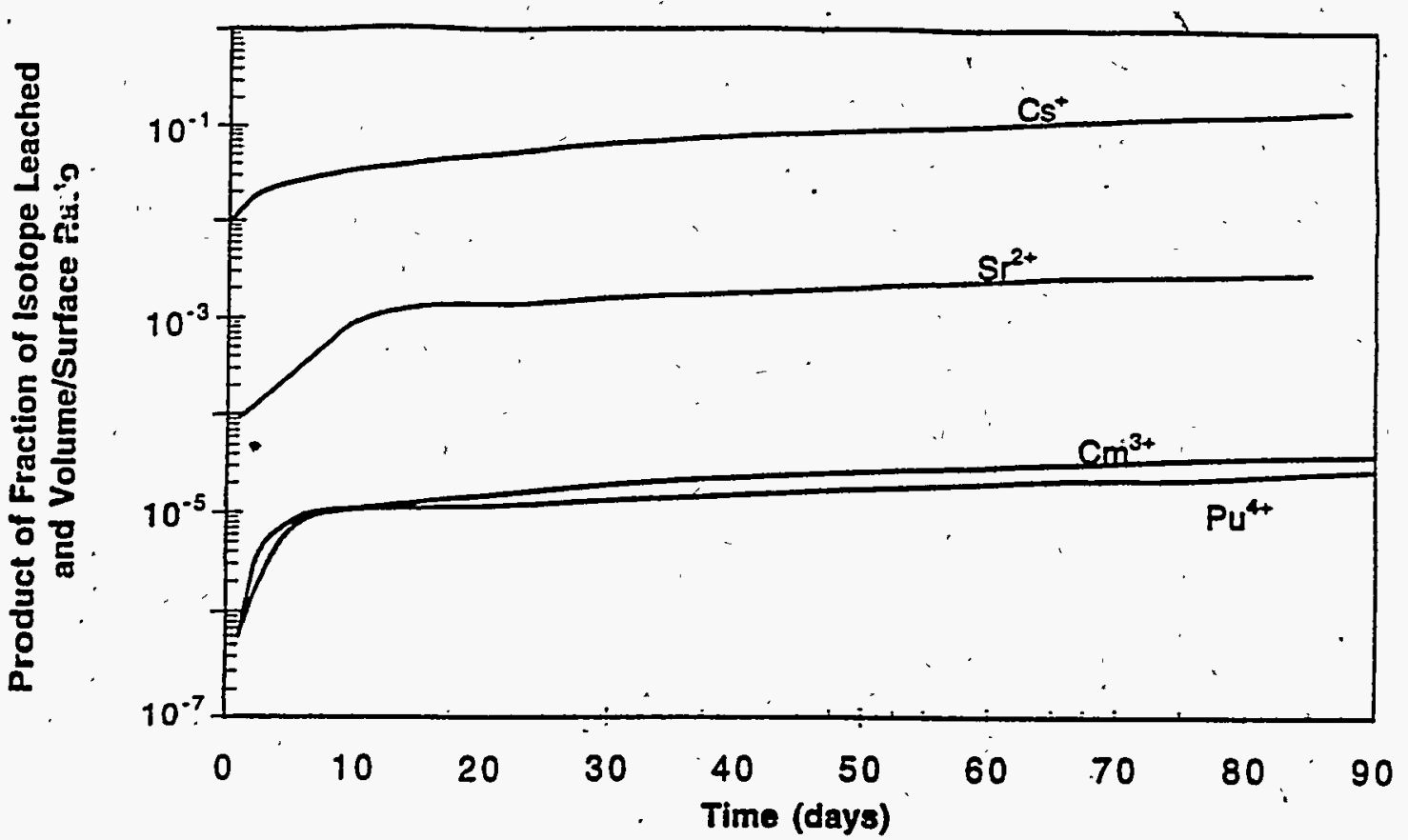

Figure 3. Product of the Cummulative Fraction of Isotope Leached and Volume to Surface Ratio for Cementitious Grouts Cured for 4 Weeks (Moore et al, 1977).

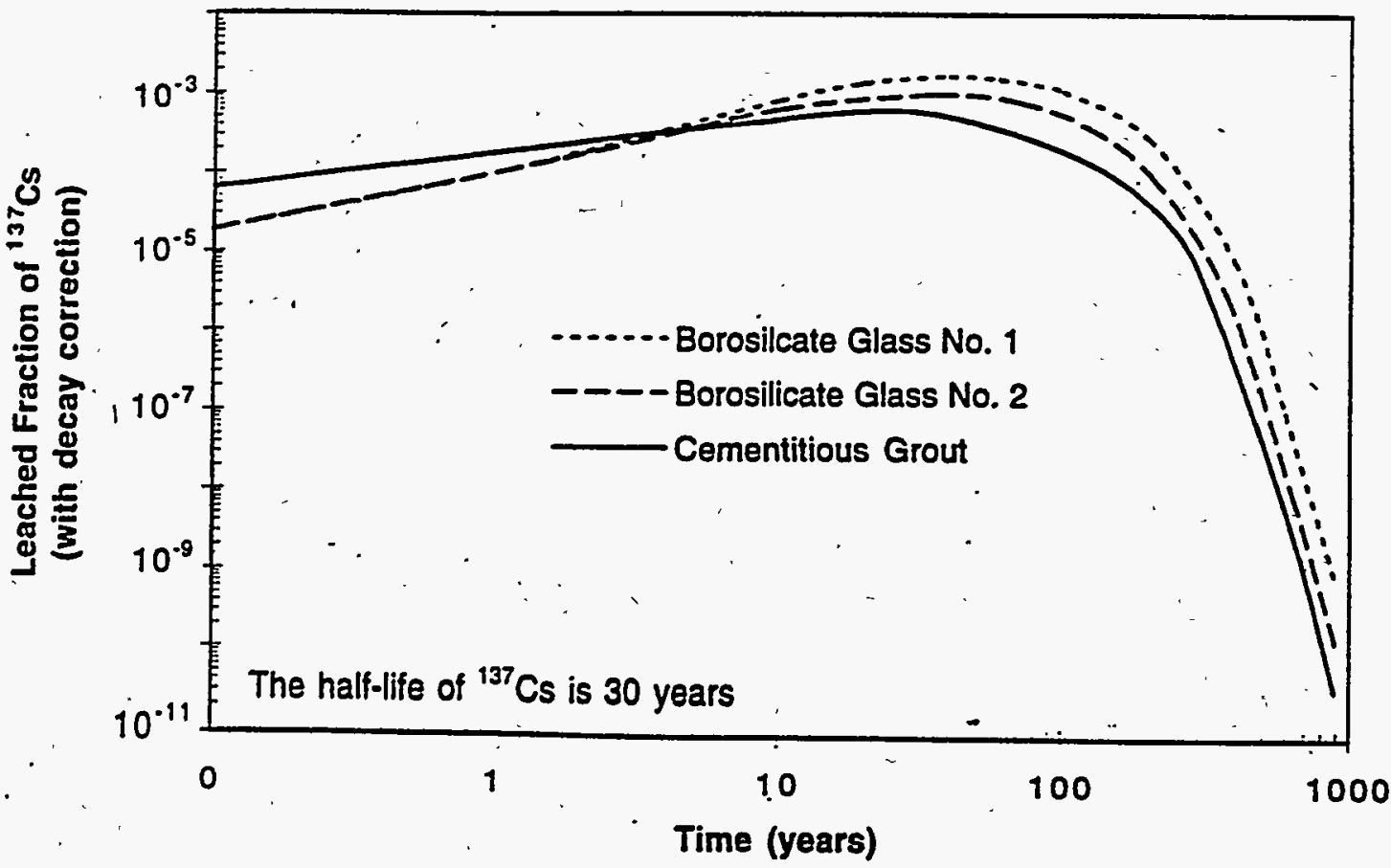

Figure 4. Comparison of the ${ }^{137}$ Cs Leached from Borosilicate Glass and.Cementitious Grout as Predicted by Mass Transportation Phenomena (Moore et al, 1977). 


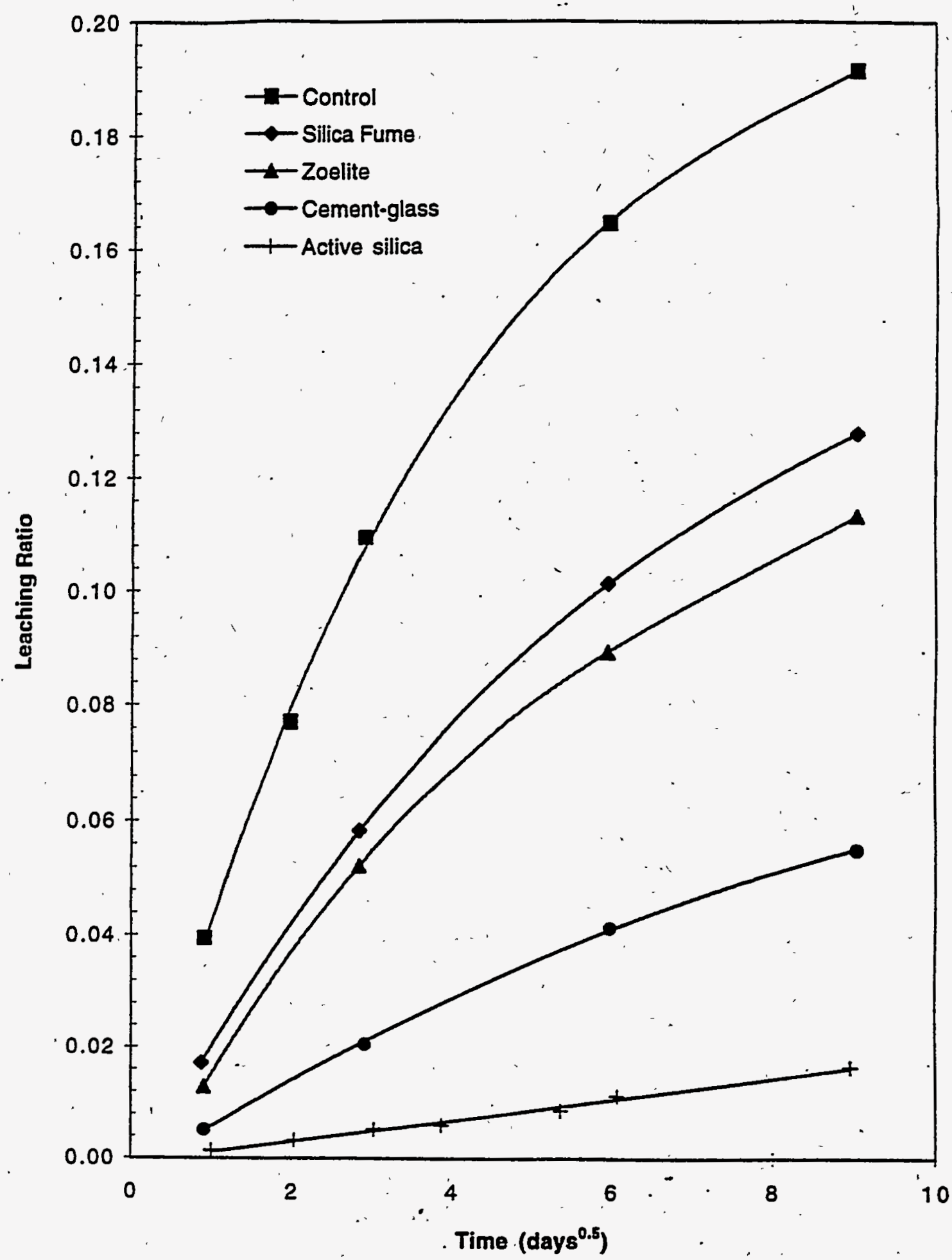

Figure 5. Effect of Cs Adsorbants on Leaching Curves from Cementitious Resin Forms (Nishi et al, 1992). 


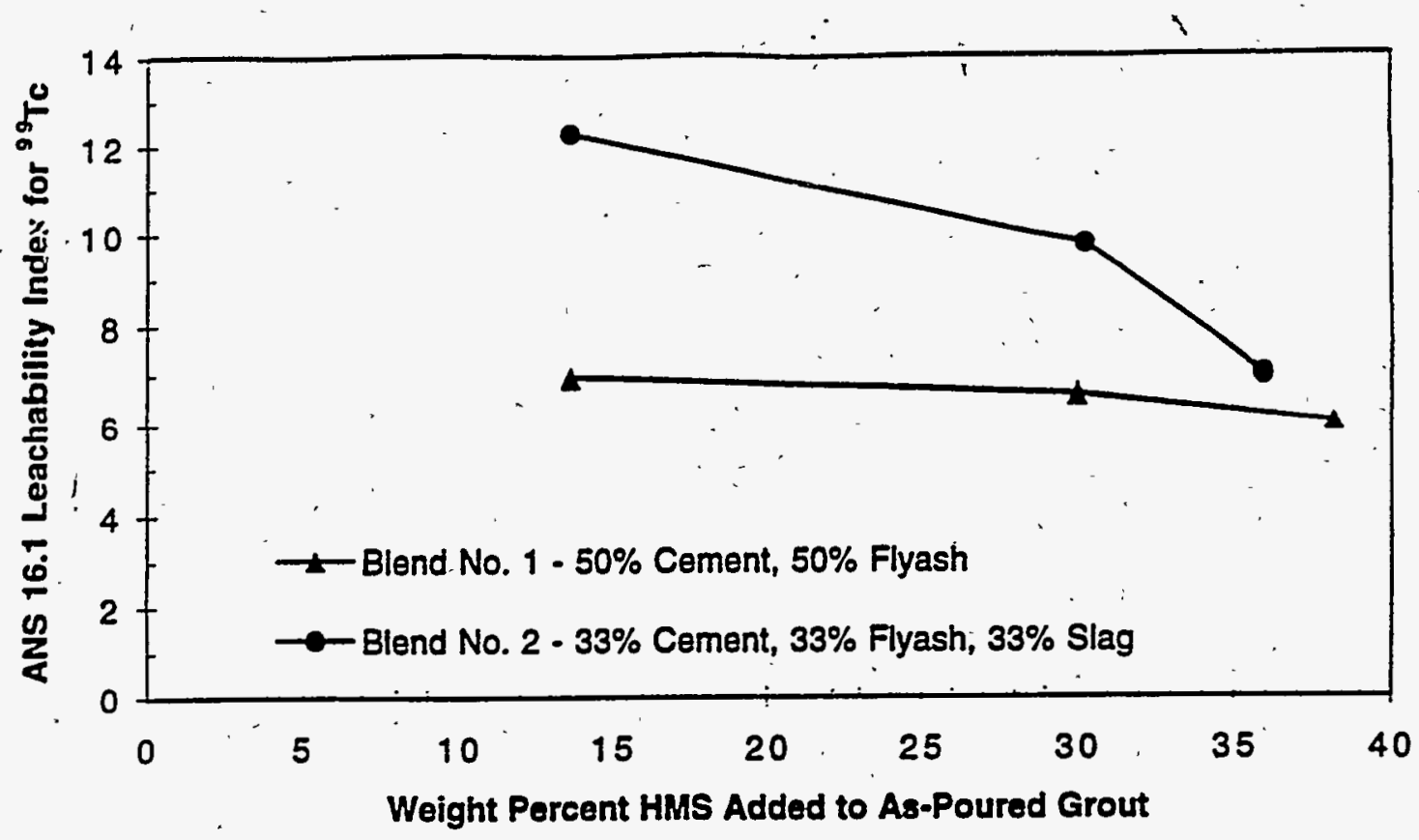

Figure 6. ANS-16.1 Leachibility Indices for ${ }^{\circ 9}$ Te as a Fùnction of Sludge Waste Loading in Grouts Prepared with Two Different Blends (Bostick et al, 1988).

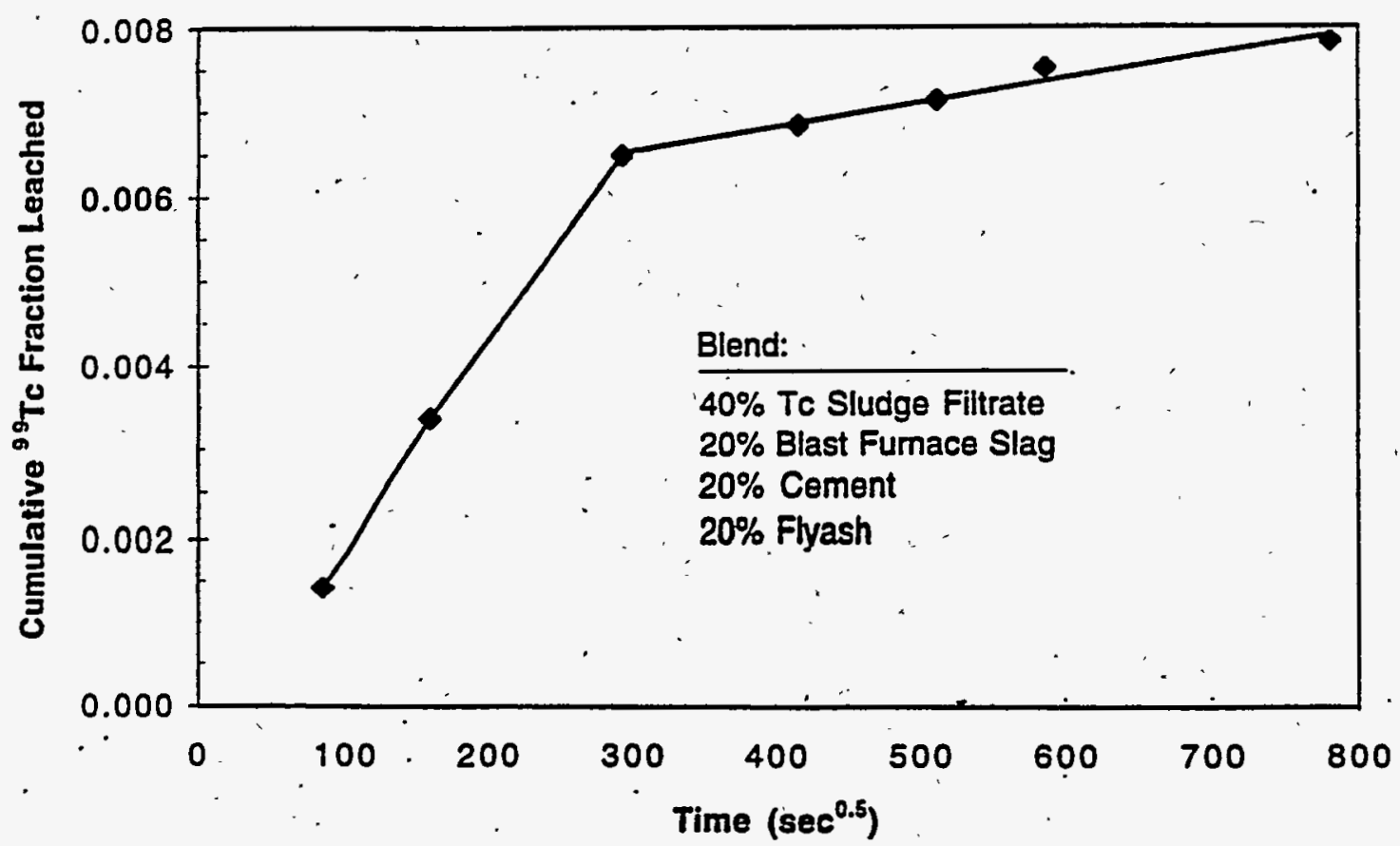

Figure 7. Cummulative Fraction of ${ }^{90}$ TC Leached from Slag-Cement Grout (Bostick et al, 1988). 


\section{References}

Allan, M.L.; Kukacka, L.E., "Performance of cementitious containment barriers," in Stabi ${ }^{\prime}$ zation and Solidification of Hazardous, Radioactive, and Mixed Wastes, Vol. 3, ASTM STP 1240, Eds. Gilliam and Wiles, pp. 186-197, 1996.

Amini, S.; Dyer, A.; Durrani, S. K., "Fixation of actinide elements into zeolites/zeotypes and Flexcrete-cement matrix," J. Radioanal. Nucl. Chem., 173(2), pp. 331-337, 1993.

Atkins, M.; Cowie, J.; Glasser, F. P.; Jappy, T.; Kindness, A.; Pointer, C., "Assessment of the performance of cement-based composite material for radioactive waste immobilization," Mat. Res. Soc. Symp. Proc.: 176 (Scientific Basis for Nuclear Waste Management - 13), pp. 117-127, 1990,

Atkinson, Alan; Claisse, Peter A.; Harris, Andrew W.; Nickerson, Allan K., "Mass transfer in water-saturated concretes," Mater. Res. Soc. Symp. Proc., 176 (Scientific Basis for Nuclear Waste Management - 13), pp. 741-749, 1990.

Aattbek, R.; Bouniol, P., Vitorge, P., Le Bescop, P., Hoorelbeke, J. M., "Cement use for radioactive waste Embedding and Disposal Purposes,". Cem. Con. Res., Vol. 22 (2/3), pp. 419-429, 1992.

Barnes, M. W.; Scheetz, B. E.; Roy, D. M., "The effect of chemically adjusting cement compositions on leachabilities of waste ions," Adv. Ceram.: 20 (Nucl. Waste Manage.- 2), pp. 313-317, 1986.

Barnes, M. W.; Scheetz, B. E.; Wakeley, L. D.; Atkinson, S. D.; Roy, D. M., "Stability of I and Sr radiophases in cement matrixes," Mater. Res. Soc. Symp. Proc.: 6 (Scientific Basis for Nuclear Waste Management ), pp. 147-154, 1982.

Bayliss, S.; Haworth, A.; McCrohon, R.; Moreton, A. D.; Oliver, P.; Pilkington, N. J.; Smith, A. J.; Smith-Briggs, J. L., "Radioelement behavior in a cementitious environment," Mater. Res. Soc. Symp. Proc.: 257 (Scientific Basis for Nuclear Waste Management - XV), pp. 641-648, 1992.

Benischek, Inge; Hess, Vera; Metzker, Eduard, "Preliminary experiments on determining the $\mathrm{Kd}$-values for cesium and strontium in disposal site studies. 2. Test with clay materials," Oesterr. Forschungszent. Seibersdorf, [Ber.] OEFZS-4631, 25 pp., 1993.

Bostick, W. D.; Shoemaker, J. L.; Fellows, R. L.; Spence, R. D.; Gilliam, T. M.; McDaniel, E. W.; Evans-Brown, B. S., "Blast fumace slag-cement grout blends for the immobilization of technetium-containing wastes," Oak Ridge Gaseous Diffusion Plant, Oak Ridge, TN, 62 pp, 1988.

Brodda, B. G., "Leachability of technetium from concrete," Sci. Total Environ.; Vol. 69, pp. 319-345, 1988.

Brodda, B. G.; Xu, Mingxia, "Leaching of chlorine, cesium, strontium and technetium from cement-fixed intermediate level liquid waste," Mater. Res. Soc. Symp. Proc.: 127 (Sci. Basis Nucl. Waste Manage.-12), pp. 481-487, 1989. 
Brownsword, M.; Buchan, A. B.; Ewart, F. T.; McCrohon, R.; Ormerod, G. J.; Smithbriggs, J. L.; Thomason, H.'P., "The solubility and sorption of uranium (VI) in a cementitious repository," Mater. Res. Soc. Symp. Proc.: 176 (Sci. Basis Nucl. Waste .Manage.-13), pp. 577-82, 1990.

Burne, W. G.; Ewart, F. T.; Hobley, J.; Smith, A. J.; Walters, W. S.; Williams, S. J., "Radj Jlytic oxidation: Task 3- Characterization of radioactive waste forms. A series of final reports (1985-89) - No. 25," Comm. Eur. Communities, EUR 13670 Report, 110 p, 1991.

Gilliam, T. Michael; Spence, Roger D.; Bostick, William D.; Shoemaker, J. L.,

"Solidification/stabilization of technetium in cement-based grouts," J. Hazard. Mater., Vol.

24(2-3), pp.189-97, 1990.

"Glasser, F.P., "Progress in the Immobilization of Radioactive Wastes in Cement," Cem. Con. Res., Vol. 22, No. 2/3, pp. 201-216, 1992.

Godbee, H. W.; Moore, J. G.; Kibbey, A. H., Joy, D.S., "Leach behavior of hydrofracture grout incorporating radioactive wastes," Am.Cer.Soc. 77th. Ann. Mtng. May 3-8, Washington D.C., 41 p, 1975.

Grutzeck, M. W.; Brown, D.; Hoyle, S., "Crystal chemistry of Portland cement hydrates as radioactive waste hosts: Final Report, June 15, 1983-June 14, 1984," Report DOE/ER/45013-2; Order No. DE84015112, 34 pp. 1984.

Guppy, R. M.; Atkinson, A., "The evolution of redox conditions in a radioactive waste repository. Preliminary investigations," U. K. At. Energy Auth., Report: AERE-R 13615, 32 p., 1989.

Henson, H. M.; Hoffmann, D. P.; Melton, R. C.; Sherles, R. S.; Schmidt, M. A.; Marsh, G. C.; Bridges, M. J., "Characterization of hydration sensitive stabilized ion-exchange resins," : Ceram. Trans.: 23 (Nucl. Waste Manage.- 4), pp. 157-169, 1991. .

Hoeglund, S.; Eliasson, L.; Allard, B.; Andersson, K.; Torstenfelt, B., "Sorption of some fission products and actinides in concrete systems," Mater. Res. Soc. Symp. Proc.: 50 (Sci. Basis Nucl. Waste Manage.-9), pp. 683-690, 1986.

Langton, C. A., "Slag-based saltstone formulations," Mater. Res. Soc. Symp. Proc.: 112 (Sci. Basis Nucl. Waste Manage. -11), pp. 61-70, 1987.

Lanza, F.; Bidoglio, G.; Zamorani, E., "Influence of solubility and insolubilization on the release of radioactive products," Proc. Int. Semin. Radioact. Waste Prod., pp. 581-590, 1985.

McCulloch, C. E.; Angus, M. J.; Crawford'R. W.; Rahman, A. A.; Glasser, F. P., "Cements in radioactive waste disposal: some mineralogical considerations," Mineral. Mag., Vol. 49(351), pp. 211-21, 1985.

Merz, E. R.; Dyckerhoff, D.; Odoj, R., "Characterization of radioactive wastes incorporated in a cement matrix," Proc. Int. Conf. Radioact. Waste Manage., 2nd.,-pp. 396-401, 1986.

Publisher: Can. Nucl. Soc., Toronto, Ont., Canada.

Moore, J. G.; Godbee, H. W.; Kibbey, A. H., "Leach behavior of hydrofracture grout incorporating radioactive wastes," Nucl. Technol., Vol. 32(1), pp. 39-52, 1977. 
Moore, J. G.; Godbee, H. W.; Kibbey, A.H., "Leach behavior of hydrofracture grout incorporating radioactive wastes," Oak Ridge Natl. Lab.; Oak Ridge, TN, Report TID-27033, $45 \mathrm{pp}, 1976$.

Morgan, I. L., Bostick, W. D., "Performance Testing of Grout-Based Waste Forms-for the Solid: “ication of Anion Exchange Resins," ASTM STP 1123, pp. 133-145, 1992

Morgan, R. D.; Pryke, D. C.; Rees, J. H., "Sorption of actinides on candidate materials for use in repositories," UKAEA, Report AERE-R-12369, DOE-RW-87.046, 33 pp., 1987.

Nishi, Takashi; Matsuda, Masami; Chino, Koichi; Kikuchi, Makoto, "Reduction of cesium leaching ratio from cementitious resin forms using natural active silica," J. Nucl. Sci.

Technol., Vol. 29(8),pp. 779-785, 1992.

Scheetz, Barry E.; Roy, Della M.; Tanner, Candace; Barnes, Mary W.; Grutzeck, "Properties of cement-solidified radioactive waste forms with high levels of loading," Am. Ceram. Soc. Bull., Vol. 64(5), pp. 687-90, 1985.

Serne, R. J.; Rai, D.; Martin, P.F; Felmy, A.R.; Rao, L., Ueta, S., "Leachability of Nd, U, $\mathrm{Th}$, and $\mathrm{Sr}$ from Cements in a $\mathrm{CO}_{2}$ free Atmosphere;" Material Research Society Symposium Proceedings, Vol. 412, pp. 459-467, 1996.

Shen Xiaodong; Yan Sheng; Wu Xuequan; Tang Mingshu, Yang Liji, "Immobilization of simulated high level wastes into AASC waste form," Cem. Conc. Res., Vol. 24, pp. 133-138, 1994

Shi Caijun, et al, "Hydrothermal synthesis of SrO.SiO, Society, Vol. 10( 2), pp. 15-17, 1991, (in Chinese).

Siegrist, R.L., Cline,-S.R., Gilliam, T.M., "In situ stabilization of mixed waste contaminated soil," in Stabilization and Solidification of Hazardous, Radioactive, and Mixed Wastes, Vol. 3, ASTM STP 1240, Eds. Gilliam and Wiles, pp. 667-684, 1996.

Tallent, O.K; McDaniel, E.W.; Del Cul G.D.; Dodson K.E.; and Trotter, D.R., "Immobilization of technetium and nitrate in cement-based materials," Mater. Res. Soc. Symp. Proc.: 112 (Sci. Basis Nucl. Waste Manage.-XI), pp. 23-32, 1988.

Vejmelka, P.; Rudolph, G.; Kluger, W.; Koester, R, "Conditioning of radioactive waste solutions by cementing," Kermforschungszent. Karlsruhe, [Ber.], KfK 4800, 85 pp., 1990.

Wu, Xuequan; Yen, Sheng; Shen, Xiaodong; Tang, Mingshu; Yang, Liji, "Alkali-Activated Slag Cement Based radioactive Waster Forms," Cem, Conc. Res., Vol. 21, pp. 16-20, 1991. 
WSRC-TR-97-0102

Revision 0

Page 202

\section{APPENDIX B}




\author{
Drat Repart \\ for \\ WESTINGHOUSE SAVANNAH RIVER COMPANY \\ and \\ UNITED STATES DEPARTMENT OF ENEROY \\ Alken, S.C. \\ DEMONSTRATION OF REDUCING GROUT AND \\ SLUDGE MIXING FOR CLOSURE OF \\ SAVANNAH RIVER SITE TANK \#2OF \\ UNDER WSRC SUBCONTRACT NO. AB94269S \\ April 15, 1997
}


WSRC-TR-97-0102

APPENDIX "B"

CTL Grout and Sludge Mixing Report

Revision 0

Page 204

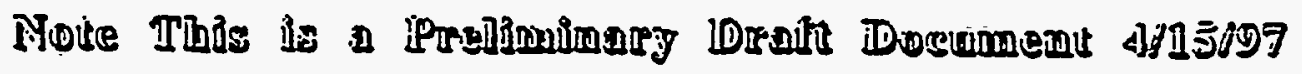

\section{Summary and Report of January and March Demonstrations of Sludge and Grout Mixing for WSRC}

\section{Summary}

Construetion Technology Laboratories, Ine. (CTL) was subcontracted by Westinghouse Savannah River Company (WSRC), the prime site contractor for the Savannah River Site (SRS) of the U.S. Department of Energy (DOE), to demonstrate the degree of mixing between the reducing, flowable grout ib $_{3}$ and a simulated sludige representative of the heel in Tank 20F, a steel tank containing 2 residue of high-level radiosctive waste at the SRS. It was anticipated that under the right conditions this high cement content reducing grout would mix with the type of sludge slurry present in Tank 20F at SRS. It was also thought necessary to pretrear the sludge siurry with hydrated lime to precipitare and remove chemical species that could adversely interact with calcium in the hydrating cement $A$ January demonstration of grout poured into a hydrated lime pretreated sludge slumy at CTL indicated there was very lintle mixing between grout and sludge. What little mixing that did occur, estimated at about $20 \%$ of the sludge, appeared to occur due to three effects. Some mixing occured adjacent to the vertical walls of the form, other mixing appeared to occur due to the rapid delivery rate of the grout entrapping sludge as the front advanced, and a considerable degree of mixing occured as the grout met the end wall of the form and folded back on the sludge pooled on top of it.

Evaluation of these results led to the conclusion that more mixing might occur when the siudge was not pretreated and, therefore, about one-third of the liquid would be present in the form. The form for the March demonstration was also redesigned so the side walls angled out at 45 degrees to decrease wall effects. Other changes had the sides aligned at 10 degrees to one another following the radii of a circle whose focus was the pour point for the grout and another change was a substantial reduetion in the grout flow rate to simulate the planned flow rate into Tank 20F. Two cases were examined in back to back forms with. adjacent mixing areas. On one side the cold sludge closely sirmulated the chemical composition of the Tank heel, and the other side a dewatered and somewhat thicker sludge was placed on the bottom of the form. This sludge was at the saturation concentration of the salts it contrined and, upon standing, a layer of crystals formed on the surface.

Grout was slowly introduced into both forms simultaneously, increasing the rate slightly as the grout level increased and taking roughly 7 hours from start to finish. Observation on removal of hardened sections of the grout indicated a very minor amount of sludge mixing and entrapment where the bottom and the walls of the form met. The very minor discoloration of the plastic liner and the bottom of the grout seemed to indicate the grout pushed the sludge ahead as effectively as a squeegee moving warer across a floor. Due to the slow flow rate, there seemed to be liwle mixing as the grout met the end of the form. The grout was retarded and continued to flow quite well over the seven hours of the pour. After the end of the pour, the grout depth on both sides varied from $21.5 \mathrm{in}$. deep to about $9 \mathrm{in}$. near the end of the form, $42.5 \mathrm{ft}$ away from the point of grout introduction. 
WSRC-TR-97-0102

APPENDIX "B"

Revision 0

CTL Grout and Sludge Mixing Report

Page 205

Sampling was planned with more cores and samples near the ends of the forms where the sludge had been relocated. Sections of cores were taken that were between 2.5 and 4 in. long so there would not be too great a variation of sample weight. Measurement of percent insolible material has a very small range indicating good distribution of paste and aggregale and uttle segregarion. The roughly 3\% nickel in the sludge and added copper were used 25 tracers and presumed to be insoluble hydroxide solids. Analysis for copper and nickel indieated that in the middle sections of the cores, there was viruully no sludge intermixed. Copper detected in the top and bottom core sections may have been due to some grour sludge mixing, but also could have resulted rrom an exterior coating of sludge. No more than $30 \%$ of the tracer metals are mixed in the grout and probably much less. Quantitative estimates of ponded sludge indicate that 60 to $90 \%$ of the tracer metals remained on top of the sludge. Visual appearance of the cores indicate less mixing of shudge and grour in the March compared to the January demonstration. Preliminary conclusions indicate very little mixing has occured although there is some entrapment of sludge within the grout.

In a separate experiment, segregation of the grout with drop beight was examined using strength as an indicator of change. Litule change of strength occured with drop beight for samples directly under the grout stream. Somewhat away from the stream, samples were lower in strength at 15 and $23 \mathrm{ft}$ drop heights. Grout can be introduced from at least $23 \mathrm{ft}$ and lower strengths and segregation should not be substantially affected

\section{Background and Information from the January Demonstration}

In 1996. CTL performed a number of experiments to develop 3 formulations of recucing grout for both their physical and chemical characteristics. Physical characteristics of the 3 grout formulations were very similar, all were flowable, nearly self-leveling, and retained flowability over several hours while exhibiting minimal sand segregation from the cementitious paste over the same time period. All grouts had high pH, adequate reciucing properties, and comparable ability to stabilize the chemical species of interest. Grout \#3, formulated with Type $V$ portland cerment, was recommended because of its effectiveness under the widest range of conditions.

By mid-1996, additional information had been obtained on the chemical composition of the heel in Tank 20F indicating that it concained 2 substancial amount of sodium oxalate, carbonate and sulfate. Experiments indicated if good mixing occured between a sludge with this chemistry and grout $\# 3$, then the grout would lose nearly all of its flowability. Pretreatment of the sludge with a $10 \%$ lime slurty, which also contained rectucing agents (sodium thiosulfate and a small amount of calcium sulfide), was considered necessary to precipitate the chemical species that caused the loss of grout flowability. In mid-September 1996, a small seale experiment was performed pouring grout into pretreated siudge contained in a form about 8 feet long and widening from 0.75 to 3 feet. Grout was slowly introduced into the pretreated sludge and good flow as well as good mixing and selfleveling was observed. Some concem was expressed that this small scale experiment may not accurately represent the behavior of the sludge and grout which would occur in the acual Tank 20F pour.

CTL was asked to perform a large scale demonstration to simulate introduction of the grout in the center of the tank and into a lime pretreated sludge. The form was roughly in the shape of a bowtie with a roughly circular 10 fr diameter center section and two long arms $37.5 \mathrm{ft}$ long. The arms were $4 \mathrm{ft}$ wide at the opening from the center circle and increased 
WSRC-TR-97-0102

in width to $8 \mathrm{ft}$ at the ends, $42.5 \mathrm{ft}$ from the center of the circle; all walls were $2 \mathrm{ft}$ high and perpendicular to the base of the form. The form was double lined with 6 mil polyethylene plastic sheets, which were one piece and continuous with no joints. The sheets were folc:d carefully into the form with no staples to make, hopefully, a leak proof form. WSRC provided the cold sludge and CTL obtained chemicals, then mixed the chemicals into the sludge to simulate the composition of the heel in Tank 20F. In addition to chemicals added to simulate the tank sludge, copper sulfate pentahydrate was also added to conver into an insoluble tracer which could be used to measure the degree of mixing between sludge and grout after the pour was completed. A description of the mixing procedure to make this sludge can be found in Appendix $A$.

Since the sludge separates on standing, the barrels were remixed and then immediately poured into the form, distributing the sludge uniformly from end to end. An unsuccessful attempt was made to clear the center circle of sludge solids and leave only supemate in the center. The combined sludge and supemate was calculated to be 1.4 in deep from the volume of the sludge and the area of the form. A ten weight percent hydrated lime slurry was made with the added redueing chemicals used previously; the volume made was sufficient to be 2 in. deep in the form. Preparation of the lime slurry is described in Appendix A. Immediately after mixing, the hydrated lime slurry was purmed uniformly into the sludge in the form, distributing it uniformly from end to end. The pretreated sludge with an approximate combined depth of $3.4 \mathrm{in}$. remained in the form for over 24 hours before grout was added to the form.

It was desired to sample by coring promptly after the grout had hardened in the form, therefore, no retarding admixture was used in the grout \$3 mix design. Laboratory experiments indicated similar flow properties would be achieved over the planned two hour length of the pour with such a modified mix design. Grout \#3 was mixed at a commercial ready-mix plant and delivered by ordinary ready-mix trucks to CTL. These trucks discharged the grout into the hopper of a concrete purnping and boom truck. The boom was outfitted with a 4 in. outlet pipe which discharged vertically 5 ft over the focus of the center mixing circle of the form. The rate of grout delivery was 17.4 cubic yards per hour, which was about $1 / 2$ the rate expected from the grout mixer at SRS but allowed enough time for smooth transitions from one unck to the next for the demonstration. A brief interuption occured when cone truck was late, however, it did not seem to significantly affect the flow of grout.

During the January demonstration, the grout pouring into the form containing the pretreated sludge indicared specific flow partems. Within the center circle there were two quiet areas of low flow; those areas were bounded by the circumference and the imaginary extension of the walls of both ams. The grout flowed smoothly out the two arms but was significantly affected by the wall. A substantial portion of the sludge was pushed ahead of the advancing front of grout. The grout flow proceeded to both ends of the form. After the grout hardened and cores were taken, it was clear that little mixing had occured in the center circle and in the first $25 \mathrm{ft}$ from the center of the circle. Further from the center than $25 \mathrm{ft}$, some mixing occured against the side walls and additional mixing was apparent near the ends of the form. A considerable volume of sludge remained on top of the grout at either end of the form. A rough colculation of this volume of pretreated sludge on top of the grout determined that about $80 \%$ of the original sludge was there and the other $20 \%$ was encapsulated, covered, or mixed with the grout.

For the March demonstration, the flow rate was decreased to match the amount of grout flow expected from the on site grout plant and proporioned to fill the form at the same rate 
of inches per hour expected when grout was actually placed in Tank 20F. The form was redesigned with the side walls of the arms angled out at 45 degrees to the botrom to decrease wall effects. The center circle was replaced with two half cireles, separated by a partison, so two different scenarios could be evaluated, one in each arm of the form. The west arm had wetter sludge, similar to that used in January; the east arm had dewarered sludge. No pretreatment was used for either amn for the March demonstration.

\section{Qualitative Flor Behavior of Grout and the Interaction with Stodge}

During the March demonstration, the grout flowed reasonably smoothly in spite of the on and off operation of the ball valves (described below) to obtain the planned slow flow rate. Most of the sludge was pushed ahead of the grout althongh a layer of sludge was observed between the grout and the walls near the grout front. The depth of sludge in front of the advancing grout front was periodically measured and kept increasing as the grout flowed toward the end of the form. The grout appeared to be advancing in the same manner on the two sides; it flowed under the sludge as might be expected from the difference in density between the two materials. After a few hours, the grout was no longer advancing at a steady rate and instead would stop advancing for awhile and then surge ahead for a short distance.

After the grout had hardened then some sections lifted out, and cores removed, very little sludge was observed on the bottom of the form under the grout. Brown material did not appear to be mixed into the hardened grout material. A thicker sludige layer was seen under the grout at the juncture between the wall and bottom of the form, probably due to a wall cffect. Somewhat more sludge was observed under the grout at the very end of the form. especially in the two corners. A small degree of mixing was seen in the cores taken very close to the end of the form, but considerably less than seen in cores from the January demonstration.

\section{The Pour set-up for Grout Delivery:}

Grout was discharged from ready mixed trucks into the hopper of a grout pump and then pumped into two hoppers. Distribution into the two forms was done using twin-hoppers, with plastic outlets. Ball valves were connected to the hoppers to control the flow of grout. The pipes from the discharge ends of the ball valves were then connected to diaphragm valves and a pipe 20 further fine-tune the flow to the required rate. There was 12-15 inches of piping between two volves. The two pipes discharged the mortar to each serni-circle section of the forms from where the grout flowed towards their farthest ends. As described previously, the sludge was prepared and processed according the specified procedures placed in both the east and west arms of the forms, two days before the pour. Darns were erected at the neck of the semi circle connected to the forms to avoid the sludge moving to the semi circles. Just before the pour the dams were removed.

\section{The first truck arrived at 9.07 .}

The grout flow and pHI from the truck was measured before the start of the pour to assure a proper flow. The flow and $\mathrm{pH}$ were acceptable. 
The grout was discharged to a pump through a coarse sieve to remove any large junk pieces, if any. The grout was pumped directly to the hoppers (one was filled after the other). The grout was discharged through the pipes to the semi-circle at a specified rate by controlling the valves. Two pumps were made available to be used simultareousty for efficient operation and to avoid delays for unforeseen ressons.

In order to achieve the required flow the following valve sequence was administered, using the diaphragm:

9:37 A.M. $4 \mathrm{~min}$ on $1 \mathrm{~min}$ off for $30 \mathrm{~min}$

10:08 AM. $4.5 \mathrm{~min}$ on $1 \mathrm{~min}$ off for $20 \mathrm{~min}$

10:28 A.M.' 5 min on $1 \mathrm{~min}$ off $\quad$ for $15 \mathrm{~min}$

The diaphragm valves did not work satisfactorily and were removed at 10:43. Then the valves were replaced with straight open piping and the following sequence was followed with the ball valves:

10:48 A.M. $3 \mathrm{~min}$ on $2 \mathrm{~min}$ off for $15-20 \mathrm{~min}$

11:05 A.M. $3 \mathrm{~min}$ on $3 \mathrm{~min}$ off for $40 \mathrm{~min}$

\section{The second truck arrived at $\mathbf{1 1 . 4 5}$}

The grout flow and pH from the truck was messured before the start of the pour to assure a proper flow. The flow and $\mathrm{pH}$ were scceprable.

12:05 A.M. One grout pump got stick; some chunks were found in the grout. There was a brief hold up.

Only one pump took turns for both the hoppers. The rate of flow was inereased to compensate for the lost time. - The valve sequence was adjusted as follows:

12:35 A.M. 3 min on $1 \mathrm{~min}$ off for the remainder of the truck

The third truck arrived at $\mathbf{1 3 . 4 5}$

The grout flow and pH from was measured before the pour. The flow and pH were scceptable..

The same purnp iwas working for both the boppers; and the same valve sequence (i.e., 3 min on 1 min off) was followed for the whole truck.

The fourth truck arrived at $\mathbf{1 5 . 1 0}$

The flow and pH of the grout from the truck was measured and found OK.

Since the same pump was working and taking turns for both the hoppers, the same pour sequence (i.e., 3 min on $1 \mathrm{~min}$ off) was followed for this truck also. 


\section{MONITORING OF GROUT FLOW AND DEPTH DURING THE POUR}

Sludge depth was measured at each $1 / 2$ hour during the pour. Measurements of the grout front and sludge depth ahead of the front at three critical locations in both the east and west fortns were recorded as follows:

\begin{tabular}{|c|c|c|c|c|c|c|c|c|}
\hline Time & \multicolumn{4}{|c|}{ East Form } & \multicolumn{4}{|c|}{ West Form } \\
\hline $\begin{array}{l}\text { (Hr.min)els } \\
\text { psed }\end{array}$ & $\begin{array}{l}\text { Grown } \\
\text { front (in } \\
\text { foet) } \\
\text { from } \\
\text { center }\end{array}$ & $\begin{array}{l}\text { Depth (") } \\
\text { of sludges } \\
15^{*} \text { aliend } \\
\text { of pous }\end{array}$ & $\begin{array}{l}\text { Deph (") } \\
\text { pf sludge } \\
72^{n} \text { ahead } \\
\text { of grous }\end{array}$ & $\begin{array}{l}\text { Depph (") } \\
\text { of sludge } \\
144^{\prime \prime} \text { ahend } \\
\text { pf grouk or } \\
\text { perend }\end{array}$ & $\begin{array}{l}\text { Grour } \\
\text { front () } \\
\text { from } \\
\text { center }\end{array}$ & $\begin{array}{l}\text { Depth (") } \\
\text { of sludge } \\
15^{*} \text { ahead } \\
\text { pf grous. }\end{array}$ & $\begin{array}{l}\text { Depth (7) } \\
\text { of shudp } \\
72^{-} \text {ahead } \\
\text { of prour }\end{array}$ & 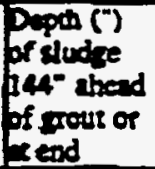 \\
\hline $1: 00$ & 15.5 & $1.8 / 32$ & 22132 & 22132 & 15.5 & $210 \sqrt{32}$ & $122 \sqrt{32}$ & 1232 \\
\hline $1: 30$ & 22.6 & $116 / 32$ & 22232 & $20 / 32$ & 22.3 & 2 IT/32 & $128 \sqrt{32}$ & $18 \sqrt{32}$ \\
\hline $2: 00$ & 28.4 & $117 / 32$ & $24 / 32$ & $\begin{array}{l}20332(0 \\
e n d)\end{array}$ & 27.7 & $216 \sqrt{32}$ & $204 / 32$ & $\begin{array}{l}122 / 32 \\
(0 \mathrm{cod})\end{array}$ \\
\hline $2: 30$ & 28.7 & $124 \sqrt{32}$ & $26 / 32$ & $22 / 32$ & 29.7 & $223 / 32$ & $2.12 / 32$ & $22 / 32$ \\
\hline $3: 00$ & 31.6 & $122 / 32$ & $25 / 32$ & 2432 & 32.2 & 3432 & $32 / 32$ & 3 \\
\hline $3: 30$ & 36.1 & $28 / 32$ & & $123 \sqrt{32}$ & 34.8 & $322 \sqrt{32}$ & & $321 / 32$ \\
\hline $4: 00$ & 137.4 & 212332 & & $26 / 32$ & 36 & $122 \sqrt{32}$ & & $416 / 32$ \\
\hline $4: 30$ & 39.3 & $315 / 32$ & & $325 / 32$ & 37.4 & $521 / 32$ & & $516 / 32$ \\
\hline $3: 00$ & 39.9 & $612 \sqrt{32}$ & & $626 / 32$ & 34.7 & $86 / 32$ & & $812 \sqrt{32}$ \\
\hline $5: 30$ & 39.3 & $820 / 32$ & & $182 \sqrt{32}$ & 36.1 & $912 \sqrt{32}$ & & 912132 \\
\hline $6: 00$ & 39.3 & 92032 & & 926132 & 36 & 11 & & 11 \\
\hline $6: 30$ & 39.9 & $1116 \sqrt{32}$ & & $1116 / 32$ & 37.4 & 12 & & 12 \\
\hline
\end{tabular}

Grout depth was also monitored once every hour(for 4 hours) starting 1:23 P.M. The depth was messured at Rib $\$ 5,10,15,20,25$, and 30 (end). The depth messurements in inches are as follows:

\begin{tabular}{|c|c|c|c|c|c|c|c|c|}
\hline Rib\# & \multicolumn{4}{|c|}{ East Form } & \multicolumn{4}{|c|}{ West Form } \\
\hline & :23 P.M. & R:23 P.M. & B.23 P.M. & 4:23 P.M. & 1:23 P.M. & R:23 P.M & B:23 P.M. & 4:23 P.M. \\
\hline $0\left(4^{\prime}\right)$ & $147 / 8$ & 15 & $181 / 4$ & $203 / 4$ & $151 / 8$ & $161 / 4$ & 19 & 22 \\
\hline $5\left(10.4^{4}\right)$ & 13 & 14 & $163 / 4$ & 19 & $135 / 8$ & $143 / 4$ & 17 & $191 / 2$ \\
\hline $10\left(16.8^{2}\right)$ & $103 / 4$ & $221 / 2$ & 15 & $171 / 2$ & $103 / 4$ & 13 & $151 / 2$ & $171 / 2$ \\
\hline $15\left(23.2^{\prime}\right)$ & 8 & $101 / 2$ & 13 & $153 / 4$ & 7718 & 1012 & $131 / 2$ & $151 / 4$ \\
\hline $20(29.77)$ & $51 / 8$ & 8 & $113 / 4$ & $141 / 4$ & $53 / 4$ & $81 / 2$ & 12 & 15 \\
\hline $25\left(36.1^{\prime}\right)$ & $=$ & & 9 & $12 / / 4$ & & & $101 / 4$ & 13 \\
\hline $30(42.5)$ & & & & $93 / 4$ & & & & $123 / 4$ \\
\hline
\end{tabular}




\section{Sampling Plan for the March Demonstration}

The grout flowed smoothly out of the mixing area and into each of the long segments of the forms. Flow was somewhat affected by the walls but less than in the previous test. A substantial portion of the sludge was pushed ahead of both advancing fronts of grout on the wetter side as well as the dewatered side.

The contaminant or tracer in this demonstration is cleariy more abundint toward the ends of the forms (the last $7 \mathrm{ft}$ ) and less abundant near the center. The sampling plan described below is a combination of two categories of samples: judgment samples where elevated tracer levels are expected, and well spaced samples near the centerline, where low tracer leveis are expected. Before samples were obtained, a survey was taken of the last $7 \mathrm{ft}$ at the end of each form, measuring the depth of clear supemare, depth of damp sludge, and thickness of grout. The area of the form, furcher than $7 \mathrm{t}$ from each end, essentially contains grout, which may be mixed with a small amount of sludge, but the grout is not covered with either supernate or sludge. After the measurements were taken, representative samples of the sludge remaining on top of the grout were taken and analyzed for copper and nickel.

Twelve of the 20 cores then were obtained for copper and nickel analysis were located within $10 \mathrm{ft}$ of the two ends of the focm. A total of twenty cores (with $33 / 4$ in. 104 in. diameters), ten from each side, were obtained. Samples were taken away from the walls, avoiding locations closer to the wall than $20 \%$ of the widh of the base of the form at the sample location. Eight cores will be obtained further than $10 \mathrm{ft}$ from the two ends of each form and none within the semicircular mixing area. Locations of all 20 cores have been numbered and their positions are indicated on the attached drawing which is drawn to scale and also indicares the width of the sloped sides.

In areas where significant wet sludge covers the grout, it may be impossible to properly sample the cylinder of sludge above the core location. Since the sludge should be homogeneous throughout its volume, composite sludge samples taken from each end for analysis, combined with the survey of the area of sludge covering the grout, should provide comparable information as a sludge sample directly above 2 grout core. The clear supernate was stirred up before the composite sludge samples were obtained, then the bulk of the sludge was removed to expose the grout for coring.

The cores of hardened grout from both sides of the form had leagths between 9 and 20 in. and were sliced into samples of roughly equal volumes. From cores $1,2, \& 3$, two 3 in. high samples were taken, one from the mid-point of the core and the other from the botrom. From cores 4 \& 5 , three adjacent sections, each about 3 in. high, were cut off and labeled BOT, MIDBOT, and MIDTOP. From the remaining 5 cores on each side, 4 roughly equal sections, were cut off, some 25 short as 2 in. The total number of samples prepared for analysis of the copper and nickel tracer metals was 64.

Each section of core was dried at $105^{\circ} \mathrm{C}$ then broken up, crushed, and pulverized to pass a 50 mesh sieve. This well homogenized powder was then sampled and digested in acid to prepare a solution for atomic absorption flame analysis. 

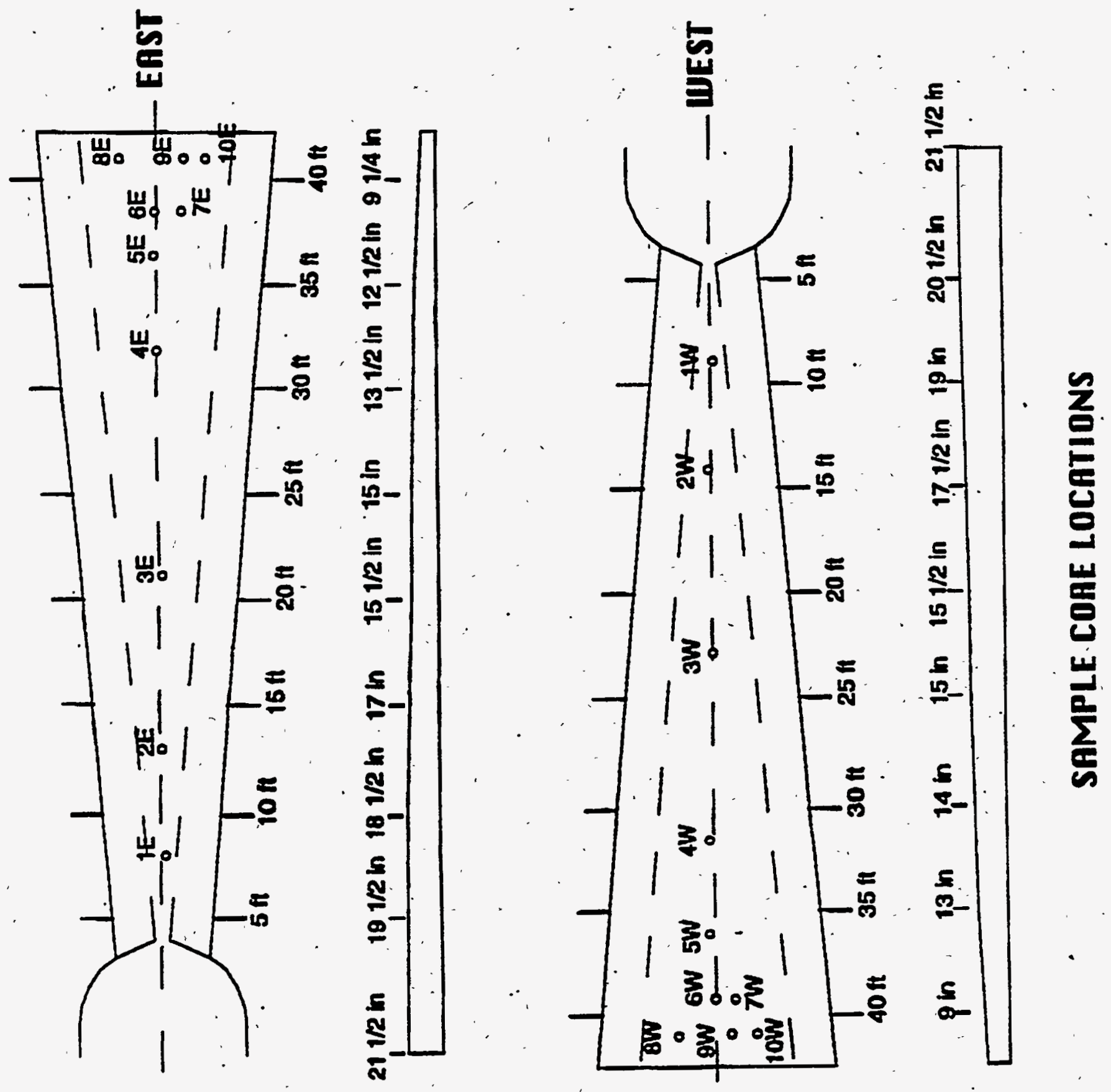


\section{Sample Analysis of the Grout for Copper and Nickel Tracers}

Samples which are identified as $\mathrm{T} 1$ through $\mathrm{T} 4$ are grout samples obtained from the ready mix trucks and should contain only background levels of copper and nickel. Preliminary review of the results and a conservative approseh has been taken and no mixing of sludge into grout is considered to have taken place unless copper levels are $>22 \mathrm{ppm}$ and nickel levels are $>7 \mathrm{ppm}$. It appears there has been only a small amount of sludge present on or in the grout in the bottom section of the cotes and near the end of the forms some studge is present on or in the grout in the top section of the cores. At the ends of either form, there appears to be no mixing of sludge into the two middle sections of those coives. These samples are identified as 8, 9, \& $10 \mathrm{E}$ (from the east end) or W (from the west end) to indicate the cores from which they were cut and have MIDTOP or MIDBOT suffixes to indicare samples from the middle sections of the cores. 
Clieul: Westinghouse Savanash Rf́ver Co

Project Building 719-4A, Room 129

M05202

Contact: Dale Bignell

Submitter: Pres Weat

Date recv'd: 10-Jan-97
CIL Project No: 407594

CIL Project Mga Pres West Annlyst Michoel Zlatokrylov 42 Approved:

Date annlyzed: C25-Mar-97

Dute reported: 14Aprest

\section{REPORT Of CHEMICAL ANALYSIS}

Sample Identification

CT.II ClientII

924247

924248

924249

924250

924251

924252

924253

924254

924255

924256

924257

924258

924259

924260

924261

924262
1E.Mrd

IE-Bot

25-Mid

2E-Bot

3E-Mid

3E-Bot

4E-Mid

4E-Mid-Bot

4E-Bot

52.Mid

5E-Mid-Bot

5E-Bot

बร-Top

GE-Mid-Top

GE-Mid-Bot

6E-Bot

\begin{tabular}{|c|c|c|c|c|}
\hline & Analyre & & & \\
\hline Canpom & Nhopm & & GoTnsol & \\
\hline $155^{\circ}$ & 3 & & 34.42 & . \\
\hline 23.8 & 3 & & 32.58 & \\
\hline 15.6 & $\beta$ & & 34.68 & \\
\hline 19.8 & 3 & - & 35.32 & \\
\hline 15.0 & $<$ & & 35.73 & \\
\hline 22.0 & $<$ & & 35.97 & \\
\hline 15.4 & $<$ & . & 35.70 & \\
\hline 16.1 & $<3$ & & 32.78 & \\
\hline 19.4 & 3 & & 34.58 & \\
\hline 16.0 & 3 & & 33.63 & \\
\hline 18.4 & 7.65 & & 33.41 - & \\
\hline 29.4 & 12.0 & . & 33.40 & \\
\hline 20.2 & 3 & & 32.31 & $\cdot$ \\
\hline 19.0 & 8.54 & & 32.22 & ' \\
\hline 15.7 & 6.7 & & 32.14 & \\
\hline 25.3 & 3.63 & & 35.40 & \\
\hline
\end{tabular}




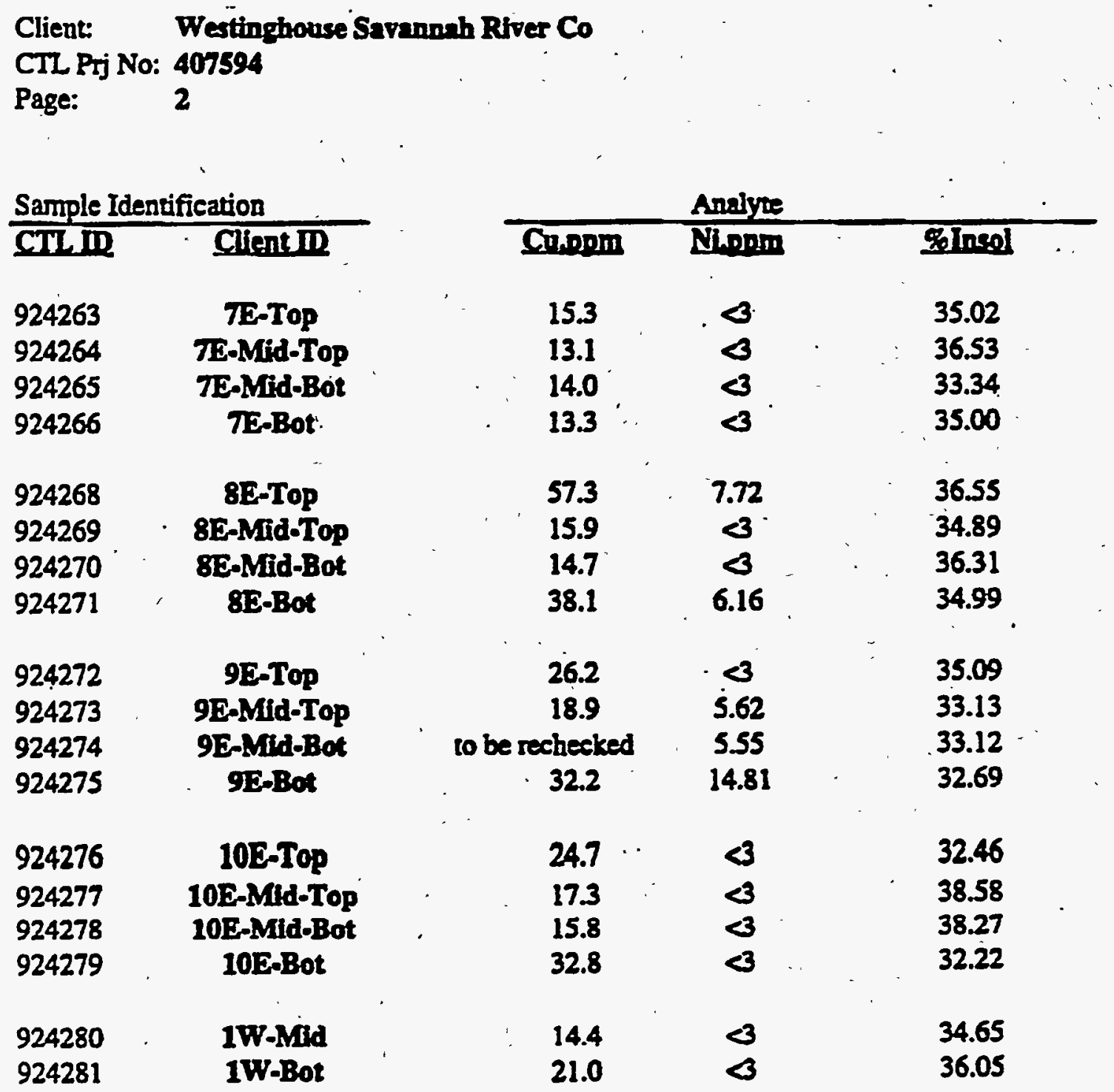


Client: Westinghouse Savaninah River Co CTL Pri No: 407594

Page: 3

Sample Identification

CTLID

Client ID

924282

924283

924284

924285

924286

924287

924288

924289

924290

924291

924292

294293

294294

294295

924296

924297

924298

924299
2W-Mid

2W-Bot

3W-Mid

3W-Bot

4W-Mid-Top

4W-Mld-Bot

4W-Bot

5W-MId-Top

SW.Mid-Bot

5W-Bot

6W-Top

6W-Mid-Top

6W-Mid-Bot

6W-bot

TW-Top

TW-Mid-Top

TW-Mid-Bot

TW-Bot-BI

\begin{tabular}{ccc} 
& Analyte & $\vdots$ \\
\hline Cuppom & Singom & SIned
\end{tabular}

14.8

$<$

36.46

20.3

.. $<3$

37.06

14.7

3

36.17

22.4

6.96

37.17

15.7

2.13

6.64

35.98

19.0

25.2

to be rechecked

35.89

36.40

17.6

1.46

35.82

16.2

23.3

3

$<3$

34.15

33.48

24.8

5.99

35.48

18.9

7.45

34.83

15.7

6.71

38.34

37.5

15.8 .

31.43

26.6

3

38.87

16.4

$<3$

$<3$

37.10

37.61

17.4

38.34 
Client: Westinghouse Savannoh River Co

CIL Prj No: 407594

Page:

4

Sample Identification

\begin{tabular}{|c|c|c|c|c|}
\hline CILII & Client JD & Cropm & Nivopm & getreol \\
\hline 924300 & TW-Bot-Lo & 123.7 & 46.5 & 39.89 \\
\hline 924301 & 8W-Top & 33.1 & 9.91 & 37.61 \\
\hline 924302 & 8W-Mid-Top & 16.1 & $<3$ & 37.74 \\
\hline 924303 & 8W-Mid-Bot & 16.5 & $<3$ & 36.88 \\
\hline 924304 & 8W-Bot & 26.4 & $\beta$ & 36.23 \\
\hline 924305 & 9W-Top & 110.4 & 32.8 & 34.39 \\
\hline 924306 & 9W-Mid-Top & 17.2 & 3 & 35.20 \\
\hline 924307 & 9W-MId-Bot & 18.0 & $<3$ & 33.47 \\
\hline 924308 & 9W-Bot & 36.3 & $<3$ & 34.91 \\
\hline 924309 & 10W-Top & 77.7 & 13.3 & 36.50 \\
\hline 924310 & 10W-Mid-Top & 16.8 & $<$ & 37.53 \\
\hline 924311 & 10W-Mid-Bot & 19.7 & 3 & 36.30 \\
\hline 924312 & 10W-Bot & 48.2 & 7.68 & 36.81 \\
\hline 924313 & $\mathbf{T}$ & 15.3 & 3 & 32.67 \\
\hline 924314 & $\mathbf{T 2}$ & 17.7 & $<3$ & 32.88 \\
\hline 924315 & $\mathbf{T}$ & 17.2 & $<3$ & 31.75 \\
\hline 924316 & T4 & 17.3 & $<3$ & 36.26 \\
\hline 924515 & EFSU/GR & 13066 & 8957 & \\
\hline 924516 & WFSL/GR & 14966 & 10653 & \\
\hline
\end{tabular}

Ansilyte 


\section{Sample Analysis of Sludge in the Form}

The composite studge slurries obtained from the material left standing in the form and on top of the grout were dried and then acid digested for analysis. The simmle from the east form is EFSL/GR and the one from the west form is WFSLGR. The east sampie contains about 1.3\% Cu and the west sample almost 1.5\% Cu by weight on a dry basis. Measurements of the sludge depth and profiles of the grout appear in Appendix D and were used to determine the volume and amount of material on the hardened grout.

\section{Measures of the Degree of Miring}

In the West form which contained the wetter shidge, it appears that there was litule mixing that occured. This sludge has been prepared to simulate the sludge of the Tank 20F heel as closely as possible. About $470 \mathrm{~L}$ were placed in the form and the caloulated depth was 1.25 in. From calculations of sludge depth and grout depth, the amount of sludge ponded on the hardened grout was within $5 \%$ of the amount of sludge placed in the form initially. The amount of copper and nickel still on the grout has been calculated from the amount of sludge on the grout and the copper and nickel analysis both before and after the pour. It appears that substantially all the tracer is on top in the sludge. These samples are somewhar difficult to accurately sample and this may lead to some large uncertainties. Nickel in the ponded sludge was within $10 \%$ of the initial amount and copper was within $20 \%$ of the initial value. In the West form, the degree of mixing deternined from changes in the amount of siudge, as well as, from the tracer metals to be less than $20 \%$ and may be only a few percent.

In the East form which contained the dewatered sludge, somewhat more mixing occured than in the other form. Starting with $275 \mathrm{~L}$ of sludge, abour $40 \mathrm{~L}$ of supernate was physically removed and an estimated $20 \mathrm{~L}$ evaporated. This amount of liquid placed in the form was calculated to have a depth of 0.6 in. From volume measurements 6 days after the pour, about $104 \mathrm{~L}$ or $48 \%$ of the initial volume remained ponded on the groul. The amount of copper was $62 \%$ and the amount of nickel was $58 \%$ of the initial amounts of these. $:$ metals. Again numerous experimental uncertainties make it diffieutt to accurately measure the metal content of the studge. The thin layer traped benesth the grout may contain around 15\% of the tracer metals. If copper was uniformly distributed in the bottom 3 in. of the grout at the average concentration measured in the bottom sections of cores, it would only consist of around $3 \%$ of the initial amount of copper.

A greater amount of mixing appears to have occured with the dewatered sludge and may be as great as 30\%. Some sludge has been trapped below the sludge but intimate mixing of sludge and grout is probably less than 5\%. A minimum of $60 \%$ of the sludge did not mix and remained ponded on the grout.

\section{Segregation of Grout 3 with Drop Height}

The purpose of this test was to evaluate grout segregation that might $\alpha c c u r$ as a function of the "free fall" height from which the grout was dropped, using core compressive strength as a measure of potential segregation. If a reduction of core compressive strength was observed, supplemental visual examination of the cores would be undertaken. It would include splitting cores longitudinally, with half of each core examined visually under the stereomicroscope. Three plastic forms, $4 \mathrm{ft} \times 2 \mathrm{ft}$ by 12 in., in size, were obtained to be 
WSRC-TR-97-0102

filled with grout dropped from $5 \mathrm{ft}, 15 \mathrm{ft}$, and $23 \mathrm{ft}$ (maximum attainable) heights. The grout No. 3 was prepared in a two-compartment grout pump, using pre-weighed quantities of dry ingredients, water, and superplasticizer. The grout was pumped through $i-1 / 2$-in od rubi.er hose, secured to the hook of the overhead crane, so that the specified drop height could be easily attained. One form per drop height was filled with grout to a a nominal level of 8 inches. Upon completion of pumping, tightly fitting plastic lids were affixed to all forms, and the grout was allowed to self-cure at ambient vernperature and humidity for 48 hours. The lids were then removed, and the contents of the forms were cored. $A$ total of six (6) cores per drop height was obtained, with 3 cores taken in the vicinity of the center of the form near the point of grout discharge, and the other 3 cores taken from the peripheral areas of the forms. The cores were moist cured for an additional 72 hours and 4 cores from each series were tested in compression at the age of 5 days, whereas the remaining 2 cores from each form were set aside for microscopic examination.

Test results are presented in Tables on the next 3 pages. The following conclusions can bc drawn from these results:

1. Somewhat higher overall compressive strengths were achieved in the grout dropped from 15 and 23 feet.

2. For all three grouts there appears to be 225 to $30 \%$ reduction in compressive 'strength in the core samples taken from the peripheral areas of the forms, with the . greatest reduction observed in the grouts dropped from 15 and 23 feet.

3. Overall magnitude of compressive strength suggests that, for the most part, the grour mix remained materially cohesive within the range of drop heights evaluated, and could be introduced into the Tanks at the Savannah River from elevations at least as high as 23 feet.

It is expected that an impending microscopic examinarion will provide more information as to the cause of the observed compressive strength reduetion..

\section{Conclusions}

Slow flowing grout poured into sludge similar to the heel in Tank 20F did not intermix in any significant amount. The degree of mixing may be as great as 10 to 20\% but. . considering sumpling and analysis uncertainties, mixing may be as low as a few percent. If the sludge is dewatered a grearer degree of mixing occurs. Based on several indicators of mixing, around $20 \%$ mixing occured but cannot exceed $40 \%$ mixing of sludge and grout. This mixing includes sludge entrapment in and below the grout; only a small amount of mixing is intimate mixing of sludge and grout. The flowable grour very effectively pushes the sludge ahead of the grout front and only a small amount of mixing occurs.

Grout \#3, when delivered from drop heights from 5 to 23 fect, remains materially cohesive, develops satisfactory strengths without substantial variation, and could be introduced from elevations of at least as high as 23 feet into the Tanks at Savannah River Site. 
Client: Westinghouse Savannah River Company

Project: Compressive Strength of Grout Dropped From 5 Feet Height

Contact: Mr. Ronald Canupbell

Submitter: Mr. Val S. Dubovoy
CTL Projecl No.: 051038, Task 17

CTL Project Mgr.: P.B. West

Technician: L. Mead

Approved: V.S. Dubovoy

Date: April 14, 1997

Table 1 - Test Results of ASTM C 42-90 Standard Tesi Method for Compressive Strength of Drilled Cores of Concrete

\begin{tabular}{|c|c|c|c|c|}
\hline Core-Identification & $5-1$ & $5-2$ & $5-5$ & $5-6$ \\
\hline Nominal Maximum Aggregale Size (in.) & No.4 & No.4 & No.4 & No.4 \\
\hline Concrele Age al Test (approximale years) & 5 days & 5 days & 5 days & 5 days \\
\hline Moisturc Condition at Test & Dry & Dry & Dry & Dry \\
\hline Orientation of Core Axis in SInucture & Vertical & Vertical & Vertical & Vertical \\
\hline Diameler I (in) & 2.99 & 2.99 & 2.99 & 2.99 \\
\hline Diameter 2 (in) & 2.99 & 2.99 & 2.99 & 2.99 \\
\hline Average Diameter (in) & 2.99 & 2.99 & 2.99 & 2.99 \\
\hline Cross-Sectional Area (sq in) & 7.00 & 7.00 & 7.00 & 7.00 \\
\hline Length Trimmed (in) & 6.0 & 6.1 & 6.1 & 6.0 \\
\hline Length Capped (in) & 6.2 & 6.2 & 6.2 & 6.4 \\
\hline Weight in Air (b) & 3.2 & 32 & 3.2 & 3.1 \\
\hline Weight in Waler (1b) & 1.7 & 1.7 & 1.7 & 1.6 \\
\hline Calculated Unit Weight (pen) & 131.0 & 130.9 & 130.5 & 129.4 \\
\hline Loading Rate, psi/sec & 35 & 35 & 35 & 35 \\
\hline Maximum Load (Jbs) & 24,900 & 24,800 & 21,900 & 14.400 \\
\hline Uncorrected Compiressive Strength (psi) & 3,560 & 3,540 & -3130 & 2,060 \\
\hline Ratio of Capped Length to Diameter (LD) & 2.07 & 2.09 & 2.08 & 2.13 \\
\hline Correction Factor (ASTM C42) & 1.000 & 1.000 & 1.000 & 1.000 \\
\hline Correcled Compressive Sirength (psi) & $3,5 \times 0$ & 3,540 & 3,130 & 2,060 \\
\hline Fraclure Paltem & Conical & Conical & Conical & Inegular \\
\hline Nates: & & & & \\
\hline
\end{tabular}

Construction Technology Laboratories, Inc. 
Client: Westinghouse Savannah River Company

Project: Compressive Strength of Grout Dropped From 15 Feet Height

Contact: Mr. Ronald Campbell

Submitter: Mr. Val S. Dubovoy
CTL Project No.: 051038, Task 17

CTL Project Mgr.: P.B. West

Technician: L. Mead

Approved: V.S. Dubovoy

Date: April 14, 1997

Table 2 - Test Results of ASTM C 42-90 Slandard Test Method for

Compressive Strength of Drilled Cores of Concrele.

\begin{tabular}{|c|c|c|c|c|}
\hline Core Identification & $15-1$ & $15-2$ & $15-5$ & $15-6$ \\
\hline Nominal Maximum Aggregate Size (in.) & No.4 & No.4 & No.4 & No.4 \\
\hline Concrele Age al Test (approximale years) & Sdays & 5 days & 5 dnys & 5 days \\
\hline Moisture Condition at Test & Dry & Dry & Dry & Dry \\
\hline Orientation of Core Axis in Struclure & Vertical & Verticul & Vertical & Vertical \\
\hline Diameler I (in) & 2.99 & 2.99 & 2.99 & 2.99 \\
\hline Dinmeter 2(in) & 2.99 & 2.99 & 2.99 & 2.99 \\
\hline Average Diameler (in) & 2.99 & 2.99 & 2.99 & 2.99 \\
\hline Cross-Sectional Area (sg in) & 7.00 & 7.00 & 7.00 & 7.00 \\
\hline Length Trimmed (in) & 6.0 & 6.0 & 5.9 & 6.0 \\
\hline Length Capped (in). & 6.2 & 6.1 & 6.1 & 6.1 \\
\hline Weight in Air (lb) & 3.2 & 3.2 & 3.1 & 3.2 \\
\hline Weight in Weter (lb) & 1.7 & 1.7 & 1.7 & 1.7 \\
\hline Calculated Unit Weight (pci) & 131.7 & 131.8 & 132.4 & 131.4 \\
\hline Loading Rale, psi/sec & 35 & 35 & 35 & 35 \\
\hline Meximum Load (lbs) & 31,000 & 28,900 & 22,200 & 22,400 \\
\hline Uncorrected Compressive Sirength (psi) & 4.430 & 4,130 & 3170 & 3,200 \\
\hline Ratio of Capped Length to Diameter (LD) & 2.07 & 2.05 & 2.04 & 2.05 \\
\hline Correction Factor (ASTM C42) & 1.000 & 1.000 & 1.000 & 1.000 \\
\hline Corrected Compressive Strength (psi) & 4,430 & 4,130 & 3,170 & 3,20 \\
\hline fracture Pattem & $\because$ Conical & Conical & Conical & Conical \\
\hline Notes: & & & & \\
\hline
\end{tabular}

Construction Technology Laboratorles, Inc. 
Client: Westinghouse Savannah River Company

Project: Compressive Strength of Grout Dropped From 23 Feet Height

Contact: Mr. Ronald Campbell

Submitter: Mr. Val S. Dubovoy
CTL Project No.: 051038, Task 17

CTL Project Mgr.: P.B. West

Technician: L. Mead

Approved: V.S. Dubovoy

Date: April 14, 1997

Table 3 - Test Results of ASTM C 42-90 Standard Test Method for Compressive Strength of Drilled Cores of Concrete

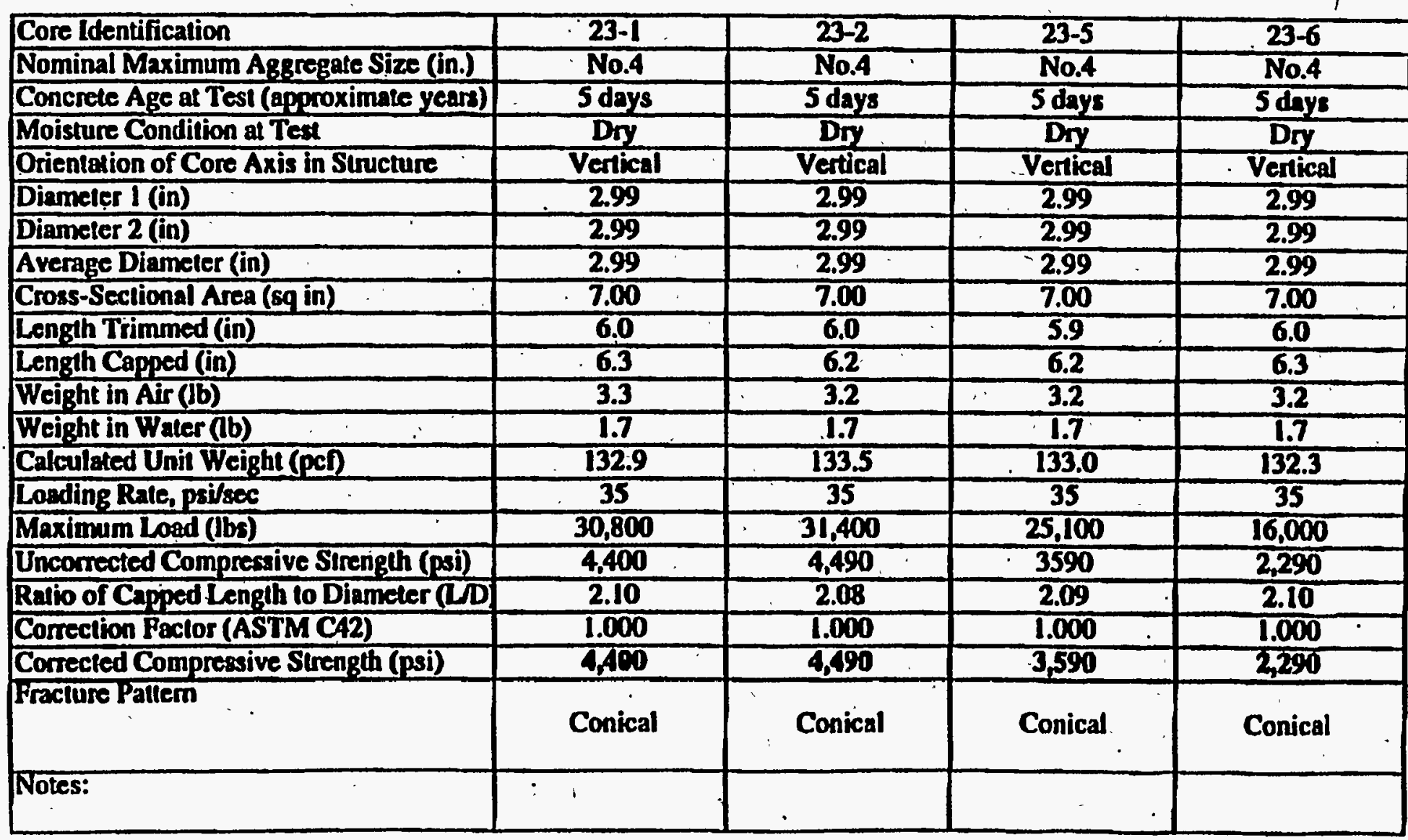

Construction Technology Laboratories, Inc. 


\section{Appendices}

\section{A. Procedures for Mixing Chemicals into the Sludge and Pretreating the Sludge}

\section{Mixing Procedures for the March S, 1997 Demonstration}

Five of the 12 drums received from the Savannah Site were selected for spiking with various chemical compounds. These five drum (\#1, 3, 5, 6, and 12) were selected. because they contained nearly equal volumes of sludge that was very close to the average. Their respective volumes were $41.68,43.41,42.55,45.15$, and 43.41 gallons; the average was 43.24 gallons.

Since, as per the program, the total siudge from these drums was to be divided into two halves and spread in the East and West forms. half sludge was mixed in open drum and the remaining in the as received closed drums.

The sludge for the East form was spiked in open drums. The drums "\#l and 3 were transferred into two open drums and mixed. However, the sludge in drum 12 was mixed in close and half of it transferred in an open drum afterward. The mixing of drums 45 and 6 was done in close.

The spiking of sludge (for both the open and closed drims) was done as follows.

a) $1.035 \mathrm{Kg}$ each of sodium hydroxide (N2OH) was added into all drums and mixed with a hight speed stirrer for 10 minutes.

b) 'Thereafter, $4.130 \mathrm{Kg}$ of copper sulfate-pentahydrate (CuSO4.5T220) was added and mixed for 10 minute. The drums were left for overnight.

c) Next day the drums were stirred for additional 10 minutes to ensure remixing and homogenizing of sludge and the chemicals.

d) $19 \mathrm{Kg}$ of sodium carbonate mosohydrate (Na2CO3.H2O) was added to each drum and mixed for 10 minutes.

e) Next, $9.467 \mathrm{Kg}$ of sodium oxalate (Na2C204) was added and mixed for 10 minutes.

f) $7.034 \mathrm{Kg}$ of sodium sulfate was added and mixed for $5 \mathrm{~min}$.

g) Lastly, to cormplete the spiking of sludge, the remaining 18.792 of sodium carbonate monohydrate (Na2CO3.H2O) was added and stirred for 10 minutes:

The two full open drums and one half taken from the dnum \$12 were transported next to the East forms and let sit for several hours (nearly 72 hours). The supermatent (about 3 inches of clear liquid) was removed from one full and one half-full dnim. The remaining sludge (thick in nante) was remixed with the stirrer and spread in the bottom of the East form and left uncovered to permit more dewarering by evaporation.

The remaining two full and one half drums (all closed) were transferred next to the West Form $a$ day before the pour. The sludge in the drums were remixed and spread on the bottom of the West form. 
Mixing Procedures for the January 31, 1997 Demonstration 


\section{WSR Grout Demonstration Project}

\section{Sludge Mixing Procedures}

Approximarely 475 gallons of spiked sludge were produced by adding various dry chemical to 405 gallons of unspiked sludge/supematant over a period of 7 to 9 days prior to the plecement of the grout. The unspiked sludge/supematant was in eight 55-gallon stainless steel drums. Approximately 60 gallons of unspiked supernatant was removed from these drums and stored for later use (such as rinsing of drums after transferring sludge). The remaining sludge/supernatant was thoroughly mixed for a period no less than 15 minutes with a drum mixer to produce a unspiked mixed sludge. Spiked sludge was produced from the unspiked mixed sludge in 10 barches in open-top 55-gallon steel dnums. In each batch the following chemical constinuents were added to approximately 38 gallons of the unspiked mixed sludge. These chemical additions were calculated based on 405 gallons of unspiked sludge/supematant and did account for the temporarily removed supernatant.

\begin{tabular}{|l|l|l|}
\hline $\begin{array}{l}\text { Material Addition } \\
\text { Sodium Hydroxide }\end{array}$ & $\begin{array}{l}\text { Chemical Formula } \\
\text { Sodium Nitrate }\end{array}$ & $\begin{array}{l}\text { grams per batch of } \\
\text { sludge }\end{array}$ \\
\hline Sodium Nitrte & $\mathrm{NaOH}$ & 959 \\
\hline Sodium Carbonate Anhydrous & $\mathrm{Nan}_{2} \mathrm{CO}_{3}$ & 854 \\
\hline Sodium Sulfate & $\mathrm{Na}_{2} \mathrm{SO}_{4}$ & 6.851 \\
\hline Sodium Carbonate Monohydrate & $\mathrm{Na}_{2} \mathrm{CO}_{3} \cdot \mathrm{H}_{2} \mathrm{O}$ & 5.929 \\
\hline Sodium Fluoride & $\mathrm{NaF}_{2}$ & 6.554 \\
\hline Sodium Oxalate & $\mathrm{Na}_{2} \mathrm{C}_{2} \mathrm{O}_{4}$ & 28.198 \\
\hline
\end{tabular}

Dry chemicals were typically added to the sludge in the order presented. Berween additions, the sludge was mixed with the dnum mixer for a minimum of 2 minutes. In addition. 6 liters of _M CuSO4 solution were added to the individual batches at various stages of dry chemical addition. After a minimum 5 minute final mixing. the spiked sludge was transferred back into the stainless steel drums. Between barches. the open-top drums were rinsed with the unspiked supernatant to remove remiaining material. The rinse supernatant was added to the stainless steel drums containing the spiked sludge. 
After all mixing and transferting of sludge was complete, approximately 450 gallons of spiked sludge was evenly discributed in 9 stainless steel drums. An additional 25 gallons of unspiked supematant remained for sinsing of the stainless steel drums after the spiked sludge was transferred to the formwork.

\section{Sludge Placement Procedure}

Spiked sludge was placed in the formwork. 3 days before the placement of the grout. The sludge from each individual batch was evenly distributed across the formwork to ensure even mixing of the individual siudge barches. The empty stainless steel drums were rinsed with the unspiked 'supematant to remove remaining material. The rinse supematunt was disuributed across the sludge in the formwork. After all transferring of sludge and rinsing of the drums. approximately 15 gallons of unspiked supernatant remained.

Approximately 2 days before the grout placement, an attempt was made to move the sludge from the center portion of the formwork. leaving mainly supernatant. A $1 / 8$ io 1/4-in of supematunt had separated from the sludge. Moving the sludge mainly caused the layers to remix. however. limired amounts of sludge appeared to be pushed out of the center area. The remaining 15 gallons of unspiked supematant was added to the center of the formwork as the last cffor to further move the sludge from the center. This process appeared to remix the sludge. and supernatant to produce $\mathbf{a}$ thinner siudge."

\section{Lime Slurry Mixing and Placement Procedures}

Calculations indicated that approximately 660 gallons (2.498 liters) of lime slumy were required for this demonstration. For ease of preparation and placement, the lime siurny was divided into 14 batches of approximately 47 gallons each. The following chemieal constituents were used in the lime slurry:

\begin{tabular}{|l|l|l|}
\hline Material Addition & $\begin{array}{l}\text { grams per liter of } \\
\text { slurry }\end{array}$ & $\begin{array}{l}\text { grams per batch of } \\
\text { slurry }\end{array}$ \\
\hline $\mathrm{Ca}(\mathrm{OH})_{2}$ & 100 & 17.848 \\
\hline $\mathrm{C} 2 \mathrm{~S}$ & 0.16 & 26.8 \\
\hline $\mathrm{Na}_{2} \mathrm{~S}_{2} \mathrm{O}_{3}$ & 10 & 1.785 \\
\hline Water & 957.59 & 170.887 \\
\hline
\end{tabular}


Dry materials were batched into separate sealed containers over a period of 5 to 7 days prior to the grout placement.

\section{Lime Slurry Placement Procedures}

The lime slumy was placed on the sludge in the formwork 2 days prior to the placement of the grout. The lime slurry was distributed across the entire surface of the sludge.

As described above. 14 barches of lime slumy were produced. All mixing was performed in a single 55-gallon steel drum. The appropriate amount of cold tap water was added to the 55 gallon steel drum. The water was stirred with a suspended sump pump and drum mixer. The dry marerials were added to the warer over a period of 2 to 3 minutes to produce the lime slumry. The lime slurry was mixed for a period of 5 minutes. then the sump pump was used to transfer the lime slumy through a 15-fi long 3/4-in. diameter hose to the sludge. The lime slumy was distributed actoss the entire surface of the sludge. 
B. Batch Plant Mixing of the Grout 
APPENDIX "B"

CTL Grout and Sludge Mixing Report
WSRC-TR-97-0102

Revision 0

Page 228

C. Analysis of Starting Materials and August 1996 Grout Poured into Pretreated Sludge. 
grveturillarehtweturd Englnearing, Tauting and Mrtarials Twehnology

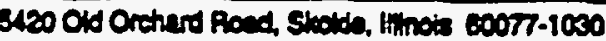

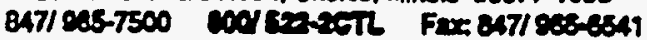

Client. Westinghouse Sovmnah Rivir Co CTL Project No: 107698

Project: Dulleting 779-4h, Room 129.

M05202

Contact Das Bignell

Submitter. Pres Weat

Date reerd: 14 to 29 -anane?

CTL Project Mgr.: Pres Wert

Analyat

Approved:

Date arabyzed: Stalan to 34Fb-97

Dule reported: 4reber

\section{REPORT OF CHEMICAL ANALYSIS}

\begin{tabular}{|c|c|c|c|c|c|c|c|}
\hline CILID & Descriotion & $\cos _{\operatorname{mon}}$ & $\underset{n}{9 x}$ & $\underset{\min }{\mathbf{M}}$ & $f$ & $\underset{20}{20}$ & $\frac{\text { Insethen }}{x}$ \\
\hline 923354 & WSACPHITV & 0.89 & 30.1 & 23.91 & & 263 & \\
\hline 923355 & wsrefitius & 0.07 & 2.92 & 5.68 & & 11.0 & $\therefore$ \\
\hline $\begin{array}{l}923358 \\
923357\end{array}$ & $\begin{array}{l}\text { WSFCPIIICES } \\
\text { WSFCALTEBS }\end{array}$ & $\begin{array}{l}0.12 \\
0.34\end{array}$ & $\begin{array}{l}6.90 \\
6.08\end{array}$ & $\begin{array}{l}<1 \\
<1\end{array}$ & & $\begin{array}{l}19.5 \\
<0.3\end{array}$ & \\
\hline 923358 & WSFCFHAF & 0.39 & 23.8 & $<1$ & & 291 & \\
\hline 923359 & Wsecpiters & 0.71 & 19.8 & 45.68 & - & 37.8 & \\
\hline 923360 & WSPCPYDeEs & 0.61 & 9.19 & 18.38 & & 47.8 & \\
\hline 923361 & WisPCPHETV & 1.49 & 33.1 & 21.6 & & $30 B$ & \\
\hline 923362 & Wsrofinas & 0.64 & 14.2 & $<1$ & & 224 & \\
\hline 923459 & WSRCPFENIN & $<0.05$ & $<0.5$ & $<1$ & & 2.9 & \\
\hline $\begin{array}{l}923460 \\
923461\end{array}$ & $\begin{array}{l}\text { SFinss } \\
\text { sppiturs }\end{array}$ & $\begin{array}{l}55.2 \\
95.6\end{array}$ & $\begin{array}{l}1210 \\
1613\end{array}$ & $\begin{array}{l}22710 \\
30676\end{array}$ & & $\begin{array}{l}3136 \\
3574\end{array}$ & \\
\hline 923462 & PHICROUTHA & 2.78 & 13.2 & 6.85 & & 128 & 52.31 \\
\hline 923463 & PHICROUTKB & 0.14 & 12.8 & 1.08 & & .137 & 54.91 \\
\hline 923464 & PSSLIMIOA & $<0.05$ & 17.7 & 1.85 & & 124 & 54.10 \\
\hline 923465 & PSSLIEOT & 3.01 & 15.2 & 10.45 & - & 117. & 54.18 \\
\hline 923466 & PSS & $<0.05$ & 19.7 & 3.14 & & 139 & 22.03 \\
\hline 923467 & PSSLEOTA & 0.37 & 12.5 & 10.28 & & 124 & 54.80 \\
\hline 923564 & Spiptess & $<0.05$ & 4225 & 3723 & & 214 & \\
\hline
\end{tabular}

Nores:

1. This analysis represents the sample submitud on a dry basis.

2. This report may not be reproduced except in its entirety.

3. The analysis was performed by fiane aromic absorption spectroscopy.

Construetion Technology Laboratories. Ine. 
StruchuraljArchltaclural Enginearing,

Tosilng and Materiale Tochnology

5420 Odd Orctard Foed, Skokde, Wrinois 80077-1030

047/ 965-7500 8001522-2CTL. Fax. 847/ 065-6541

\begin{tabular}{|c|c|}
\hline $\begin{array}{l}\text { Cliont: } \\
\text { Project: } \\
\text { Contect: } \\
\text { Submilitor: }\end{array}$ & 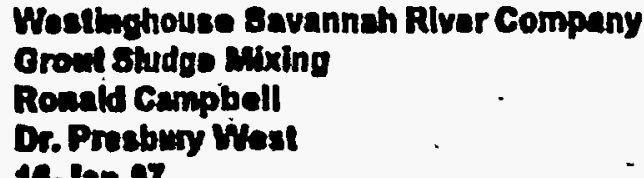 \\
\hline
\end{tabular}

CTL Projoct No.:

CTL PTOJ. Mot:

Anabret:

Approind:

Diso Anabred:

Dalo Reportad:
407503

Dr. Prestury West Scott Nettios

8 in 72

IJian-07

24 Joiter

\section{REPORT OF CHEIMGLL ANLYYA}

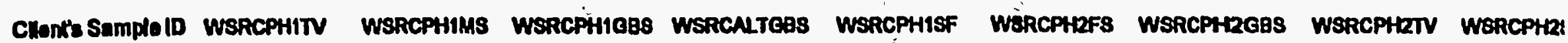

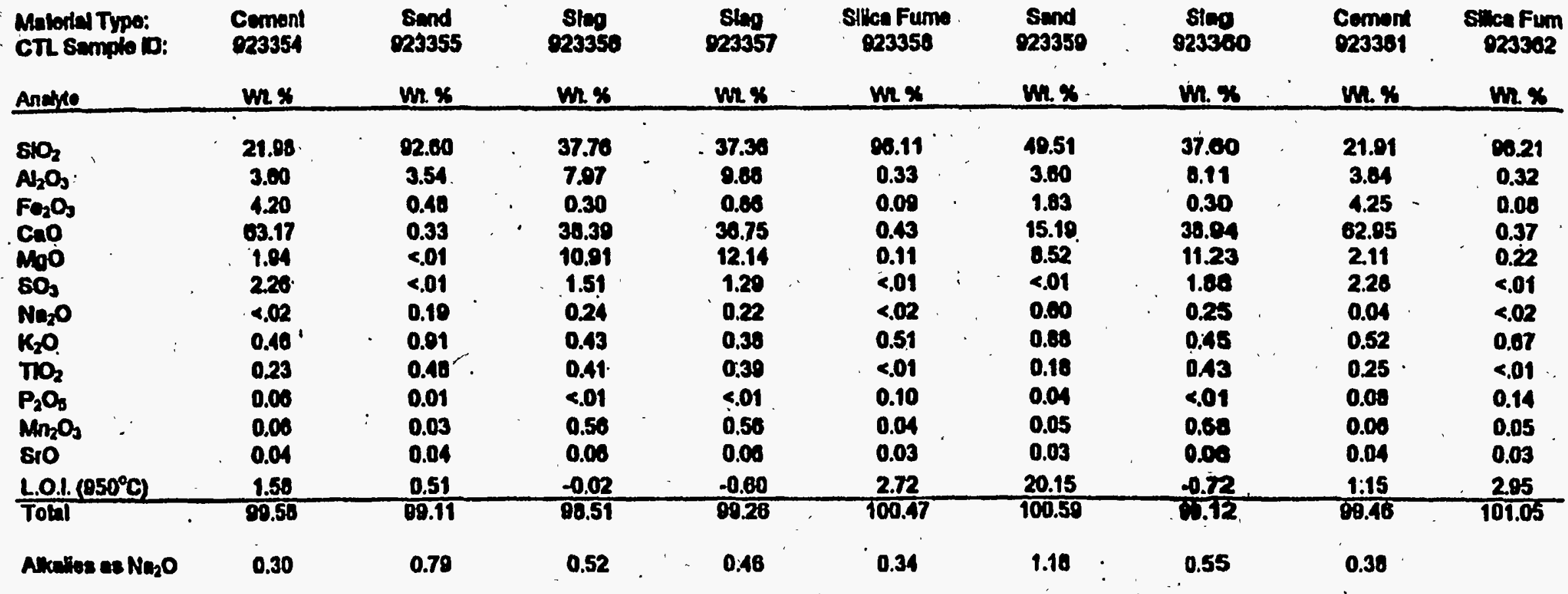

Nolos:

1. This enatris mpresonts spechically tho sample stbmitlod.

2. Reauli roportod on en as recoived binsts.

3. Oxide enshyls by $X$-ray, fluorescence spectometry.

4. This repoit maynot be reproduced except in the entrohy. 


\section{Measurements of Grout and Sludge after the Pours}

The profile lines ünder the form drawings indicate the depth of hardened grout.

The graph indicates the temperature reached within the March grout during curing. 


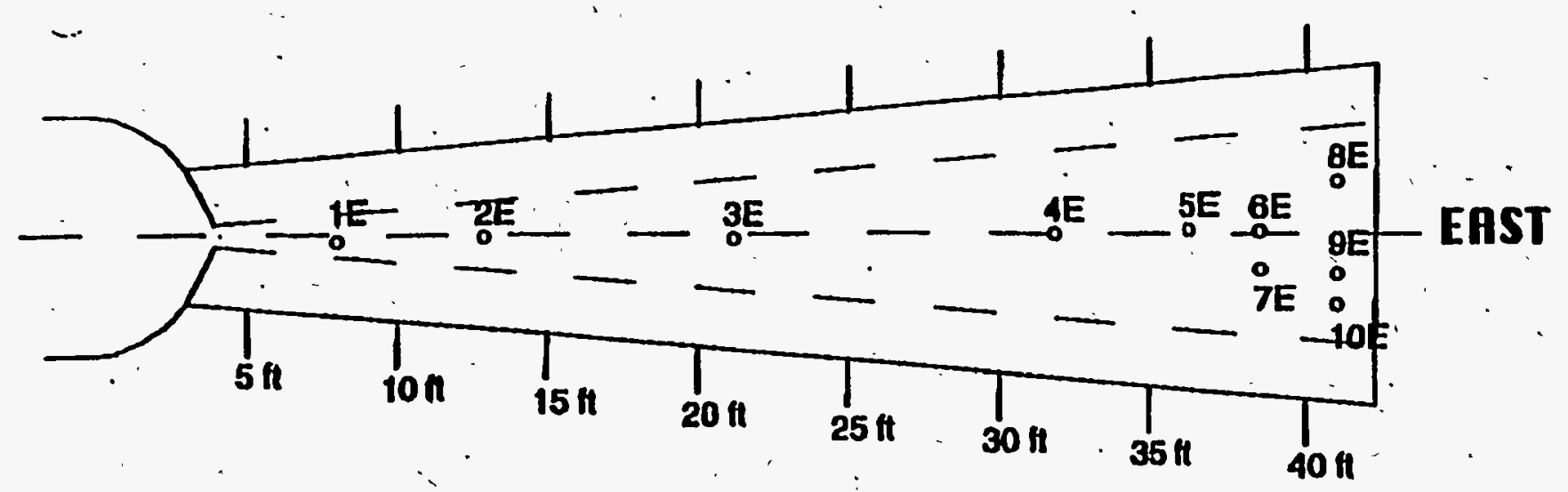

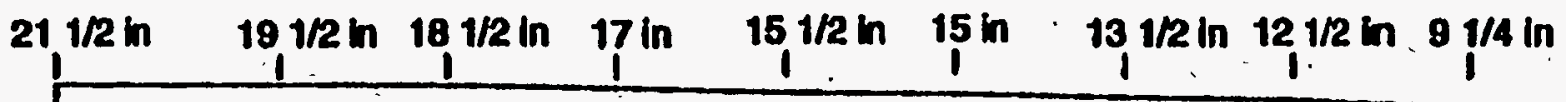

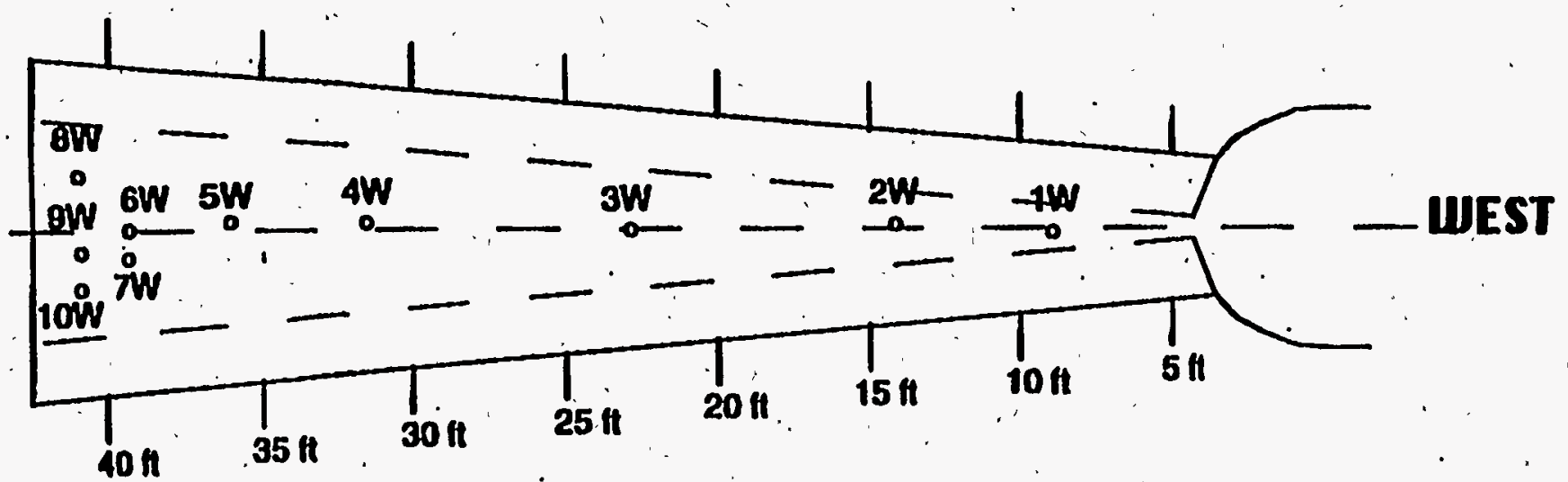

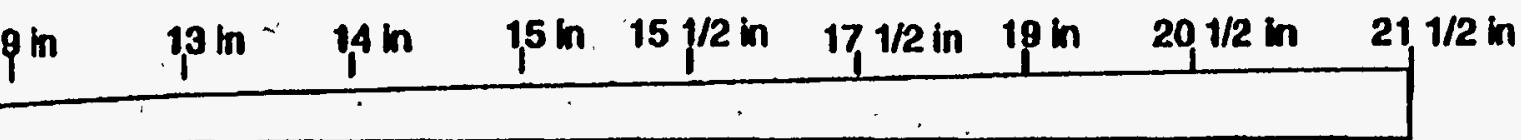

SAMPLE CORE LOCATIONS 


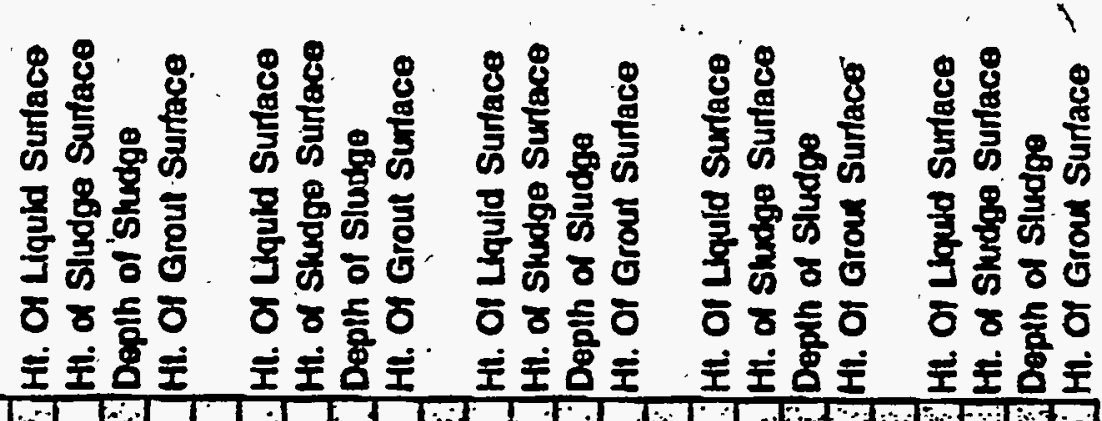

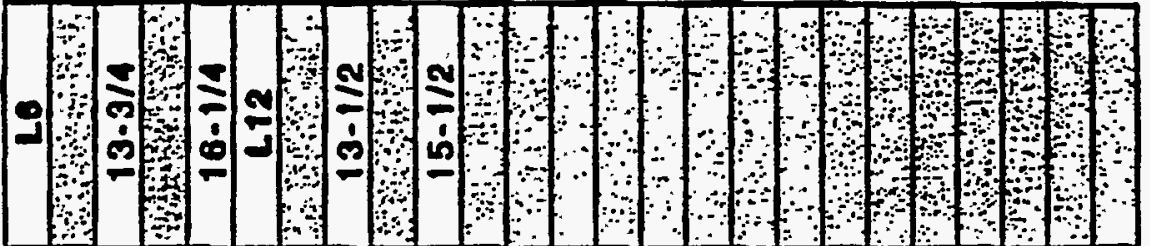

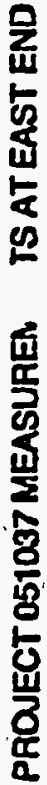
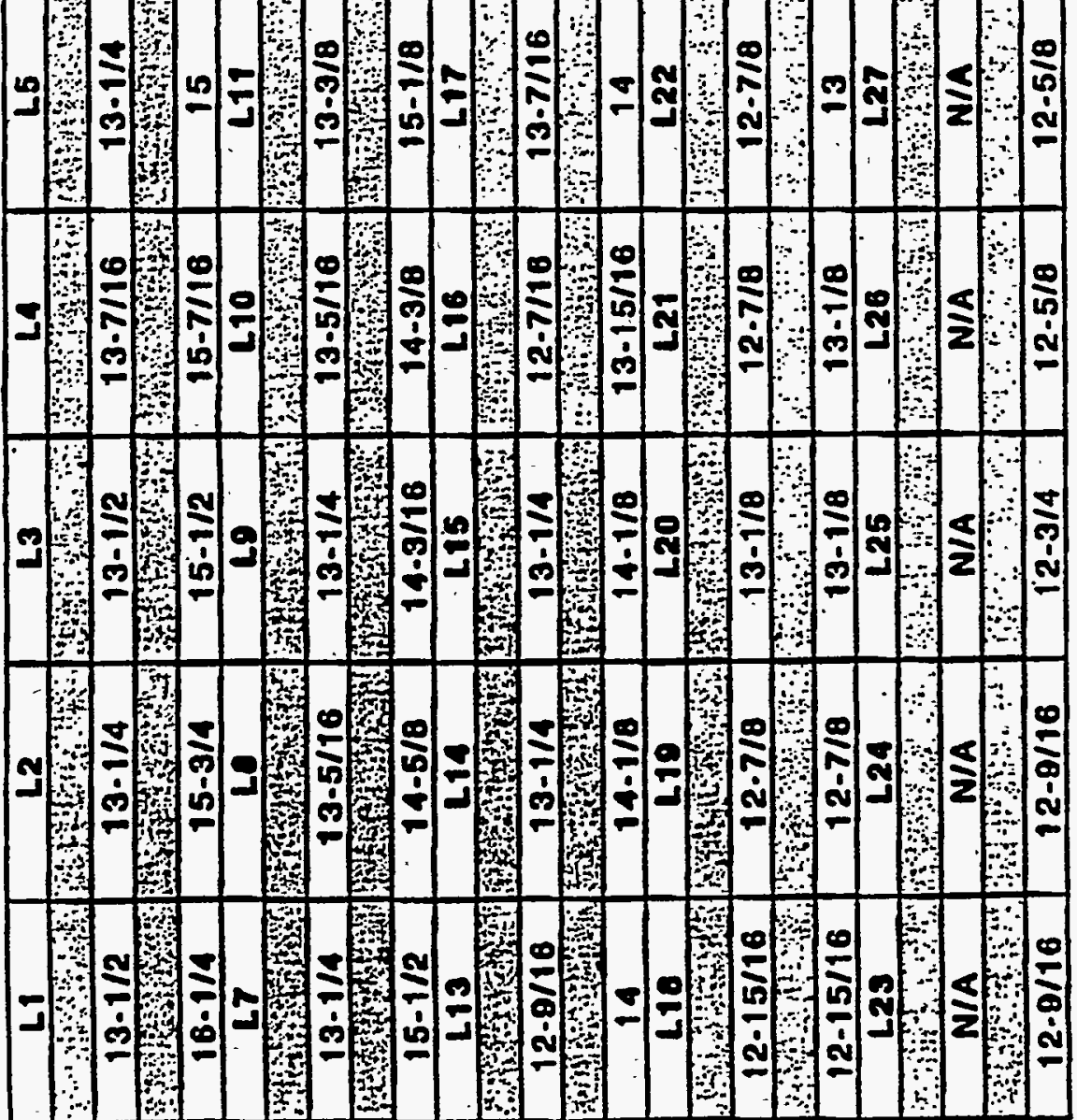

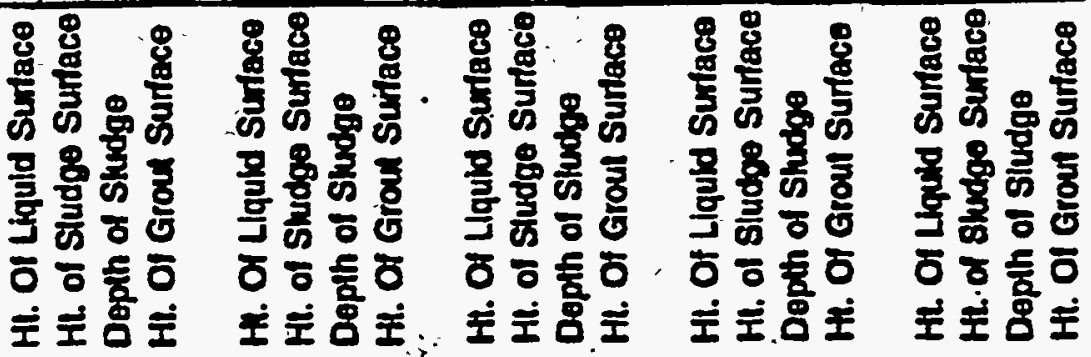




\begin{tabular}{l}
\cline { 2 - 7 } \\
\cline { 2 - 7 }
\end{tabular}



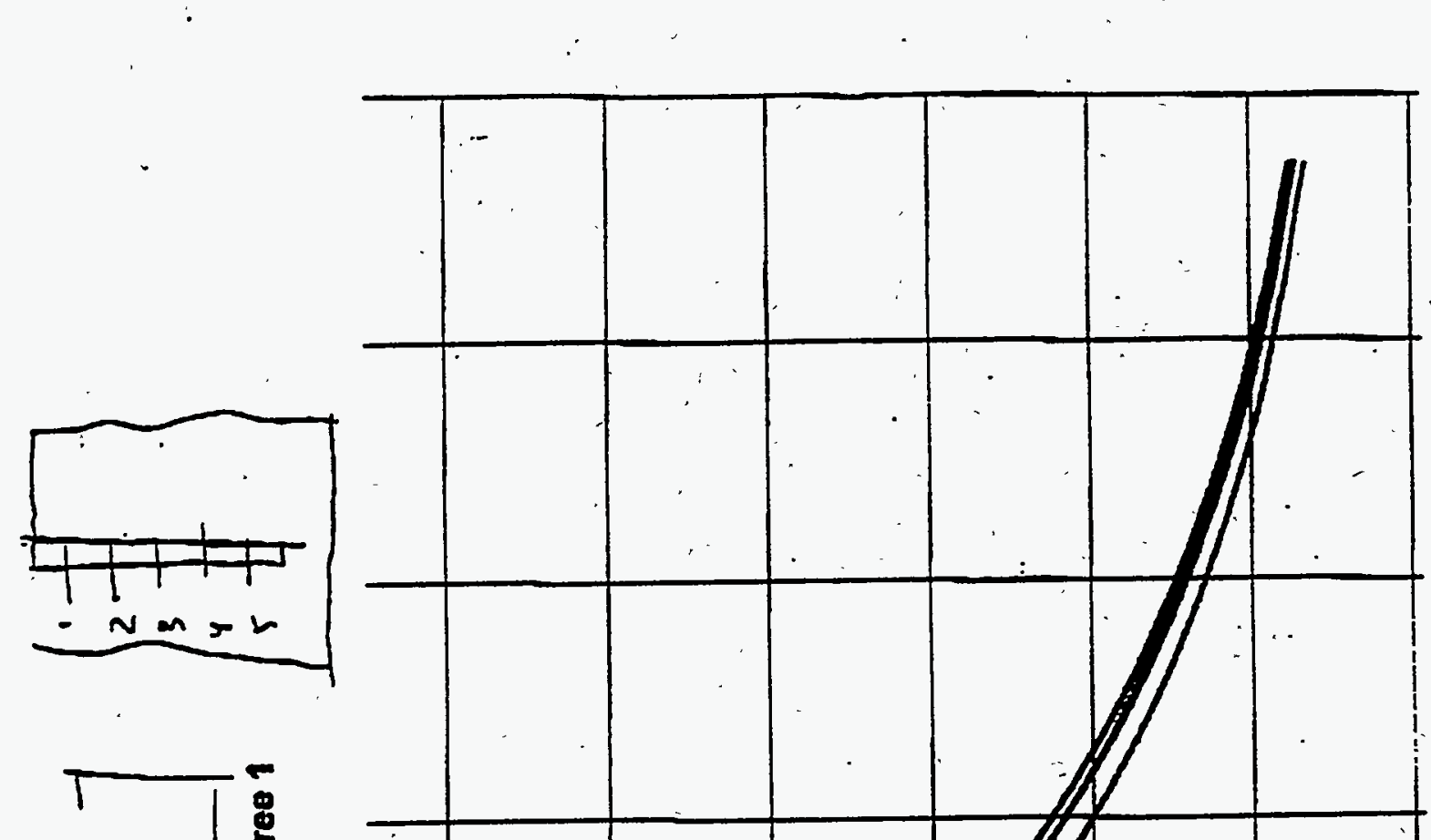

\&ั.
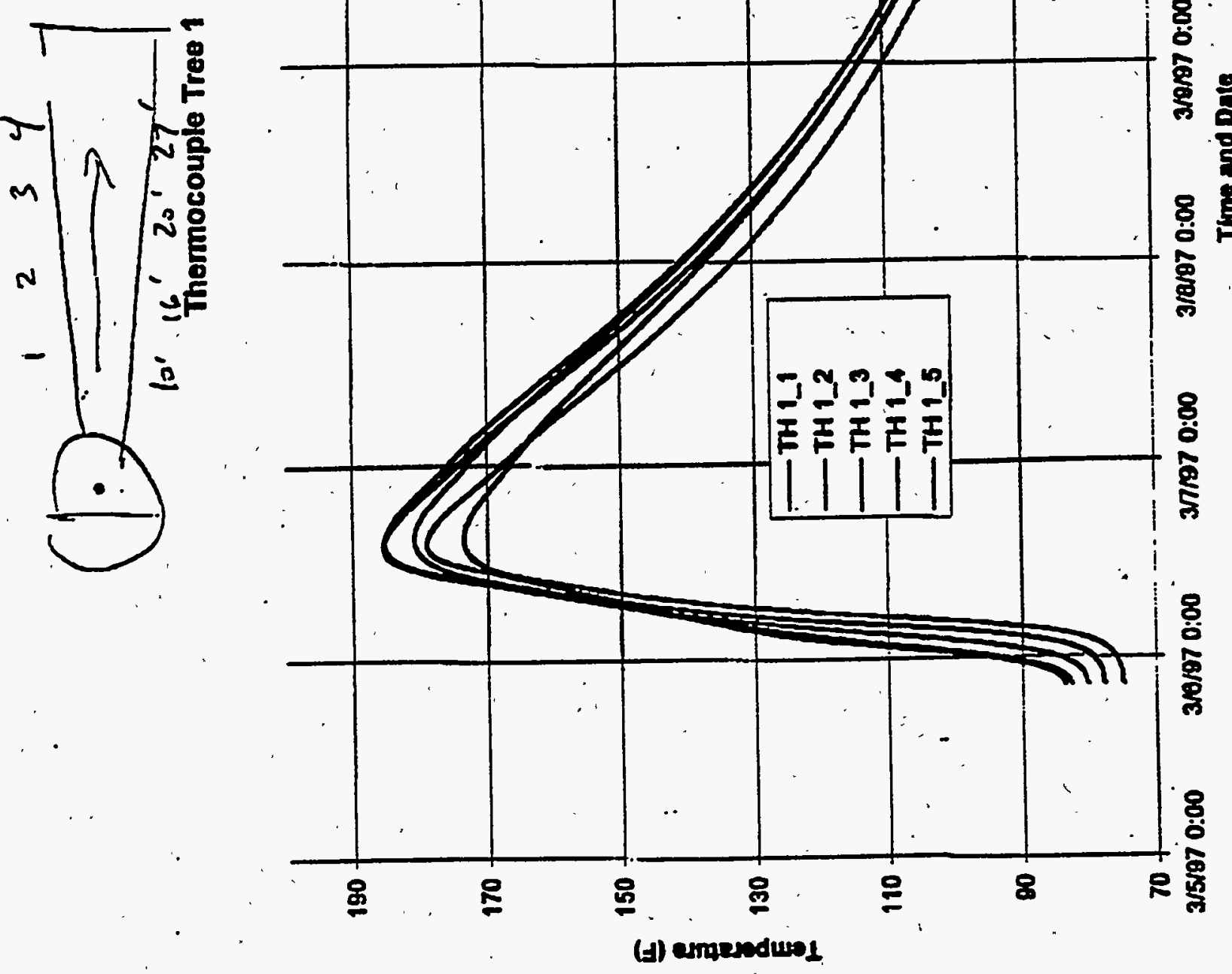
1

WSRC-TR-97-0102

APPENDIX "B"

CTL Grout and Sludge Mixing Report
Revision 0

Page 236

E. Petrographic and Photographic Evaluation of Sample Cores. 